\title{
Summaries of FY 1993 Geosciences Research
}

December 1993

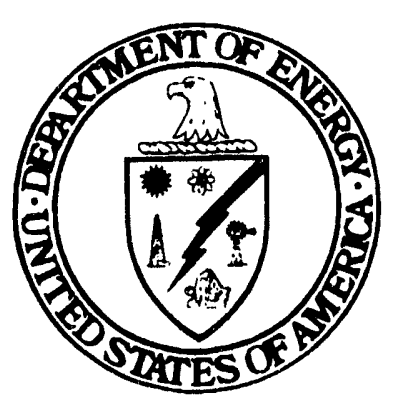

U.S. Department of Energy

Office of Energy Research

Office of Basic Energy Sciences

Division of Engineering and Geosciences

Washington, DC 20585 


\section{CONTENTS}

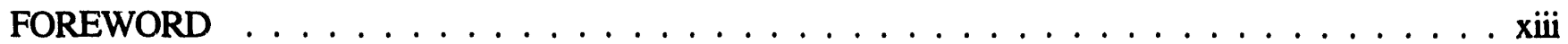

THE GEOSCIENCES RESEARCH PROGRAM IN THE OFFICE

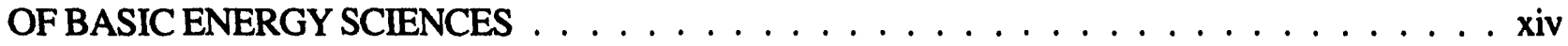

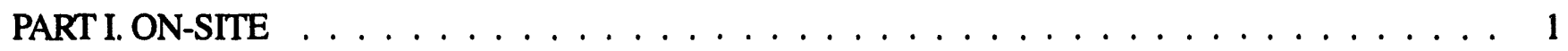

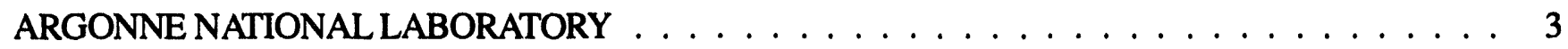

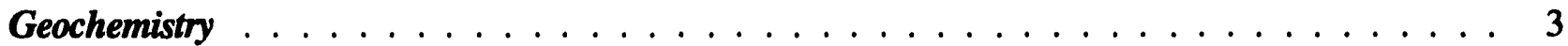

A. Mineral-Fluid Interactions: Experimental Determination of Atomic-

Scale Processes Using Synchrotron Radiation . . . . . . . . . . . . . . . . . . . . . . 3

B. Hydrothermal System Evolution . . . . . . . . . . . . . . . . . . . . . . 3

C. Petroleum Maturation Processes . . . . . . . . . . . . . . . . . . . . . . . . . . . . 4

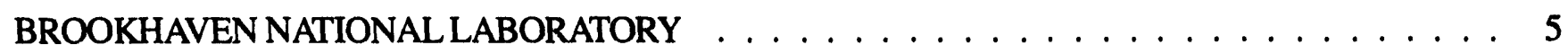

Geophysics and Earth Dynamics . . . . . . . . . . . . . . . . . . . . 5

Measurement of Fluid Flow and Fluid-Rock Interactions Using

Geochemistry ............................. 5

Geochemistry of Organic Sulfur in Marine Sediments . . . . . . . . . . . . . . . 5

IDAHO NATIONAL ENGINEERING LABORATORY . . . . . . . . . . . . . . . . . . . . . 7

Energy Resource Recognition, Evaluation, and Utilization . . . . . . . . . . . . . . . . . . . . 7

Volcanic Stratigraphy of the Idaho National Engineering

Laboratory Core Hole WO-2 . . . . . . . . . . . . . . . . . . . . . . . . 7

LAWRENCE BERKELEY LABORATORY . . . . . . . . . . . . . . . . . . . . . . . . 8

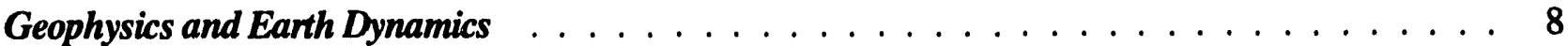

A. High-Resolution Imaging of Electrical Conductivity Using

Low-Frequency Electromagnetic Fields . . . . . . . . . . . . . . . . . . . 8

B. Center for Computational Seismology (CCS) . . . . . . . . . . . . . . . . . . 9

C. Microcrack Growth in Rock . . . . . . . . . . . . . . . . . . . . . . . . . . . 9

D. Process Definition in Fractured Hydrocarbon Reservoirs . . . . . . . . . . . . . . . . . . 10

E. Coupled Thermal-Hydraulic-Mechanical Processes in

Petroleum Reservoirs . . . . . . . . . . . . . . . . . . . . . . . 10

F. Controls on Pull-Apart Basin Evolution: Integrated Geological,

Geophysical, and Modeling Studies . . . . . . . . . . . . . . . . . 11

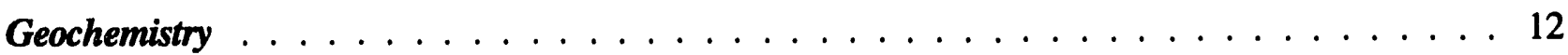

A. Thermodynamics of High-Temperature Brines . . . . . . . . . . . . . . 12

B. Integrated Isotopic Studies of Geochemical Processes . . . . . . . . . . . . . . . 12 
Energy Resource Recognition, Evaluation, and Utilization . . . . . . . . . . . . . . . . . . . 13

A. Hydrothermal Chemistry . . . . . . . . . . . . . . . . . . . . . . . 13

B. Geophysical Measurements Facility (GMF) . . . . . . . . . . . . . . . . . . . . . . 14

LAWRENCE LIVERMORE NATIONAL LABORATORY . . . . . . . . . . . . . . . . . . . . . . 15

Geophysics and Earth Dynamics . . . . . . . . . . . . . . . . . . . . . . . . . . 15

A. Rheology of Partially Molten Crustal Rocks . . . . . . . . . . . . . . . . . . . . . . . 15

B. Quantitative Image Analysis to Determine Rock Properties . . . . . . . . . . . . . . . . . 16

C. Modification of Fracture Transport Properties of Rocks by Mechanical and Chemical Processes . . . . . . . . . . . . . . . . . . . 16

D. Poroelasticity of Rock . . . . . . . . . . . . . . . . . . . . . . . . . . . . . . . . 17

E. The Role of Carbon and Temperature in Determining Electrical

Conductivity of Basins, Crust, and Mantle . . . . . . . . . . . . . . . . . . . 17

F. Interpretation of Geodetic Crustal Strains Using Nonlinear Dynamical

Models for the Deformation of Solids . . . . . . . . . . . . . . . . . . . . 18

G. Oxygen and Cation Diffusion in Oxide Materials . . . . . . . . . . . . . . . . . . . . . 19

H. Advanced Concepts . . . . . . . . . . . . . . . . . . . . . . . . . . 20

Geochemistry . . . . . . . . . . . . . . . . . . . . . . . 20

A. Compositional Kinetic Model of Petroleum Formation . . . . . . . . . . . . . . . . . . 20

B. Thermodynamic and Transport Properties of Aqueous Geochemical

Systems . . . . . . . . . . . . . . . . . . . . . 21

C. Experimental Determination of Mineralogical Controls on U-Th-Pb

Redistribution: Implications for Crust/Mantle Differentiation . . . . . . . . . . . . 22

Energy Resource Recognition, Evaluation, and Utilization . . . . . . . . . . . . . . . . . . 23

A. New Approaches to Underground Imaging . . . . . . . . . . . . . . . . . . . . . 23

B. Investigation of Active Processes in Long Valley Caldera Using the

Magma Energy Deep Exploration Well Phase II Drilling Activities . . . . . . . . . . . . . 24

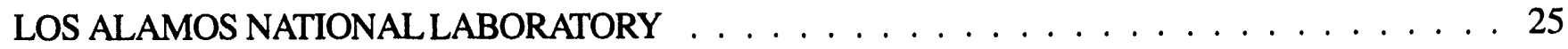

Geophysics and Earth Dynamics . . . . . . . . . . . . . . . . . . . . . . . . 25

A. Imaging of Reservoirs and Fracture Systems Using Microearthquakes
Induced by Hydraulic Injections $\ldots \ldots \ldots \ldots$$\ldots \ldots \ldots$

B. Jemez Imaging and Tomography Experiment (JTEX) . . . . . . . . . . . . . . . . . . 26

C. Advanced Concepts . . . . . . . . . . . . . . . . . . . . . . . . . . . 26

D. The Role of Carbon and Temperature in Determining Electrical

Conductivity of Basins, Crust, and Mantle . . . . . . . . . . . . . . . . . . . 27

E. Basic Research on Nonlinear Elastic Phenomena in Rock . . . . . . . . . . . . . . . . 28

Geochemistry . . . . . . . . . . . . . . . . . . . . . . 28

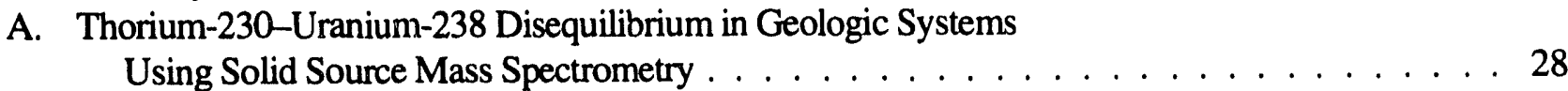

B. Dynamics of Rock Varnish Formation . . . . . . . . . . . . . . . . . . . . . . . . . . 29

C. Geochemistry of Technetium . . . . . . . . . . . . . . . . . . 30

D. Tracer Tomography in Geological Reservoirs . . . . . . . . . . . . . . . . . . . 31 
E. A Search for Evidence of Large Comet or Asteroid Impacts

at Extinction Boundaries . . . . . . . . . . . . . . . . . . . . . . . . 31

F. Direct Speciation of Metal Ions by Optical Spectroscopies . . . . . . . . . . . . . . . 32

G. Dating young surfaces using cosmogenic Helium and Neon . . . . . . . . . . . . 32

Energy Resource Recognition, Evaluation, and Utilization . . . . . . . . . . . . . . . . . 33

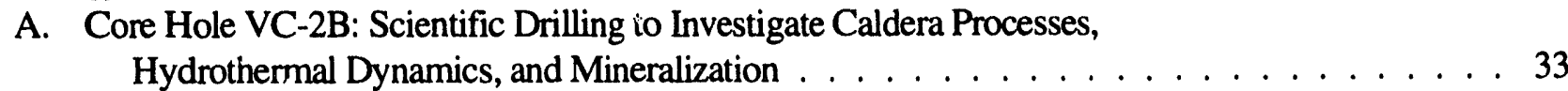

B. Hydrogeochemistry of Nevada Oil Field Waters and Brines . . . . . . . . . . . . . 33

C. Operation of a Sample Management System for the Continental

Scientific Drilling Program . . . . . . . . . . . . . . . . . . . . . . . 34

D. Intracaldera Processes-Creede Caldera, San Juan

Volcanic Field, Colorado . . . . . . . . . . . . . . . . . . . . . . . . . . . 34

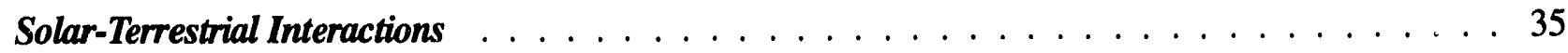

A. Energy Transport in Space Plasma . . . . . . . . . . . . . . . . . . . . . . . . 35

B. The Solar Wind-Magnetospheric Interaction . . . . . . . . . . . . . . . . . . . . 35

C. Energetic Particle Acceleration . . . . . . . . . . . . . . . . . . . . 36

D. Radiation from Space and Astrophysical Plasmas . . . . . . . . . . . . . . . . 36

OAK RIDGE NATIONAL LABORATORY $\ldots \ldots \ldots \ldots$

Geophysics and Earth Dynamics . . . . . . . . . . . . . . . . . . . . . . . . 37

A. Coupled Acoustic Seismic Imaging and Geochemical Studies of

B. Superresolution in Shallow Geophysics . . . . . . . . . . . . . . . . . . . . 37

Geochemistry . . . . . . . . . . . . . . . . . . . . 38

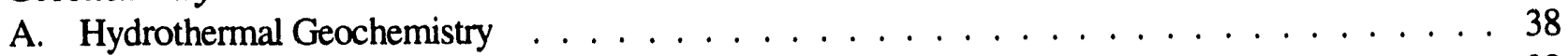

B. Stable Isotope Systematics of Fluid-Rock Interactions $\ldots \ldots \ldots$

C. Thermodynamics of Rock-Forming Crystalline Solutions 39

and Silicate Melts $\ldots \ldots \ldots \ldots \ldots \ldots$

D. Crustal Stability of C-O-H-N Fluids . . . . . . . . . . . . . . . . . . . . 40

E. Fundamental Research in the Geochemistry of

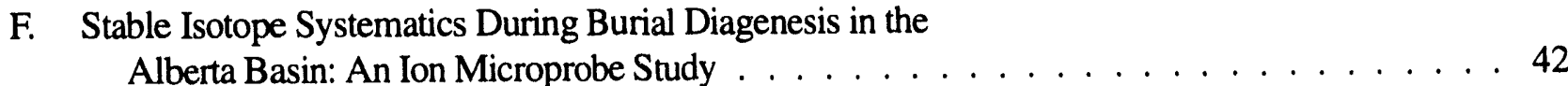

G. Advanced Concepts . . . . . . . . . . . . . . . . . . . . . . . . . . . . . . 42

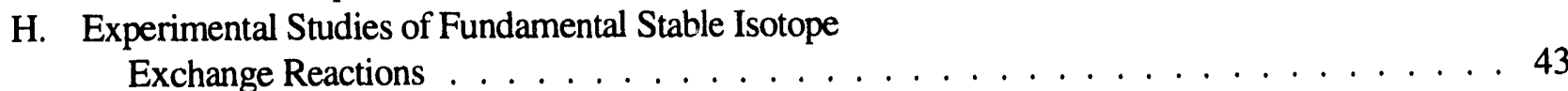

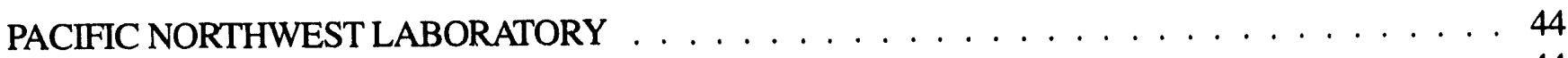

Geochemistry . . . . . . . . . . . . . . . . . . . . . . 44

Structure and Reactivity of Oxide and Hydroxide Surfaces . . . . . . . . . . . . . . . 44 
Energy Resource Recognition, Evaluation, and Utilization . . . . . . . . . . . . . . . . . . 45

A. Remote Geologic Analysis . . . . . . . . . . . . . . . . . . . . . . . . . . 45

B. Remote Sensing: Geoscience Data Analysis and Integration . . . . . . . . . . . . . . . . . 46

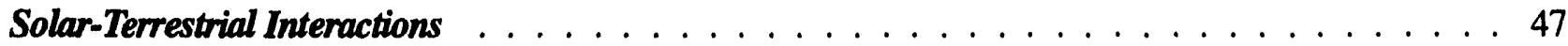

Aeronomy/nsolation Studies . . . . . . . . . . . . . . . . . . 47

SANDIANATIONAL LABORATORIES . . . . . . . . . . . . . . . . . . . . . . 49

Geophysics and Earth Dynamics . . . . . . . . . . . . . . . . . . . . . . . . . . . . . . 49

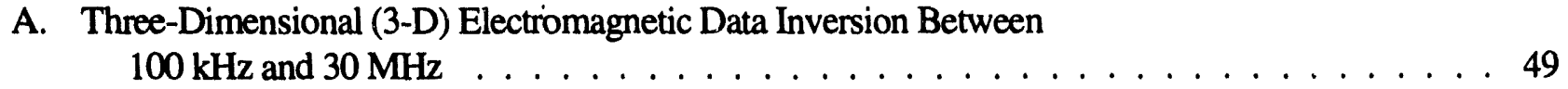

B. Effects of Microscopic Reactions and Buoyancy on Macroscopic

Transport in Geologic Media: A Lattice Gas Study of

Retardation and Dispersion . . . . . . . . . . . . . . . . . . . . . . . . . . 49

C. Reservoir Characterization as Applied to a Reef-Type Reservoir . . . . . . . . . . . . . . . . 50

D. Advanced Concepts . . . . . . . . . . . . . . . . . . . . . . 51

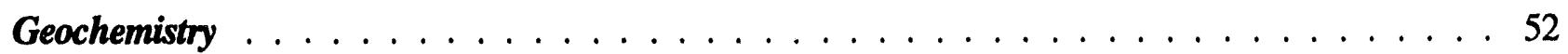

A. Cation Diffusion Rates in Selected Silicate Minerals . . . . . . . . . . . . . . . . . . . . 52

B. Isotopic and Mineralogical Indicators of Infiltration and Vertical

Fluid Movement in Unsaturated Zones of Semiarid Terrain . . . . . . . . . . . . . . . . 52

C. An Investigation of Mineral Hydrolysis Kinetics . . . . . . . . . . . . . . . . . . . . 53

Energy Resource Recognition, Evaluation, and Utilization . . . . . . . . . . . . . . . . . . . . . 54

A. Geoscience Research Drilling Office (GRDO) . . . . . . . . . . . . . . . . . . . . . 54

B. Seismicity Induced by Hydrocarbon Production . . . . . . . . . . . . . . . . . 55

C. Investigation of Active Processes in Long Valley Caldera Using the Magma

Energy Deep Exploration Well Phase II Drilling Activities . . . . . . . . . . . . . . . . . 55

D. Development of a Smart, High-Temperature Fluid Sampling Tool . . . . . . . . . . . . . 56

PART II OFF-SITE $\ldots \ldots \ldots \ldots \ldots \ldots \ldots \ldots$

UNIVERSITY OF ALASKA . . . . . . . . . . . . . . . . . . . . . . . . . . . . 59

A Study of Magnetic Reconnection Processes and Plasma Processes

in the Magnetosphere and the Solar Corona . . . . . . . . . . . . . . . . . . . . . 59

Katmai Sicientific Drilling Project . . . . . . . . . . . . . . . . . . . . . . . . 60

AMERICAN MUSEUM OF NATURAL HISTORY . . . . . . . . . . . . . . . . . . . . . . . . 62

The Role of Carbon and Temperature in Determining Electrical

Conductivity of Basins, Crust, and Mantle . . . . . . . . . . . . . . 62

ARIZONA STATE UNIVERSITY . . . . . . . . . . . . . . . . . . . . . . . . 63

Organic/Inorganic Interactions of Nitrogen in Oil Fields

Part I: Geochemistry . . . . . . . . . . . . . . . . . . 63 
THE UNIVERSITY OF ARIZONA $\ldots \ldots \ldots \ldots$. . . . . . . . . . . . . . . . . . . 64

Electrochemical Determination of the Gibbs Free Energies of

Rock-Forming Minerals . . . . . . . . . . . . . . . . . . . . . . 64

Solar Variability Observed Through Changes in Solar Figure

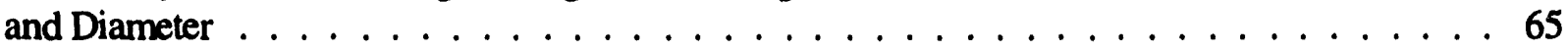

BROWN UNIVERSITY . . . . . . . . . . . . . . . . . . . . . . . . . . . . . . . . 66

Grain Boundary Transport and Related Processes in Natural

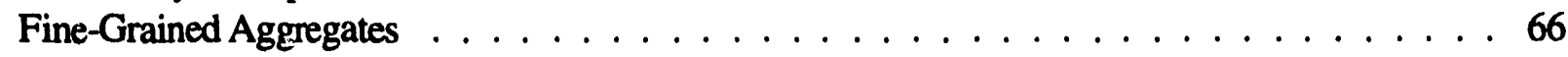

CALIFORNIA INSTTTUTE OF TECHNOLOGY . . . . . . . . . . . . . . . . . . . . . 67

Infrared Spectroscopy and Hydrogen Isotope Geochemistry of Hydrous

Silicate Glasses . . . . . . . . . . . . . . . . . . . . . . . . . . 67

Isotope Tracer Studies of Diffusion in Silicates and of Geological

Transport Processes Using Actinide Elements . . . . . . . . . . . . . . . . . 68

UNIVERSITY OF CALIFORNIA AT BERKELEY . . . . . . . . . . . . . . . . . . . . . . . . 69

Experimental Measurement of Thermal Conductivity in Silicate Liquids . . . . . . . . . . . . . . 69

Advective-Diffusive/Dispersive Transport of Chemically Reacting

Species in Hydrothermal Systems . . . . . . . . . . . . . . . . . . 70

Multistation Magnetotellurics $\ldots \ldots \ldots \ldots \ldots \ldots \ldots$

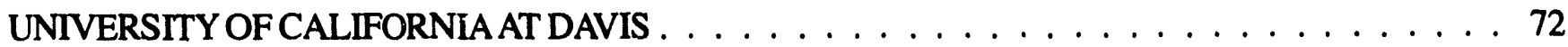

A New Method for Determining the Thermodynamic Properties of

Carbonate Solid-Solution Minerals . . . . . . . . . . . . . . . . . . . 72

Energetics of Melts from Thermal-Diffusion Studies . . . . . . . . . . . . . . . . . 74

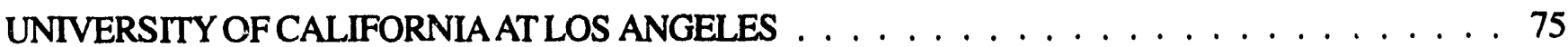

K-Feldspar Thermochronometry . . . . . . . . . . . . . . . . . . . 75

Oxygen and Cation Diffusion in Oxide Materials . . . . . . . . . . . . . 76

UNIVERSITY OF CALIFORNIA AT SAN DIEGO $\ldots \ldots \ldots \ldots \ldots$

Deuterium/Hydrogen Ratios and Scanning Electron Microscopy

Imaging of Fossil Organic Matter from California's Monterey Formation . . . . . . . . . . 77

UNIVERSITY OF CALIFORNIA AT SANTA BARBARA . . . . . . . . . . . . . . . 78

Physical Modeling of Sedimentary Basins, Magma Mechanics, and

Molecular Dynamics of Geological Solutions . . . . . . . . . . . . . . 78

CARNEGIE INSTITUTION OF WASHINGTON . . . . . . . . . . . . . . . . . . . . 79

Water Rock Interaction in the Earth's Upper Mantle: Application of

Combined Oxygen Isotope and Infrared Spectroscopic Analytical Techniques . . . . . . . . . 79 
Synchrotron X-Ray Microprobe and Microspectroscopy: Technical

Development for Advanced Photon Source Research and Low-

Temperature Geochemistry Applications . . . . . . . . . . . . . . . . . . . . . . . . 80

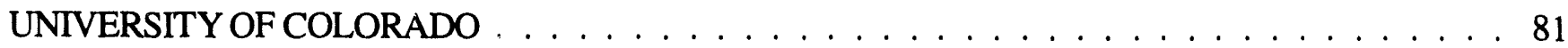

Crystal Chemistry of Hydroxyl and Water in Silicate Minerals . . . . . . . . . . . . . . . . . 81

Seismic Absorption in Fluid-Filled Porous Rocks as a Function of

Seismic Frequencies, Pressure, and Temperature . . . . . . . . . . . . . . . . 82

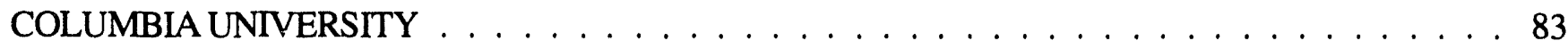

Energetics of Silicate Melts from Thermal-Diffusion Studies f . . . . . . . . . . . . . . . . 83

UNIVERSITY OF DELAWARE . . . . . . . . . . . . . . . . . . . . . . . . . . . . . . . 84

Development of an Experimental Data Base and Theories for Prediction

of Thermodynamic Properties of Aqueous Electrolytes and

Nonelectrolytes of Geochemical Significance at Supercritical

Temperatures and Pressures . . . . . . . . . . . . . . . . . . . . . . . 84

EARTH RESOURCES LABORATORY . . . . . . . . . . . . . . . . . . . . . . . . . . . . . 85

Reservoir Characterization by Cross Hole Measurements . . . . . . . . . . . . . . . . . . 85

UNIVERSITY OF HOUSTON . . . . . . . . . . . . . . . . . . . . . . . . . . . . 86

Cross Hole Geotomography in a Partially Depleted Reservoir . . . . . . . . . . . . . . . . . 86

INDIANA UNIVERSITY . . . . . . . . . . . . . . . . . . . . . . . . . . . . . . . 87

Mechanochemical Self-Organization and Nonlinear Dynamics in

Sedimentary Basins . . . . . . . . . . . . . . . . . . . . . . . . . . . 87

THE JOHNS HOPKINS UNIVERSITY $\ldots \ldots \ldots$

High-Resolution Transmission Electron Microscopy/Analytical Electron Microscopy

and Scanning Electron Microscopy Study of Fluid-Rock Interactions: Interaction

of Copper-, Silver-, Selenium-, Chromium-, and Cadmium-Bearing Solutions

with Geological Materials at Near-Surface Conditions, with an Emphasis

on Phyllosilicates . . . . . . . . . . . . . . . . . . . . . . 88

LEHIGH UNIVERSITY . . . . . . . . . . . . . . . . . . . . . . . . . . . . . . . . . . . . . . . . .89

Surface and Solution-Interface Geochemistry of Lead Sulfide and

Lead Selenide Minerals . . . . . . . . . . . . . . . . . . . . . . . . . . . . 89

LOUISIANA STATE UNIVERSITY . . . . . . . . . . . . . . . . . . . . . . . . . . . 90

Organic/Inorganic Interactions of Nitrogen in Oil Fields

Part II: Mineralogy and Microbiology . . . . . . . . . . . . . . . . . . . . . . 9 90 
MASSACHUSETTS INSTITUTE OF TECHNOLOGY $\ldots \ldots \ldots \ldots$

In Situ Permeability Determination Using Borehole and Seismic

Logging Data . . . . . . . . . . . . . . . . . . . . . . . 91

UNIVERSITY OF MIAMI . . . . . . . . . . . . . . . . . . . . . . . . . . . . . . . 92

Testing the Correlation Between Sequence Stratigraphy, Seismic

Reflectors, and Diagenetic Changes in Carbonates: Implication

for the Distribution of Porosity and Permeability . . . . . . . . . . . . . . . . . 92

MINERALOGIC SOCIETY OF AMERICA . . . . . . . . . . . . . . . . . . . . . . 93

Workshop on Health Effects of Mineral Dusts . . . . . . . . . . . . . . . . . . 93

UNIVERSITY OF MINNESOTA, TWIN CITIES . . . . . . . . . . . . . . . . . . . . . . . . 94

Physical Modeling of Sedimentary Basins, Magma Mechanics, and

Molecular Dynamics of Geological Solutions . . . . . . . . . . . . . . . . . . 994

NATIONAL ACADEMY OF SCIENCES $\ldots \ldots \ldots \ldots \ldots \ldots$

Basic Energy Sciences Studies . . . . . . . . . . . . . . . . . . . . 95

UNIVERSITY OF NEW MEXICO . . . . . . . . . . . . . . . . . . . . . . . . . . . . . . . 96

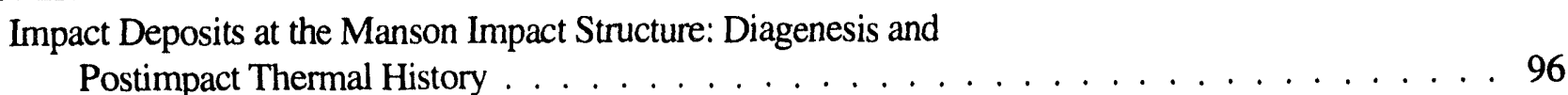

THE CITY COLLEGE OF THE CITY UNIVERSITY OF NEW YORK . . . . . . . . . . . . . . . . . 97

Stochastic Transport in Heterogeneous Flows and Media . . . . . . . . . . . . . . . . . . 97

CITY UNIVERSITY OF NEW YORK, QUEENS COLLEGE _ . . . . . . . . . . . . . . . . . 98

Evaporites as a Source for Oil $\ldots \ldots \ldots \ldots$

STATE UNIVERSTTY OF NEW YORK (SUNY) AT STONY BROOK . . . . . . . . . . . . . . . . . . . . 99

Geochemistry and Origin of Regional Dolomites . . . . . . . . . . . . . . . . . . . . . . . . 99

Three-Dimensional Imaging of Drill Core Samples Using
Synchrotron-Computed Microtomography . . . . . . . . . . . . . . . . . . . . . 100

NORTHEASTERN UNIVERSTTY . . . . . . . . . . . . . . . . . . . . . . . . . . 101

Superresolution in Shallow Geophysics . . . . . . . . . . . . . . . . . . . . . . 101

NORTHWESTERN UNTVERSTTY . . . . . . . . . . . . . . . . . . . . . . . . . . . . 102

Shear Strain Localization and Fracture Evolution in Rocks . . . . . . . . . . . . . . . . 102

UNIVERSITY OF NOTRE DAME . . . . . . . . . . . . . . . . . . . . . . 103

Energy Partitioning of Seismic Waves in Fractured Rocks . . . . . . . . . . . . . . . . 103

THE OHIO STATE UNIVERSITY . . . . . . . . . . . . . . . . . . . . . . . . . . . . . . 104

Investigation of Ultrasonic Wave Interactions with Fluid-Saturated

Porous Rocks 
Construction of a Calibrated Sea-Level Curve: Mid-Cretaceous Through Mid-Tertiary . . . . . . . . . . . . . . . . . . . . . . 105

UNIVERSTTY OF OKLAHOMA . . . . . . . . . . . . . . . . . . . . . . . . . 106

A Study of Hydrocarbon Migration Events: Development and Application of New Methods for Constraining the Time of Migration and an Assessment of Rock-Fluid Interactions . . . . . . . . . . . . . . . . . . 106

A Study of the Source Materials, Depositional Environments, Mechanisms of Generation, and Migration of Oils in the Anadarko and Cherokee Basins

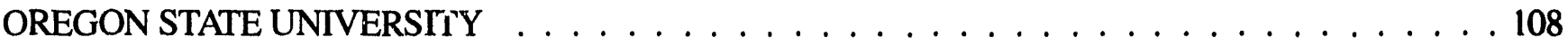

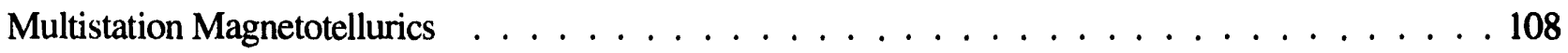

PENNSYLVANIA STATE UNIVERSITY . . . . . . . . . . . . . . . . . . . . . . . . . . . . 109

Cretaceous Shallow Drilling in the U.S. Western Interior:

Core Research

PRINCETON UNIVERSITY . . . . . . . . . . . . . . . . . . . . . . . . . . . . . . . . 110

The Effects of Natural and Radiation-Induced Defects on Noble

Gas Transport in Silicates: A Study of Argon Using Laser,

$\mathrm{X}$-Ray, and Electron Microprobes

Thermodynamics of Minerals Stable Near the Earth's Surface . . . . . . . . . . . . . . . . 111

PURDUE UNIVERSITY . . . . . . . . . . . . . . . . . . . . . . . . . . 112

Hyperfiltration-Induced Fractionation of Lithium Isotopes in

Geologic Systems . . . . . . . . . . . . . . . . . . . . . . . . . . . . . . 112

Character and Origins of Ground Rupturing and Ground Deformation

During the June 28, 1992, Landers, California, Earthquake . . . . . . . . . . . . . . . . 113

RICE UNIVERSITY . . . . . . . . . . . . . . . . . . . . . . . . . . . . . . . . 113

Transition Metal Catalysis in the Generation of Petroleum and

Natural Gas . . . . . . . . . . . . . . . . . . . . . . . . . . 113

UNIVERSITY OF SOUTHERN CALIFORNIA . . . . . . . . . . . . . . . . . . . . . . . . 114

The Seismology of Geothermal Regimes . . . . . . . . . . . . . . . . . . . . . . 114

UNIVERSITY OF SOUTH FLORIDA . . . . . . . . . . . . . . . . . . . . . . . . 115

Clay Mineral Diagenesis in the Monterey Formation, California . . . . . . . . . . . . . . . 115

STANFORD UNIVERSTTY . . . . . . . . . . . . . . . . . . . . . . . . 116

Cation Chemisorption at Oxide Surfaces and Oxide-Water Interfaces:

X-Ray Spectroscopic Studies and Modeling . . . . . . . . . . . . . . . . . . 116

Fluid Flow, Element Migration, and Petrotectonic Evolution of the Early

Mesozoic Central Klamath Island Arc, Northwesternmost California . . . . . . . . . . . . . 117

Experimental Investigation of Kinetics and Rheology During Diagenesis . . . . . . . . . . . 118 
Porous Reservoir Rocks with Fluids: Acoustic and Reservoir Transport

Properties . . . . . . . . . . . . . . . . . . . . . . . . . . . . . . . . . . . . 119

Models of Natural Fracture Connectivity: Implications for Reservoir

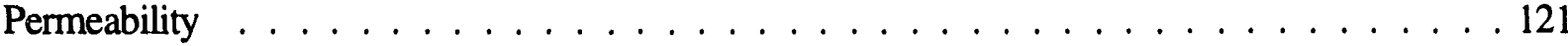

Induced Seismicity . . . . . . . . . . . . . . . . . . . . . . . . . . . 122

TEXAS A\&M UNIVERSITY . . . . . . . . . . . . . . . . . . . . . . . . . . . . 123

Mechanical Properties and Modeling of Seal-Forming Lithologies . . . . . . . . . . . . . . . 123

THE UNIVERSTTY OF TEXAS AT AUSTIN _. . . . . . . . . . . . . . . . . . . . . . . . . . . . 124

Energy Flux and Hydrogeology of Thermal Anomalies in the Gulf of

Mexico Sedimentary Basin—South Texas Example . . . . . . . . . . . . . . . . . . 124

The Role of Mudrocks in Burial Diagenesis . . . . . . . . . . . . . . . . . . . . 125

UNIVERSTTY OF TULSA . . . . . . . . . . . . . . . . . . . . . . . . . . . . . 126

Stability of Natural Gas in the Deep Subsurface . . . . . . . . . . . . . . . . . . . . . 126

U.S. GEOLOGICAL SURVEY . . . . . . . . . . . . . . . . . . . . . . . . . . . . . . . . . . . . 127

Cretaceous Shallow Drilling in the U.S. Western Interior: Core Research . . . . . . . . . . . . . 127

Causes of Abnormally High Pore Fluid Pressures in the Uinta Base, Utah . . . . . . . . . . . 128

UNIVERSTTY OF UTAH . . . . . . . . . . . . . . . . . . . . . . . . . . . . . . . . . . . . . . . 129

High-Resolution Imaging of Electrical Conductivity Using Low-Frequency

Electromagnetic Fields

UNIVERSITY OF UTAH RESEARCH INSTITUTE . . . . . . . . . . . . . . . . . . . . . . . 130

Tensor Controlled-Source Audiomagnetotelluric (CSAMT) Survey over the

Sulphur Springs Thermal Area, Valles Caldera: Structural Implications

and Tensor CSAMT Methodology . . . . . . . . . . . . . . . . . . . . . . . . 130

Assessing the Role of Active and Ancient Geothermal Processes in

Oil-Reservoir Evolution in the Basin and Range Province . . . . . . . . . . . . . . 131

VIRGINIA POLYTECHNIC INSTITUTE AND STATE UNIVERSITY . . . . . . . . . . . . . . . . 132

PVTX Properties of Fluid Systems: $\mathrm{H}_{2} \mathrm{O}-\mathrm{CO}_{2}-\mathrm{NaCl} \ldots$. . . . . . . . . . . . . . . . . . . . . . . 132

Zircons and Fluids: An Experimental Investigation with Applications

for Radioactive Waste Storage . . . . . . . . . . . . . . . . . . . . . . . . . 133

WASHINGTON STATE UNIVERSTTY . . . . . . . . . . . . . . . . . . . . . . . . . . . 134

Origin of Flood-Basalt Volcanism on the Columbia Plateau: An

Integrated Approach Using Geology, Geophysics, and Petrology . . . . . . . . . . . . . . . 134

WASHINGTON STATE UNIVERSITY, TRI-CITIES . . . . . . . . . . . . . . . . . . . . . . . . . . 135

Transport in Porous and Fractured Media of the Creede Formation . . . . . . . . . . . . . 135 
WASHINGTON UNIVERSITY

Development of an Experimental Data Base and Theories for Prediction

of Thermodynamic Properties of Aqueous Electrolytes and

Nonelectrolytes of Geochemical Significance at Supercritical

Temperatures and Pressures . . . . . . . . . . . . . . . . . . . . . . 136

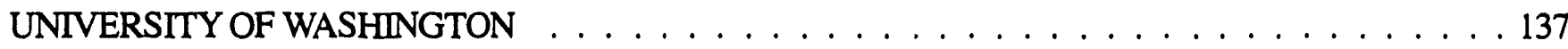

Two- and Three-Dimensional Magnetotelluric Inversion . . . . . . . . . . . . . . . . . 137

UNIVERSITY OF WISCONSIN . . . . . . . . . . . . . . . . . . . . . . . 138

HRTEM Investigation of Interactions between Minerals, Fluids, and

Lithobiotic Communities During Natural Weathering . . . . . . . . . . . . . . . . 138

The 34th U.S. Symposium on Rock Mechanics . . . . . . . . . . . . . . . . . . . . . . . . . . . 139

Microanalysis of Stable Isotope Ratios in Geothermal Systems:

Long Valley and Skye . . . . . . . . . . . . . . . . . . . . . . . . . . 140

Poroelasticity of Rock . . . . . . . . . . . . . . . . . . . . . . . . . . . . 141

WOODS HOLE OCEANOGRAPHIC INSTITUTION . . . . . . . . . . . . . . . . . . . . . . . 142

Geochemical Incorporation of Sulfur into Organic Matter: Role of

Sulfur in the Formation and Diagenesis of Macromolecular

Organic Matter in Sediments . . . . . . . . . . . . . . . . . . . . . . . . 142

Organic Geochemistry of Outer Continental Margins and Deep-

Water Sediments . . . . . . . . . . . . . . . . . . . . . . . . . . . 143

YALE UNIVERSITY . . . . . . . . . . . . . . . . . . . . . . . . . . . 145

Reactive Fluid Flow and Applications to Diagenesis, Mineral Deposits,

and Crustal Rocks . . . . . . . . . . . . . . . . . . . . . . . . . . . 145

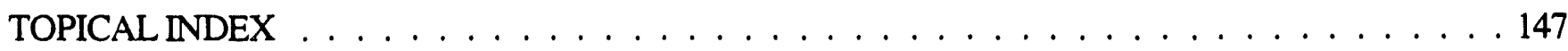

INDEX OF TECHNICAL CONTRIBUTORS . . . . . . . . . . . . . . . . . . . . . . . 148

TABLE 1. DOE/OBES GEOSCIENCES RESEARCH HISTORICAL SUMMARY

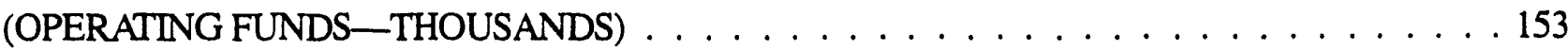




\section{FOREWORD}

The Department of Energy supports research in the geosciences in order to provide a sound foundation of fundamental knowledge in those areas of the geosciences that are germane to the Department of Energy's many missions. The Division of Engineering and Geosciences, part of the Office of Basic Energy Sciences of the Office of Energy Research, supports the Geosciences Research Program. The participants in this program include Department of Energy laboratories, academic institutions, and other governmental agencies. These activities are formalized by a contract or grant between the Department of Energy and the organization performing the work, providing funds for salaries, equipment, research materials, and overhead.

The summaries in this document, prepared by the investigators, describe the scope of the individual programs. The Geosciences Research Program includes research in geophysics, geochemistry, resource evaluation, solar-terrestrial interactions, and their subdivisions including earth dynamics, properties of earth materials, rock mechanics, underground imaging, rock-fluid interactions, continental scientific drilling, geochemical transport, solar/atmospheric physics, and modeling, with emphasis on the interdisciplinary areas. All such research is related either directly or indirectly to the Department of Energy's long-range technological needs. 


\section{THE GEOSCIENCES RESEARCH PROGRAM IN THE OFFICE OF BASIC ENERGY SCIENCES}

The Geosciences Research Program is directed by the Department of Energy's (LOE's) Office of Energy' Research (OER) through its Office of Basic Energy Sciences (OBES). Activities in the Geosciences Research Program are directed towards the long-term fundamental knowledge base necessary to provide for energy technologies of the future.

Future energy technologies and their individual roles in satisfying the nation's energy needs are uncertain in their particulars. It is clear, however, that these future energy technologies will involve consumption of energy and mineral resources and generation of technological wastes. The earth is a source for theseenergy and mineral resources and is also the host for wastes generated by technological enterprise. Viable energy technologies for the future must contribute to a national energy enterprize that is efficient, economical, and environmentally sound.

The Geosciences Research Program emphasizes research leading to fundamental knowledge of the processes that transport, modify, concentrate, and emplace (1) the energy and mineral resources of the earth and (2) the energy byproducts of man. The Geosciences Research Program is divided into five broad categories:

- Geophysics and Earth Dynamics;

- Geochemistry;

- Energy Resource Recognition, Evaluation, and Utilization;

- Hydrogeology and Exogeochemistry; and

- Solar-Terrestrial Interactions.

The following outline of current research in these categories is intended to be illustrative and evolves with time and progress in these fields. Individual research projects supported by this program at DOE laboratories, national laboratories, academic institutions, research centers, and other federal agencies typically have components in more than one of the categories or subcategories listed. Also, it is common for research activities to involve a high level of collaboration between investigators at different institutions.

\section{GEOPHYSICS AND EARTH DYNAMICS}

A. Large-Scale Earth Dynamics. Research on the physics of lithospheric dynamics such as plate motion, mountain building, basin development, and regional scale uplift/subsidence and its concomitant effects.

B. Evolution of Geologic Structures. Research on the physical controls and physical effects of the dynamic evolution of geologic structures (e.g., folds, faults, basins, volcanoes) on a local or regional scale.

C. Properties of Earth Materials. Research on physical properties of rocks and minerals determined in the laboratory or in the field (in situ), by direct or indirect techniques, and applicable on the spatial and temporal scales of geologic processes.

D. Rock Mechanics, Fracture, and Fluid Flow. Research on the response of rock and rock units to induced stress and the role of fluid flow as a cause and/or effect. 
E. Underground Imaging. Research to characterize the layering, mineralogy, lithology, geometry, fracture density, porosity, fluid content, and composition of the lithosphere using geophysical methods.

\section{GEOCHEMISTRY}

A. Thermochemical Properties of Geologic Materials. Research on the thermodynamic and chemical properties of geologic materials and their kinetic/dynamic interactions.

B. Rock-Fluid Interactions. Research on the chemical and mechanical consequences of rock-fluid interactions and the mass and energy transport controls of such interactions.

C. Organic Geochemistry. Research on naturally occurring carbonaceous and biologically derived substances of geologic and energy importance.

D. Geochemical Transport. Research (both experimental and theoretical) on the geochemical separation, transport, and concentration of materials in the earth's crust induced by the spatial and temporal dynamics of lithospheric processes leading to a predictive capability.

\section{ENERGY RESOURCE RECOGNITION, EVALUATION, AND UTILIZATION}

A. Resource Definition and Utilization. Research to develop new and advanced bases for the physicochemical dynamics needed for improved energy and energy-related resource exploration, definition, and use.

B. Reservoir Dynamics and Modeling. Research on the physicochemical dynamics of geothermal and hydrocarbon reservoirs in their natural and perturbed (by production, injection, or reinjection) states.

C. Properties and Dynainics of Magma. Research on the origin, migration, emplacement, and crystallization of natural silicate liquids and their heat energy.

D. Continental Scientific Drilling. Research on the scientific objectives of the OBES Geosciences Research Program using advanced technologies in shallow, intermediate, and deep drilling for earth observation iacilities. Scientific research and advanced drilling technologies development are coordinated by an Interagency Coordinating Group (DOE, the U.S. Geological Survey, and the National Science Foundation) under the aegis of the Interagency Accord on Continental Scientific Drilling.

\section{HYDROGEOLOGY AND EXOGEOCHEMISTRY}

A. Fluid Transport Dynamics and Modeling. Research on the chemical transport and energy/mechanical consequences of fluid interactions and transport, leading to a predictive capability. 
B. Thermochemical Properties of Energy Materials. Research on the thermodynamic and chemical properties of materials and their kinetic/dynamic interactions in fluid-rock systems.

C. Perturbations of Fluid Flow. Research on the physicochemical dynamics and chemical transport of fluid-rock systems in response to mechanical and energy perturbations, leading to a predictive capability.

\section{SOLAR-TERRESTRIAL INTERACTIONS}

A. Magnetospheric Physics. Research on the fundamental interactions of the solar wind with the terrestrial magnetic field and the earth's magnetosphere as a model magnetohydrodynamic generator and associated plasma physics research.

B. Upper Atmosphere Chemistry and Physics. Research on thermal, compositional, and electrical phenomena in the upper atmosphere and the interactions induced by solar radiation.

C. Solar Radiation and Solar Physics. Research on the structure and dynamics of the sun and the characteristic interactions of solar radiation with the earth, including the effects of solar radiation on the climate. 
PART I

ON-SITE

1 
CONTRACTOR:

CONTRACT:

CATEGORY:

PERSON IN CHARGE:
ARGONNE NATIONAL LABORATORY

Argonne, Illinois 60439

W-31-109-Eng-38

Geochemistry

N. C. Sturchio

\section{A. Mineral-Fluid Interactions: Experimental Determination of Atomic-Scale Processes Using Synchrotron Radiation (N. C. Sturchio [708-252-3986; FAX 708-252-6476; E-mail sturchio@cmt.anl.gov], R. P. Chiarello, and R.A. Wogelius)}

Objectives: The objective of this program is to advance the basic understanding of rock-fluid interactions through experimental studies of atomic-scale processes at mineral-fluid interfaces. This is crucial to establishing the relation between atomic-scale processes and macroscopic geochemical transport in large-scale natural systems.

Project Description: The principal approach is to observe single-crystal mineral surfaces in situ during chemically controlled reaction with fluids in a flowthrough reaction cell using X-ray scattering and $\mathrm{X}$-ray absorption spectroscopy techniques with high-brilliance synchrotron radiation. Experiments are being performed on common rock-forming minerals under conditions representative of near-surface environments. Types of reac- tions being investigated include dissolution-precipitation, adsorption, and oxidation.

Results: Progress during the past year included successful demonstrations of the ability to perform in situ $\mathrm{X}$-ray reflectivity and $\mathrm{X}$-ray diffraction studies of reacting mineral surfaces in chemically controlled conditions. Several sets of experiments were conducted to observe changes in the surface roughness and the crystal truncation rod of the (104) calcite cleavage plane as a function of dissolution at constant $\mathrm{pH}$ and temperature. Other experiments used X-ray diffraction and X-ray absorption spectroscopy to characterize the structure of sub-micron $\mathrm{PbSrCO}_{3}$ overgrowths on calcite. Reconnaissance $\mathrm{X}$-ray reflectivity studies of galena, sphalerite, plagioclase, and halite cleavage surfaces were also performed.

\section{B. Hydrothermal System Evolution (N. C. Sturchio [708-252-3986; FAX 708-252-6476; E-mail sturchio@cmt.anl.gov], G.B. Arehart, and B.D. Holt)}

Objectives: The objective of this program is to achieve a better understanding of rock-water interactions and geochemical transport in shallow portions of the Earth's crust.

Project Description: Active hydrothermal systems are being examined through field-based studies that include detailed chemical and isotopic analyses to determine the sources of fluids and solutes, the mechanisms and rates of geochemical transport processes, and the relation of hydrothermal systems to larger-scale tectonomagmatic and climatic processes. Emphasis is given to applications of actinide ( $\mathrm{U}$ and $\mathrm{Th}$ ) decay-series disequilibria and stable isotopes ( $\mathrm{H}, \mathrm{B}, \mathrm{C}, \mathrm{N}, \mathrm{O}, \mathrm{S}$, and $\mathrm{Sr})$ to understand hydrothermal processes. Chemical equilibrium and mass transfer calculations are used to interpret phase equilibria and element redistribution. Such work is of basic importance to a wide variety of energy-related concerns involving mass transport in rock-water systems.

Results: Progress during the past year included studies of: (1) fumaroles in the crater of the Galeras Volcano, Colombia, and the relation of their compositional changes to seismic and eruptive activity; (2) thermal waters and associated gases of the Alvord (Oregon) geothermal system; (3) thermal waters along the Gulf of Suez and Nile River near Cairo (Egypt); (4) isotopic compositions of hypogene alunites from the Great Basin; and (5) isotopic compositions of fluid inclusions from a Mexican ore deposit. In addition, techniques were developed for chemical and isotopic analysis of dissolved gases in water, gamma spectrometric analysis of actinide decay-series isotopes in 
rocks and waters, and analysis of boron isotopes using resonance ionization mass spectrometry of sputtered atoms. Finally, results from a number of previous studies were published.

\section{Petroleum Maturation Processes (N. C. Sturchio [708-252-3986; FAX 708-252-6476; E-mail sturchio@cmt.anl.gov] and A.J.Bakel)}

Objectives: The objective of this program is to contribute to a better understanding of the origin and history of petroleum in sedimentary basins. Fundamental questions addressed by this work include: the relation between oil composition and source rock type; the nature of chemical changes that occur within organic matter during diagenesis and catagenesis; the effects of maturation, migration, and biodegradation on oil composition; and the validity of oil-source rock and oil-oil correlations.

Project Description: The principal approach employed in this research is gas chromatography/isotope ratio mass spectrometry for compound-specific analysis of carbon isotope ratios in complex organic mixtures. Suites of well-characterized petroleum samples, obtained from collaborating scientists, are being analyzed. The results of this work have significant applications in hydrocarbon resource exploration and production.

Analyses of $n$-alkane fractions of oils from different reservoirs within the Phillipsburg oil field showed that these are derived from the New Albany Shale, as are most other oils in the Illinois Basin. Biodegradation of these oils did not affect n-alkane isotopic compositions. Analyses of the $\mathrm{C}_{4}$ to $\mathrm{C}_{19}$ range of whole oils from Western Canada showed clear isotopic differences in certain compounds as a function of maturation. A set of experimental samples are being analyzed. These samples are reaction products from experiments in which petroleum source rocks are artificially matured under carefully monitored pressure and temperature conditions and in which the liquid products closely resemble natural crude oils. We anticipate that the data from this study will be useful in describing the isotopic changes in petroleums as a result of maturation processes. Considerable effort has been devoted to development of methods for analysis of $\delta^{15} \mathrm{~N}$ in crude oils. Optimization of instrumental sensitivity and sample preparation techniques has allowed us to make a set of measurements on oils from southern California. 
CONTRACTOR:

CONTRACT:

CATEGORY:

PERSONS IN CHARGE:
BROOKHAVEN NATIONAL LABORATORY

Associated Universities, Inc.

Upton, Long Island, New York 11973-5000
DE-AC02-76CH00016

Geophysics and Earth Dynamics

K. W. Jones and P. Spanne

\section{Measurement of Fluid Flow and Fluid-Rock Interactions Using Synchrotron-Computed Microtomography ( $K$. W. Jones [516-282-4588; FAX 516-282-7905; E-mail jones@bnlx26.nsls.bnl.gov], P. Spanne, and W. B. Lindquist)}

Objectives: This project is aimed at determination of the microgeometry of rocks and the effect of rock microstructure on fluid flow and fluid-rock interactions.

Project Description: The microgeometry of rocks is studied using the technique of synchrotron X-ray-computed microtomography at the Brookhaven National Synchrotron Light Source. Tomographic volume images are analyzed to obtain porosity and pore characteristics, that is, pore connectivity, throat size, and surface roughness. The purpose is to obtain precise data for fluid-flow modeling calculations. Measurements with fluids present in the rocks are used to improve understanding of fluid flow and fluid-rock interactions at pore-scale resolution.

Results: Measurements made during the past year have concentrated on production and analysis of volume images of several types of dry sandstones. The data were analyzed using 2-point autocorrelation theory. The results of the analysis give the porosity, specific surface area, and average grain size of the rock. Interpretation of the surface roughness of the pores is now in progress. Measurements will soon be extended to include investigation of the penetration of fluids into the pore spaces so as to directly investigate the connectivity of the pores, fluid-rock interactions at the pore level, and interfacial regions of two fluids and the rock. Appreciable effort was made in developing methods for visualization of the data and in improvements to the tomographic apparatus that will lead to more rapid data acquisition rates.

\section{CATEGORY: Geochemistry}

PERSONS IN CHARGE: $\quad$ A. Vairavamurthy and B. Manowitz

Geochemistry of Organic Sulfur in Marine Sediments (A. Vairavamurthy [516-282-5337; FAX 516-282-5526] and B. Manowitz [516-282-2458; FAX 516-282-5526])

Objectives: The broad objectives are to understand the geochemical mechanisms of sulfur incorporation into sedimentary organic matter, study the changes in the abundance and forms of sulfur during early diagenesis in various organic-rich sedimentary environments, and examine the influence of sulfur incorporation in the preservation of sedimentary organic matter.
Project Description: Sulfur is believed to be involved in preserving organic matter in sediments, converting this organic matter to petroleum, and controlling the timing of petroleum generation from a source rock. The fundamental geochemical issue here is the mechanism of sulfur incorporation into sedimentary organic matter. Although there is compelling evidence to indicate that reactions of reduced inorganic sulfur species with organic molecules 
occur during the early stages of diagenesis and under mild conditions, the molecular mechanisms are still not well understood. Previously, hydrogen sulfide has been considered to be the primary sulfur reactant for organic sulfur formation in sediments. Evidence is emerging that $\mathrm{H}_{2} \mathrm{~S}$ oxidation products, especially polysulfides, are also important. The roles of elemental sulfur, sulfite, and thiosulfate in the formation of organic sulfur are still not clear. This project, which is aimed at understanding the formation and transformation of sedimentary organic sulfur during early diagenesis, has four major components: (1) studies of sulfur speciation in sediments, (2) mechanistic studies of organic sulfur formation, (3) mechanistic studies of sulfide oxidation to understand the formation of different oxidation intermediates, and (4) analytical methods development. An important goal of this project is to use synchrotron radiation-based $\mathrm{X}$-ray absorption nearedge structure (XANES) spectroscopy, in addition to other state-of-the-art techniques, for characterization and determination of sulfur species.

Results: Studies of sulfur speciation based on XANES analysis of sediment core samples from several organic-rich locations (including coastal intertidal and saltmarsh sediments from Long Island locations and the Peru margin sediments) have provided important new information concerning the occurrence of particle-bound organic polysulfides and sulfonic acids. The nature of particles that serve as attachment points for polysulfides in sediments is not known; however, we speculated that organic structures, rather than inorganic particles, (silica?) are probably involved. Sulfonic acids constitute about 20 to $30 \%$ of the total organic sulfur in near-surface sediments, and their geochemical significance is still not clear. The mechanism of sulfonic acid formation in sediments is not well understood; however, the very fast kinetics $\left(t_{1} / 2=\right.$ $5.5 \mathrm{~min}$ ) of sulfite reaction with a model unsaturated compound (acrylic acid ethyl ester) suggests that this mechanism may be important for the formation of sulfonic acids in sediments. XANES spectroscopy was used to study air oxidation of aqueous sulfide under conditions typical of marine sediments. Thiosulfate was detected as the predominant product of sulfide oxidation, with sulfite and sulfate amounting to $<5 \%$ of the product sulfur. Added $\mathrm{Ni}^{2+}$ caused significant formation of polysulfides in addition to accelerating the oxidation rate to the maximum, suggesting that catalysis is probably important in the formation of polysulfides in sediments. In sulfide solutions containing added $\mathrm{Ni}^{2+}$, we obtained the first evidence for the transient occurrence of a +2 oxidation state intermediate, which has been characterized as the sulfoxylate ion $\left(\mathrm{SO}_{2}^{2-}\right)$. The mechanisms that generate the sulfoxylate ion in the oxidation of aqueous sulfide and how this intermediate is converted to other intermediates (e.g., polysulfides and thiosulfate) are not known. 
CONTRACTOR:

CONTRACT:

CATEGORY:

PERSON IN CHARGE:
IDAHO NATIONAL ENGINEERING LABORATORY

Geology \& Seismology Unit

EG\&G Idaho, Inc.

Idaho Falls, Idaho 83415-2107

DE-AC07-76ID01570

Energy Resource Recognition, Evaluation, and Utilization

W. R. Hackett

\section{Volcanic Stratigraphy of the Idaho National Engineering Laboratory Core Hole WO-2 (W. R. Hackett [208-526-6963; FAX 208-526-0875])}

Objectives: The primary objectives are: (1) thorough characterization of the intracaldera rhyolitic tuffs intersecied in the basal $1,250 \mathrm{ft}(385 \mathrm{~m})$ of the WO-2 core hole; (2) correlation with outflow tuffs exposed outside the Eastern Snake River Plain (ESRP); and (3) refinement of the silicic-volcanic stratigraphy of the ESRP associated with passage of the Yellowstone mantle plume.

Project Description: Five thousand $\mathrm{ft}(1.5 \mathrm{~km})$ of rock core have recently been recovered from core hole WO-2 at the Idaho National Engineering Laboratory, on the ESRP. The ESRP is a large bimodal igneous province that developed in the wake of the Yellowstone mantle plume. The basal 1,250 $\mathrm{ft}(385 \mathrm{~m})$ of WO-2 core are composed of Neogene rhyolites, the first complete section of silicic volcanics yet continuously cored from this igneous province. The rhyolites are predominately ash-flow tuffs, erupted from inferred but now buried calderas.
Rock lithology, petrography, paleomagnetic properties, phenocryst compositions, and single-crystal argonisotopic age determinations are used to characterize the core hole rhyolites and to correlate them with subaerially exposed, outflow tuffs from the surrounding terrain.

Results: The regional-stratigraphic framework of Neogene silicic volcanism on the ESRP has been substantially refined through investigation of the WO-2 rock core. Rock lithology suggests that the WO-2 rhyolites are intracaldera tuffs. The WO-2 drillcore records ESRP silicic volcanism and caldera formation from about 6.6 to $6.3 \mathrm{Ma}$. During that interval, at least five major ash-flow tuffs erupted, all part of the Heise volcanic field. Three of the borehole tuffs are correlated with known outcrop equivalents, but two others are new, previously undescribed units. The project is near completion. 
CONTRACTOR:

CONTRACT:

CATEGORY:

PERSON IN CHARGE:
LAWRENCE BERKELEY LABORATORY

University of California

Berkeley, California 94720

DE-AC03-76SF00098

Geophysics and Earth Dynamics

\section{A. High-Resolution Imaging of Electrical Conductivity Using Low-Frequency Electromagnetic Fields (K. H. Lee [510-486-7468; FAX 510-486-5686; E-mail kiha@csem.lbl.gov], H. F. Morrison, and $A$. Becker)}

Objectives: Objectives are to develop numerical and field techniques for high-resolution imaging of electrical conductivity using magnetotelluric (MT) and controlledsource electromagnetic (CSEM) methods. Applications of high-resolution conductivity imaging include the mapping of groundwater, resource exploration and reservoir characterization, subsurface process monitoring, and general geological mapping of the earth's crust.

Project Description: In spite of the great progress in EM methods, many fundamental questions relating to resolution, depth of exploration, required bandwidth in frequency, and spatial sampling rate remain to be answered. To resolve some of these questions, the following four main tasks have been selected in this project: (1) improvement of the q-domain imaging method using the wavefield transform and tomographic inversion, (2) development of an approximate analysis and imaging method using the Born inversion, (3) development of a rapid and practical three-dimensional (3-D) inversion scheme, and (4) development of a borehole time-domain EM (TEM) system. Some of these tasks are driven by the pressing need to interpret the increasing amount of field data available. These data are now in the frequency domain, at only a few frequencies, and can be interpreted only with the products of tasks 2 and 3 . However, the evident success of the q-domain tomographic imaging process strongly argues for the development of a suitable wideband borehole system (task 4).

Results: The summary of this year's research includes application of the Born inversion to borehole data, im- provement in the q-domain imaging method, development of a 3-D nonlinear inversion scheme, and finally the borehole TEM system.

The Born inversion scheme developed earlier has been further improved by implementing an iterative algcrithm. In this development, the target area of unknown conductivity is assumed to be "electrically" small. The iterative Born inversion has been tested successfully using data obtained from the controlled field experiment at the University of California's Richmond Field Station.

A new method for imaging low-frequency EM data has been developed using the wavefield transform. In this method, numerically calculated transient magnetic fields are first transformed to wavefields. A two-point ray equation has been developed for the ray tomography. Rays are allowed to bend smoothly. Incorporating smoothly bending rays is important when the velocity contrast is large. The initial numerical study has been published (Lee and Xie, Geophysics 58, 1993).

A 3-D nonlinear inversion algorithm has been developed using the integral equation method. Initial results with the 3-D nonlinear inversion scheme developed here show that high-resolution imaging of electrical conductivity is possible using CSEM data collected on the surface. This requires a great deal of quality data for frequencies. Development of a prototype downhole TEM transmitter has just begun. An initial system analysis indicates that the specifications of the transmitter include a minimum of $300 \mathrm{~A} / \mathrm{m}^{2}, \mathrm{DC}$ supply at the surface, current turn-off time of less than $2 \mu \mathrm{s}$, and a base frequency of $90 \mathrm{~Hz}$. 


\section{B. Center for Computational Stismology (CCS) (T. V. McEvilly [510-486-7316; FAX 510-486-5686; E-mail tvmcevilly@lbl.gov] and E. L. Majer [510-486-6709; FAX 510-486-5686; E-mail elmajer@lbl.gov])}

Objectives: The objectives of this project are to

1. maintain a state-of-the-art computing environment in support of various seismological and other geophysical research programs,

2. develop new methods in this environment for imaging the subsurface and its processes and new methods for visualizing results, and

3. apply such methods to real research problems in U.S. Department of Energy scientific programs.

Project Description: CCS provides a core research facility for many Basic Energy Sciences programs as well as other government and private industry research ventures. A wide variety of software and hardware is developed and maintained to support high-level research. Research focuses on subsurface imaging using active and passive sources at scales ranging from meters to wholeEarth dimensions. Research activities in the previous year include the processing and interpretation of vertical seismic profiles for fracture detection and fault delineation, seismic reflection imaging, cross-hole seismic profiling for two-dimensional imaging and fracture detection between wells, and processing and analysis of microearthquake data for imaging of geothermal fields. The wide range of $\mathrm{CCS}$ research content is demonstrated in the listing of recent publications available through E-mail from E. L. Majer (see address in heading).

Present resources available to users of CCS include:

- Solbourne 902 and 602 compute server and file server with over 25 Gbytes of data storage;

- Solbourne 902 and 602 compute server and file server Multiple Sun workstations, X-terminals, and Macintosh computers for desktop use;

- 9-track and 8-mm tape drives, color printer, and 36-in. black and white plotter for seismic sections;

- various commercial processing packages including DISCO, ProMAX, SierraSeis, AIMS, NAG, SAC, and CA DISSPLA; and

- internet access for visitors.

Results: The major accomplishments of CCS come largely from the breadth of research support provided by CCS and the cross-fertilization of applications and fundamental studies. Primary strengths are in elastic wave generation and propagation, inverse methods, data processing, and tomographic imaging methods. A list of reports, peerreviewed journal articles, and $\mathrm{Ph} . \mathrm{D}$. theses that acknowledge the support of CCS can be obtained by E-mail from T. V. McEvilly and E. L. Majer.

\section{Microcrack Growth in Rock (L. R. Myer [510-486-6456; FAX 510-486-5686; E-mail myer@lbl.gov] and N.G.W. Cook)}

Objectives: This work is aimed at developing a fundamental understanding of the relationship between grainscale microstructure and properties and between macroscopic deformation and failure.

Project Description: The approach to this rese.ırch involves both theoretical modeling and laboratory testing. In the first phase of research, linear elastic fracture mechanics was used to model deformation and failure. By assuming microcrack growth and propagation under extensile mechanisms and incorporating crack interaction, it was possible to account quantitatively for dilation, strain hardening, and strain softening. Experimentally, a Wood's metal casting technique was developed to preserve microstructures as they exist under load. Triaxial tests, hollow cylinder tests, and indentation tests were performed on clastic rocks. Results showed that extensile cracking is an important mechanism of failure at the grain scale in clastic rocks under complex compressive stress conditions.

Results: Current research efforts are directed toward analysis of the role that spatial geometry and the stochastic properties of grains play in determining the strength and relative amount of strain hardening and strain softening and localization to form macro-fractures. A numerical model based on the boundary element technique has been developed to study the deformation and failure of an assemblage of circular grains. Each grain is discretized, but all unknowns are expressed in terms of stresses and displacements at the contacts between grains. Results from a model with a regular packing of grains and uniform distribution of grain strength show strong strain softening and localization of failure. Results for the same grain geometry but with a random strength distribution show more strain hardening and less localization. 


\section{Process Definition in Fractured Hydrocarbon Reservoirs (L. R. Myer [510-486-6456; FAX 510-486-5686; E-mail myer@lbl.gov], N. G. W. Cook, J. C. S. Long, E. L. Majer, T. V. McEvilly, and H. F. Morrison)}

Objectives: This program addresses the fundamental problems associated with detecting and characterizing fractures and fracture systems in hydrocarbon reservoirs.

Project Description: An integrated interdisciplinary approach has been adopted that involves laboratory studies of basic physical processes and properties of fractures, development of complementary seismic and electromagnetic methods for imaging of fractures and heterogeneities, numerical studies of flow in fracture networks of heterogeneous geometry, and hardware development for seismic imaging.

In the areas of fracture detection by geophysical methods, several goals have been accomplished. Complementary tomographic techniques have been developed for imaging of fractures using seismic and electromagnetic energy. A seismic diffraction tomography program has been developed and successfully applied to a data set from a small-scale in situ test. An electromagnetic diffusion tomography algorithm has also been developed with application to detection of planar fractures illuminated by a dipolar magnetic field.

In an activity complementing the seismic diffraction tomography development, a new approach to modeling wave propagation through fractured media is being studied. In this approach, each fracture is represented by a zero-thickness nonwelded interface with varying rheological properties. The theory has been successfully used to model results of laboratory tests on natural fractures under different stresses and under dry and saturated conditions. Subsequently, the theory has been successfully used to model compressional wave data from a cross-hole experiment in fractured basalt. Other laboratory measurements in support of the seismic theoretical studies have shown that the chemical interactions at the solid-liquid interface in a saturated fracture strongly affect, along with liquid viscosity and film thickness, the transmission of shear waves across the fracture. Seismic measurements on an anisotropic schistose rock have shown that commonly used first-order scattering theories can be used to model shear wave velocity birefringence in such rocks but do not provide an adequate model for attenuation.

Fundamental laboratory studies of fluid flow in single natural fractures revealed significant deviations from the parallel-plate model for fractures in which the change in aperture between the plates is taken to be equivalent to the mechanical deformation of the fracture. The volumetric change in fracture void space and change in contact area must also be taken into account.

Results: Current research efforts are centered in two areas: (1) study of the propagation of interface waves and guided waves incorporating the zero-thickness interface model and (2) completion of the downhole swept-frequency resonant shear wave source for fracture characterization. A model solution for the problem of a shear wave with in-plane particle motion propagating in a layer bounded by two fractures was solved analytically. Results showed that the model of a fracture as a non-welded interface resulted in more modes than would be predicted by assuming a welded interface. A numerical code based on the boundary integral equation method is being developed to model general wave propagation in layered media with non-welded interfaces.

Finally, modification of the electronics for stabilized resonance operation of the shear wave source was completed. Testing of the operating characteristics of the source over the frequency range 50 to $400 \mathrm{~Hz}$ was carried out prior to on-site testing in boreholes at the Geophysical Measurements Facility.

\section{E. Coupled Thermal-Hydraulic-Mechanical Processes in Petroleum Reservoirs ( $C$. $-F$. Tsang [510-486-5782; FAX 510-486-.5686; E-mail chinfu@lbl.gov] and J. Noorishad)}

Objectives: Development and application of the numerical simulator ROCMAS for the analysis of thermalhydraulic-mechanical processes in saturated fractured porous media.

Project Description: The work involves development of the formulation equations and numerical algo- rithms that simulate the simultaneous occurrences of heat flow, fluid flow, and deformation in the complex environments of geologic media. Coupled equations of conservation of mass, momentum, and energy are used. The solution of the initial and boundary value problem is then expressed as a finite element matrix formulation. The use 
of proper constitutive models that govern the macroscopic behavior of the media is a critical aspect of this development. Realistic models of pre- and post-failure mechanical behavior of brittle and ductile continua as well as fractured continua are considered, along with temperature-dependent fluid density and viscosity and stress-dependent fracture permeability. Treatment of material nonlinearities, in the context of an incremental loading path, is another crucial part of the work. Alternative schemes of linearization, mainly based on the Newton-Raphson method, are employed.

\section{Results:}

1. Plasticity algorithms, in the context of hydroelasticity phenomena, were implemented in the ROCMAS code. This material constitutive law will serve as a basis for consideration of continuum-based failure theories.

2. A new method has been developed for treating sharp fronts in convection-dominated transport problems in the context of the space-time finite element method.

3. A !-boratory verification of normal and shear testing of a fractured rock sample has been achieved for the ROCMAS code.

\section{F. Controls on Pull-Apart Basin Evolution: Integrated Geological, Geophysical, and Modeling Studies (P. L. Williams [510-486-7156; FAX 510-486-5686; E-mail plw@geo.lbl.gov] and T. V. McEvilly)}

Objectives: In a variety of Earth science and technology problems it is becoming increasingly critical to identify and characterize in three dimensions the geologic structure of sedimentary basins. This project will develop a better understanding and predictive capability for the three-dimensional (3-D) structure of pull-apart basins.

Project Description: This project is directed at the development of a predictive capability for the 3-D structure of pull-apart basins. Stage one of this work is the integration of surface geology and high-resolution subsurface geological and geophysical data in full 3-D basin representation. This project will complete 3-D representations, or "empirical models," of the bounding geometry, structural elements, stratigraphy, and sedimentology of selected basins. This provides a point of departure (and constraints) for stage two of the project: the development of a new generation of 3-D numerical or "theoretical mechanical basin models."

The development of realistic mechanical models of an extensional basin's evolution will require the encoding of accurate basin geometries and deformation history. Subsequent modeling will test how fault geometry and fault displacement affect basin structure in three dimensions.
Improving understanding of pull-apart basins will contribute to better predictions of (1) the nature of subsurface fluid flow, (2) the propagation of extensional faults in the upper crust, and (3) the extent and nature of surface deformation associated with pull-apart areas. A structural basin model that incorporates the basin's sedimentological history will reveal tectonic processes of the basin's growth and evolution.

Results: Results to date include the interpretation of multiple high-resolution data sets (0-100-m depth) across extensional basins. Data include trench, borehole, highand very high-resolution seismic reflection representations of basin stratigraphy and structure. "Flank-collapse," possibly a new class of extensional structure, was found along the perimeter of the primary pull-apart basins of this study (Tule Pond and San Pablo trough). These collapse features may limit the permitted geometries and slip distributions of basin-bounding faults.

New methods for very high-resolution seismic reflection profiling have been introduced under this grant, and a paper entitled "Geophysical Detection of Fault Activity, Geometry, and Recurrence Behavior: Rodgers Creek and Pinole Faults, California" was submitted to Science during summer 1993. 


\section{CATEGORY:}

PERSON IN CHARGE:

\section{Geochemistry}

\author{
S. M. Benson
}

\section{A. Thermodynamics of High-Temperature Brines (K. S. Pitzer [510-486-5456; FAX 510-642-6911; E-mail kspitzer@lbl.gov])}

Objectives: This project covers theoretical and experimental studies concerning the thermodynamic properties of aqueous electrolytes and other systems at high temperatures. The components important in natural waters and other geochemical fluids are emphasized. The resulting data are important in understanding various geological processes, in exploiting geothermal and other natural resources, and in fission-product waste disposal. Moreover, this information has a wide range of applicability because similar fluids arise in many industrial processes and in high-pressure steam power plants.

Project Description: The project includes both experimental and theoretical programs. The experimental program involves measuring heats of mixing or dilution of solutions at temperatures extending above $350^{\circ} \mathrm{C}$ and pressures to $1 \mathrm{kbar}$. The new calorimeter is being tested, and measurements will proceed for the mixing of $\mathrm{NaCl}(\mathrm{aq})$ with $\mathrm{CaCl}_{2}$ (aq).

Results: Recent theoretical results included a comprehensive model for both saturated liquid $\mathrm{NaCl}-\mathrm{KCl}-\mathrm{H}_{2} \mathrm{O}$ and solid $\mathrm{NaCl}-\mathrm{KCl}$ over a wide range of temperatures and pressures and the full range of composition. Recent research also yielded a new general equation of state for $\mathrm{CO}_{2}$ and for $\mathrm{H}_{2} \mathrm{O}$, valid over the broad range 218 to $1600 \mathrm{~K}$ and 0 to 100 kbars. This equation can be generalized to the binary $\mathrm{H}_{2} \mathrm{O}-\mathrm{CO}_{2}$ in a manner consistent with the statistical mechanics of multicomponent systems. Currently, an equation is being developed for $\mathrm{CaCl}_{2}-\mathrm{H}_{2} \mathrm{O}$ extending to solid saturation, which is at very high concentration. Equilibrium with the saturating solid hydrate is also a part of this treatment, and improved property values are obtained for the solids.

\section{B. Integrated Isotopic Studies of Geochemical Processes (D. J. DePaolo [510-486-4975, 510-643-7686; FAX 510-486-5686, E-mail depaolo@garnet.berkeley.edu or ddepaolo@geo.lbl.gov] and B. M. Kennedy [510-486-6451; FAX 510-486-5686; E-mail bmkennedy@geo.lbl.gov])}

Objectives: To combine high-precision measurements of isotopic ratios in natural materials with mathematical models to understand the spatial and time scales of geochemical processes of interest for energy management.

Project Description: Current effort is concentrated on $\mathrm{Sr}, \mathrm{Ca}, \mathrm{O}, \mathrm{C}, \mathrm{He}, \mathrm{Ne}, \mathrm{Ar}$, and $\mathrm{Nd}$ isotopic ratios and on problems of mass transport in fluid-rock systems, interpretation of past global climatic change, stratigraphy and structure of sedimentary basins, and crustal magmatic and tectonic processes. A mathematical basis for the application of isotopic measurements of fluids and rocks to the field-scale parameterization of hydrological systems is a major effort. This approach is supplemented by systematic measurements of relatively simple natural systems and by the development of improved sampling and measuring techniques to enhance information return. Emphasis in development is on microsampling of geological materials, on high-precision measurement of the small amounts of recovered material, and on rapid, automated low-blank chemical separation of trace elements. Other efforts are aimed at geochemical techniques for dating and correlating sedimentary and volcanic rocks and for understanding the time scales and mechanisms of crustal processes such as extensional faulting, mountain building, and volcanism. These efforts are aimed at improving geological characterization for regulatory purposes and at improving subsurface characterization of sedimentary reservoirs.

Results:

1. One- and two-dimensional models of isotopic evolution of migrating groundwaters in saturated media have been developed and applied to the interpretation of isotopic data in subsurface vein deposits at Yucca Mountain, Nevada. New measurements have been made of strontium isotopic variations in modern 
groundwaters at Yucca Flat to determine empirically the equilibration length scale (or the Damköhler number) of the fluids.

2. New neodymium isotopic measurements of postcaldera silicic lavas at Long Valley, California, provide a time series that gives the history of intensity of basaltic input to the system over the past $800 \mathrm{Kyr}$ and can be used to estimate the rate of accumulation and current maximum size of the magma reservoir in the subsurface.

3. Oxygen isotopic data on dsep-sea pore fluid have been inverted using a model for diffusive transport to esti- mate the isotopic composition of ocean water at the 20-Ka glacial maximum; the results constrain temperatures of precipitation in sites of continental ice accumulation and show that pore fluid data are a source of geohistorical data that may be valuable in contaminaied lakes and rivers.

4. Strontium isotopic data on carbonate from estuarine sediments in San Francisco Bay have been used to reconstruct the salinity of the bay and hence the freshwater inflow from the Sacramento and San Joaquin rivers for the past 4300 years.

\section{CATEGORY:}

\section{PERSON IN CHARGE:}

\section{Energy Resource Recognition, Evaluation, and Utilization}

\section{S. M. Benson}

\section{A. Hydrothermal Chemistry (H. A. Wollenberg [510-486-5344; FAX 510-486-5686])}

Objectives: Investigation of rock-fluid interactions and fluid pathways associated with calderas.

Project Description: Alteration mineralogy and isotope ratios in rock matrix and fracture linings are combined with chemistries and isotope ratios of ciownhole fluid samples and springs and with mineralogy of drill core and cuttings to determine the extent of rock-water interaction. Oxygen, carbon, hydrogen, and strontium isotope ratios and radioelements are used to trace the paths of hydrothermal fluids from precipitation in recharge areas, through the hydrothermal system, to surface manifestations. Alteration mineral assemblages are used to reconstruct thermal regimes associated with earlier hydrothermal circulation.

Results: Most recently, the loci and abundance of radioelements were examined in rocks encompassing the Valles and Long Valley calderas. Examination of radioelements in core from scientific drill holes at these sites was done by gamma-ray spectrometry and fission-track radiography. In the hydrothermal system at Long Valley, uranium is concentrated in iron-rich zones associated with varved tuff and with calcite-cemented breccia. Uraniumseries disequilibrium in some samples suggests localized mobilization/deposition of parent uranium and/or its daughters. In the vapor zone of the Valles caldera's hydrothermal system, the concordance of high uranium, low thorium/uranium, and decreasing whole-rock oxygen-isotope ratios indicates that uranium was concentrated in response to hydrothermal circulation when the system was formerly liquid dominated. In the liquid-dominated zone, uranium occurs preferentially with pyrite and iron-oxide minerals. Uranium is also concentrated in iron-rich zones in the Valles outflow zone and is found with carbonaceous material in the Paleozoic calcareous rocks that underlie the Quaternary tuffs. Springs recharging the Valles hydrothermal system have relatively high concentrations of uranium, while considerably lower concentrations occur in waters of the system's outflow plume suggesting that uranium is concentrating in the hotter part of the system. These caldera observations indicate that uranium and radium are locally mobile under hydrothermal conditions and that reducing conditions associated with iron-rich minerals and carbonacenus ruaterial is an important factor in the adsorption of uranium and thus can retard its transport in water at elevated temperature-important considerations for nuclear waste isolation in tuffaceous rocks. 


\section{B. Geophysical Measurements Facility (GMF) (T. V. McEvilly [510-486-7316; FAX 510-486-5686; E-mail tumcevilly@lbl.gov], H. F. Morrison [510-624-3804; FAX 510-642-3805], and E. L. Majer [510-486-6709; FAX 510-486-5686; E-mail elmajer@lbl.gov])}

Objectives: The objectives of this project are to

1. maintain a state-of-the-art multidisciplinary field instrumentation facility in support of various environmental, geophysical, and hydrogeological research programs at Lawrence Berkeley Laboratory (LBL);

2. assist in developing (a) new instrumentation and field methods for investigating the subsurface and its processes and (b) in-field visualization of results; and

3. provide professional in-field training for scientific staff and management of complex and varied field studies required in U.S. Department of Energy scientific research programs.

Project Description: GMF is the focal point for an extensive inventory of complex scientific equipment used for LBL projects, with responsibility for maintenance, upgrading, training, and field operations for this hardware. Although individual research projects provide funds for specific operations in the field, GMF funding provides the infrastructure support. GMF is a valuable and necessary core function, supporting a broad range of field research activities with an excel'ent complement of modern geotechnical instrumentation. GMF allows for manage- ment of a growing complement of sophisticated field instrumentation and associated support vehicles and of test and maintenance gear for LBL the Earth Sciences Division. The facility addresses the problem of poor readiness of hardware when needed for research projects (with resulting unacceptable mobilization costs incurred by individual projects) by maintaining equipment between uses by research projects. GMF supports projects ranging from deep-well geothermal fluid sampling to hydrogeological and geochemical measurements in groundwater to highresolution cross-well tomography and operation of modern digitally telemetered microearthquake recording networks.

Results: The major accomplishments of GMF are largely in the quality and breadth of field support provided by the facility and in the influence of this resource on LBL research breadth and quality. A list of reports and publications for which GMF was used for data collection can be obtained by E-mail from T. V. McEvilly (address in heading). Examples for 1993 include velocity structure of the Long Valley Caldera, microearthquake clusters in the study of fault zone dynamics, and application of the seismic displacement discontinuity theory to laboratory and cross-well data. 
CONTRACTOR:

CONTRACT:

CATEGORY:

PERSON IN CHARGE:
LAWRENCE LIVERMORE NATIONAL LABORATORY

University of California

Livermore, California 94550

W-6405-ENG-48

Geophysics and Earth Dynamics

\section{A. Rheology of Partially Molten Crustal Rocks (F. J. Ryerson [510-422-6170; FAX 510-422-1002; E-mail ryerson@s91.es.llnl.gov], W. B. Durham, and B.P. Bonner)}

Objectives: The objective of this project is to characterize the rheological behavior of crustal lithologies as they evolve through their melting interval, and to characterize the microstructural evolution so that polycrystalline deformation mechanisms can be determined. Such data should lead to an improved understanding of melt migration, segregation, and convection.

Project Description: The deformation of synthetic crustal rocks is being experimentally determined using an internally heated gas-media deformation apparatus. Synthetic polycrystalline aggregates have been made using two methods. The first method is based upon spray drying of dilute colloidal silica producing a free-flowing amorphous powder, which subsequent to calcination and hotpressing results in a fine-grained $(<5 \mathrm{~mm})$ quartz aggregate. This powder may also be mixed with solutions of other elements prior to a second spray drying step to produce a quartz-melt aggregate for deformation. The second method uses an air-driven particle pulverizer to produce fine-grained powders of bulk samples of natural melt compositions. These powders can then be spray dried with colloidal silica to produce aggregate precursors. Both methods produce fine-grained quartz-melt aggregates with a homogeneously distributed melt phase. Such samples display ductile deformation at $\mathbf{2}$ kbar confining pressures. Samples are characterized by scanning electron microscopy and infrared spectroscopy before and after deformation.

Results: Deformation experiments have been performed on (1) nominally melt-free quartzites, (2) quartz- ites containing $\sim 5$ vol $\%$ sodium silicate melt, and (3) quartzites containing up to $30 \%$ granitic melt. All runs were performed at $2 \mathrm{kbar}$ and $1000^{\circ} \mathrm{C}$. The behavior of melt-free samples is highly variable, showing strengths up to $300 \mathrm{MPa}$, and steady-state behavior is rarely attained under these conditions. The samples contain numerous pores, presumably filled with fluid at run conditions, and show ubiquitous microcracking. The microcracking is thought to be a result of embrittlement caused by the decreased effective stresses imposed by high fluid pressures. Sodium silicate-bearing samples display steadystate behavior with strengths of $100 \mathrm{MPa}$. No porosity is observed, and microfracturing is absent. We believe that the melt acts as a "getter" for water in these samples, reducing the fluid pressure and transforming the behavior from brittle to ductile. An interesting implication of these results is that shearing of fluid-bearing quartzites may lead to microfracturing and increased permeability. This is in contrast to the low premeabilities expected from equilibrium fluid-crystal textures in quartzites, which predict no interconnected fluid phase. Samples containing $~ 30 \mathrm{vol} \%$ granitic melts remain surprising strong with strengths of $\sim 65 \mathrm{MPa}$. This value implies that the "rheologically critical melt-fraction," that fraction at which the solid matrix collapses, occurs at higher melt fraction. This conclusion is in agreement with predictions based upon solid contiguity based on melt-solid wetting angles, which predict that matrix collapse should not occur until at least $50 \%$ melting. 


\section{B. Quantitative Image Analysis to Determine Rock Properties (J. G. Berryman [510-423-2905; FAX 510-422-1002; E-mail berrymanl @llnl.gov] and S. C. Blair [510-422-6467; FAX 510-423-1057; E-mail blair@s55.es.llnl.gov])}

Objectives: The objective of this project is to use advanced image processing and analysis techniques to characterize the physical and mechanical properties of rocks. Important features of the topology of the pore space of rocks can be usefully quantified by analyzing digitized images of rock cross sections.

Project Description: Statistical correlation functions are computed using modern image processing techniques, and these techniques have been successfully used to aid in prediction of the permeability of several different sandstones. Experimental results on permeability of sandstones are compared to explicit predictions of the method using image processing and to continued extension of this analysis to include the mechanical properties of rocks.

Results: In our previous studies of relative permeability, we investigated two-phase flow in a sandstone. This was accomplished by first producing and analyzing images of a sample of Berea sandstone in which the pore space was segregated into regions occupied by wetting and non-wetting pore-casting phases. The Kozeny-Carman relation was then applied to the total pore space and the pore space occupied by each phase. Estimation of the overall permeability of the sample was within a factor of two of the measured permeability. Analytical expressions that incorporate the percolation thresholds were developed as well as a simple but rigorous analytical expression relating the surface area of fluid-fluid interfaces to other surface areas considered in multiphase flow. Work also continues on measuring higher-order correlation functions using image processing methods and their application to predicting rock properties.

In an ongoing mechanical study, a general methodology is being developed that can predict the mechanical behavior of rocks and other heterogeneous materials in the brittle field, based on properties of their microstructure. Rock fracture is known to be sensitive to disorder over many scales, and image processing is being used to characterize the various types of disorder observed. The mechanical properties of rocks are greatly influenced by cracks and fractures, which nucleate at the grain scale. Initial efforts were focused on investigating the effect of strength disorder on the process of fracture. A discrete element approach has been used to study these phenomena. In our model the rock is represented with a network of elements, where each element has properties corresponding to a mechanical device such as a spring or a beam. A breaking rule is associated with each element. Broken elements may be removed or assigned new physical properties. The codes have been developed to the point where a video tape is now available showing the results of some numerical experiments.

\section{Modification of Fracture Transport Properties of Rocks by Mechanical and Chemical Processes (W. B. Durham [510-422-7046; FAX 510-423-1057; E-mail durham@s38.es.llnl.gov] and B. P. Bonner)}

Objuctives: This project aims to understand the hydraulic and mechanical properties of individual fractures in crustal rock and identify processes by which joints are modified or resist modification over long time scales.

Project Description: The project is a laboratory study of the relationships between applied normal stress, joint normal deformation, joint fluid conductivity, and joint shape. Samples are usually low-permeability granitic rocks containing a single fracture, and measurements of permeability and deformation are made in a pressure vessel under pressures to $160 \mathrm{MPa}$. We identify systematics of the above relationships and look for models that satisfy these systematics, or, because modeling has not reached the level of detail that is definable by our measurements, we try to develop explanations for observed behavior. We have the means to vary parameters such as surface roughness and normal force to see the effect they have, and we have the means for physically measuring the shape of surfaces and joint space at a fine scale to help us understand the physical mechanisms behind the phenomena we observe macroscopically. An important premise of the work is that the elastic and inelastic deformation and fluid permeability of a fracture are functions of its physical shape and that the relevant characteristics of the physical shape can follow from a statistical treatment of the fracture as a random process.

Results: Three joints in Westerly granite have been measured in detail. Clearly when joints are well mated, the application of confining pressures to $160 \mathrm{MPa}$ is sufficient to close the joint hydraulically. However, if the joint is 
constructed by offsetting the sides of the joint laterally by a small amount ( $0.5 \mathrm{~mm}$ over a 150 -mm-long specimen), pressures of even $160 \mathrm{MPa}$ are insufficient to close the joint. Study at near microscopic levels of the joint space and surfaces before and after testing reveals the surprising result that at $160 \mathrm{MPa}$ no more than about $20 \%$ of the surfaces of the joint walls are in contact with each other and only half of that contact results from inelastic deformation. The parallel plate approximation (i.e., the cubic dependence of permeability on mean aperture) seems to break down for both well-mated and poorly mated joints after the first increments of pressure have closed the joint a small amount. For both kinds of joints, permeability drops faster than expected because increasing wall-to-wall contacts lead to more tortuous flow paths and lower flow rates.

Existing models have been unsatisfactory in fitting our observations, especially at low values of mean aperture. A modified effective medium theory model is being formulated that will allow percolation (i.e., water flow through the joint) where wall-to-wall contact areas exceed $50 \%$ of the total area, the point where conventional models suggest that flow stops. Initial results are promising.

\section{Poroelasticity of Rock (B. P. Bonner [510-422-7080; FAX 510-423-1057] and H. F. Wang, University of Wisconsin)}

Objectives: The objective of this project is to improve treatment of poroelastic problems involving the coupled processes of deformation and fluid flow by obtaining improved theoretical estimates of the poroelastic coefficients and by performing experiments designed to test and extend the theory.

Project Description: Geologic processes and geophysical interpretations that involve significant coupling between deformation and fluid flow are at the interface between rock mechanics, seismology, and geohydrology. For example, results are applied to problems of wave propagation in saturated rock, simulation of underground flow, hydrofracturing, and measurements of in situ stress from borehole measurements of strain and breakouts. The theoretical approach is to obtain improved methods of calculating the porcelastic coefficients by removing the restrictive assumptions inherent to existing theory. The experimental approach, taken in collaboration with $\mathrm{H}$. Wang at the University of Wisconsin and D. Green of Ohio University, is to collect measurements of the poroelastic coefficients, or of quantities that depend directly on them, over frequencies that range from near static to ultrasonic for a sample suite of well-characterized natural and synthetic sandstones.
Results: Considerable progress has been made on the experimental component of the project during this year. Synthetic "sandstones" have been manufactured from glass beads to span the porosity range from 2 to $40 \%$. The dynamic elastic constants, pore pressure buildup (Skemptons) coefficient, permeability, and low-frequency shear modulus and attenuation have all been measured for this material for comparison with natural sandstones. Samples were also prepared for collaborative measurements of low-frequency Young's mode attenuation to be taken by H. Spetzler at the University of Colorado. Preliminary measurements of the low-frequency shear modulus and attenuation were also made for Berea sandstone containing pore fluid from $30 \mathrm{MHz}$ to $180 \mathrm{~Hz}$. The theoretical component of the project led to an extension of the effective pressure law for permeability. It is not possible to match experimental observations of the change of permeability with pore pressure with an equivalent medium approximation, as has been assumed previously. The properties of a second phase, typically the clay fraction in sandstone, must be taken into account properly. By combining theoretical estimates and experimental data for the bulk modulus of the synthetic sandstones, it was demonstrated that a theory sensitive to microstructure can predict the modulus reduction to porosities of $40 \%$.

\section{E. The Role of Carbon and Temperature in Determining Electrical Conductivity of Basins, Crust, and Mantle (A. G. Duba [510-422-7306; FAX 510-423-1057; E-mail alduba@llnl.gov] and T. J. Shankland, Los Alamos National Laboratory)}

Objectives: The intent of this work is to comprehend the electrical conduction mechanisms in carbon-bearing rocks and mantle minerals for the purpose of relating electrical conductivity $(\sigma)$ measured in the field to forma- tion conditions and existing state of crustal rocks and to temperatures in the mantle.

Project Description: Electrical conductivity depends strongly on temperature $\mathrm{T}$ (for mantle conditions) and on 
the presence of other phases such as carbon, fluids, or ore minerals at the lower temperatures of the crust and basins. Thus, one research approach is to measure $\sigma$ of mantle minerals as functions of temperature, orientation, oxygen fugacity $f \mathrm{O}_{2}$, and iron content; samples at ultrahigh pressures were measured in the diamond anvil cell. These data supply the best models for "electrogeotherms" yet available. Another approach is to document textures of carbon in crustal rocks from basins and metamorphic zones and relate them to rock conductivity. In this case, texture of carbon distribution is mapped with electron microscopy in the same samples used for $\sigma$ measurement.

Results: Because the lower mantle makes up the bulk of the earth, its electrical conductivity is a property of great interest for propagation of core geomagnetic disturbances and possible core-mantle coupling, as well as problems of bulk composition, mineralogy, and temperature. Conductivities were measured in the diamond anvil cell of magnesio-wustite + pyroxene-perovskite [mw+pv, bulk compositions $\mathrm{x}=0.11$ and 0.16 in $\left.\left.\left(\mathrm{Mg}_{1-\mathrm{x}} \mathrm{Fe}_{\mathrm{x}}\right)_{2} \mathrm{SiO}_{4}\right)\right]$ and of pyroxene-perovskite (pv, composition $x=0.11$ in $\mathrm{Mg}_{1-\mathrm{x}} \mathrm{Fe}_{\mathrm{x}} \mathrm{SiO}_{3}$ ) at pressures of 1.2 to $40 \mathrm{GPa}$ over the temperature range 20 to $400^{\circ} \mathrm{C}$. Each data set was fitted to an equation of the form $\sigma=\sigma_{0} \exp [-(\Delta \mathrm{U}+\mathrm{P} \Delta \mathrm{V}) / \mathrm{kT}]$, where $\mathrm{P}=$ pressure in $\mathrm{GPa}, \mathrm{T}=$ temperature in $\mathrm{K}$, and $\mathrm{k}$ is Boltzmann's constant. Having a functional form at lower mantle depths $z$ enables calculation of $\sigma(\mathrm{z}, \mathrm{T}, \mathrm{P})$ that agrees well with field geophysical models. A robust conclusion is that conductivity varies only by about a factor of 5 across the entire lower mantle, and combined effects of pressure and temperature cause $\sigma \rightarrow \sigma_{0}$ at the base of the mantle. Thus, lateral temperature variations of a few $100 \mathrm{~s}$ of degrees should be hard to detect, and a convecting lower mantle may be well approximated by radial symmetry in $\sigma$.

We have also measured the electrical conductivity of crustal rocks collected from surface exposures near the Denali Fault Zone in the Yukon-Tanana Terrane of Alaska at pressures to $500 \mathrm{MPa}$ to see if pressure causes the reconnection of carbon conductors that are present in the rock. No increase of conductivity with pressure was seen, but a smaller than expected decrease of conductivity of some of these saturated rocks with pressure was observed and may be the result of a small amount of reconnection partially offsetting the conductivity decrease caused by the loss of pore saturant as crack porosity decreases with pressure increase. However, a dramatic increase of conductivity was observed for saturated rocks from the German deep drillhole up to pressures of $400 \mathrm{MPa}$. The good conductor in this case is ilmenite along the lineation that was broken by the cracking caused by pressure release and temperature release as the core was brought to the surface. However, the ilmenite was not altered by oxidation and weathering as was in the Alaskan rocks during their more leisurely journey to the surface, so the good conductor that existed at depth is unaltered and is easily reconnected by pressure for the unaltered rocks from the drill core. This is a good example of the utility of drill holes in addressing the interpretation of field geophysical measurements.

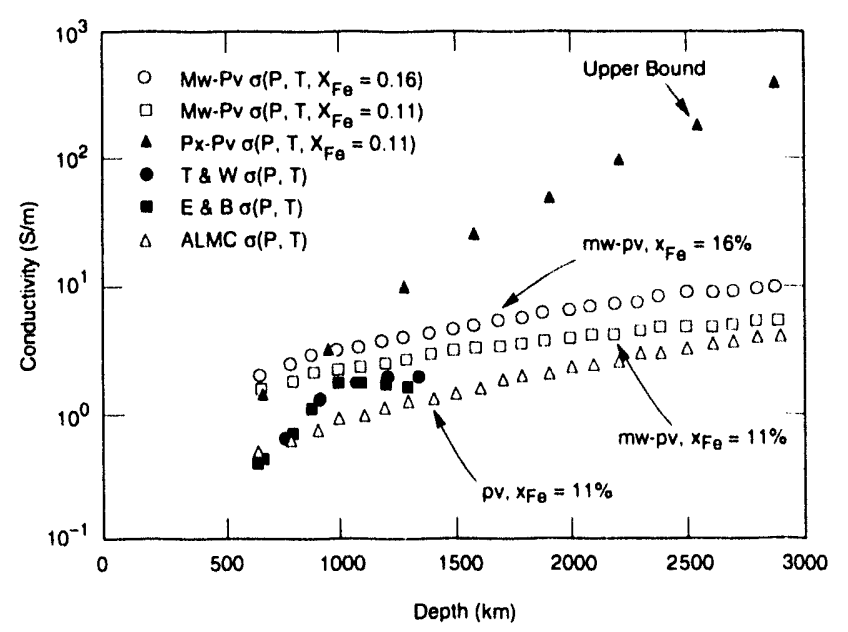

\section{F. Interpretation of Geodetic Crustal Strains Using Nonlinear Dynamical Models for the Deformation of Solids (J. B. Rundle [510-424-5236; FAX 510-422-1002; E-mail rundle@s37.es.llnl.gov])}

Objectives: Objectives of this project are to (1) develop analytical and numerical modeling techniques to interpret deformation mechanisms associated with earthquakes and other sources of crustal strain and (2) validate modeling techniques by comparing predictions to numerical simulation, laboratory, and field data.
Project Description: A variety of critical energy facilities face significant natural hazards from several kinds of tectonic instabilities, notably earthquakes, volcanic eruptions, and landslides. The most promising approach to understanding these instabilities is to analyze, using appropriate dynamical models, crustal strains using a variety of land- and space-based field geodetic and other data. Re- 
cent progress in numerical simulation techniques involving faults, fracture systems, and landslides has been made by developing nonlinear dynamical simulations of these complex systems. Models are based on cellular automaton techniques, field theories using Langevin dynamics, and on the nearest neighbor Burridge-Knopoff model for earthquakes. Analysis of results employs ideas borrowed from studies of scaling theories, including critical phenomena, nucleation in thermal and magnetic systems, and percolation problems. Simulations are being carried out on a variety of machines ranging in size from desktop workstations to high-performance, massively parallel supercomputers.

Results: Results have been obtained in four basic areas: (1) computing kinematic Green's functions, (2) fracture models, (3) lattice automata and nonlinear maps, and (4) applications to data. In the first area, numerical codes have been written to solve the problem of calculating surface deformation and gravity change arising from various sources in general inelastic earth models. Second, field theory concepts from statistical mechanics are being used to understand fracture of materials. Results indicate that fracture is isomorphic to nucleation in thermal and magnetic systems, and the formulation allows for modes of failure more general than the classical Griffith mode, similar to results seen in the laboratory. Third, lattice automata models for two surfaces sliding in frictional contact have been constructed using governing equations that are isomorphic to simple dynamical equations used elsewhere in statistical mechanics. These define a nonlinear map propagating the system state forward in time and exhibit behavior that is isomorphic to nonclassical nucleation near a spinodal, with the same scaling exponents and properties seen in thermal and magnetic systems. Finally, validation of the Green's functions and dynamical models is being carried out using field geodetic and laboratory data.

\section{G. Oxygen and Cation Diffusion in Oxide Materials (F. J. Ryerson [510-422-6170; FA: 510-422-1002; E-mail ryerson@s91.es.llnl.gov] and K. D. McKeegan, University of California at Los Angeles, Dept. of Earth and Space Sciences, Los Angeles, CA 90024 [310-825-3580; FAX 310-825-2779; E-mail kdm@argon.ess.ucla.edu])}

Objectives: The objective of this work is to measure the diffusion parameters for various cations and oxygen in important rock-forming minerals to constrain both geochemical transport processes and diffusive mechanisms affecting physical properties such as creep and electrical conductivity.

Project Description: Diffusion rates are strongly affected by temperature, pressure, and crystal orientation. They may also depend upon additional variables such as oxygen fugacity and the activity of water in the system. Experiments are being conducted in which all of these variables are controlled and selectively varied. The pressures of current experiments (concentrating on olivine, plagioclase, diopside, garnet, and spinel) range from $1 \mathrm{~atm}$ to $10 \mathrm{GPa}$. The primary analytical tool used in these investigations is an ion microprobe.

Results: Oxygen self-diffusion coefficients have been measured for three natural clinopyroxenes, a natural anorthite, a synthetic magnesium aluminate spinel, and a synthetic akermanite over oxygen fugacities ranging from the $\mathrm{Ni}-\mathrm{NiO}$ to $\mathrm{Fe}-\mathrm{FeO}$ buffers. The experiments employed a gas-solid isotopic exchange technique using $99 \%{ }^{18} \mathrm{O}$-enriched $\mathrm{CO}-\mathrm{CO}_{2}$ gas mixtures to control both the oxygen fugacity and the isotopic composition of the exchange reservoir. The experimental results yield the following Arrhenius parameters: cpx: $D_{0}=4.3 \times 10^{-4} \mathrm{~m}^{2} \mathrm{~s}^{-1}$, $\mathrm{Q}=457 \mathrm{~kJ} \mathrm{~mol}{ }^{-1}$, akm: $\mathrm{D}_{0}=4.7 \times 10^{-7} \mathrm{~m}^{2} \mathrm{~s}^{-1}, \mathrm{Q}=278 \mathrm{~kJ}$ $\mathrm{mol}^{-1}$, sp: $2.2 \times 10^{-7} \mathrm{~m}^{2} \mathrm{~s}^{-1}, \mathrm{Q}=404 \mathrm{~kJ} \mathrm{~mol}^{-1}$, an: $\mathrm{D}_{0}=8.4$ $\times 10^{-13} \mathrm{~m}^{2} \mathrm{~s}^{-1}, \mathrm{Q}=162 \mathrm{~kJ} \mathrm{~mol}^{-1}$. The clinopyroxenes, from DeKalb, N.Y., Rajasthan, India and Ala, Piemonte, are all nominally diopside end member, and their oxygen self-diffusion coefficients are indistinguishable. At a given temperature, oxygen diffuses about 100 times more slowly in diopside than indicated by previous bulk-exchange experiments. Our data for anorthite, spinel, and akermanite agree well with prior results obtained by gas-solid exchange and depth profiling methods. Because these other experiments were conducted at different oxygen fugacities, this agreement indicates that diffusion of oxygen in these nominally iron-free minerals is not greatly affected by $f \mathrm{O}_{2}$ in the range between pure oxygen and the $\mathrm{Fe}-\mathrm{FeO}$ buffer.

Oxygen diffusion in a series of garnets is being measured. Efforts are concentrated on determining the surface stability of these minerals under various conditions prior to contact with a tracer gas or solution. 


\section{H. Advanced Concepts (F. J. Ryerson [510-422-6170; FAX 510-422-1002; E-mail ryerson@s91.es.llnl.gov])}

Objectives: This project provides support to encourage the development of new ideas and research directions in the earth sciences.

Project Description: New topics are selected each year based on scientific merit and relationship to the mission and interests of the Earth Sciences Department. Typically, research is oriented toward de veloping capabilities that will be needed by Laboratory programs in the future. Seed money is also provided to assess the feasibility of a given research direction to develop experimental or computational requirements.

Results: This project has supported exploratory studies in the application of atomic force microscopy to the investigation of mineral dissolution and precipitation $\mathrm{ki}$ netics at elevated temperature. A prototype cell was constructed that allows real-time atomic force microscopy measurements at up to $90^{\circ} \mathrm{C}$ under flowing conditions and up to $170^{\circ} \mathrm{C}$ in air. The sample platform and sample are resistively heated with wound copper wire. Use of lowexpansion alloy Invar as a platform material results in minimal sample motion during heating, a problem that hindered our first attempts at elevated temperature work. Even at $17^{\circ} \mathrm{C}$ no image distortion was detected. The sample platform has been coated with nonreactive epoxy to make it chemically inert.

A linear $\mathrm{Vp}$-Vs relationship under pressure and/or temperature was observed for the experimental data of many materials as well as the earth model within a "homogeneous" region of no phase transition (Mao 1971). This relationship provided additional constraint on the calculation of velocities to mantle conditions and on the estimation of the composition of the earth's interior. Many more experimental data and earth models have been published since the last study. A linear $\mathrm{Vp}-\mathrm{V}$ s relationship was found to be consistent with all data. The lower mantle compositional implications of these data are being investigated.

To study the nature and spatial and temporal distribution of microseismic sources beneath the center of Long Valley Caldera and to assess the value of downhole seismometry at other geothermal systems and in deep boreholes, a 3-component downhole high-frequency seismic sensor was designed to be operated at a depth of $2005 \mathrm{~m}$ $(6740 \mathrm{ft})$ in the bottom of the cased portion of the Long Valley Exploratory Well. By placing a seismometer at depth, contamination of the data by scattering and attenuation in the caldera fill is minimized.

The sensor package, which was optimized to record the high-frequency signals that do not reach surface seismometers, consists of a triaxial set of Wilcoxon hightemperature accelerometers and a $10-\mathrm{Hz}$ vertical geophone mounted and sealed within a high-pressure casing. The sensor is mounted in a shortened version of the Geotech model 23900 borehole seismometer outer casing, which is pressure sealed with O-rings and is designed for operation in pressures up to $7500 \mathrm{psi}$ and temperatures up to $107^{\circ} \mathrm{C}$.

As was anticipated, the borehole seismograms have a much higher frequency content, sharper and more definite $\mathrm{P}$ and $\mathrm{S}$ arrivals, and a greater ratio of the direct arrival to the coda energy. We think that the future holds promise for borehole seismometry at higher temperatures than $120^{\circ} \mathrm{C}$ where the right conditions exist. We have identified (but not tested) seismic that can function up to $250^{\circ} \mathrm{C}$. One approach would be a series of piezoelectric sensors operating in the charge monitoring mode, which would avoid downhole electrical components. We are working with the KTB seismologists to help define possible configurations for a $250^{\circ} \mathrm{C}$ seismometer for use in the KTB drill hole.
CATEGORY: PERSON IN CHARGE:

\section{Geochemistry}

F. J. Ryerson

\section{A. Compositional Kinetic Model of Petroleum Formation (A. K. Burnham [510-422-7304; FAX 510-422-3118], R. L. Braun, J. J. Sweeney, and J. G. Reynolds)}

Objectives: The overall objective of this project is to develop and test models of petroleum generation, migration, and stability. The ultimate goal of this work is to reduce the cost of petroleum exploration and production by improving the reliability of integrated basin analysis, a modeling technique that incorporates many aspects of 
geology, geophysics, geochemistry, and hydrology, to determine when and where oil is generated, migrates, and accumulates.

Project Description: Generation kinetics are being measured by a variety of experimental techniques including isothermal hydrous pyrolysis and temperature-programmed pyrolysis using physical product collection and FID, MS, and TQMS detectors. The results are compared with geological predictions, and geothermometers are developed thai can be used to calibrate paleothermal models used to test the kinetic models. Current efforts are concentrated on the kinetics of oil cracking. Mathematical techniques and computer programs of varying complexity are also being developed to predict oil and gas generation, including the effects of maturation on oil composition and expulsion of the oil from source rock. The computational approaches are tested against geological data. Reliable modeling can improve oil exploration efficiency, and technology transfer is an important part of this work.

Results: Oil and gas generation kinetics have been measured by a variety of experimental techniques. The non-hydrous pyrolysis kinetics are self-consistent, leading to the conclusion that both individual species and lumped groups (e.g., oil) often require activation energy distribution models to obtain kinetic parameters that extrapolate reasonably to geologic heating rates. Measurements on whole rock samples usually give results that agree well with bitumen-free rocks and isolated kerogens. The resulting kinetics predict generation rates of important products in hydrous pyrolysis, with the exception of $\mathrm{CO}_{2}$. Kinetic analysis of hydrous pyrolysis data is subject to great uncertainties, but kinetics derived from the Rock-Eval potential of hydrous pyrolysis residues agree well with open system kinetics. Even so, open system kinetics miss some important aspects of geologic maturation. Current pyrolysis experiments are addressing oil stability, initially with hexadecane and then with isotopically labeled hexadecane in several oils. Another area examined was the use of ICP-MS to detect both the source and maturity of oil. We have incorporated most of our understanding of the oil and gas generation and expulsion processes into a computer program called PMOD. Because different kinetic modeling approaches are appropriate in different circumstances, the program allows the user to interactively construct balanced reaction networks. The user can choose from four reactor types: open system, closed system, compacting reactor with excess fluid expelled immediately, and a compacting reactor with fluids expelled by a pseudoone-dimensional approximation of Darcy's law. The fourth expulsion model calculates pore pressures and fluid volumes by a modified RKS equation of state. The model has been tested against geological data in the Maracaibo and Williston Basin.

\section{B. Thermodynamic and Transport Properties of Aqueous Geochemical Systems (J. A. Rard [510-422-6872; FAX 510-422-0208] and D. G. Miller [510-422-8074; FAX 510-422-6363; E-maildmiller@llnl.gov])}

Objectives: Objectives of this project are to (1) measure accurate osmotic/activity coefficients, densities, and Fickian diffusion coefficients for aqueous brine salts and their mixtures and osmotic/activity coefficients for acidic sulfate mixtures and (2) develop reliable methods to estimate such properties for multicomponent solutions, which will be tested against these data.

Project Description: General techniques of classical thermodynamics and irreversible thermodynamics are used to understand and model equilibrium and transport processes in brines and other electrolyte mixtures of interest to energy programs. Being measured are osmotic/activity coefficients and solubilities by the isopiestic method, densities by pycnometry, and diffusion coefficients by use of Rayleigh and Gouy interferometry.

One goal is to measure highly accurate data of these types for systems directly related to geochemical brines, diagenetic processes, radioactive waste isolation, and en- vironmental pollutants. These systems are also chosen to be used as "test-beds" for testing new estimation methods for the properties of multicomponent electrolyte solutions. The second goal is to find estimation methods that make trustworthy predictions of electrolyte mixtures of arbitrary complexity. Transport data are being analyzed as Onsager transport coefficients and as osmotic/activity coefficients with Pitzer's equations. Both types of equations should be capable of yielding reliable estimates.

Results: Isopiestic measurements at $25^{\circ} \mathrm{C}$ were completed for aqueous $\mathrm{NaCl}+\mathrm{SrCl}_{2}$ mixtures and were started for $\mathrm{H}_{2} \mathrm{SO}_{4}+\mathrm{MgSO}_{4}$ mixtures. The first system applies to radioactive waste isolation, the second to acidic mine wastes and atmospheric aerosols. An analysis of earlier results for $\mathrm{H}_{2} \mathrm{SO}_{4}+\mathrm{Na}_{2} \mathrm{SO}_{4}$ mixtures with Pitzer's equations was published in collaboration with Jamey Hovey (Switzerland) and Kenneth Pitzer (Berkeley). Equations were derived relating mean molal activity coefficients of 
different solutes in separate solutions at isopiestic equilibrium. It was shown that published calculations for $\mathrm{Na}_{2} \mathrm{WO}_{4}$ and $\mathrm{Na}_{2} \mathrm{MoO}_{4}$ are seriously in error because of neglect of a valence factor term.

Data reduction and analysis were completed for the last part of the extensive (Fickian) diffusion coefficient measurements for aqueous $\mathrm{NaCl}-\mathrm{MgCl}_{2}$ solutions at $25^{\circ} \mathrm{C}$. The published paper also contains a comprehensive description of the methods for reading the locations of and analyzing Rayleigh fringe positions on a photographic plate to yield diffusion coefficients.

Computer programs were prepared for computation of the nine diffusion coefficients of a four-component system and were tested on Gouy interferometric data obtained at the University of Naples and on a second more accurate data set obtained at Texas Christian University. These are the first diffusion coefficients for four-component systems from optical interferometry.

\section{Experimental Determination of Mineralogical Controls on U-Th-Pb Redistribution: Implications for Crust/Mantle Differentiation (H. F. Shaw [510-423-4645; FAX 510-423-1057; E-mail shaw4@llnl.gov] and F. J. Ryerson [510-422-6170; FAX 510-422-1002; E-mail ryerson@s91.es.llnl.gov])}

Objectives: Mineral/silicate liquid and mineral/aqueous fluid partition coefficients for $\mathrm{U}, \mathrm{Th}, \mathrm{Pb}$, and other trace elements of interest are being experimentally determined under conditions relevant to partial melting and fluid metasomatism in the upper mantle. The results of the project will provide important constraints on the petrogenetic interpretation of trace elements, $\mathrm{U}-\mathrm{Th}-\mathrm{Pb}$, and $\mathrm{U}$ series disequilibrium data obtained on igneous rocks.

Project Description: Along with the formation of the earth's core, the differentiation of the crust and mantle represents the major chemical fractionation process occurring on the earth. The nature of this process has been constrained by a wide variety of trace element and isotopic analyses of crust- and mantle-derived samples. Effective use of these data, however, requires a quantitative understanding of the fractionation of the elements of interest between minerals and both silicate melts and aqueous fluids. For many elements, however, the relevant min$\mathrm{eral} / \mathrm{melt}$ partition coefficients are poorly known, and there is an almost complete lack of data for the partitioning of trace elements between minerals and aqueous fluids. The goal of this project is to provide quantitative information of the partitioning of trace elements of geologic interest between minerals and melts and aqueous fluids, with emphasis on the partitioning of $\mathrm{U}, \mathrm{Th}, \mathrm{Pb}$, and the high field strength elements ( $\mathrm{Zr}, \mathrm{Hf}, \mathrm{Nb}$, and $\mathrm{Ta}$ ). Partition coefficients for elements of interest are being obtained as a function of $f \mathrm{O}_{2}, \mathrm{~T}, \mathrm{P}$, and fluid or melt composition. Experimental charges are produced using standard and newly developed techniques that use 1-atm gas-mixing furnaces and high-pressure piston cylinder devices. The trace element composition of the charges is being measured primarily by quantitative ion microprobe techniques, supplemented by electron microprobe analyses and isotope-dilution solid-source mass spectrometry.
Results: To constrain the interpretation of U-series disequilibrium data on young volcanic rocks, a series of measurements has been completed of the partitioning of $\mathrm{U}, \mathrm{Th}, \mathrm{B}, \mathrm{Sr}$, and $\mathrm{Zr}$ between chromian diopside and a modified haplobasaltic melt at $1 \mathrm{~atm}, 1280^{\circ} \mathrm{C}$, and oxygen fugacities between the iron-wustite buffer and air (Lundstrom et al., 1993, EOS 76:341). DTh ${ }^{\text {cpx/melt }}$ and Du ${ }^{\text {cpx/melt }}$ were found to vary systematically as a function of diopside composition, which varied from run to run because the charges were open to the $f \mathrm{O}_{2}$-controlled atmosphere of the furnace and suffered variable degrees of sodium loss. The compositional effect appears to be similar for both uranium and thorium, however, as $\mathrm{D}_{T h}{ }^{\mathrm{cpx} / \text { melt }} / \mathrm{DU}_{\mathrm{U}^{\mathrm{c}} \mathrm{px} / \mathrm{mell}}$ varies

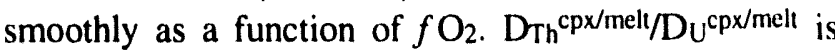
indistinguishable from unity at conditions relevant to midocean range basalt (MORB) genesis and increases with increasing $f \mathrm{O}_{2}$ because of the increasing $\mathrm{U}^{5+, 6+} / \mathrm{U}^{4+}$ ratio in the melt. These results imply that equilibrium partial melting of a peridotite in secular equilibrium cannot produce melts with $\left[{ }^{230} \mathrm{Th}\right] /\left[{ }^{238} \mathrm{U}\right]$ activity ratios greater than unity, as long as clinopyroxene is the phase controlling the behavior of uranium and thorium. Therefore, this mechanism cannot explain the ubiquitous occurrence of $\left[{ }^{230} \mathrm{Th}\right] /\left[{ }^{238} \mathrm{U}\right]$ ratios greater than unity in young MORBs. On the other hand, if our measured value for $\mathrm{DBa}^{\mathrm{cpx} / \text { melt }}$ of $\sim 0.0002$ can be taken as an upper limit to the value of

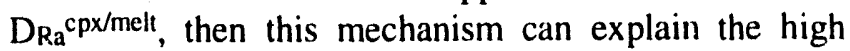
$\left[{ }^{226} \mathrm{Ra}\right] /\left[{ }^{230} \mathrm{Th}\right]$ activity ratios of young MORBs if the porosity of the melting region is sufficiently low. Experiments are being conducted to more precisely determine the effects of composition on uranium and thorium partitioning. Experiments in sealed capsules are also being conducted that will allow determination of the partition coefficient for lead in this system. 
In the past year, the necessary techniques have been developed to measure partitioning of trace elements between aqueous fluids and minerals at high temperatures and pressures. This work is of vital importance for understanding the role of slab-derived fluids in the chemical modification of the mantle sources for subduction-related volcanism. A study has been completed of the partitioning of $\mathrm{U}, \mathrm{Th}, \mathrm{Nb}, \mathrm{Ta}$, and $\mathrm{Ba}$ between rutile and fluid at $900^{\circ} \mathrm{C}$ and $10 \mathrm{GPa}$ (Brenan et al., 1993, EOS 76:340). Measured values for $\mathrm{D}^{\text {rutile/fluid }}$ are $\sim 220(\mathrm{Nb}), \sim 160(\mathrm{Ta}), \sim 10(\mathrm{U})$, and $\sim 0.04$ (Th). These results confirm the profound control exerted by residual rutile on the niobium and tantalum content of slab-derived fluids. In addition, these results indicate that residual rutile has the potential for affecting the uranium/thorium ratio in such fluids. Experiments are being conducted to determine values for $D^{c p x / f l u i d}$ and Dgamet/fluid for a variety of trace elements. Preliminary results for pyropic garnet indicate that for $\mathrm{U}, \mathrm{Th}, \mathrm{Pb}, \mathrm{Ba}$, $\mathrm{Sr}, \mathrm{Nb}$, and $\mathrm{Ta} \mathrm{D}^{\text {pyrope/fluid }}$ values are very similar to reported values for Dpyrope/melt. This suggests that metasomatism by water-rich fluids and silicate melts will produce similar trace element signatures for these elements if the fluid composition is controlled by equilibrium with garnet.
CATEGORY: PERSON IN CHARGE:

\section{Energy Resource Recognition, Evaluation, and Utilization}

\section{A. New Approaches to Underground Imaging (J. G. Berryman [510-423-2905; FAX 510-422-1002, E-mail berryman1@llnl.gov] and W. D. Daily [510-422-8623; FAX 510-422-3013])}

Objectives: The objective of this project is to analyze various methods of underground imaging to achieve more accurate and reliable estimates of physical properties of the earth and to seek the optimal resolution possible for the imaging technique considered. The main focus of this work has been to explore the implications of variational ("feasibility") constraints in applications to underground imaging without restricting attenuation to any particular imaging scheme.

Project Description: The two primary methods studied have been seismic cross hole and electrical impedance cross hole tomography. The main goal of all these efforts has been to find reliable methods that are fast (so real-time applications become feasible) and reasonably accurate. The results of this project benefit many U.S. Department of Energy programs including dynamic stripping of underground contaminants using electrical heating and imaging, enhanced oil recovery by steam flood, and basic research through imaging the detailed flow patterns of fluids in fractured rocks.

Using either seismic or electrical methods, it was found that the stability theory for reconstruction methods is surprisingly similar for these two methods, even though the physics is very different for electrical and acoustical imaging. In particular, it was discovered that rigorous variational constraints based on physical principles (like Fermat's principle of least time for determining acoustic ray paths and Dirichlet's principle of least dissipation for electrical conduction problems) may be used successfully to stabilize the geophysical reconstruction algorithms.

Results: A new imaging method called electrical impedance (or resistance) tomography (EIT/ERT) is being developed into a practical tool for cross hole imaging. EIT/ERT uses low-frequency current input and voltage output to estimate impedance/resistivity distributions in the earth. This approach has the advantage that signal attenuation is significantly lower than that in high-frequency electromagnetic tomography (developed earlier at Lawrence Livermore National Laboratory). The disadvantage of this approach is that new, more sophisticated reconstruction methods must be developed to analyze the data because the location of the electrical field lines depends on the resistivity distribution to be determined. Feasibility constraints require the measurement of power dissipation (current times voltage across the injection electrodes) as well as the more traditional voltage measurements across numerous output electrodes. Both resistor network models and finite-element simulations have shown that the additional information in the power measurements provides constraints so that reconstructed images are much less susceptible to noise in the voltage data. This premise has been tested on experimental data, and the results are in agreement with the results of the simulations.

The other major focus of this project is to make seismic tomography more reliable. Reliability in this sense implies not only that the images produced are (practically) 
unique and indicative of the information contained in the data but also that quantitative checks are available to determine how well resolved the various image elements may be. One approach that has commonly been used to analyze the results of tomographic reconstructions is the resolution matrices for the model data. Recently it has been shown that model and data resolution matrices can be constructed during the course of the iterative algorithms used for large tomographic reconstructions. New work has been started on fast ray tracing techniques, especially those based on shortest time-path methods and finite difference (Vidale's) methods, and progress has been made on improving the speed of ray tracing.

\section{B. Investigation of Active Processes in Long Valley Caldera Using the Magma Energy Deep Exploration Well Phase II Drilling Activities (J. B. Rundle [510-424-5236; FAX 510-422-1002; E-mail rundle@s37.es.llnl.gov] and W. R. Wawersik [505-844-4342; FAX 505-844-7354], D. J. Holcomb, and L. W. Teufel, Sandia National Laboratories)}

Objectives: Objectives of this project are to test the validity of competing models for magma chamber location and geometry in Long Valley Caldera by measuring and interpreting in situ stress and comparing results from different techniques, including hydrofracture, an elastic strain recovery, acoustic emission, and borehole breakout analyses.

Project Description: Geodetic and seismic data collected in Long Valley from 1975 to the present define a pattern of uplift and strain that has been explained by geophysical models involving dike injection and magma intrusion at depths as shallow as $5 \mathrm{~km}$ beneath the caldera floor. A program of in situ stress measurements in the Long Valley Deep Exploratory well has been designed to test the validity of the geophysical models for the location, size, shape, and depth of active magma chambers. Moreover, the comparison of core-based and downhole stress measurements will help to evaluate the applicability of far less expensive core-based methods for determining stress directions and magnitudes.

Results: Data on in situ stress have been obtained in the Office of Basic Energy Sciences-funded core hole following Phase II drilling, between 2363 and $2378 \mathrm{~m}$ in basement rock, using core-based and acoustic televiewer methods. Acoustic emission signatures in biaxially loaded subcores using the Kaiser effect method and relaxation data obtained from an elastic strain recovery were less useful than hydraulic fracturing in obtaining stress data in this complex volcanic regime. Good pressure-time signatures were obtained in the hydraulic fracturing experiments, and these data, together with detailed fracture logs and borehole breakout information, indicate that the least principal stress is oriented in the direction N52 ${ }^{\circ} \mathrm{E}$. The hydraulic fracturing results constitute an excellent example of the Cornet-Valette method of interpreting hydraulic fracturing data in jointed rock. Magnitudes and directions for the stress data are being modeled using Mogi point source models and finite-element models. Results indicate that a spatially extended source of magma injection is needed to accurately model the data and that the simple Mogi model does a poor job of fitting the vertical principal stress data. The best fitting model is an inflating roughly prolate spheroidal source whose center is at a depth of $7 \mathrm{~km}$. A value for background stress caused by Basin and Range extension has also been obtained, with a magnitude of $\sim 7 \mathrm{MPa}$ and a direction of $N 75^{\circ} \mathrm{E}$. 
CONTRACT:

CATEGORY: PERSON IN CHARGE:
W-7405-ENG-36

\author{
Geophysics and Earth Dynamics
}

\section{A. Imaging of Reservoirs and Fracture Systems Using Microearthquakes Induced by Hydraulic Injections (L. House [505-667-1912; FAX 505-667-8487; E-mail house@lsh.lanl.gov] and M. Fehler)}

Objectives: This work aims to characterize and image hydraulically fractured rock volumes using arrival times and waveforms of microearthquakes induced by the fracturing.

Project Description: In spite of the extensive use of hydraulic fracturing by the oil and gas and geothermal industries, fluid paths created by the fracturing are often not well known. This information is crucial, however, for most effectively exploiting the fractured reservoirs. Hypocenters of the induced microearthquakes give some information about fluid paths but do not provide the spatial resolution or detail that is needed. Using arrival times and waveforms of microearthquakes induced by hydraulic injections, this study is developing methods of analysis to extract more information about the fluid system created. Microearthquakes are much more energetic sources, particularly for shear waves, than the artificial sources used in active experiments. Furthermore, they are distributed throughout the rock mass that is to be interrogated.

Two principal analysis methods are used. First is a velocity tomography approach that simultaneously determines a three-dimensional velocity structure and new hypocenters for the earthquakes. Creation of fluid paths within rock will decrease particularly the shear wave velocity of the rock, and the velocity tomography is intended to identify these changes. Second, conspicuous secondary seismic phases that arrive after the direct $P$ and $S$ waves provide the information needed to identify and locate features in the rock that scatter seismic waves effectively. These features may contain some major fluid pathways.
Results: The basic methods were developed already by this study. Recent accomplishments have been to improve the reliability of the methods. One difficulty with velocity tomography as previously developed was its inability to deal with changes of the velocity structure during the injection. The seismic velocities of the rock will decrease with increasing fluid volume injected, yet the calculations assumed that the velocities were constant. To solve for a varying velocity structure in a fully general way would require a prohibitive amount of both earthquake data and computing time. A simple and physically reasonable assumption was made to simplify the problem. The rock is assumed to be undisturbed by the fluid injection (i.e., the velocities are those of the intact rock) until a threshold condition is met, which is the ucisurrence of specified number of microearthquakes in each block of the rock. The velocity structure calculated with this new approach should be more representative of the actual velocities at any specific time during the injection.

The initial method of imaging seismic scatterers assumed a single homogeneous velocity within the rock mass, which was not realistic but simplified the problem. That assumption reduced the computer time needed but produced fairly complicated scatterer images. Drawing on the velocity tomography work, the method was changed to use the three-dimensional velocity structure calculated by the tomography. Compared to the homogeneous velocity structure, results using the three-dimensional velocity structure show fewer scattering features, but they are better focused (sharper). Those results are believed to more faithfully represent the true state of the rock mass. 


\section{B. Jemez Imaging and Tomography Experiment (JITEX) (M. Fehler [505-667-1925; FAX 505-667-8487; E-mail fehler@seismo5.lanl.govl and W. S. Baldridge)}

Objectives: The objective of this study is to construct a model of the crust and upper mantle beneath the Valles Caldera that incorporates data from as many geophysical and geological disciplines as possible.

Project Description: A majority of the effort will involve collecting and interpreting seismic data to be used in imaging the subsurface structure beneath the caldera. Active seismic data will be collected along three lines, each about $170 \mathrm{~km}$ in length. A total of six explosions will be fired along each line. The reflection, wide-angle reflection, and refraction data from these six lines will be interpreted to obtain a detailed image of the crust beneath the Jemez volcanic field. In addition, two passive seismic arrays consisting of up to 35 seismic instruments will be set up to record teleseisms. The teleseismic data will be used to constrain the mid-crustal and upper-mantle seismic structure. Part of the teleseismic array will consist of one or more sub-arrays, with instrument spacing of as little as $1 \mathrm{~km}$. We will study converted phases recorded on these sub-arrays to obtain more constraints on locations of velocity anomalies in the crust. The existing gravity data set will be supplemented with new data. Gravity and magnetotelluric data will be analyzed along with the seismic data. Models will be tested for the geometry of the caldera structure and fill, geometry and internal structure of the composite pluton underlying the caldera, and the structure and composition of the middle to lower crust beneath the pluton. This work is expected to lead to a fundamental new understanding of the origin, evolution, and modern thermal regime of a major intraplate magmatic system.

Results: Permitting is completed for the first active seismic line, which will be conducted in fall 1993. Permitting and planning for the second and third lines are in process. Permitting for the teleseismic array is complete, and we will deploy a teleseismic array consisting of 21 stations in July 1993. The gravity data set has been assessed, and new gravity stations are being acquired.

A study using a multiple scattering theory was conducted to determine regional values for intrinsic and scattering attenuation. This study was made using recordings of regional earthquakes by the Los Alamos seismic network. We found that the data could not be fit by a body wave model but were well fit by a surface wave model. Thus, it was concluded that the scattered purtion of the wave train from regional earthquakes in northern New Mexico is composed mostly of surface waves. Surface waves may dominate because the earthquakes in this region are shallow and/or because scattering in the region generates mostly surface waves. These ideas are being investigated.

\section{Advanced Concepts (C. W. Myers [505-667-3644; FAX 505-667-3494; E-mail wmyers@lanl.gov] and R.W. Charles [505-667-4958; FAX 505-667-3494; E-mail 081948@incdpl.lanl.gov])}

Two projects are under way in 1993.

Quaternary Geochronology (A. Laughlin and R. Charles).

Objectives: Because the last one million years of geologic time is critically important to many programs in the U.S. Department of Energy, this work is designed to initiate the process to improve the accuracy and precision of Quaternary dating methods by developing the ZuniBandera volcanic field as a test area for the application of these techniques.

Project Description: The work involves collection of samples and collaborations with a number of internal and external experts using $\mathrm{K} / \mathrm{Ar},{ }^{40} \mathrm{Ar} /{ }^{39} \mathrm{Ar},{ }^{3} \mathrm{He},{ }^{14} \mathrm{C}$, uranium series disequilibrium, and other methods to resolve dating discord. Part of the implementation was the Quaternary Dating Field Conference held in Grants, New Mexico, April 26-28, 1993.
Volcanic Gas, Stable Isotope, and Tritium Studies (F. Goff).

Objectives: Collection and analysis of gases and steam condensates from Mount St. Helens (Washington), Pu'u O'o (Kilauea, Hawaii), Pacaya (Guatemala), and Galeras (Columbia) have been undertaken to determine the isotopic composition of primary magmatic water at a variety of active volcanoes.

Results: We have found that the deuterium content of magmatic waters at these sites range from -8 to $-35 \%$ SD, considerably more enriched than most accepted values for magmatic water $\left(-50\right.$ to $-80 \%$ ). The tritium $\left({ }^{3} \mathrm{H}\right)$ contents of magmatic waters at these sites are 3.O T.U. (Mount St. Helens), 3.0 T.U. (Pu'u O'o), 0.7 T.U. (Pacaya), and O.O T.U.(Galeras). Satsuma Iwo-Jima volcano (Japan) will be sampled next. A major objective of this work is to deter- 
mine if the ${ }^{3} \mathrm{H}$ anomalies observed in some magmatic waters result from deep ${ }^{3} \mathrm{H}$ in the earth (caused by cold nuclear fusion?) or whether relatively young, ${ }^{3} \mathrm{H}$-bearing groundwaters can contaminate magmas during their ascent to eruption sites.

\section{The Role of Carbon and Temperature in Determining Electrical Conductivity of Basins, Crust, and Mantle (T. J. Shankland [505-667-4907; FAX 505-667-8487; E-mail shankland@seismo5.lanl.gov] joint research with A. G. Duba, Lawrence Livermore National Laboratory)}

Objectives: The intent of this work is to comprehend the electrical conduction mechanisms in carbon-bearing rocks and mantle minerals for the purpose of relating electrical conductivity $(\sigma)$ measured in the field to formation conditions and existing state of crustal rocks and to temperatures in the mantle.

Project Description: Electrical conductivity depends strongly on temperature ' $\Gamma$ (for mantle conditions) and on the presence of other phases such as carbon, fluids, or ore minerals at the lower temperatures of the crust and basins. Thus, one research approach is to measure $\sigma$ of mantle minerals as functions of temperature, orientation, oxygen fugacity $f \mathrm{O}_{2}$, and iron content; samples at ultrahigh pressures were measured in the diamond anvil cell. These data supply the best models for "electrogeotherms" yet available. Another approach is to document textures of carbon in crustal rocks from basins and metamorphic zones and relate them to rock conductivity. In this case, texture of carbon distribution is mapped with electron microscopy in the same samples used for $\sigma$ measurement.

Results: Because the lower mantle makes up the bulk of the Earth, its electrical conductivity is a property of great interest for propagation of core geomagnetic disturbances and possible core-mantle coupling, as well as problems of bulk composition, mineralogy, and temperature. Conductivities were measured in the diamond anvil cell of magnesio-wustite + pyroxene-perovskite [ $\mathrm{mw}+\mathrm{pv}$, bulk compositions $\mathrm{x}=0.11$ and 0.16 in $\left.\left.\left(\mathrm{Mg}_{1-\mathrm{x}} \mathrm{Fe}_{\mathrm{x}}\right)_{2} \mathrm{SiO}_{4}\right)\right]$ and of pyroxene-perovskite ( $\mathrm{pv}$, composition $\mathrm{x}=0.11$ in $\mathrm{Mg}_{1-\mathrm{x}} \mathrm{Fe}_{\mathrm{x}} \mathrm{SiO}_{3}$ ) at pressures of 1.2 to $40 \mathrm{GPa}$ over the temperature range 20 to $400^{\circ} \mathrm{C}$. Each data set was fitted to an equation of the form $\sigma=\sigma_{0} \exp [-(\Delta \mathrm{U}+\mathrm{P} \Delta \mathrm{V}) / \mathrm{kT}]$, where $\mathrm{P}=$ pressure in $\mathrm{GPa}, \mathrm{T}=$ temperature in $\mathrm{K}$, and $\mathrm{k}$ is Boltzmann's constant. Having a functional form at lower mantle depths $z$ enables calculation (hollow points) of $\sigma(\mathrm{z}, \mathrm{T}, \mathrm{P})$ as shown below. Field geophysical models (solid points) agree well. A robust conclusion is that conductivity varies only by about a factor of 5 across the entire lower mantle, and combined effects of pressure and temperature cause $\sigma \rightarrow \sigma_{0}$ the base of the mantle. Thus, lateral temperature variations of a few 100 s of degrees should be hard

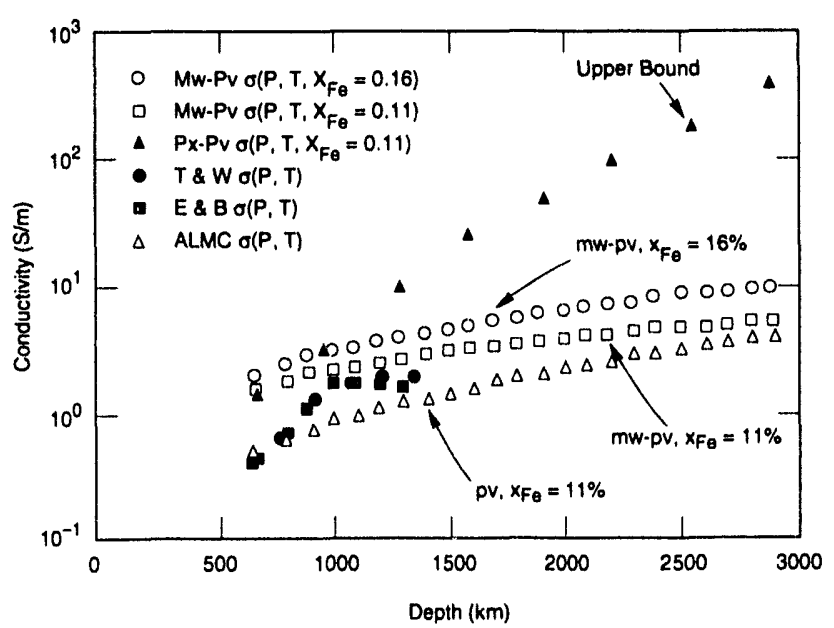

to detect, and a convecting lower mantle may be well approximated by radial symmetry in $\sigma$.

We have also measured the electrical conductivity of crustal rocks collected from surface exposures near the Denali Fault Zone in the Yukon-Tanana Terrane of Alaska at pressures to $500 \mathrm{MPa}$ to see if pressure causes the reconnection of carbon conductors that are present in the rock. No increase of conductivity with pressure was seen, but a smaller than expected decrease of conductivity of some of these saturated rocks with pressure was observed and may be the result of a small amount of reconnection partially offsetting the conductivity decrease caused by the loss of pore saturant as crack porosity decreases with pressure increase. However, a dramatic increase of conductivity was observed for saturated rocks from the German deep drillhole up to pressures of $400 \mathrm{MPa}$. The good conductor in this case is ilmenite along the lineation that was broken by the cracking caused by pressure release and temperature release as the core was brought to the surface. However, the ilmenite was not altered by oxidation and weathering as was in the Alaskan rocks during their more leisurely journey to the surface, so the good conductor that existed at depth is unaltered and is easily reconnected by pressure for the unaltered rocks from the drill core. This is a good example of the utility of drill holes in addressing the interpretation of field geophysical measurements. 


\section{E. Basic Research on Nonlinear Elastic Phenomena in Rock (P. A. Johnson, [505-667-4907; FAX 505-667-8487; E-mail johnson@seismo5.lanl.gov] and T. J. Shankland; joint research with B. P. Bonner, Lawrence Livermore National Laboratory, and T. V. McEvilly and L. R. Myer, Lawrence Berkeley Laboratory)}

Objectives: Research objectives are to (1) investigate the physical manifestations of nonlinear elasticity, including those indicating reservoir/repository characteristics and those affecting seismic observations; (2) characterize nonlinear properties of rocks; and (3) study the possibility of developing a low-frequency directed source by nonlinear elastic wave mixing of two primary frequency waves.

Project Description: Because rocks contain easily compressed microstructures such as cracks and grain junctions, they display strong elastic nonlinearity. This project's approach is to use this feature to examine new classes of geophysical phenomena. Experimentally examined are spectral band shifts and production of harmonics by propagating waves, resonant frequency shifts caused by the large strains possible in bar resonance, and torsional harmonics (Lawrence Livermore National Laboratory). Materials studied include the crystalline rocks basalt and granite as well as the model reservoir rock Berea sandstone. For each experiment, theories have been developed describing effects of crack density, fluid content, stress-strain hysteresis, and anisotropy on nonlinear interactions; emphasis is on the effects of different kinds of nonlinearity on wave propagation. Field experiments employing Vibroseis ${ }^{\circledR}$ sources are conducted in cooperation with Lawrence Berkeley Laboratory.
Results: By increasing wave intensity and monitoring amplitudes of waves traveling down a bar, it was quantitatively shown that a primary frequency produces a rich harmonic spectrum as elastic wave fields interact nonlinearly. Green functions in first and second order provide theoretical explanations of amplitude and frequency dependencies of these phenomena. Incorporating hysteresis in the theoretical rock stress-strain model is leading to an explanation of why still higher harmonics appear in almost equal strength. Large shifts of spectral content mean that seismic frequency content observed in the far field may not reflect the true character of the source. A uniform bar of rock set into longitudinal resonance (Young's mode) can attain strains up to $10^{-5}$, the resonant frequency shifting downward by as much as $25 \%$. Using the simplest theoretical model of the rock as a spring-mass-dashpot system, it was demonstrated that the responsible nonlinear modulus varies by $10^{3}$ and thus is a sensitive indicator of rock microstructure. In macroscopic phenomena, it was shown how differential stress applied to a rock can introduce elastic anisotropy. The frequency domain travel time technique that originally produced sharp wave arrivals for complex geometries has also afforded an elegant way to determine seismic $Q$, a measure of attenuation that is a valuable diagnostic in geophysical interpretation.

\section{CATEGORY: $\quad$ Geochemistry}

PERSON IN CHARGE: $\quad$ D. Janecky

\section{A. Thorium-230-Uranium-238 Disequilibrium in Geologic Systems Using Solid Source Mass Spectrometry (M. T. Murrell [505-667-4299; FAX 505-665-4955; E-mail $099691 @$ incdp3.lanl.gov], D. A. Pickett, S. J. Goldstein, and K. W. W. Sims)}

Objectives: One goal of this project is to provide an improved capability for Quaternary dating. Current emphasis is on evaluating ${ }^{231} \mathrm{~Pa} /{ }^{235} \mathrm{U}$ disequilibrium as a geochronometer. In addition, uranium-series disequilibrium is being used to probe the recent evolution of magmatic systems.
Project Description: Uranium-series disequilibrium techniques are well-established, valuable tools in geochronology and geochemistry. Such measurements have typically been made by decay counting; however, significant improvements are possible with mass spectrometric techniques. We have previously developed mass spectrometric methods for measuring ${ }^{230} \mathrm{Th} /{ }^{238} \mathrm{U}$ and ${ }^{226} \mathrm{Ra} /{ }^{230} \mathrm{Th}$ and are 
now evaluating ${ }^{231} \mathrm{~Pa} /{ }^{235} \mathrm{U}$ disequilibrium as a geochronometer. These techniques are being used to provide a better understanding of recent volcanism through examination of the timing, recurrence rate, and evolution of sources and magma chambers. These issues are critical to understanding the mechanisms that control dynamic geologic processes, such as the formation of the earth's crust and in evaluating geologic hazards associated with volcanism.

Results: To explore the potential for ${ }^{231} \mathrm{~Pa} / 235 \mathrm{U}$ dating of volcanic rocks as old as 200,000 years, we have measured ${ }^{238} \mathrm{U}$ - and ${ }^{235} \mathrm{U}$-series nuclides in minerals separated from a trachyandesite erupted in 1982 at El Chichon volcano, Mexico. The minerals fall on a zero-age ${ }^{230} \mathrm{Th} /{ }^{38} \mathrm{U}$ isochron, suggesting that ${ }^{231} \mathrm{~Pa}{ }^{235} \mathrm{U}$ should yield zero-age systematics. The minerals and groundmass display a large range in $\left({ }^{231} \mathrm{~Pa}{ }^{235} \mathrm{U}\right)$ activity ratios, from 0.32 to 1.31 , which is advantageous for geochronology. We are engaged in ICP-MS measurements to find a stable trace-element analogue for ${ }^{231} \mathrm{~Pa}$ that will allow construction of an isochron (analogous to the ${ }^{226} \mathrm{Ra}-\mathrm{Ba}$ approach). These are the first-ever data on ${ }^{231} \mathrm{~Pa}$ in mineral separates, yielding important information on protactinium partitioning in magmatic systems. In addition, as part of our efforts to understand better uranium-series disequilibrium in volcanic systems, we have also measured $\left({ }^{231} \mathrm{~Pa} /{ }^{235} \mathrm{U}\right)$ activity ratios in volcanic rocks from a variety of settings. Most have ratios of 1.1 to 2.9 , with varying relationships to $\left({ }^{230} \mathrm{Th}{ }^{238} \mathrm{U}\right)$ disequilibrium. These results point to the recency of magmatic processes that fractionate trace elements and place constraints on models of ${ }^{230} \mathrm{Th} /{ }^{238} \mathrm{U}$ disequilibrium calling on, for example, nonequilibrium partial melting and fluid-phase enrichment of uranium in magmas and their sources. These large activity ratios are also promising for age-dating in cases where initial $\left.{ }^{231} \mathrm{~Pa}^{235} \mathrm{U}\right)$ can be assumed. We have used this approach to date basalts from the East Pacific Rise.

\section{B. Dynamics of Rock Varnish Formation (R. Raymond, Jr. [505-667-4580; FAX 505-665-3285; E-mail robert@esslab.lanl.gov] S. L. Reneau, D. L. Bish, and G. D. Guthrie, Jr.)}

Objectives: The main objective of this research is to isolate the major environmental variables responsible for variations in rock varnish chemistry and morphology. Supplemental objectives are to: (1) use rock varnish micro-stratigraphy to understand the nature of environmental changes in different parts of the southwest deserts; (2) use variations in rock varnish micro-stratigraphy to map out the extent of specific environmental changes, such as changes in rainfall patterns associated with changes in regional atmospheric patterns; and (3) document the climatic conditions present at the time of formations of major landscape features.

Project Description: Rock varnish is a microns-thick coating, composed primarily of manganese and iron oxides and clay minerals, that is ubiquitous on exposed rock surfaces in arid and semiarid regions. Rock varnish contains distinct micro-stratigraphic layers that record environmental changes during the period of varnish formation, and these layers have potential to provide an improved understanding of paleoenvironmental changes in desert regions. However, the effects that relationships between varnish mineralogies, varnish elemental contents, varnish diagenesis, and the mechanism of varnish formation have on elemental and mineralogic attributes used in paleoclimatic studies are not yet understood.

A combination of optical microscopy, electron microanalysis, $\mathrm{X}$-ray diffraction, $\mathrm{X}$-ray fluorescence, and chemical analysis is being used to evaluate the mineralogic and elemental composition of rock varnish as a function of local geology, geochemical environments, and varnish source environments.

Results: Backscattered-electron images (BEIs) and secondary-electron images (SEIs) of varnish show that both laminar and botryoidal varnish are composed dominantly of fine-grained material, the grain size of which is not easily resolved by scanning electron microscopy $(<0.5 \mathrm{~mm})$. Within this fine-grained material, and especially between botryoids, a detrital component is often observable, but this component is much coarser grained than the component making up most of the laminar and botryoidal varnish. Although manganese commonly comprises greater than $15 \mathrm{wt} \%$ of rock varnish, no crystalline manganese phase was identified by $\mathrm{X}$-ray diffraction (XRD) for numerous samples analyzed from Nye County, Nevada, from Cima, and from California City. In addition to identifying species of the minor coarse-grained detrital component in varnish, XRD showed the presence of a poorly crystalline clay. The clay has a broad reflection at approximately $1.1 \mathrm{~nm}$, suggesting that it is a poorly crystalline 2:1 layer silicate. Peak position and width vary inversely, and the diffraction data are consistent with the presence of an illitic material having crystallites only 2-5 layers thick. TEM EDS of this material showed $\mathrm{K}, \mathrm{Al}$, and $\mathrm{Si}$, and possibly minor $\mathrm{Mg}$. 
Long-scan XRD methods were unable to confirm the presence of any crystalline manganese-rich phase. Considering the ability of XRD to identify and to characterize fine-grained iron-oxide and clay species at least as small as $10 \mathrm{~nm}$ in crystallite size, the absence of X-ray diffraction lines for a crystalline manganese mineral cannot be explained by small particle size. Furthermore, the lack of contrast variations in bright-field or dark-field TEM images of manganese-rich regions from the Buckboard Mesa sample, as would be expected if a crystalline phase were present, do not support the presence of a crystalline manganese-rich phase in this sample. However, TEM data support the presence of a noncrystalline manganese-rich phase, in agreement with the XRD data. Although XRD patterns are broadly consistent with the presence of a poorly crystalline 2:1 layer silicate, no peak shifts are observed following glycolation, implying that these clays are not smectite. However, both broadness of diffraction peaks in conjunction with shift of peak position are consistent with illite occurring as crystallites 2-5 layers thick. TEM analysis of aggregates containing clays shows that most of the clays are fine-grained (e.g., $<0.1 \mu \mathrm{m}$ ) and probably potassium aluminosilicates (possibly with minor manganese) cemented by manganese- and iron-rich amorphous material.

These results suggest that (1) most crystalline and amorphous material present in the manganese-rich varnish layers is authigenic and (2) the evaporation of rainwater can provide the constituents necessary for formation of rock varnish. The basic model-chemical precipitation of varnish from rainwater-implies that varnish chemistry may reflect changes in rainwater chemistry. Consequently, chemical variations within varnish stratigraphy may provide information on paleoclimates.

\section{Geochemistry of Technetium (D. B. Curtis 1505-667-4845; FAX 505-665-4955; E-mail 083769@incdp3.lanl.gov], P. R. Dixon, J. T. Fabryka-Martin, and D. J. Rokop)}

Objectives: The objective of this project is to develop and use methodologies that utilize radioactive nuclides, produced by nuclear processes in minerals and groundwater, to study fission product and actinide transport processes in the geologic environment.

Project Description: Certain radionuclides exist naturally solely as a result of production by nuclear processes. Because of their mode of production, they exist in nature in very low abundances and for geologically short periods. Some of these nuclides, such as ${ }^{99} \mathrm{Tc}$ and ${ }^{239} \mathrm{Pu}$, are the only naturally occurring isotopes of these elements and thus provide the opportunity to obtain unique information regarding the geochemical behavior of rare elements. Because these elements have mean radioactive lifetimes of $10^{4}$ to $10^{7}$ years, studies of their geochemical cycles characterize the affects of geologically modern processes on element transport and retention. Concentrations of the radionuclides of interest are measured in groundwater, rocks, and minerals. The results are integrated into an understanding of mass transport processes using the interpretative tools provided by models of nuclide production, geochemical speciation and solubility, and mass transport. Information produced by the work can be used to assist in evaluating the conformance of geologic radioactive waste repositories to long-term performance objectives.
Results: Koongarra is an unmined uranium deposit in the Alligator Rivers region of the Australian Northern Territory. For a depth of roughly $30 \mathrm{~m}$, uranium-rich rock is altered. Uranium and other elements have been dispersed by groundwater movement in response to weathering processes. Below about $30 \mathrm{~m}$, uranium-rich rock has not been weathered. There is evidence for release and transport of ${ }^{129} \mathrm{I}$ in both the weathered and unweathered portions of this deposit. There is no evidence of technetium release from host phases in the unweathered zone. However, measurable concentrations of ${ }^{99} \mathrm{Tc}$ in groundwater suggest that teci netium is being released and transported in this region of the deposit. Source-term models predicting ${ }^{239} \mathrm{Pu}$ abundances in uranium minerals lead to ambiguous conclusions. Results are insufficiently precise to provide measures of plutonium retention or release.

Details of this work are reported in the final report of the Alligator Rivers Natural Analogue Project. The report is a summary of all work by this project on natural nuclear reaction products.

A more comprehensive study of radionuclide retention and transport is being conducted at the Cigar Lake uranium deposit. This is an unaltered uranium deposit located in a strongly reducing environment deep in the Canadian Athabasca sandstone. In many ways it represents a sharp geochemical and geophysical contrast to the Koongarra deposit. 


\section{Tracer Tomography in Geological Reservoirs (David R. Janecky [505-665-0253;}

FAX 505-665-4955; E-mail janecky@lanl.gov] and W. Dale Spall [505-667-2772])

Objectives: The objective of this project is to develop approaches to evaluate large-scale porous flow heterogeneities and integrated chemical processes by combining multicomponent injected tracers, coupled with detailed characterization of natural chemical compositional variability in space and time. Coupled processes of interest include spatially distributed flow, dispersion, sorption, partitioning, displacement, and chemical reactions. Applications and basic geochemical information tailored to petroleum reservoir, geothermal, and environmental systems are being developed in consultation with industry.

Project Description: New classes of conservative and reactive nonradioactive organic tracers for both laboratory and field experiments are being defined and tested using stable isotopic labeling schemes. Laboratory experiments, including chromatography and core floods, provide basic geochemical information in well-constrained systems, which isolate aspects of natural processes for evaluating and quantifying flow and reaction processes.

Interpretation of multicomponent tracer information in a consistent, integrated framework requires integration of computational models, including classical and nonequilibrium thermodynamics chromatographic models, coupled fracture and matrix permeability models, lattice gas automata models, and large-scale hydrologic models.
Results: Labeling of organic compounds has focused initially on use of deuterium. Working with industry, commercial sources have been developed for relatively large amounts of isotopically labeled compounds. A range of labeled compounds are on hand for laboratory experiments and relatively large quantities of labeled compounds have been utilized for experiments by an industrial collaborator. The choice of stable isotope labeled organic molecules as tracers provides significant advantages in simultaneous multicomponent analysis; however, it also requires a commensurate emphasis in complex analytical methods. Development of GC/MS analyses for environmental samples and expertise developed through analytical work for oil shale processing programs, along with continuously improving analytical equipment, has been combined to successfully complete analyses of stable isotope labeled organic compounds in gas and liquid petroleum matrices, in addition to water.

Detailed evaluation of our initial multicomponent tracer experiment below the Mammoth Terraces in Yellowstone National Park indicates general consistency between a range of simple tracers as a function of the first acid dissociation constants. Subtle differences in individual tracer behavior between sampled springs is apparent.

\section{E. A Search for Evidence of Large Comet or Asteroid Impacts at Extinction Boundaries (M. Attrep, Jr. [505-667-0088; FAX 505-665-4955; E-mail 908804@incdp3.lanl.gov])}

Objectives: Objectives of this investigation are to identify signatures in the geological record of large-body impacts and/or massive volcanism in relation to the known extinction boundaries in the fossil record. In addition, the team investigates the environmental consequences of local releases of ultra-high amounts of energy (impacts), helps establish and develop the field of chemostratigraphy, and establishes geochemical time markers in the geological record. Our unique analytical capabilities and these unique geological markers are used to investigate trace-element migration of the chemical element as a means to understand the dynamics of nuclear waste storage and burial strategies.

Project Description: Instrumental neutron activation analysis is used to routinely measure the elemental abundance for more than 40 elements (major, minor, and trace). For determining the more rare elements, the platinum group elements ( $\mathrm{Ir}, \mathrm{Au}, \mathrm{Os}, \mathrm{Re}$, and $\mathrm{Pt}$ ), radiochemical methods are used. This includes the irradiation of samples in high neutron fluxes, radiochemical separation of the individual element, and gamma spectrometric measurements. Our limit of detection for iridium, for example, is at about the one part per trillion level.

Results: Work has been completed on several samples collected at Chixulub, the suspected crater site for the Cretaceous-Tertiary (K-T) boundary extinction event. The site is located on the Yucatan peninsula in Mexico. Only one of the five samples indicated a slightly elevated iridium content. We do not think that the analyzed samples contained any melt material from the impact. Chemostratigraphic measurements have also been made at the Cretaceous-Tertiary boundary, where we continue to identify other sites in the western interior of the United States. Samples collected in Wyoming and North Dakota, however, did not reveal the location of the K-T boundary. We have continued to collaborate in numerous investigations 
at the Frasnian-Famennian (China, Canada, and Europe) boundary. An iridium spike is found near the boundary in sections in China and France. An additional iridium enrichment has been confirmed about $2.3 \mathrm{~m}$ below the Frasnian-Famennian boundary. The site is at Laohudong hill (Luoxiu Town, China). Our value was lower than the value reported by Professor Hou Hongfei. This sample repre- sents an anoxic event in the Xiangtian formation of the Frasnian. A Cenomanian-Turonian (C-T) section in the Czech Republic has been completed, and no iridium enrichment is found at the $\mathrm{C}$ - $\mathrm{T}$ boundary where the boundary is marked by a dip in the $\delta^{18} \mathrm{O}$ and a rise in $\delta^{13} \mathrm{C}$. This is consistent with the results we found in a C-T section in Poland.

\section{F. Direct Speciation of Metal Ions by Optical Spectroscopies (C. D. Tait [505-665-0008; FAX 505-665-3166] and D. R. Janecky)}

Objectives: The objective of this project is to quantify the effects of organic complexation in low- to moderatetemperature systems involving secondary ore formation, rock weathering, and sedimentary basin diagenesis. Ultraviolet/visible (UV/Vis) absorption, vibrational [Raman and infrared (IR)], and luminescence spectroscopies are being used to probe $\mathrm{Pd}(\mathrm{II}), \mathrm{Al}(\mathrm{III})$, and $\mathrm{Fe}(\mathrm{III})$ speciation.

Project Description: Improved characterization of chemical speciation in aqueous fluids is required to further understand geochemical processes involving solutions in geothermal, oil field, and environmental systems. Organic interactions with the rock matrix can have significant consequences for mobility or sequestering of metals, mineral (matrix) dissolution, and fossil fuel/reservoir interactions. Furthermore, the temperature dependence of these interactions is especially lacking from the present geochemical data base. Techniques to be employed include vibrational (Raman and IR), UV/Vis absorption, and luminescence spectroscopies. These techniques, especially the vibrational spectroscopies, contain structure-specific information and can be used to monitor species transformations with systematic changes in variables such as $\mathrm{pH}$ and temperature.

Results: Spectroscopic investigations on organic-palladium(II) interactions were integrated with the solubility results of Scott Wood (University of Idaho). Complex formation between simple carboxylic acids (acetate, oxalate, and phthalate) and even platinum group elements demonstrates the potential importance of organics in geochemistry. Complexation experiments between rare earth elements (REEs) and carboxylic acids has been initiated, and spectroscopic signatures for the low-solubility neodymium-oxalate complex was found using photothermal absorption spectroscopy. The REEs serve as models for actinide species (e.g., $\mathrm{Nd}^{3+}$ for $\mathrm{Am}^{3+}$ ) to help determine the potential mobility of radionuclides from waste sites, especially those containing mixed wastes. Temperature dependencies to $130^{\circ} \mathrm{C}$ on the palladium and REE organic systems were also examined.

Although the association constant between the rockforming $\mathrm{Al}^{3+}$ and oxalate was found to increase with temperature, competition experiments between $\mathrm{Al}^{3+}$ and $\mathrm{Fe}^{3+}$ for oxalate determined that it increases less quickly than for iron. Because iron is abundant in important geochemical systems like sedimentary basins, care must be taken in postulating the porosity-generating effects of such organic compounds.

Finally, progress has been made in adapting Raman and luminescence spectroscopy to microscopes to study organics in fluid inclusions. To avoid luminescence, excitation in the red/near IR has yielded encouraging results. To get more structure-specific luminescence data, synchronously scanned luminescence is being used. In laboratory samples, the sharp peak from perylene has been observed down to $5 \mathrm{ppm}$.

\section{G. Dating young surfaces using cosmogenic Helium and Neon (Jane Poths [505-665-2636; FAX 505-665-6637; E-mail 096378@incdp3.lanl.gov])}

Objectives: The objective of this project is to understand quantitatively the processes affecting use of cosmogenic noble gases as chronometers for dating young $(<0.5 \mathrm{Ma})$ surfaces.

Project Description: Geomorphic surfaces start accumulating cosmogenic helium and neon once they are created (e.g., by flood or volcanic eruption). Concentra- tions of cosmogenic helium and neon can be determined by ultrasensitive mass spectrometry, providing the ages of such events. The conditions under which the assumptions inherent in this new technique are satisfied are being determined. Testing is being performed on surfaces in the arid Southwestern United States formed by two processes: lava flows (3 to $220 \mathrm{ka}$ ) and paleo-shorelines. Our ap- 
proach includes: (1) comparison with dates from other experimental techniques, (2) use of in situ cosmogenic ${ }^{14} \mathrm{C}$ to monitor erosion, (3) determining reproducibility for multiple samples from a single surface, and (4) use of helium/neon ratios to identify additional components and check for gas loss. Results will provide the time scale for geochemical evolution of volcanic fields and the timing of climatic events recorded by lake highstands.
Results: Cross calibration with other chronometers between 3 and 60 ka shows agreement within analytical uncertainties. Dates for multiple samples from individual flows also agree within analytical uncertainty. Excess ${ }^{40} \mathrm{Ar}$ from a magmatic component is present in all four volcanic fields that were examined. This observation provides an explanation for anomalously old $\mathrm{K}$-Ar dates for these fields and suggests caution in relying on $\mathrm{K}$-Ar dates for young basalts.
CATEGORY:

\section{PERSON IN CHARGE:}

\section{Energy Resource Recognition, Evaluation, and Utilization}

\section{A. Core Hole VC-2B: Scientific Drilling to Investigate Caldera Processes, Hydrothermal Dynamics, and Mineralization (J. N. Gardner [505-667-1799; FAX 505-665-3285, E-mail gardner@essxrf.lanl.gov] and F. E. Goff, joint research with J. B. Hulen, University of Utah Research Institute)}

Objectives: The scientific objectives of VC-2B were to (1) penetrate the entire Sulphur Springs hydrothermal system, (2) penetrate Precambrian rocks beneath the collapsed floor of the caldera, (3) acquire additional information on intra-caldera structure and stratigraphy, and (4) acquire additional information on ore deposit mechanisms.

Project Description: This project terminates at the end of FY 1993. Work in FY 1993 focused on completion of plug and abandonment and preparation of the first 20 papers by many authors for a special volume of the Journal of Volcanology and Geothermal Research (JVGR).

Results: As of July 1993, plug and abandonment of the 1762 -m-deep, $295^{\circ} \mathrm{C} \mathrm{VC-2B}$ was still not completed because of a leak at the wellhead around the annulus. A new plan was being developed. About 20 draft papers were either reviewed or were being reviewed for the special $J V G R$ volume.

\section{B. Hydrogeochemistry of Nevada Oil Field Waters and Brines (F. E. Goff [ 505-667-8060; FAX 505-665-3285; E-mail @essxrf.lanl.gov], joint research with J. B. Hulen, University of Utah Research Institute)}

Objectives: The object of this project is to characterize the chemical and isotopic composition of waters and brines associated with several unique oil fields in Railroad and Pine Valleys, Nevada.

Project Description: The chemical and isotopic composition of waters, gases, and rocks in several of the Nevada oil fields are being characterized. Some of the waters are distinctly geothermal in their temperature $\left(120^{\circ} \mathrm{C}\right)$ and geochemistry; thus, we are trying to find possible parallels between Basin and Range geothermal systems and the fluids produced with oil at the Nevada oil fields.
Results: Samples suites are relatively complete from six Nevada oil fields (Grant Canyon, Bacon Flat, Kate Springs, Eagle Springs, Trap Springs, and Blackburn). Most of the oil field waters have trace element anomalies (As, B, Br, Li, etc.) that resemble low- to moderate-temperature geothermal fluids. Chemical geothermometry indicates maximum reservoir equilibration temperatures similar to maximum temperatures measured downhole $\left(\leq 120^{\circ} \mathrm{C}\right)$. Stable isotopes $\left(\delta \mathrm{D} / \delta^{18} \mathrm{O}\right)$ show that end-member formation fluids in each field are not recharged from meteoric waters in adjacent ranges. Modeling of tritium data indicates maximum mean residences times of 3,000 
to - 10,000 years. Carbon- 13 measurements suggest reservoir $\mathrm{CO}_{2}$ comes mainly from Paleozoic carbonates. Gas compositions at Grant Canyon field resemble geothermal gas (high $\mathrm{CO}_{2}$ and some $\mathrm{H}_{2} \mathrm{~S}$ ); other fields have typical oil field gases (mostly straight-chain hydrocarbons).

\section{Operation of a Sample Management System for the Continental Scientific Drilling Program (S. J. Goff [505-667-7200; FAX 505-667-8487; E-mail 102063@eesdpl.lanl.gov] and L. Fakui, UNC, Grand Junction)}

Rigorous and effective sample management is a key part of a Continental Scientific Drilling Program (CSDP). Curatorial policy guidelines and procedures for sample curation have been formulated for the U.S. Department of Energy (DOE) Office of Basic Energy Sciences drilling efforts by Los Alamos National Laboratory, in cooperation with UNC Geotech. Grand Junction operations continue to provide sample management of current and proposed CSDP core holes. Investigations continue for other potential uses within DOE for the Grand Junction facility.

\section{Intracaldera Processes-Creede Caldera, San Juan Volcanic Field, Colorado (Grant Heiken [505-667-8477; FAX 505-665-3285; E-mail heiken@esslab.lanl.gov] and Donathan Krier)}

Objectives: The petrologic data from this study will supply information on extent and volume of the caldera lake (the whole crater or an annulus around the resurgent dome) and post-caldera eruptive and depositional processes affecting the thermal regime.

Project Description: The processes occurring within calderas after their formation greatly affect the thermal state of those calderas and the geothermal systems developed there. Deformation of larger calderas follows resurgence of the underlying magma body and not only raises this thermal source but fractures and faults the overlying caldera fill deposits, allowing fluid circulation. Postcaldera eruptions of gas-poor lavas and ash provide yet more heat to the system and provide a window to the petrology of the cooling magma body. Within the Creede caldera, Colorado, many of the answers to its post-caldera volcanic and structural history lie within the sequence of tuffaceous clastic sedimentary rocks and tuffs known as the Creede Formation. The entire sequence of caldera fluviatile and lacustrine rocks and interbedded ash deposits was sampled by core holes Creede 1 and 2, drilled during the fall of 1991 in the caldera moat. The ash beds and tuffaceous sediments sampled by these core holes are being studied.

Results: In our earlier study of the Creede Formation, based on surface outcrops and shallow mining company core holes, it was concluded that the process of caldera structural resurgence was rapid and that a caldera lake was developed in an annulus located between the resurgent dome and caldera wall. This conclusion is in agreement with observation. of a modern resurgent caldera, Iwo Jima, Japan, where the structure is rising at $20 \mathrm{~cm} /$ year. Our approach to el aluating the timing of caldera resurgence has been to study the provenance of clastic rocks throughout the Creede Formation. We are looking for the first appearance of welded Snowshoe Mountain Tuff, the caldera-fill deposit that makes up the Creede resurgent dome. So far, our data indicate that resurgence was rapid and that debris from the resurgent dome are present throughout the 600-m-thick Creede Formation.

All ash beds within the Creede Formation have been characterized and are being compared petrologically with the intracaldera Fisher quartz latite lavas, which at the surface are interbedded with the Creede Formation. Highresolution ${ }^{40} \mathrm{Ar} /{ }^{39} \mathrm{Ar}$ geochronology of the tuffs will be performed by M. Lanphere of the U.S. Geological Survey. So far we have a picture of intracaldera activity consisting of hydrovolcanic eruptions through a caldera lake and the ashes deposited within relatively shallow water at the core hole in the northwestern moat (perhaps over the distributaries of a delta) and in deeper water in the northern moat, where the caldera was intersected by a graben (most of the Creede District ore deposits were emplaced along this series of N-S-trending faults). Results or the post-caldera volcanism and provenance studies will be integrated into a larger picture of both igneous and structural processes occurring after caldera collapse. 


\section{PERSON IN CHARGE: $\quad$ S. Peter Gary}

\section{A. Energy Transport in Space Plasma (S. P. Gary [505-667-3807; FAX 505-665-3332; E-mail pgary@lanl.gov])}

Objectives: The objective of this program is to carry out theoretical and experimental research on the plasma physics of the solar wind and the earth's magnetosphere and on theoretical plasma astrophysics. The long-term purpose of these studies is to improve scientific understanding of the coupling of solar variations to the nearearth environment.

Project Description: The long-term goal of this research is to understand the flow of plasma energy in the near-earth space environment from a small-scale point of view. Particle distribution functions observed by plasma instruments on scientific spacecraft as well as by computer simulations developed at Los Alamos are used to carry out fundamental studies of plasma instabilities and associated transport in and near the solar wind, the earth's bowshock, and the terrestrial magnetosphere.

Results: The most important accomplishment of this program in 1993 has been the development of a closure relation for ion anisotropies in the earth's magnetosheath.
Beginning with observations from satellite data that there is an inverse correlation between ion anisotropies and the proton beta (the ratio of plasma pressure to magnetic field pressure) in the sheath, this effort showed that this correlation can be described in terms of the linear theory of thresholds of three distinct growing modes: the proton cyclotron and helium cyclotron anisotropy instabilities and the mirror instability. Computer simulations were used to show that the nonlinear consequences of instability growth were to drive ion parameters toward the correlation conditions and that the cyclotron instabilities were more effective at accomplishing this than the mirror instability. These simulations are being used to quantify this correlation, that is, to develop an analytic expression that will provide a closure relation for anisotropic fluid models of the magnetosheath. If successful, the result will become one of the rare examples of a first-principle microphysics expression useful in macroscopic fluid code descriptions of space plasmas.

\section{B. The Solar Wind-Magnetospheric Interaction (J. Bi थ [505-667. 9232; FAX 505-665-3332; E-mail jbirn@lanl.gov] and E.W. Hones, Jr. [505-667-4727])}

Objectives: The goal of this research is to further the understanding of the earth's magnetosphere, coupled to the fast-flowing solar wind plasma on one hand and to the ionosphere on the other.

Project Description: The focus is primarily the study of the magnetosphere's large-scale structure and dynamics using theory, numerical modeling, and correlative studies of data from multiple sites within and near the magnetosphere (including the earth itself as well as scientific satellites).

Results: Major 1993 achievements concerned (1) the determination of the quasi-static structure of the tail under the influence of boundary conditions provided by the solar wind and (2) acceleration of protons, investigated by tracing particles in the fields obtained from a three-dimensional resistive magnetohydrodynamic simulation.
Characteristic acceleration processes and source regions of energetic ions were identified: a "quasi-potential" acceleration, caused by particle motion in the direction of the cross-tail electric field, and a "quasi-betatron" effect, which consists of multiple energy gains from repeated crossings of the acceleration region in the spatially varying induced electric field. The major source region for accelerated particles in the hundreds of kiloelectron volt range was found to be the central plasma sheet at the dawn flank outside the near-earth reconnection site. Because this source plasma is already hot and dense, its moderate energization by a factor of about two may be sufficient to explain the observed increases in the energetic particle fluxes. Particles from the tail were identified as the source of beams at the plasma sheet/lobe boundary, consistent with observations. 


\section{Energetic Particle Acceleration (G. D. Reeves [505-665-3877; FAX 505-665-4414; E-mail reeves@lanl.gov])}

Objectives: The goal of this research is to develop a better understanding of the earth's energetic particle environment near geosynchronous orbit.

Project Description: This effort concerns the analysis of data from a series of geosynchronous spacecraft that carry Los Alamos energetic particle detectors. The measured energies range from tens of kiloelectron volts to hundreds of million electron volts. The lower end of this range lies somewhat above the thermal plasma energies and is therefore sensitive to local acceleration processes such as magnetospheric substorms. The higher end of the energy range is in the realm of cosmic rays and is therefore well suited to the study of energetic particles that can penetrate the earth's magnetic field such as galactic cosmic rays and particles produced in solar flares.

Results: In 1993 the modeling and data analysis capabilities developed earlier were applied to important problems in understanding energetic particle acceleration.

Recent advances in the understanding of magnetospheric substorms have been obtained through greater availability of data from spacecraft simultaneously measuring different regions of the magnetosphere, satellitebased auroral imagers, sophisticated magnetic field models that allow investigation of the magnetic connectivity between observed phenomena, and increased com- puting and data processing capabilities. These advances were used to reexamine the relationship between substorm phenomena including substorm injections, plasmoid formation, auroral displays, and ionospheric currents and flows. A major result of this work was the identification of two coupled acceleration regions that are activated during substorms - one in the mid-magnetotail and one near geosynchronous orbit. A major goal of substorm physics is to determine the relationship between these two acceleration regions and to understand why they activate at nearly the same time in very different regions of space.

The large solar energetic particle events observed throughout 1989 and in March 1991 have been studied. A better understanding of the response of silicon detectors to these extremely energetic particles yielded spectral time profiles of the events, which provided information on acceleration and transport mechanisms.

The Earth flyby of the Galileo spacecraft on its way to Jupiter brought it in proximity to a geosynchronous spacecraft bearing Los Alamos instruments during energy storage in the magnetotail prior to substorm onset. Particle motions and field reconfigurations were quite different in different regions of the magnetotail and could be quite localized. This result may help explain the localization of energization in substorm injections.

\section{Radiation from Space and Astrophysical Plasmas (G. R. Gisler [505-667-1375; FAX 505-665-4414; E-mail gisler@sstcxl.lanl.gov])}

Objectives: The goal of this research is to understand how relativistic charged particles originate in both astrophysical and solar system plasmas and how these energetic particles couple with background thermal plasma and electromagnetic radiation.

Results: The most important accomplishment of 1993 came from the study of magnetically driven astrophysical jets. Such jets originate from accretion disks around massive objects in a variety of astrophysical circumstances, including galactic nuclei, neutron stars, and protostellar nebulae. This effort used a magnetohydrodynamics com- puter simulation code developed in the magnetic fusion community to simulate a jet, or bipolar outflow, emanating from the equatorial accretion disk of a protostar. The rotation of the disk twists the magnetic field that threads the original nebula. This twisting produces a strong axial gradient in magnetic pressure, driving material, energy, and angular momentum perpendicularly away from the disk. The simulation of this case has been run to an approximate steady state and has yielded solutions that agree remarkably well with the observations of bipolar outflows from protostellar nebulae. 
CONTRACTOR:

CONTRACT:

CATEGORY:

PERSON IN CHARGE:

\section{OAK RIDGE NATIONAL LABORATORY}

Martin Marietta Energy Systems, Inc.

Oak Ridge, Tennessee 37831

DE-AC05-840R21400

Geophysics and Earth Dynamics

B. R. Appleton

\section{A. Coupled Acoustic Seismic Imaging and Geochemical Studies of Magmatic Processes \\ (R. T. Williams [615-974-2366; FAX 615-974-2368; E-mail williamsrt@ornl.gov], M. T. Naney, \\ A. J. Witten, and G. K. Jacobs)}

Objectives: Objectives of this project are to (1) improve geophysical methods for imaging magma bodies in the earth's crust and (2) improve understanding of magmatic processes through investigation of melting, solidification, and volatilization in a well-characterized artificial magma body.

Project Description: An artificial basaltic magma produced by in situ vitrification (ISV) technology provided an analog for a natural magma and offered opportunities to study geophysical imaging methods and petrological processes in a silicate melt. Seismic and resistivity data were acquired following standard methods, but a more comprehensive data set was obtained than is possible from an actual magma chamber because of the melt size and accessibility. Numerous images of the melt were produced from the geophysical data, permitting evaluation of the type of data and imaging methods most effective for producing useful images. Temperatures were measured to monitor the size and shape of the melt body, magma convection, crystallization, and hydrothermal activity. Gas and particulate emissions from the melt were collected using methods developed for sampling active volcanoes. Thermal, petrologic, and geochemical data were used to develop or test models for melt solidification.
Results: Four different kinds of images of the melt and ISV rock were produced by: (1) migration of seismic reflection data, (2) diffraction tomography using data from borehole geophones and hydrophones, (3) three-dimensional inversion of resistivity measurements, and (4) ground-penetrating radar. Reflection data recorded with shots and geophones on the same side of the melt were more effective than wide-angle data recorded with shots and geophones on opposites of the melt. Resistivity data revealed a conductive melt surrounded by a concentric, resistive sheath. Following solidification, both the sheath and ISV rock were resistive. Studies of gas emissions and thermal data provided insight into magma volatilization, cooling, and solidification. Fractionation of the artificial basalt produced intercrystaliine volumes of trapped rhyolite, supporting the hypothesis that large, contiguous volumes of thyolite cannot be produced by single-stage basalt fractionation. Mineral assemblages and volumes calculated by the MELTS model closely match field observations, and a newly developed heat and mass transfer model calculated cooling profiles consistent with thermocouple data. Time-dependent emissions of trace elements indicated that volatilization was not a steady-state process.

\section{B. Superresolution in Shallow Geophysics (A. J. Witten [615-574-5805], A. J. Devaney, and S. Norton)}

Objectives: The objective for this project is enhanced resolution in shallow geophysical imaging, particularly for ground-penetrating radar, by the exploitation of evanescent waves (waves that exponentially decay in space rather than propagate). These waves contain information at higher spatial frequencies than propagating waves and, thus, promise to be a means of achieving superresolution.

Project Description: In this project, methods will be investigated for inversion of the wave equation subject to a weak scatter approximation. In conventional wave-based geophysical imaging, consideration is given only to that 
portion of the spatial frequency spectrum for which waves are propagating. Higher spatial resolution can be achieved by considering the highest portion of this spectrum where waves are evanescent. Mathematical and computational complications arise from the incorporation of evanescent waves in imaging algorithms as a result of imaginary or complex components of the wave vector. For propagating waves only, the acquired data can be analytically related to the desired image quantity, the spatial variations in refractive index, and by spatial Fourier transforms. When evanescent waves are included in the analysis, the cited relationship involves a generalized integral transform that cannot be inverted by standard numerical methods. Several mathematical and computation approaches will be considered for inversion of this integral transform. These will include regularization procedures, analytic filters, and iterative methods.

Results: This project will begin in FY 1994.

\section{CATEGORY:} PERSON IN CHARGE:

\section{Geochemistry}

\section{B. R. Appleton}

\section{A. Hydrothermal Geochemistry (D. J. Wesolowski [615-574-6903; FAX 615-574-4961; E-mail dqw@ornl.gov], D. R. Cole, and J. L.S. Bell)}

Objectives: This project seeks to obtain quantitative experimental information on the speciation of geologically significant metals, acids, and bases; the solubility of major mineral phases; and the thermodynamic and kinetic parameters controlling fluid-rock interactions in the earth's crust.

Project Description: A wide array of hydrothermal facilities, including high-pressure-temperature, gold-bag rocking autoclaves and a unique hydrogen-electrode potentiometric laboratory, are employed to obtain precise and unambiguous data on the principal aqueous reactions controlling elemental transport and porosity development in geothermal, hydrocarbon, and groundwater reservoirs. High-pressure-temperature Raman and ultraviolet-visible spectroscopic studies are performed to provide independent evidence of speciation in aqueous solutions and the properties of C-O-H-N fluids.

Results: Water-soluble organic acids may play a major role in mineral dissolution, metal transport, and primary hydrocarbon migration in a wide array of geologic settings. This year, we determined the acid dissociation constants of the following naturally occurring organic acids in 0 to 5 molal $\mathrm{NaCl}$ brines: formic acid $\left(0\right.$ to $\left.200^{\circ} \mathrm{C}\right)$, benzoic acid $\left(0\right.$ to $\left.250^{\circ} \mathrm{C}\right)$, and succinic acid $\left(0\right.$ to $\left.250^{\circ} \mathrm{C}\right)$. Succinic acid exhibited unexpectedly high thermal stability, suggesting that this difunctional carboxylic acid may be more important than oxalic acid in diagenetic and geothermal alteration reactions over geologic time.

Extensive studies of the thermal decomposition kinetics of oxalic and formic acids were also performed as a function of temperature, $\mathrm{pH}$, and salinity, using poten- tiometric and conventional hydrothermal techniques. The results demonstrate that the continuous and precise monitoring of $\mathrm{pH}$ possible with our high-temperature electromotive force cells allows detailed analysis of the decomposition of individual organic acid species.

The hydrolysis of $\mathrm{Mg}^{2+}$ to $\mathrm{Mg}(\mathrm{OH})^{+}$in $0-5$ molal $\mathrm{NaCl}$ brines was determined in the 0 to $250^{\circ} \mathrm{C}$ range using the potentiometric titration technique. These are the first reliable experimental results for this reaction in the temperature-salinity regime of oil and gas formation and are important in modeling porosity changes resulting from chlorite formation and dolomitization of limestone.

The sorption of hydrogen ions on the surface of $\mathrm{TiO}_{2}$ (rutile) was quantitatively measured in 0.01 to 1.0 molal $\mathrm{NaCl}$ brines from 25 to $2.50^{\circ} \mathrm{C}$, and the point of zero charge of the rutile surface w.Ls determined. These are the first direct measurements of proton adsorption ever performed at high temperature. The results are applicable to modeling mineral dissolution and precipitation kinetics as well as sorption of contaminants in geologic media.

A rigorous model has been developed for the activity coefficients of $\mathrm{CO}_{2}$ in dilute $\mathrm{H}_{2} \mathrm{O}-\mathrm{NaCl}$ solutions to high temperatures, which is being applied in the interpretation of our previous studies of the solubility of calcite and dolomite to $300^{\circ} \mathrm{C}$ and 1300 bars. Finally, Raman spectral parameters of $\mathrm{CO}_{2}-\mathrm{N}_{2}-\mathrm{CH}_{4}$ gas mixtures have been measured as a function of pressure and composition at room temperature and have been applied in the quantitative analysis of the composition and internal pressures of fluid inclusions in quartz from a carbonaceous sedimentary environment. 


\section{B. Stable Isotope Systematics of Fluid-Rock Interactions (D. R. Cole [615-574-5473; FAX 615-574-4961; E-mail me@cole.chem.ornl.gov], D. J. Wesolowski, and T. Burch)}

Objectives: Objectives of this project are to experimentally determine the rates of isotope fluid-rock exchange reactions, demonstrate isotope disequilibrium conditions in natural geothermal systems, and enhance our knowledge of geological processes through the application of stable isotope studies and advanced interpretation schemes.

Project Description: A wide array of hydrothermal rocking autoclaves and cold-seal pressure vessels are employed to obtain $\mathrm{C}-\mathrm{O}-\mathrm{H}-\mathrm{S}$ isotope partition functions and rates of isotope exchange in mineral-fluid systems at conditions relevant to hydrocarbon generation and geothermal system evolution. The theory of isotope exchange kinetics via bulk diffusion and mineral dissolution-precipitation processes is being advanced and is shown to be related to the fundamental thermodynamic and structural properties of minerals and solvated ions in aqueous solution. Stable isotope studies are performed on selected natural systems in which major geologic processes can be elucidated and quantified and which contribute to our ability to model the global effects of human energy usage.

Results: Experimental data on the oxygen and carbon isotope exchange rates among calcite, water, and $\mathrm{CO}_{2}$ at elevated temperatures and pressures obtained previously are shown to be controlled by either intracrystalline vol- ume diffusion or bulk recrystallization, depending on temperature and fluid composition. Rates of exchange are also shown to be strongly dependent on salinity in $\mathrm{NaCl}$ brines.

Correlations have been demonstrated between the activation parameters of oxygen isotope exchange rates between water and minerals and mineral chemical parameters, such as cation radius and oxygen bonding characteristics. These correlations offer the possibility of predicting rates for reactions relevant to fluid-rock isotope exchange but for which experimental data are unavailable.

Oxygen isotope disequilibrium between rocks and circulating fluids in active and paleo-geothermal systems has been demonstrated from a detailed analysis of data from a large number of field settings. The degree of disequilibrium is a function of temperature and salinity of the circulating brine. This analysis suggests that the time scales of fluid-rock interaction processes may be revealed by natural stable isotope distributions.

The carbon and oxygen isotopic compositions of pedogenic carbonates in paleosols of the southwestern United States provided the basis for paleoclimate reconstructions in the Permian and Pliocene-Holocene periods in this region. The results indicate that a major shift in plant communities at ca. $9,000 \mathrm{yr}$. B.P. was directly related to a major increase in atmospheric $\mathrm{CO}_{2}$ content.

\section{Thermodynamics of Rock-Forming Crystalline Solutions and Silicate Melts (J. G. Blencoe [615-574-7041; FAX 615-574-4961; E-mail jblencoe@blencoe.chem.ornl.gov])}

Objectives: Computer modeling techniques are applied to determine the thermodynamic mixing properties of common rock-forming minerals and natural magmas. Emphasis is given to "granitic" (Na-K-Ca aluminosilicate) minerals and melts because granites and granitic metamorphic rocks are abundant in the earth's continental crust. The ultimate purpose of this project is to develop thermodynamic equations of state for synthetic mineral and melt mi.stures that serve as geochemical analogs for natural aluminosilicate crystalline solutions and granitic magmas.

Project Description: Multiple, independent data sets obtained from carefully performed hydrothermal experiments, calorimetric measurements, and spectroscopic studies are analyzed to develop empirical equations for representing the thermodynamic mixing properties of aluminosilicate melts and crystalline solutions. Modeling is performed in strict accordance with fundamental princi- ples of classical thermodynamics, and emphasis is placed on minimizing the number of assumptions.

Results: New computational procedures were developed to determine the thermodynamic mixing properties of multicomponent synthetic granite ("haplogranite") melts. Only small amounts of phase-equilibrium data are required to initiate the modeling process. If phase relations are tightly constrained by experimental data, additional steps can be taken to increase the accuracy of the results.

The new techniques were applied to model the melting relations of the albite-quartz-water ( $a b-q z-w)$ system (" $q z$ " $\left.=\mathrm{Si}_{4} \mathrm{O}_{8}\right)$ at $2.5 \mathrm{kbar}$. For these calculations it was assumed that the thermodynamic mixing properties of $a b-q z-w$ melts can be represented accurately by a six-parameter excess free energy $\left(G^{e x}\right)$ equation of the Margules type. The six parameters in this equation are binary interaction parameters, two parameters for each binary subsystem; 
thus, it was assumed that there are no ternary molecular interactions in $a b-q z-w$ melts. Equations for the free energy of albite and quartz fusion were obtained from literature sources. Calculations were conducted for $2.5 \mathrm{kbar}$ and 750 , 800,900 , and $1000^{\circ} \mathrm{C}$. The results are consistent with the limited phase equilibrium data acquired by previous investigators. Phase-equilibrium experiments are being performed in a parallel project to determine the accuracy of the predicted melting relations. The new data will be used to refine the modeling calculations and to develop a polythermal $G^{e x}$ equation for $a b-q z-w$ melts at $2.5 \mathrm{kbar}$.

In research performed on aluminosilicate crystäline solutions, geochemical data for 139 natural paragonitemuscovite $(P g-M s)$ pairs were compiled and analyzed to determine the effects of ferromagnesian components on the $P-T-X$ topology of the $P g-M s$ solvus. The pairs were selected on the basis of reasonably accurate knowledge of the $P-T$ conditions of formation, evidence for close approach to equilibrium at peak metamorphic conditions, exclusion of pairs in which paragonite contains more than $5 \mathrm{~mol} \%$ margarite, and exclusion of pairs from polymetamorphic rocks that contain more than one set of cogenetic $P g-M s$ pairs. Graphical analysis reveals considerable scatter in the data; nevertheless, it is evident that the $M s$ limb of the solvus shifts markedly toward end-member muscovite with increasing pressure from $\sim 7$ to $21 \mathrm{kbar}$. This shift is attributed to a pressure-induced increase of the ferromagnesian content of $M s$, which increases the size of the $\mathrm{XII}$ alkali site to the effect that $\mathrm{K}$ is more readily accommodated than $\mathrm{Na}$. The data also suggest that the $P g$ limb of the solvus migrates slightly toward end-member $P g$ with increasing pressure.

\section{Crustal Stability of C-O-H-N Fluids (J. G. Blencoe 1615-574-7041; FAX 615-574-4961; E-mail jblencoe@blencoe.chem.ornl.gov], J. L. S. Bell, D. B. Joyce, and J. C. Seitz)}

Objectives: Experimental studies are performed to delineate the thermodynamic mixing properties of $\mathrm{C}-\mathrm{O}-\mathrm{H}$ $\mathrm{N}$ fluids and the decomposition kinetics of acetic acid and sodium acetate. The data are used to develop equations of state and to model the role of carboxylic acids in the migration of natural gas in sedimentary basins.

Project Description: A variety of experimental techniques are employed to determine the thermodynamic and kinetic characteristics of C-O-H-N fluids at elevated pressures and temperatures. Excess free energies for mixtures of $\mathrm{H}_{2} \mathrm{O}, \mathrm{CO}_{2}, \mathrm{CH}_{4}$, and $\mathrm{N}_{2}$ are deduced from $P-V-T$ and activity-composition data. Autoclave experiments are performed to investigate the possibility that acetate decarboxylation is accelerated significantly by the presence of geologically relevant solid substrates. Results of the research are widely applicable in modeling (1) the geochemical properties of $\mathrm{H}_{2} \mathrm{O}$-hydrocarbon fluids and (2) the dynamics of geothermal and hydrocarbon reservoirs.

Results: $P-V$ - $T$ data were collected for pure $\mathrm{CO}_{2}$, pure $\mathrm{CH}_{4}$, and binary and ternary $\mathrm{CO}_{2}-\mathrm{CH}_{4}-\mathrm{N}_{2}$ mixtures at 100 to 1000 bars and $50,100,200$, and $300^{\circ} \mathrm{C}$ using a unique vibrating-tube densimeter designed to measure the volumetric properties of fluids at $P-T$ conditions as high as 3500 bars and $500^{\circ} \mathrm{C}$. An isobaric, isothermal flowthrough method was employed to obtain a statistically significant number of measurements $(n=100$ to 400$)$ for the period of vibration at each $P-T-X$ condition. High-accuracy $( \pm 0.05 \%)$ positive-displacement pumps were used to deliver the gases to the vibrating tube. Gas mixtures were formed by flowing pure gases $\left(\mathrm{CO}_{2}, \mathrm{CH}_{4}\right.$, and $\left.\mathrm{N}_{2}\right)$ into T-junctions on the upstream side of the vibrating tube. Pressure and temperature were controlled to $\pm 0.1 \mathrm{bar}$ and $\pm 0.01{ }^{\circ} \mathrm{C}$, respectively. Conservative estimates of accuracy are: $P, \pm 2.0$ bar and $T, \pm 0.2^{\circ} \mathrm{C}$. Precisions of experimentally determined molar volumes typically range from 0.05 to $0.5 \%$ and vary as a function of the density and composition of the gas mixture. Principal experimental results for the mixtures are summarized as follows.

1. Depending on the particular $P-T-X$ conditions, excess molar volume $\left(V^{e x}\right)$ for $\mathrm{CO}_{2}$-bearing binary and ternary mixtures can be either positive or negative.

2. The majority of $V^{e x}$ data for binary mixtures is accurately represented by two-parameter Margules equations.

3. $V^{e x}$ for binary and ternary $\mathrm{CO}_{2}$-bearing mixtures increases sharply near the critical point of $\mathrm{CO}_{2}\left(31.1^{\circ} \mathrm{C}\right.$, 73.6 bars).

4. For all binary and ternary $\mathrm{CO}_{2}-\mathrm{CH}_{4}-\mathrm{N}_{2}$ mixtures, $V^{e x}$ increases sharply from zero at very low density $(P$ near 0 ) to a maximum value at a pressure between 100 and 300 bars. Above this maximum, $V^{e x}$ decreases rapidly with increasing pressure.

5. Between 50 and $200^{\circ} \mathrm{C}$, the effect of temperature on $V^{e x}$ is small (except near the critical point of $\mathrm{CO}_{2}$, as noted previously).

6. The volumetric properties of ternary $\mathrm{CO}_{2}-\mathrm{CH}_{4}-\mathrm{N}_{2}$ mixtures can be estimated accurately from $V^{e x}$ data for the binary mixtures using several different types of geometric projection techniques. 
Experiments designed to determine the activity-composition relations of $\mathrm{H}_{2} \mathrm{O}-\mathrm{CO}_{2}$ fluids were performed in a hydrogen-service, internally heated pressure vessel. Control and measurement of hydrogen fugacity $\left(f_{2}\right)$ as accomplished using an $\mathrm{H}_{2}$-permeable membrane. During experimentation, the fugacity of hydrogen in Ag-Pd encapsulated samples was essentially equal to hydrogen pressure in the membrane. Experiments were performed at 500 to 1000 bars, 400 to $700^{\circ} \mathrm{C}$. The resulting data yielded bracketed (reversed) values of water activity $\left(\mathrm{aH}_{2} \mathrm{O}\right)$ for various values of $\mathrm{X}_{2} \mathrm{O}$ at each set of experimental $P$-T conditions. To date, 25 reversed values of $\mathrm{X}_{\mathrm{H}_{2} \mathrm{O}}$ have been determined. These $\mathrm{aH}_{2} \mathrm{O}$ data have been used to evaluate the mixing parameters of the two-parameter Margules formulation $\left(W_{G}, \mathrm{H}_{2} \mathrm{O}\right.$ and $\left.W_{G}, \mathrm{CO}_{2}\right)$, which yield calculated $a-X$ relations for $\mathrm{H}_{2} \mathrm{O}-\mathrm{CO}_{2}$ mixtures at each set of experimental $P-T$ conditions. The activity data indicate that $\mathrm{H}_{2} \mathrm{O}-\mathrm{CO}_{2}$ fluids exhibit small positive deviations from ideal behavior at high temperatures $\left(600\right.$ to $\left.700^{\circ} \mathrm{C}\right)$, but large positive deviations from ideality at low temperatures $\left( \pm 400^{\circ} \mathrm{C}\right)$.

In addition to these studies, several manuscripts were submitted for publication based on previous work on acetate decomposition in the presence of natural catalysts.

\section{E. Fundamental Research in the Geochemistry of Geothermal Systems (D. J. Wesolowski [615-574-6903; FAX 615-574-4961; E-mail dqw@ornl.gov], D. R. Cole, and J. Horita)}

Objectives: The objective of this project is to provide fundamental information on elemental and isotopic speciation, distributions, and exchange reactions, which play pivotal roles in a wide range of geological processes, but which specifically impact our understanding of reservoir dynamics, corrosion, and heat extraction in active geothermal systems.

Project Description: At Oak Ridge National Laboratory, a long-term basic research program in experimental hydrothermal geochemistry, stable isotope exchange, and igneous petrology has lead to the development of unique methodologies for extracting rigorous and unambiguous information on a wide range of geochemical processes. This capability enables us to efficiently and definitively address specific problems hampering our ability to quantitatively model fluid-rock interaction processes related to the discovery and exploitation of geothermal resources. Research topics in this project are selected in close cooperation with geothermal industry representatives and are frequently augmented by parallel research on more applied aspects of the same problems funded by the U.S. Department of Energy's (DOE's) Geothermal Program.

Results: Recently, this effort has been focused on both the geochemistry of aluminum and the liquid-vapor partitioning of $\mathrm{H}$ and $\mathrm{O}$ isotopes in aqueous solutions as a function of salinity and temperature. These results are relevant in modeling permeability development, rock alteration, fluid sources and fluxes, and reservoir temperatures in geothermal systems, but they also have broad generic applicability in a wide range of geologic processes relevant to the DOE mission.

A general model for the hydrolysis speciation of aluminum, $\mathrm{Al}(\mathrm{OH})_{y}^{3-y}$, in $\mathrm{NaCl}$ brines to $350^{\circ} \mathrm{C}$ at low salini- ties and to $100^{\circ} \mathrm{C}$ in concentrated brines has been developed and submitted for publication. This model is based on studies of the solubility of gibbsite, $\mathrm{Al}(\mathrm{OH})_{3}$, in acidic, basic, and near-neutral $\mathrm{pH}$ solutions, on potentiometric measurements of the formation constants of $\mathrm{Al}(\mathrm{OH})^{2+}$ over a wide range of temperatures and salinities conducted in this laboratory in previous years and on recent literature data for the solubility of boehmite, $\mathrm{AlOOH}$, at near infinite dilution and high temperatures. The solubility of aluminum minerals is shown to be strongly dependent on slight variations in $\mathrm{pH}$, salinity, and the concentration of acetate in the mildly acid solutions encountered in geothermal reservoirs and recharge zones.

A large number of measurements of the effect of dissolved salts in the system $\mathrm{Na}-\mathrm{K}-\mathrm{Mg}-\mathrm{Ca}-\mathrm{Cl}-\mathrm{SO}_{4}$ on the partitioning of hydrogen and oxygen isotopes between brines and coexisting water vapor have been determined as a function of salinity and temperature. Large oxygen isotope effects have been found for $\mathrm{MgCl}_{2}, \mathrm{CaCl}_{2}$, and $\mathrm{Na}_{2} \mathrm{SO}_{4}$ at temperatures up to at least $100^{\circ} \mathrm{C}$; however, $\mathrm{NaCl}$ and $\mathrm{KCl}$ have little or no oxygen isotope salt effect at temperatures up to $350^{\circ} \mathrm{C}$. All salts studied have large hydrogen isotope salt effects that, as the oxygen effect, are linearly related to the salt molality. For the chloride salts, the hydrogen isotope effect is roughly proportional to the chloride concentration and more weakly related to the nature of the cation. The consequences of incorporating the salt effect into interpretation of stable isotope data from fluids and minerals in saline geothermal and sedimentary systems has been investigated, and it has been shown that reservoir temperature estimates can be in error by as much as $80^{\circ} \mathrm{C}$ if the effect is ignored. 


\section{F. Stable Isotope Systematics During Burial Diagenesis in the Alberta Basin: An Ion Microprobe Study (D. R. Cole [615-574-5473; FAX 615-574-4961; E-mail me@cole.chem.ornl.gov] and L. R. Riciputi)}

Objectives: The principle objective of this research is to use elemental and isotopic compositions coupled with detailed mineralogy and fluid inclusion studies to quantify the mass transfer processes influencing porosity and permeability during burial diagenesis of carbonates and clastics in the Western Canada Sedimentary Basin.

Project Description: In this project, the micron-scale spatial resolution, elemental and isotopic imaging, and quantitative trace element and isotope ratio capabilities of the Cameca $4 \mathrm{f}$ ion microprobe are being developed and used in a study of fluid-rock interactions associated with burial and hydrocarbon generation in the Alberta basin. The probe studies are augmented by information obtained from a variety of other geochemical techniques, including but not limited to conventional gas-source isotope ratio mass spectrometry, electron microprobe, scanning electron microscopy, neutron activation, and fluid inclusion microthermometry. These techniques have been applied to a study of fine-scale chemical and isotopic diagenetic features of carbonates of the Upper Devonian Nisku Formation, an important petroleum and natural gas host rock in the Alberta basin.

Results: Trace element data obtained on diagenetic calcites and dolomites by ion microprobe on sample spots $\sim 20 \mu \mathrm{m}$ in diameter are comparable to those obtained by inductively coupled plasma spectroscopy. Detection limits on the ion microprobe are $<\mathrm{ppm}$ for most of the trace elements of interest. Trace element variations in and between Upper Devonian diagenetic calcites from the Nisku Formation aid in the interpretation of the fluid composition during precipitation and/or recrystallization, as well as in the interpretation of primary carbonate mineralogy (e.g., high-magnesium calcite vs aragonite). Using the ion probe, microenvironments, as well as temporal variations in diagenetic fluid compositions, have been resolved. The presence of significant trace element variations in Nisku carbonates on a scale of $<100 \mu \mathrm{m}$ suggests that fluid-rock interaction during burial of up to $4000 \mathrm{~m}$ and during more than 300 million years was very restricted and channelized. The development of these rock-dominated microenvironments depends, in large part, on the complex interplay between primary composition, changes in fluid chemistry, temperature, and flux of fluids through time.

Sulfur isotope compositions have been measured in pyrites, marcasites, sulfates, and bitumen using the ion probe. Pyrite and marcasite from three wells in the Nisku area have an overall range of $\delta{ }^{34} S$ of -35 to $+20 \%$, with $90 \%$ of the data falling between -35 and $0 \%$. Sulfates exhibit a range of +23 to $32 \%$, whereas the bitumen samples range from +5 to $25 \%$. Significant within-sample (sub-thin section scale) variations have been observed, up to $25 \%$ o. We also observed a trend of increasing $\delta^{34} S$ with increasing grain size. The isotopically light values were produced from kinetic isotope effects accompanying bacterial sulfate reduction of sulfate. The trend of increasing $\delta{ }^{34} \mathrm{~S}$ with increasing grain size (and time, based on paragenesis) suggests a possible control by a Rayleigh fractionation process involving nonequilibrium reduction of sulfate in a closed system. The heaviest sulfur isotope values occur in sulfides associated with late-stage hightemperature $\left(100^{\circ} \mathrm{C}\right)$ saddle dolomite and may be indicative of thermochemical sulfate reduction during deep burial.

\section{G. Advanced Concepts (D. R. Cole 1615-574-5473; FAX 615-574-4961; E-mail me@cole.chem.ornl.gov], J. G. Blencoe [615-574-7041; FAX 615-574-4961; E-mail jblencoe@blencoe.chem.ornl.gov], and D. J. Wesolowski [615-574-6903; FAX 615-574-4961])}

Objectives: This project explores topics in the geosciences that offer the opportunity to open new frontiers of scientific inquiry or methodology.

Project Description: Innovative techniques are employed to gather information that is either new or inaccessible by other approaches. Goals are commonly achieved by developing unique laboratory facilities and theoretical models. New ideas that originate in this program provide the impetus for full-scale research programs that can make full use of new information. The benefits of this exploratory program impact many areas related to domestic energy supplies.

Results: Construction of a new high-temperature flowing electromotive force cell for potentiometric measurements of protolytic aqueous reactions to at least $400^{\circ} \mathrm{C}$ and $1 \mathrm{kbar}$ was completed this year. Additionally, construction of a new hydrogen-electrode concentration cell specifically designed to allow mineral solubility studies with 
in situ $\mathrm{pH}$ measurement to $300^{\circ} \mathrm{C}$ and $1 \mathrm{kbar}$ is near completion.

The unique capabilities of our hydrogen-service internally heated pressure vessel were used in collaboration with R. N. Compton of Oak Ridge National Laboratory's (ORNL's) Health Sciences Research Division to investigate the possibility of producing novel hydrogenated fullerene ( $\mathrm{C}_{60}$ "buckyball") molecules. Up to 18 hydrogen atoms per $\mathrm{C}_{60}$ have been produced at $300^{\circ} \mathrm{C}$ under 600 bars hydrogen pressure. These hydrogenated molecules have potential as a hydrogen storage material for use in fuel cycles.

Much of the activity of the past year involved investigation of new geoscience applications of ion microprobes in collaboration with scientists from ORNL's Analytical Chemistry Division and the University of Tennessee. Ion imaging and trace element analyses were carried out with the Cameca ion probe on glass and crystalline run products from the in situ vitrification experiment. These studies found evidence for fractional crystallization, formation of high silica glass from a basaltic precursor, and localization of cesium in this glass. Rare earth element (REE) analyses were carried out on diamondiferous eclogite xenoliths from the Mir kimberlite of the Yakutia kimberlite province in Siberia. Clinopyroxene REE analyses indicate convexupward light REE patterns, common to this area, but absent in xenoliths from South African kimberlites. The clinopyroxenes also exhibit a prominent europium anomaly, which may indicate a cumulate origin. In addition to this work, trace element compositions of $<50 \mu \mathrm{m}$ calcite and dolomite grains have been measured in a suite of highly altered carbonaceous chondrites. Sizeable variations are observed in all trace element concentrations from grain to grain within a single thin section. $\mathrm{Sr} / \mathrm{Ca}$, $\mathrm{Mn} / \mathrm{Ca}$, and $\mathrm{Fe} / \mathrm{Ca}$ ratios suggest a low-temperature origin for the carbonates.

\section{H. Experimental Studies of Fundamental Stable Isotope Exchange Reactions (D. J. Wesolowski [615-574-6903; FAX 615-574-4961; E-mail dqw@ornl.gov], D. R. Cole, and J. Horita)}

Objectives: Objectives of this project are to obtain reliable information on the temperature dependence and reaction rates and mechanisms of stable $\mathrm{C}-\mathrm{O}-\mathrm{H}$ isotope exchange among minerals and fluid components associated with fluid-rock interaction.

Project Description: This research will focus on filling significant gaps in current knowledge of stable isotope exchange processes in natural systems. We will seek to obtain information on the partitioning of oxygen isotopes between water and the major iron oxides found in natural systems, magnetite and hematite. Because these fractionations are believed to be very large and highly ternperature dependent, iron oxides can provide a wealth of information on fluid sources and temperatures of geochemical processes. We will also investigate the kinetics and equilibrium partitioning of carbon, hydrogen, and oxygen isotopes among the gases $\mathrm{CH}_{4}, \mathrm{C}_{2} \mathrm{H}_{6}, \mathrm{H}_{2}, \mathrm{H}_{2} \mathrm{O}$, and $\mathrm{CO}_{2}$ at temperatures relevant to geothermal systems and sedimentary basins. The role of carboxylic acids, such as acetic acid, will be investigated as a potential enhancer of isotope exchange in both systems. Preliminary studies demonstrate that acetate promotes the recrystallization of iron oxides and may act as a reaction intermediate in gas exchange reactions.

Results: Research will begin in FY 1994. 
CONTRACTOR:

CONTRACT:

CATEGORY:

PERSON IN CHARGE:
PACIFIC NORTHWEST LABORATORY

Battelle Memorial Institute

Richland, Washington 99352

\title{
DE-AC06-76RLO 1830
}

\author{
Geochemistry
}

\author{
J. R. Rustad
}

Structure and Reactivity of Oxide and Hydroxide Surfaces (A. R. Felmy [509-376-1134; FAX 509-376-5368; E-mail ar_felmy@ccmail.pnl.gov] and D. M. Sherman [509-375-6561; FAX 509-375-6916; E-maildm_sherman@mail.pnl.gov])

Objectives: The objective of this research is to obtain an understanding of microscopic surface site heterogeneity in solvated oxide mineral-water interfaces in terms of (1) the structure of different binding sites and (2) the acidities and proton affinities at these sites. This understanding is built using a model that will allow full consideration of the effects of solvation on each of these issues. This will enable the model to be used to improve existing thermodynamic adsorption models for oxide surfaces.

Project Description: A molecular dynamics model for dissociating water was applied to investigate: (1) solvation of ferric ions in aqueous solution, (2) the structure of proton distributions on the goethite (100) surface, (3) the distribution of proton-binding energies at this surface, and (4) the effect of proton distributions on the hydrogen bond network in water overlying the surface.

Results: Computations predict that triply coordinated $\left(\mu_{3}\right)$ oxo ions that connect double chains are never protonated at room temperature. Several types of proton arrangements were identified that occur on the lowest energy proton distributions on this surface. These distributions involve transfer of protons from inter double chain $\mu_{3}$-hydroxo ions to hydroxo ions (bound to one ferric ion) to create aqua ligands at Lewis acid sites. There is also appreciable transfer of protons off the $\mu_{3}$-hydroxo ions underlying the hydroxo ions. Disorder in surface proton positions lowers the total energy of the system and results in a distribution of proton-binding energies. The molecular dynamics calculations indicate that neare, $t$ neighbor and next-nearest neighbor effects on proton binding are strong. Disorder in surface proton distributions results in lowering of the total energy of the surface and yields a continuous range of binding energies for protons that varies between 350 to $420 \mathrm{kcal} / \mathrm{mol}$. This has broad implications for modeling the adsorption behavior of goethite in terms of site binding models. Results from the molecular dynamics modeling indicates that a continuum of surface $\mathrm{pK}$ is required for a realistic representation of the surface. The calculations also show that proton disorder at the surface provides a much better environment for the development of hydrogen bond networks in water molecules overlying the surface as all the water molecules need not be oriented with their protons pointed upwards from the surface plane. It is advantageous for solvation if some of the surface oxide ions release protons and accept hydrogen bonds from water molecules in the interfacial layer. 


\section{CATEGORY:}

PERSON IN CHARGE:
Energy Resource Recognition, Evaluation, and Utilization

\author{
E. W. Kleckner
}

\section{A. Remote Geologic Analysis (M. G. Foley, [509-376-8635; FAX 509-376-5368; Internet mg_foley@pnl.gov], K. A. Hoover, P. G. Heasler, and B. R. Shaw)}

Objectives: Objectives for this project are to develop and test automated analytical methods for extracting and interpreting three-dimensional crustal structure and related information from digital topography and geophysical data.

Project Description: For this project it was assumed that basement structures project through overlying, differently deformed rocks to influence topography. Project focus was on identifying the imprint of large-scale, active or reactivated planar basement structures on topography. The hypothesis was that basement faults not identified with mapped surface faults should be expressed in topography by zones of warping and diffuse fracturing along their traces. It was assumed that covert, nearly planar fractures could be identified because preferential erosion would constrain segments of valleys to lie within the fracture plane; identification of these coplanar valley segments would then define the orientations of the controlling fractures.

The Pacific Northwest Laboratory (PNL) geomorphic pattern-recognition approach to identifying the imprint of reactivated basement faults uses semiautomated featureextraction and feature-classification methods applied to gridded topographic elevation data. The feature extractor consists of a valley-detection algorithm, a vector-segmentation algorithm, and a coplanar-correlation algorithm. The valley-detector algorithm searches the data for all points lower in elevation than their neighbors and strings these low points together into more or less continuous valley bottoms. The vector-segmentation algorithm breaks the valley strings into linear segments and uses a leastsquares method to fit vectors to the segments. Valley-segment vectors are compared with one another by the coplanar algorithm to find those that are coplanar and to calculate the locations and orientations of the resulting planes. A cluster analysis approach was developed for automated feature classification.

Results: The Yucca Flat area of the Nevada Test Site was analyzed to test the PNL approach in an area where subsurface geology and geologic structures are relatively well known. The coplanar pattern-recognition analysis identified 26,473 individual planes in a $30-\mathrm{m}$ resolution digital elevation model for a 33- $\times 42-\mathrm{km}$ area. In the 21 most significant clusters of planes, the surface traces were compared with the following: topographic features, mapped geology and geologic structures, fractures activated during nuclear tests, lithostratigraphic isopach and structural contour maps, gravity anomaly plots, a plot of basin-fill thickness modeled on gravity anomalies, and a magnetic anomaly map of the northern part of Yucca Flat. Strong correlations were found between plane clusters, segments of surficial faults, and apparent structures in the subsurface.

The automated analysis apparently detects associations of subparallel fractures in the upper few kilometers of the earth's crust that are inferred to be upward-diverging fault or fracture splays reflecting faults or folds at greater depth. This inference suggests that PNL's approach could be useful for identifying fracture systems that control the migration of fluids (e.g., natural gas, hydrothermal fluids, contaminated groundwater) in low-permeability rocks. The capability to detect fracture zones and infer the nature of the underlying structure would also be applicable to seismic hazard analysis, especially for predicting earthquakes that may be generated by faults having little or no mapped surface expression.

A paper summarizing these results has been submitted to the Journal of Geophysical Research. 


\section{B. Remote Sensing: Geoscience Data Analysis and Integration (H. P. Foote 1509-376-8418; FAX 509-376-5368; Internet hp_foote@pnl.gov], G. E. Wukelic [509-376-5860; FAX 509-376-5368; Internet ge_wukelic@pnl.gov], and J.S. Risch [509-376-4445; FAX 509-376-5368; Internet js_risch@pnl.gov])}

Objectives: Historically, this project has focused on the development of advanced, interactive computer techniques for processing, displaying, and analyzing remote sensing data and integrating remote sensing data with other geoscientific data types. Current efforts are directed towards evaluating the potential of emerging immersive virtual environment (IVE) technology for enhancing multidimensional geosciences data visualization, interaction, and analysis.

Project Description: Past research conducted under this project has included the development of a number of unique image processing, display, and analysis techniques, as well as pioneering work in the areas of digital mapping and the generation of shaded terrain relief models. More recent work includes the development of techniques for generating animated fly-bys of integrated remote-sensing data and digital terrain models, as well as animated displays of time-dependent geoscientific data such as seismic events and groundwater flow. This research has highlighted the value of increased interactivity, such as control over viewpoint location and other viewing parameters, for improving understanding of complex spatial and temporal interrelationships within multidimensional geoscientific data and conceptual models. Consequently, efforts are focused on evaluating the utility of advanced human-computer interfaces, in particular, IVE systems, for further enhancing data interaction and facilitating the development and understanding of three-dimensional (3-D) conceptual models. IVE systems, specifically integrated high-performance graphics computers, wide field-of-view stereoscopic display devices, and six degree-of-freedom (6DOF) position tracking systems are facilitating improved understanding of 3-D information in a variety of fields and may have considerable value in a wide range of geoscience data analysis applications as well.

Results: FY 1993 research concentrated on identifying constraints to existing 3-D data analysis methodologies and on developing techniques for overcoming these constraints through the application of IVE concepts and technology. Integrated use of stereoscopic display systems and 6DOF "mice," for specifying location and orientation within 3-D space, can enable geoscientists to directly observe 3-D spatial interrelationships within data and to quickly and intuitively select and manipulate data in efficient and powerful ways. Early results indicate that IVE- based data analysis tools may enable geoscientists to significantly accelerate the performance of a number of common geoscience data analysis tasks, improve understanding of complex multidimensional and multitemporal geoscientific phenomena, and facilitate the communication of difficult geoscientific concepts, both among geoscience researchers and to the public.

Ongoing research is addressing the geoscientific applications of IVE technology in three primary areas: (1) 3-D geostatistical data analysis and modeling, (2) 3-D hydrogeological modeling, and (3) seismic hypocenter data analysis. Additional work is directed towards investigating the utility of IVE systems for facilitating geosciences data management and data integration. Work to date has included the development of a series of prototype data analysis systems using Application Visualization System (AVS) software running on Pacific Northwest Laboratory (PNL) Silicon Graphics and Stardent computers. The goal of this effort is the refinement of preliminary data interaction and analysis concepts prior to their implementation in fully immersive, follow-on systems. An additional goal is the determination of the hardware and software requirements for the real-time display of, and interaction with, large geoscience data sets. Additional research includes experimentation with 6DOF electromagnetic position tracking systems and the evaluation of a variety of wide field-of-view stereoscopic display devices as to suitability for geoscientific data analysis applications.

In addition to technical research, FY 1993 efforts were devoted to the establishment of a series of anticipated collaborative research programs. The purpose of these collaborative programs is to guide the development of a series of prototype geoscientific IVE data analysis applications and to evaluate their utility. Collaborative research is planned with geoscientists at the U.S. Geological Survey, the University of Washington Department of Geophysics, and other PNL researchers. Additional collaborative work related to IVE systems design and implementation and human interface design is planned with researchers at the University of North Carolina at Chapel Hill Department of Computer Sciences, the University of Washington Human Interface Technology Laboratory, and Sandia National Laboratories. 
CATEGORY:

\section{PERSON IN CHARGE:}

\section{Solar-Terrestrial Interactions}

\author{
E. W. Kleckner
}

Aeronomy/Insolation Studies (E. W. Kleckner [509-376-8425; FAX 509-376-5368; Internet ew_kleckner@pnl.gov], D. W. Slater, and N.R. Larson)

Objectives: This research program addresses the following questions in Aeronomy and Insolation. What are the mechanisms governing the transfer of energy from the ring current to plasmasphere and the upper atmosphere at mid-latitudes? What are the relative roles of atmospheric composition, energy spectrum, and spatial distributions in the energy transfer? What is the time evolution of the size distribution of stratospheric aerosols resulting from major volcanic eruptions? What are the latitudinal and longitudinal distributions following a significant event?

Project Description: One consequence associated with energy storage within the magnetosphere is the transfer of energy from highly energetic ions to thermal electrons within near-earth space and ultimately into the upper atmosphere where ambient electron temperatures can reach several degrees. The resulting excitation of atomic oxygen leads to optical emissions that are useful indicators of this energy influx. We use ground-based photometers and low-light-level charge coupled device (CCD) cameras, operated at various sites within the United States and Canada, to study the intensity and spatial and temporal characteristics of the upper atmospheric emissions. Studies are usually conducted in concert with observations from satellite instruments and collaborations with other research groups operating ground-based instruments.

Volcanic eruptions can introduce significant material into the stratosphere, and these aerosols may have a lifetime of several years. Using small, portable, inexpensive, and very accurate instruments developed in this program (multi-filter rotating shadow-band radiometers), we have carried out studies of the evolution of aerosol size distribution and the temporal evolution of mid-latitude stratospheric aerosol loading. Studies are now targeted toward using data available from multiple sites in the United States as we attempt to understand the nature of latitudinal and longitudinal transport of aerosols in the stratosphere.

Results: The occurrence frequency, photometric intensity, and location of stable auroral red (SAR) arcs have been characterized over an entire solar cycle. SAR arcs are the visible manifestation of energy transfer into the midlatitude thermosphere and as such can be used to determine the spatial, temporal, and energy distributions associated with energy influx into the thermosphere. Studies have proceeded in concert with observations from satellite instruments of plasma parameters and with detailed modeling studies. The variation in not only the energy influx but also the thermospheric composition over a solar cycle provides a crucial test of our understanding of the physical processes occurring in this important region of the atmosphere. In situ measurements of the ring current over its entire energy range, including compositional data, was acquired, and with the ground-based optical observations from Pacific Northwest Laboratory (PNL), was used to carry out extensive calculations of the entire system. Results suggest that the compositional evolution of the ring current population may have significant effects on the rate of heat flow to the upper atmosphere. We have also developed two low-light-level CCD cameras capable of imaging the upper hemisphere at a variety of wavelengths (e.g., $427.8,557.7$, and $630.0 \mathrm{~nm}$ ). These instruments are automatically controlled by a computer system and acquire data nightly when operated at a field site. One instrument is deployed at the Bear Lake Multi-Instrument Aeronomy site in Utah, and one is located at the Rattlesnake Mt. Observatory in Richland, Washington.

A major result of this program is the spectral characterization of volcanic aerosols that have perturbed the stratosphere and affected the availability of solar flux at ground level. One consequence of a major eruption, such as Mt. Pinatubo in the Phillipines in June of 1991, has been a net reduction of $11 \%$ in the solar radiation available to the northern United States in the mid-visible region of the spectrum. The following figure shows the smoothed perturbation record of stratospheric aerosol optical depth for PNL (latitude $46.4 \mathrm{~N}$ ). Optical depths below 0.15 are roughly equivalent to the fractional loss of solar irradiance. The evolution of the Mt. Pinatubo aerosol was examined by inverting the multispectral optical depths to obtain size distributions. Seasonally averaged data showed that the aerosols evolved from an initial distribution of very small particles with radii less than $0.1 \mu \mathrm{m}$ into a distribution at the time of maximum optical depth nine months later that 
had a strong bimodal form with a large-mode maximum near $0.5 \mu \mathrm{m}$ radius. The technology developed by PNL for the rotating shadow-band instruments has been transferred to the commercial sector via an agreement with the State University of New York at Albany, New York.

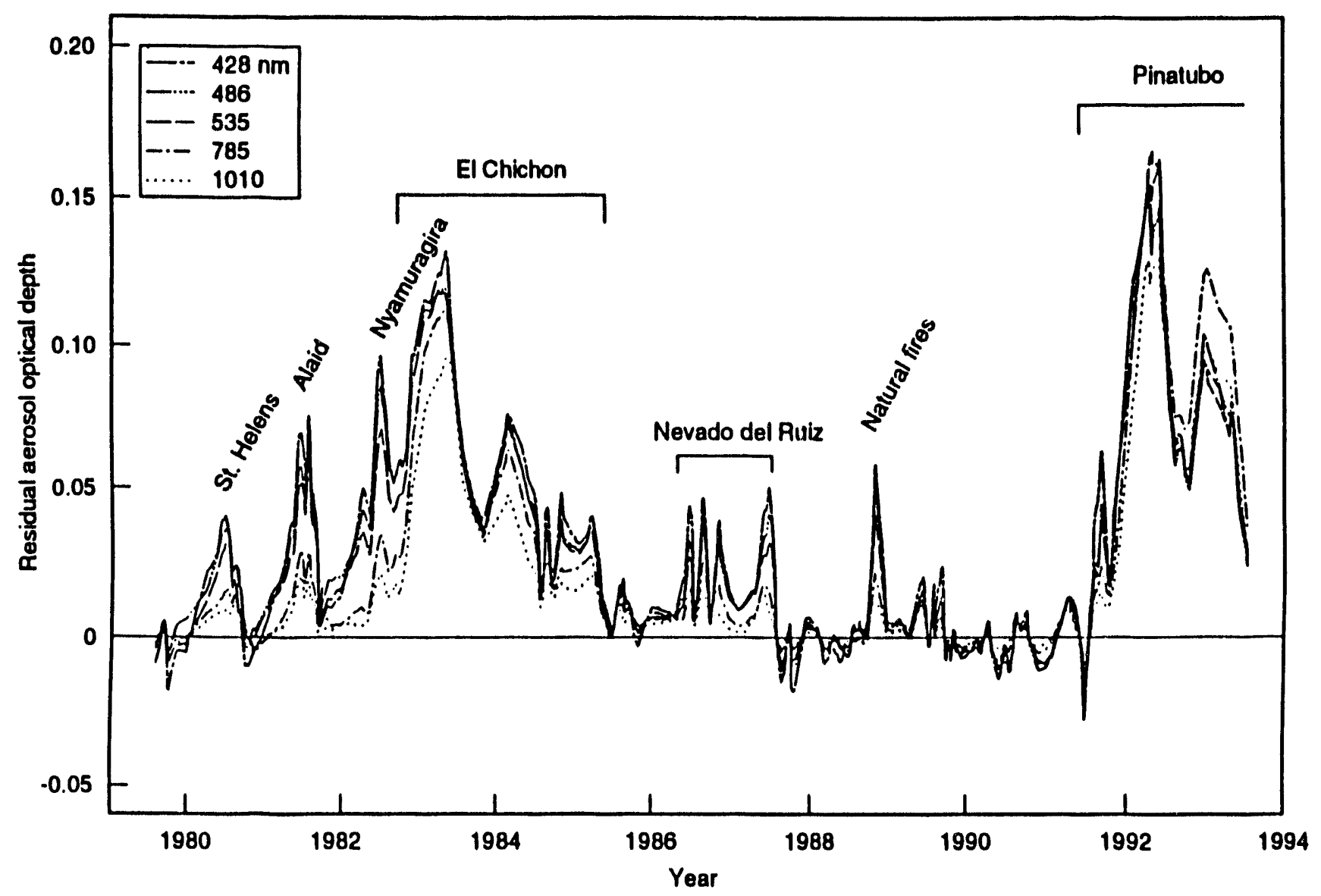

PNL aerosol minus background at five wavelengths. 
CONTRACT:

CATEGORY:
DE-AC04-76DP00789

Geophysics and Earth Dynamics

Gregory A. Newman

\section{A. Three-Dimensional (3-D) Electromagnetic Data Inversion Between $100 \mathrm{kHz}$ and $30 \mathrm{MHz}$ (Gregory A. Newman [505-844-8158; FAX 505-844-7354; E-mail ganewma@california.sandia.gov])}

Objectives: Objectives of this project are to develop three-dimensional electromagnetic data inversion capabilities in the frequency band $100 \mathrm{kHz}$ to $30 \mathrm{MHz}$ and use the capabilities to image the earth's electrical properties and describe geologic systems.

Project Description: Data inversion capabilities are to be developed for 3-D reconstructions of electrical conductivity and dielectric permittivity within the earth. The inversion capability is to use electromagnetic (EM) data in the radio to lower radar range $(100 \mathrm{kHz}$ to $30 \mathrm{MHz})$ arising from electric and magnetic dipole transmitters. Little is known about imaging of 3-D electrical structures in this frequency range, which is above low-frequency inductive sounding and very high-frequency radar, commonly used in geophysical exploration. The inversion capability will provide fundamental understanding in a frequency band scarcely investigated.

The 3-D reconstruction of electrical data will be carried out by the inversion of an integral equation. This equation predicts the EM fields that arise from the earth's 3-D electrical properties. Because inversion is nonlinear, the problem is solved iteratively by updating the fields from the previous electrical model update; the fields are calculated directly from Maxwell's equations using finite differences. The data inversion capability is to be tested using synthetic data with random noise. Field data will then be inverted to further access the robustness and reliability of the inversion capability.

Results: A modeling technique for computing EM fields in multidimensions has been developed. This technique solves Maxwell's equations directly for the fields on a staggered grid using finite differences. Checks on the technique include comparisons with 3-D integral equations and 1-D modeling codes. The modeling technique is being implemented into a 3-D data inversion code.

The inversion code is being checked with the inversion of synthetic and field data below 100$) \mathrm{kHz}$. Electrical reconstructions thus far produced are highly encouraging. Inversion of field data in the frequency band 100$) \mathrm{kHz}$ to 30 $\mathrm{MHz}$ has not yet been attempted because of its scarcity. However, synthetic reconstructions in this frequency band are now being examined.

\section{B. Effects of Microscopic Reactions and Buoyancy on Macroscopic Transport in Geologic Media: A Lattice Gas Study of Retardation and Dispersion (Harlan W. Stockman 1505-844-0975; FAX 505-844-7354;E-mail hwstock@ca.sandia.gov])}

Objectives: Objectives of this project to use lattice gas automata (LGA) to determine the effects of surface reactions and buoyancy on macroscopic transport of solutes and colloids through geologic media and to test common dispersion and retardation approximations.

Project Description: The macroscopic dispersion and retardation coefficients can be approximated from models proposed by Turner |Chem. Eng. Sci. 7, 156 (1958)] or Coats and Smith [J. Soc. Petr. Eng. 4, 73 (1964)]. These models view the fracture or porous medium as one or more straight channels lined with stagnant deadend pores and use several simplifying assumptions to derive macroscopic coefficients from the microscopic geometry and molecular diffusion and sorption rates. The 
approximation from dispersion is widely applied, but its accuracy is poorly constrained, particularly for complex geometries; approximations for retardation are even less tested.

This project uses LGA to calculate breakthrough curves of solute in a variety of geometries, ranging from simple Turner structures to more complex, irregular fractures lined by porous walls. The results of LGA calculations are fitted to the approximations suggested by Turner and by Coats and Smith, which yields apparent molecular diffusion and distribution coefficients and the apparent stagnant pore volume. By comparing the input diffusion and distribution coefficients used in the LGA calculations, the accuracy of the Turner and the Coats and Smith models can be assessed.

Results: A flexible LGA code was written to allow calculation of simultaneous flow, diffusion, sorption, immiscibility, forced flow, and buoyancy in automata of any size and shape. The averaging algorithms were improved so that they place relatively little overhead ( 10 to $50 \%$ ) on the calculations. The LGA diffusion coefficients were measured and shown to be isotropic in the fluid phase. The study by Koplik et al. [Phys, Fluids A 5, 1333 (1993)], which tested the Coats and Smith approximation with spectral calculations, is being used to benchmark the LGA codes.

The sorption algorithms were rewritten to ensure isotropy and allow Freundlich sorption. Unlike LGA fluid properties, LGA solid properties (such as sorption or dissolution rates) are not implicitly isotropic because the spacing of sorption or reaction sites inherently varies with lattice direction. For solids that obey Langmuir sorption, it is necessary to make particle flux and solid site density corrections so that a fluid flowing through a solid channel in the " $x$ " direction will lose particles to sorption at the same rate as a fluid flowing through a channel oriented in the " $y$ " direction. Freundlich solids are created from Langmuir solids by allowing the desorption coefficient kd to vary; the variation is applied randomly in time so that each site has the average frequency distribution $f(k \mathrm{~d})=\alpha\left(k_{\mathrm{d}}\right)^{1 / n}$

\section{Reservoir Characterization as Applied to a Reef-Type Reservoir (Gregory J. Elbring [505-844-4904; FAX 505-844-7354; E-mail gjelbri@ca.sandia.gov/ and R. M. Turpening, Massachusetts Institute of Technology)}

Objectives: The primary objective of this research is to contribute to improvement in the resolution of seismic subsurface reservoir imaging. This is to be accomplished by using cross hole geometries to provide higher frequency energy at the target zone and by using downhole sources to directly generate both vertically polarized shear (SV) and compressional $(P)$ wave energy.

Project Description: The Sandia portion of this research concentrates on the development and fielding of the SV downhole source. This source must be capable of performing to depths of $60(0) \mathrm{ft}$ in fluid-filled boreholes and of generating recordable seismic energy out to a 2000 - $\mathrm{ft}$ distance with frequencies above $100 \mathrm{~Hz}$. This source will be used to generate a suite of shear wave cross hole data for imaging the reservoir. In addition, P-wave high-frequency cross hole data will be collected and inverted. Each data set will provide higher resolution images than can be obtained from traditional surface seismic techniques. In addition, combining the velocity models obtained from the $\mathrm{S}$ - and $\mathrm{P}$-wave data will result in $\mathrm{Vp} / \mathrm{Vs}$ ratios that can provide additional information about reservoir properties, such as fluid saturation levels.

Results: This year work concentrated on determining the cause of the previously observed loss of tool energy output observed at depths below 250() $\mathrm{ft}$. It was discovered that airflow restrictions in the regulator combined with inadequate mass flow caused by low input pressures contributed to this lack of energy. A new regulator was installed, and calculations were performed to determine the input pressure needed to maintain the proper mass flow rate as depth and pressure increase in the borehole.

Data were collected at the MIT well site near Traverse City, Michigan, between wells located 20()() $\mathrm{ft}$ apart. Data at shallow depths were compared with previously collected data from this site and showed a markedly improved signal-to-noise ratio under the same recording parameters. Good data were also recorded to source depths of $430(0 \mathrm{ft}$, with signal recorded in the receiver hole at 55()$(\mathrm{ft}$, giving a total source-to-receiver separation of over $2300 \mathrm{ft}$. These ray paths also passed through the reef reservoir. Unfortunately, tool failure from contamination by particulates sloughing of airline supplying air to the tool prevented the collection of enough data to properly image the reef reservoir or to test the tool to depths near 60)(0) ft. However, no significant loss in amplitude was observed that would lead us to believe that the tool would not perform in a similar fashion at greater depths. 


\section{Advanced Concepts (Marianne C. Walck [505-844-0121; FAX 505-844-7354;}

E-mailmcwalck@ca.sandia.gov])

Objectives: Objectives of this project are to investigate new and innovative ideas in geosciences research through the level of feasibility studies and scoping experiments. Advanced Concepts funds are also used to support staff in the event of Basic Energy Sciences (BES)-requested activities that are not directly related to their research projects.

Project Description: Projects supported by Advanced Concepts funds change from year to year. Funds support research concept development, including literature searches, initial laboratory experiments, and scoping computer modeling exercises. Areas investigated in the past fiscal year include application of a bridge configuration for permeability measurements on tight rocks, development of a technology to measure gas flow velocity in the vadose zone, and kinematics of faults and basins during extension with application to the southern Basin and Range Province. Limited support funds are also supplied to staff for BES duties unrelated to a specific funded project. Examples of these activities are Office of Program Analysis reviews of projects completed in the prior fiscal year and participation in BES review processes of facilities or proposal solicitations.

Results: Application of a Bridge Configuration for Permeability Measurements on Tight Rocks. A new technique is being investigated where single-phase, steadystate permeability measurements of porous rock can be obtained without the use of expensive and troublesome mass flowmeters. A bridge configuration of flow resistors is used to determine permeability values directly from pressure differentials across the bridge network. An experimental program is in progress to construct the device and conduct flow resistor characterization and bridge configuration studies (N. Warpinski and D. Graf).

Technology Development to Measure Gas Flow Velocity in the Vadose Zone. Proof-of-concept experiments are being conducted to determine the feasibility of a new technology to measure gas-flow velocity in the unsaturated zone near the earth's surface. The technology uses a long, thin, heated cylinder deployed at the appropriate point for gas-flow velocity measurement. The temperature on the cylinder's surface reflects the direction and magnitude of the gas-flow velocity. Prototype instruments are being constructed and deployed in simulated boreholes in the laboratory; airflow past the probes is induced, and the thermal effects are documented. The instruments will also be deployed directly in a sand tank with induced airflow. Experimental results will determine if the technology is capable of sufficiently measuring small velocities to be useful in field situations (S. Ballard).

Kinematics of Faults and Basins During Extension with Application to the Southern Basin and Range Province. The role of shear vs normal faulting in accommodating continental extension was studied through an extensive literature search, colleague discussions, and review of available geologic data, particularly at the Nevada Test Site. A research plan was developed that includes four components: analysis of drill hole data, analysis of Quaternary movement, analysis of fault lineations, and mapping of the continuation of low-angle normal faults in the region (D. Borns).

Staff Support. Advanced Concepts funds supported the following nonprogrammatic staff activities: (1) preparation for and execution of Office of Program Analysis reviews for two projects completed in FY 1992 but selected for review in FY 1993 (D. Holcomb and S. Brown); (2) participation of $\mathrm{H}$. Westrich on a review panel for the Hanford Environmental and Molecular Sciences Laboratory; and (3) assistance of G. Elbring to the BES Geosciences Office for processing Small Business Innovation Research proposals related to underground imaging. 


\section{CATEGORY:}

PERSON IN CHARGE:

\section{Geochemistry}

\section{A. Cation Diffusion Rates in Selected Silicate Minerals (Randall T. Cygan 1505-844-72 l6; FAX 505-844-7354; E-mail rtcygan@ca.sandia.gov/, H. R. Westrich, and Craig S. Schwandt)}

Objectives: Objectives of this research are to determine experimental cation diffusion coefficients for garnet and pyroxene minerals at temperatures less than $10000^{\circ} \mathrm{C}$ for evaluating disequilibrium behavior in geological, nuclear waste, energy, and materials applications.

Project Description: Evaluation and modeling of geochemical processes related to nuclear waste, energy, and materials problems require the accurate determination of cation ciiffusion data in a variety of silicate minerals. A new technique for the prenaration of diffusion couples using thin film technology was developed in an effort to evaluate the relatively slow diffusion of $\mathrm{Mg}^{2+}, \mathrm{Mn}^{2+}$, and $\mathrm{Ca}^{2+}$ in phases such as garnet and pyroxene (where diffusion rates are on the order of $10^{-22}$ to $10^{-16} \mathrm{~m}^{2} / \mathrm{s}$ in the temperature range of 700 to $\left.1(0)()^{\circ} \mathrm{C}\right)$. Resistive evaporation of enriched stable isotopes onto polished mineral surfaces is used to create a thin film-mineral diffusion couple. Diffusion couples are annealed in a controlled oxygen fugacity furnace for periods up to three months to provide a diffusive penetration depth of $0.2 \mu \mathrm{m}$. Depth profiles of the tracer isotope are obtained using an ion microprobe and are then fit to appropriate diffusion models to obtain precise and reproducible diffusion coefficients.

Results: An experimental matrix of pyrope, grossular, and enstatite samples has been used to cover a range of temperatures $(750 \text { to } 1000)^{\circ} \mathrm{C}$ ) and oxygen fugacities $\left(10^{-18}\right.$ to $\left.10^{-10}\right)$ for the diffusion runs. The sample matrix for each mineral provides data for evaluation of the activation energy and pre-exponential values for the diffusion process. Comparison of the diffusion coefficients determined under various oxygen fugacities provides additional information about the diffusion mechanism and the defect structure of the mineral sample. An Arrhenius plot of the experimental ${ }^{25} \mathrm{Mg}$ diffusion coefficients for pyrope yields an activation energy of $87 \pm 11 \mathrm{~kJ} / \mathrm{mol}$ and a pre-exponential factor of $2.5 \pm 3.5 \times 10^{-18} \mathrm{~m}^{2} / \mathrm{s}$. These results suggest a slower mechanism for magnesium diffusion in pyrope for relatively reducing conditions. In addition, the Arrhenius parameters appear to follow a compensation law relative to other experimental diffusion data for garnet. A diffusion anneal using a ${ }^{44} \mathrm{Ca}$-enriched thin film with grossular garnet at $1(0) 0^{\circ} \mathrm{C}$ and $\mathrm{QFM}$ oxygen fugacity provides a self-diffusion coefficient for ${ }^{44} \mathrm{Ca}$ of $3.0 \pm 0.5 \times$ $10^{-22} \mathrm{~m}^{2} / \mathrm{s}$.

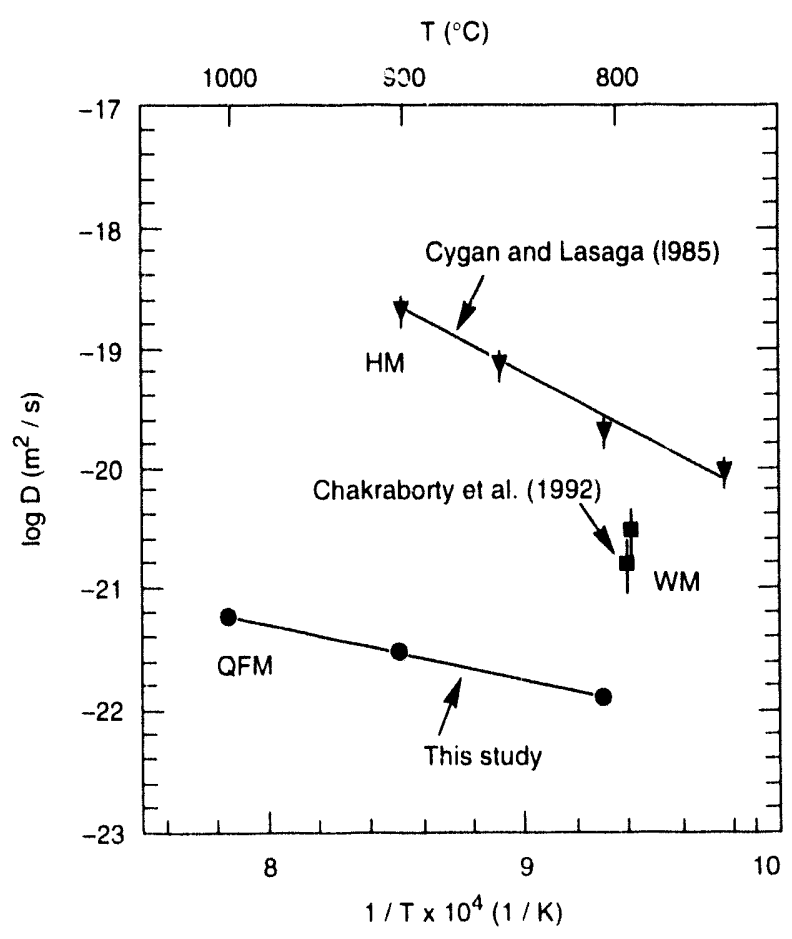

\section{B. Isotopic and Mineralogical Indicators of Infiltration and Vertical Fluid Movement in Unsaturated Zones of Semiarid Terrain (Steven J. Lambert [505-844-7876; FAX 505-844-7354; E-mail sjlambe @somnet.sandia.govl)}

Objectives: Objectives of this research are to (1) determine how the depth, volume, and rate of infiltration and groundwater travel-time between surface and subsurface are governed by seasonal distribution of episodic precipi- 
tation and storm intensity and (2) investigate the relationships between meteoric events and the transient and steady-components of infiltration and groundwater recharge in a desert environment.

Project Description: This work seeks to identify climatic and hydrological parameters that govern recharge and which potentially contribute to contaminant transport in unsaturated zones. In arid and semiarid terrain, the uncertainty in the recharge term (used in water budget calculations) is commonly large; furthermore, losses resulting from evapotranspiration in the root zone may be significant. A natural cavern system developed in fractured limestone, underlying a desert environment, provides for direct measurement and sampling of water recharging an unsaturated zone, without the perturbations of borehole sampling. Specifically, time-series (monthly) data are obtained for subsurface flux; concentrations of natural isotopic tracers $\left({ }^{18} \mathrm{O}\right.$ and deuterium) in both the infiltrate water and surface precipitation are measured in samples collected during flux measurements. Domains of unsaturated flow, represented by variations in flux (indicative of changes in hydrostatic potential) and tracer concentration (indicative of mass transport) are then correlated with surface recharge events using local precipitation records and the variations in tracer concentration in precipitation.

Results: A subsurface monitoring network has been established in Carlsbad Caverns, New Mexico. For the past 18 months, monthly infiltration rates have been measured and water samples collected at 13 permanent and 2 intermittent, precisely relocatable catchment stations distributed geographically over $\sim \mathrm{km}^{2}$ and vertically over $\sim 250 \mathrm{~m}$ and located at or near visible fractures. The water samples were analyzed for their $\delta^{18} \mathrm{O}$ values. Samples of meteoric precipitation were also collected and analyzed during this period. The correlations of flux and tracer concentration between surface and subsurface water demonstrate the sensitivity of infiltration and recharge to such factors as the frequency, intensity, and seasonal distribution of storms.

Despite higher evapotranspiration, summer rainfall appears to dominate infiltration and recharge. Mass-transport pulses generally lag pressure pulses by intervals of $<4$ weeks to $\sim 8$ months. Both mass and pressure pulses have been observed at multiple catchment stations, at multiple depths. Variations in flux and 180 concentration at some stations are consistent with "piston"-type hydraulic behavior, while dripwater from other stations may originate in a well-mixed groundwater perched on the unsaturated zone. Variations in ${ }^{18} \mathrm{O}$ concentrations at the greatest depths $(250 \mathrm{~m})$, though damped, are significant relative to analytical variations and mimic seasonal variations in ${ }^{18} \mathrm{O}$ concentrations in rainfall.

\section{An Investigation of Mineral Hydrolysis Kinetics (Henry R. Westrich 1505-844-9092; FAX 505-844-7354; E-mail hrwestr@ sandia.gov/, R. T. Cygan, G. W. Arnold, and W. H. Casey)}

Objectives: Objectives of this research are to provide a fundamental understanding of the aqueous dissolution of simple silicate minerals, such as end member and mixedcation orthosilicate minerals, by measurement of their dissolution kinetics, chemical and structural characterization of their reacted surfaces, and simulation of the mineral-surface interface.

Project Description: Silicate mineral weathering can be predicted successfully if the kinetics of mineral dissolution can be related to ligand-exchange reactions where the rate-controlling step is cleavage of a similar metal-oxygen bond with an unchanged cation coordination chemistry. We are testing this relationship with a comprehensive experimental, analytical, and theoretical program using simple orthosilicate minerals. In the experimental part of this study, predictions about the relative dissolution rates of end member and mixed-cation orthosilicates were tested by batch dissolution measurements at 25 to $50^{\circ} \mathrm{C}$ under acid conditions. Structural and chemical characterization of acid-reacted single crystals and powders was done by electron (scanning electron microscopy/transmission electron microscopy) and ion beam (elastic recoil detection/Rutherford backscattering spectroscopy (ERD/RBS) | techniques, as well as by interpretation of vibrational (Raman) spectra. Finally, these data will be incorporated in ionic modeling and molecular dynamics (MD) computer simulations of the crystalline solid, aqueous solution, and the solid-liquid interface.

Results: The dissolution rates of end member and mixed-cation orthosilicate minerals were examined as a function of composition, $\mathrm{pH}$, and temperature. Although dissolution rates at $\mathrm{pH}=2$ and $25^{\circ} \mathrm{C}$ vary by many orders of magnitude, they seem to correlate well with the rates of solvent $\left(\mathrm{H}_{2} \mathrm{O}\right)$ exchange around the corresponding diva- 
lent cation (see figure). This correlation, combined with TEM images and ion beam (RBS) spectra of reacted mineral surfaces, indicates that silicate tetrahedra are released intact after protonation and hydration of metal-oxygen bonds. That is, orthosilicate dissolution is congruent in acid solutions and is strongly influenced by local metal-oxygen bond properties. The acid-base properties of the orthosilicate mineral surface apparently control both the $\mathrm{pH}$ - and temperature-dependencies of mineral dissolution rates and are not sensitive to homovalent substitutions of cations in the mineral structure, even though such substitutions dramatically affect mineral reactivities and calculated mineral lattice energies. Calculated lattice energies do not correlate well with water exchange rates probably because important interactions, such as relaxation of bonds among surface atoms, interactions with solvent molecules, and interactions with counterions are missing from these purely ionic calculations.

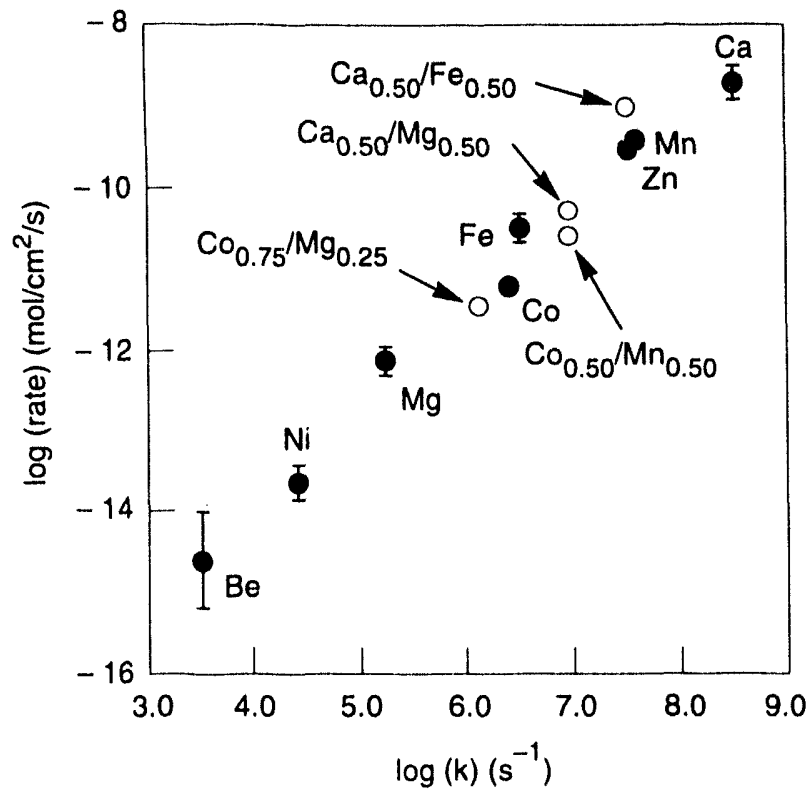

CATEGORY: PERSON IN CHARGE:
Energy Resource Recognition, Evaluation, and Utilization

\author{
M. C. Walck
}

\section{A. Geoscience Research Drilling Office (GRDO) (P. Lysne [505-844-8885; FAX 505-844-3952; E-mail pclysne@sandia.gov], A. Sattler, and R.Jacobson)}

Objectives: Objectives of this research are to support research scientists requiring drilling and other field operations to investigate processes in the earth's crust, contribute to advanced downhole measurements in harsh environments, and to maintain scientific drilling links with the U.S. Department of Energy (DOE) geothermal division (GD), the Ocean Drilling Program (ODP), and industry.

Project Description: GRDO support includes implementation of drilling and logging programs, consultation regarding permitting issues, and development of cost estimates. Current efforts are focused on the Katmai Scientific Drilling Project, a proposed drilling project that would extract continuous core from a series of holes at the site of the 1912 eruption in a wilderness area of Katmai National Park, Alaska. Two deep holes close to the lava dome plus one hole three miles away in the ash-flow field are planned. The project would be a significant logistical effort because of the site's remoteness and because it requires approval from the National Environmental Protection Agency (NEPA).
GRDO is also involved in the development of a suite of slim-hole, high-temperature logging tools for use in harsh environments, including a precision pressure/temperature tool and a spectral gamma tool. Costs for portions of this program are shared with DOE/GD. Basic Energy Sciences/Geosciences separately funds development of a downhole fluid sampler.

Results: Katmai. A revised operations plan and ten addenda were published in support of the environmental impact statement necessary for the project. These documents include such topics as a detailed drilling fluids program, scientific logging, and reclamation programs. The operations plan also formed the basis for the DOE Mitigation Action Plan. Field work included visits to the Valley of Ten Thousand Smokes to refine the drilling site and water-line layout, to place weather-monitoring equipment, and to support various sampling exercises. An extensive outreach program was continued that included federal, state, and local officials; Native American asso- 
ciations; and environmental groups. Interfaces were maintained with both the Department of the Interior and NEPA. Support was provided to the project proponents for various briefings and publications.

Downhole Measurements in Extreme Environments. Sandia is developing a suite of memory logging tools that are operable to $400^{\circ} \mathrm{C}$ and that will fit into slim, diamondcored holes. Memory tools have an advantage over conventional tools that use an electric wireline to transmit data to the surface because an expensive cable is not needed. The new suite of tools will be "smart" in that they can make "decisions" downhole. Tools under development include a precision temperature/pressure tool and a spectral gamma-ray tool.

Interactions with Other Programs. The GRDO maintains contact with the ODP through participation in the JOIDES Downhole Measurements Panel and with other U.S. continental scientific drilling programs through DOSECC, Inc. The GRDO actively seeks methods to share drilling and instrumentation resources with the international scientific drilling community.

\section{B. Seismicity Induced by Hydrocarbon Production (D. F. McTigue, Department of Geological Sciences, AJ-20, University of Washington, Seattle, Washington [206-685-9514; FAX 206-543-3836; E-mail mctigue@u.washington.edu] and P. Segall, Stanford University)}

Objectives: The goal of the current research program is to develop a fundamental understanding of the mechanics of hydrocarbon pumping-induced seismicity through analyses of field data, model development, and comparisons of observations and simulations.

Project Description: Seismicity associated with extraction of hydrocarbons is observed routinely at numerous localities. This is contrary to intuition, because a reduction in fluid pore pressure increases the magnitude of the effective confining stress in the reservoir rock and stabilizes it against frictional failure. Results from previous years of this research, however, show that contraction of the reservoir rock induces stress changes in surrounding strata that, in some aspects, are consistent with observed locations and focal mechanisms of seismicity.
Results: The earthquake locations for the Lacq, France, gas field suggest that the lithology may have a significant influence on induced stress distribution. A model has been developed that accounts for mechanical stratigraphy. In particular, the stresses are found to be concentrated within the stiff carbonate reef unit. This result is interesting because, according to Grasso and Feignier (1990), most of the seismicity is located within the carbonate reef. They suggested that the marls deformed ductilely, whereas the reef deformed in a brittle (seismic) fashion. The present numerical simulations suggest that the spatial association of earthquakes with the reef, if supported by careful earthquake relocations, may simply be an effect of varying elastic properties.

\section{Investigation of Active Processes in Long Valley Caldera Using the Magma Energy Deep Exploration Well Phase II Drilling Activities (W. R. Wawersik [505-844-4342; FAX 505-844-7354; E-mail wrwawer@sandia.gov], D. J. Holcomb, and L. W. Teufel and J. B. Rundle, Lawrence Livermore National Laboratory)}

Objectives: Objectives of this research are to test the validity of competing models for magma chamber location and geometry in Long Valley Caldera by measuring and interpreting in situ stress and comparing results from different techniques, including hydrofracture, anelastic strain recovery, acoustic emission, and borehole breakout analyses.

Project Description: Geodetic and seismic data collected in Long Valley from 1975 to the present define a pattern of uplift and strain that has been explained by geophysical models involving dike injection and magma intrusion at depths as shallow a $5 \mathrm{~km}$ beneath the caldera floor. A program of in situ stress measurements in the Long
Valley deep exploratory well has been designed to test the validity of the geophysical models for the location, size, shape, and depth of active magma chambers. Moreover, the comparison of core-based and downhole stress measurements will help evaluate the applicability of far less expensive core-based methods for determining stress directions and magnitudes.

Results: Data on in situ stress were obtained in the Office of Basic Energy Sciences-funded core hole following Phase II drilling, between 2363 and $2378 \mathrm{~m}$ in basement rock, using core-based and acoustic televiewer methods. Acoustic emission signatures in biaxially loaded subcores using the Kaiser effect method and relaxation 
data obtained from anelastic strain recovery were less useful than the hydraulic fracturing in obtaining stress data in this complex volcanic regime. Good pressure-time signatures were obtained in the hydraulic fracturing experiments, and these data, together with detailed fracture logs and borehole breakout information, indicate that the least principal stress is oriented in the direction $N 52^{\circ} \mathrm{E}$. The hydraulic fracturing results constitute an excellent example of the Comer-Valette method of interpreting hydraulic fracturing data in jointed rock.

\section{Development of a Smart, High-Temperature Fluid Sampling Tool ( $P$. Lysne [505-844-8885; FAX 505-844-3952; E-mail pclysne@sandia.gov])}

Objectives: Past fluid-sampling tools have leaked when withdrawn from holes drilled into geothermal formations. The goal of the present program is to develop a proper sampling device compatible with a borehole environment in excess of the critical point of sea water $\left(407^{\circ} \mathrm{C}\right.$, 298.5 bar).

Project Description: Sampling devices that use oneway valves similar to those found in an internal combustion engine leak when withdrawn from wells possessing even a modest temperature gradient. This possibility exists whenever the thermal contraction of the trapped fluid causes the pressure internal to the tool to fall below the local hydrostatic pressure of the borehole. Electrically actuated valves are dependable, but electrical wirelines are unreliable at extreme temperatures. Thus, the present tool will be self-contained in that batteries and other components designed to record borehole data are contained within a Dewar/pressure vessel. Because diagnostic and scientific information cannot be transmitted to the surface, the onboard computer is programmable to make many of the "decisions" usually trusted to the tool operator.
A parallel program, supported by the Ocean Drilling Program, is focused on retrieving specimens from the sampler, perhaps under in situ conditions.

Results: An Onset, Model 5F computer is the heart of the sampling device, and this machine was temperature tested to $150^{\circ} \mathrm{C}$, the anticipated maximum temperature within the Dewar. Ancillary circuit boards have been constructed and tested. These boards support pressure and temperature measurements as well as input ports for future options. Dewar/pressure vessels have been designed and manufactured; the valve system is in the design stage.

Memory tools must carry their own measurement standards. Standards chosen for the sampler tool are frequency (for directly recording the output of the resonating quartz pressure gauge) and a voltage-to-frequency converter (for recording the voltage of the platinum resistance thermometer). Calibration equipment traceable to national standards was established and used to test the tool standards. While the temperature dependence of the frequency standard has been established, the voltage standard is not as precise as desired, and additional work is anticipated. 
PART II

OFF-SITE 
GRANTEE:

GRANT:

TITLE:

PERSONS IN CHARGE:
UNIVERSITY OF MLASKA

Geophysical Institute

Fairbanks, Alaska 99777-0800

\section{A Study of Magnetic Reconnection Processes and Plasma Processes in the Magnetosphere and the Solar Corona}

\author{
L. C. Lee and S.-I. Akasofu \\ (907-474-7410; FAX 907-474-7290; \\ E-mail giuaf::Iclee [span] fflcl@alaska.edu)
}

Objectives: To examine and understand (1) the basic plasma processes associated with magnetic reconnection, (2) the coupling between the solar wind and the earth's magnetosphere, and (3) the formation and eruption of solar prominences and flares.

Project Description: In this project we studied magnetic reconnection processes that play an important role in the transfer of mass, momentum, and energy of the solar wind into the Earth's magnetosphere, the onset of substorms in the magnetotail, the onset of solar flares, and the formation and eruption of solar prominences. The relevant processes have been examined using both analytical methods and computer simulations. In particular, we have used two- and three-dimensional models in the framework of magnetohydrodynamics and collisionless kinetic dynamics. Our research includes (1) a unified simulation model of two-dimensional steady-state magnetic reconnection; (2) the changes of the magnetic field topology and the plasma flow patterns in three-dimensional magnetic reconnection processes; (3) collisionless magnetic reconnection processes, including the form of Ohm's law near the reconnection line; (4) the role of collisionless slow shocks, rotational discontinuities, and intermediate shocks in magnetic reconnection; and (5) the formation and eruption of solar prominences.
Specifically, the three-dimensional topology of reconnected field lines, the kinetic aspects of magnetic reconnection in the collisionless magnetosphere, and prominence formation were emphasized.

Results: A comprehensive study was conducted on two-dimensional magnetic reconnection processes, including magnetic reconnection with small separatrix angles, the structure of plasma jets along separatrices, and a simulation test of the nonlinear reconnection model.

Three-dimensional aspects of the magnetic reconnection processes were examined. In particular, the topology of three-dimensional multiple $\mathrm{X}$ line reconnection, FTE signatures in different reconnection models, and core magnetic field enhancements in magnetic flux ropes.

Magnetic reconnection in a collisionless plasma was examined. This portion of the study included the form of Ohm's law near a collisionless reconnection $X$ line, the $\beta$ dependence of the collisionless tearing instability, and chaos and heating in collisionless slow shocks.

A semi-implicit MHD code including gravity and radiative cooling was successfully developed and used to study the formation and eruption of solar prominences with normal polarity. 
GRANTEE:

GRANT:

TITLE:

PERSONS IN CHARGE:
UNIVERSITY OF ALASKA

Geophysical Institute

Fairbanks, Alaska 99775-0800

DE-FG06-92ER14232

Katmai Scientific Drilling Project

J. C. Eichelberger and S. E. Swanson (907-474-5530;

FAX 907-474-7290; E-mail eich@dino.gi.alaska.edu)

Objectives: This project will test models for explosive eruption of and subsequent chemical and heat transport in a silicic igneous system through three-dimensional exploration of an exemplary young volcano. Near-term objectives are to constrain rates of magmatic degassing, mixing, and crystallization and to characterize contents of the vent.

Project Description: The Katmai Project is part of the national Continental Scientific Drilling Program, which seeks to understand fundamental processes of crustal evolution through three-dimensional investigation of the continental crust. The 1912 eruption near Mt. Katmai on the Alaska Peninsula was the outstanding volcanic event of this century in both the United States and the world. The eruption is ideally suited to investigation of explosive volcanism because it was relatively simple, both in terms of geologic setting and chronology of the event itself. Objectives of the project are to improve models for explosive eruptions, determine the source and mechanisms of metals transport in fumaroles of the 1912 ignimbrite, and establish the rates and mechanisms of ongoing cooling of the system. The project was selected for implementation based on peer and panel reviews by the U.S. Department of Energy (DOE), the National Science Foundation, and the U.S. Geological Survey (USGS) and a panel review (as to suitability of the site) by the National Academy of Sciences. The approximately 40 scientists involved in the project come from numerous universities, the USGS, and several DOE laboratories. About half of this group was active during the surface phase of the project. The main surface effort took place in 1989-90, when a coordinated suite of geophysical surveys defined a 2-km-diam vent for the eruption buried beneath its own ejecta at the head of the Valley of Ten Thousand Smokes. This work also provided evidence of a huge magma body still present beneath the region. The project plan calls for drilling into the 1912 vent over a 2-year period beginning in 1995. Two holes will prove a complete cross section of the vent and sample its still-cooling feeder to a depth of $1.2 \mathrm{~km}$. An environmental impact statement (EIS) is nearing completion, written under the management of the Alaska Region Office of the National Park Service (NPS).

Tasks under this grant are coordination of the project and a surface-based investigation of the degassing and mixing behavior of the 1912 magmas. The former effort consist primarily of representing the project during the National Environmental Policy Act (NEPA)-mandated process. The second task uses the exceptional suite of variably quenched 1912 magmatic material to investigate the timing and processes of volatile release and magma mixing. The suite encompasses rapidly quenched air-fall pumice, variably welded pyroclastic vent fill rapidly quenched during ejection in late explosion, and Novarupta lava ranging from glassy to fully devitrified. The vent-fill ejecta also provides the best indication of what will be encountered in drilling and a chemical baseline by which post-emplacement mass transport can be assessed.

Following completion of the NEPA process, NPS is scheduled to issue a record of decision. If the drilling is approved, it will provide an unprecedented view of the processes and structures that give rise to explosive eruptions as well as new insights into processes of ore formation and hydrothermal circulation.

Rı зults: Two breccia types are distinguished by proportions of the three magmatic components. Type $1 \mathrm{brec}$ cia ("vitrophyre") is rhyolite and andesite rich, is found throughout deposits of the eruption's second and third days, and corresponds to magmatic proportions erupted toward the end of the first day. Type 2 is dacite rich, occurs only at the surface, and corresponds to magmatic proportions erupted during the second and third (final) days. A pyroclastic dike exposed in a bomb of Type 2 vent breccia is petrologically related to Novarupta lava. Water is strongly, but not completely, degassed from vent breccias (Type $\mathrm{I}$ breccia at $0.30 \mathrm{wt} \% \mathrm{H}_{2} \mathrm{O}$ and Type 2 breccia at 
0.15 wt $\% \mathrm{H}_{2} \mathrm{O}$, even where blocks are bread crusted) and more thoroughly degassed from dome lava (rhyolite and andesite at $<0.1 \mathrm{wt} \% \mathrm{H}_{2} \mathrm{O}$ ). However, the pyroclastic dike retains significant water (averages $0.90 \mathrm{wt} \% \mathrm{H}_{2} \mathrm{O}$ ), and its host breccia likewise contains elevated water concentrations $\left(0.30-0.40 \mathrm{wt} \% \mathrm{H}_{2} \mathrm{O}\right)$. The mafic component in Novarupta dome is derived from andesitic, rather than dacitic, magma and has crystallized substantially in response to mixing with its cooler host.

Above the fragmentation level (calculated to be about $500 \mathrm{~m}$ deep, following assumptions of Sparks, 1978), the vent should consist of an annulus of Type 1 material, formed during backfilling of the vent during the close of the first day dominantly rhyolitic outburst, enclosing an inner cone of Type 2 material formed similarly during waning stages of the dacite-dominant second and third days. Although occurrence of Falling Mountain material in Type 1 requires some downward motion of components comprising the breccia, the modestly elevated water contents, andesite-enrichment relative to eruptives, and tex- tural contrasts to ignimbrite suggest that Type I may not be fall back but could represent material aggraded on vent walls at depth, resulting in gradual constriction of the vent. Ejection of such material without vesiculation suggests rapid cooling in situ, a conclusion now verified with heating experiments, which in turn suggests invasion of groundwater into the vent during the eruption. The pyroclastic dike provides evidence that intrusion of Novarupta lava began immediately after the explosive phase and suggests a possible mechanism for formation of thin dikes of viscous magma at shallow depth-hydrofracturing with injection of magmatic dusty gas.

Principal NEPA-process activities were two cycles of review of the Katmai Scientific Drilling Project EIS, and representation of the project at meetings with NPS and EIS-contractor personnel in Menlo Park, Anchorage, and King Salmon. In addition, three presentations concerning the 1912 eruption and the project were made to visitors at Katmai National Park. 


\section{GRANTEE;}

GRANT:

TITLE:

\author{
AMERICAN MUSEUM OF NATURAL HISTORY \\ Department of Mineral Sciences \\ New York, New York 10024
}

DE-FG02-92ER14265

\author{
The Role of Carbon and Temperature in Determining Electrical \\ Conductivity of Basins, Crust, and Mantle
}

\title{
PERSON IN CHARGE:
}

E. A. Mathez (212-769-5379; FAX 212-769-5339)

Objectives: Determine the influence of carbon abundance and distribution on electrical conductivities of mantle, deep crustal, and sedimentary rocks.

Project Description: This is a collaborative project with A. G. Duba (Lawrence Livermore National Laboratory) and T. J. Shankland (Los Alamos National Laboratory) to investigate the effect of carbon on electrical conductivities of rocks. The great sensitivity of conductivity to small concentrations of fluids, ores, and carbons and also to temperature make electromagnetic methods a unique probe of the Earth. For the most part conductivity profiles have been interpreted without consideration of the effects of carbon because carbon contents of crystalline and some sedimentary rocks are low. However, in the few rocks in which its distribution has been studied in detail, carbon has been found to be present along microfractures and mineral grain boundaries. This raises the possibility that carbonaceous compounds form interconnected networks over megascopic regions and thus exert a dominant influence on bulk-rock conductivities, even in rocks in which concentrations are small.

The research involves mapping the distribution of carbon in microfractures and grain boundaries of rocks, characterizing the carbons on these natural surfaces and correlating carbon distribution, connectivity, and concentration with electrical conductivity. The investigations are focused mainly on mantle peridotites, deep crustal rocks, and oil shales. The data will provide the basis to derive relationships describing conductivity of carbon-bearing rocks at conditions relevant to basins, crust, and mantle.

Results: Methods for carbon mapping with the electron probe and scanning electron microscope (SEM) have been developed further. Such analysis requires a conductive coating. Aluminum had been used for this purpose, but because it rapidly oxidizes, alternatives were sought. It was found that both gold and chromium coats are far superior to aluminum because they are relatively transparent to carbon X-rays and do not readily oxidize. Gold has been chosen for the present experiments because it requires no special coating equipment, remains stable for several months, and can be chemically removed. It has been found necessary to adopt analytical strategies analogous to those employed in field mapping. Thus, a "base map" of a thin section is made from a low-magnification back-scattered electron photomosaic produced by an SEM. Carbon-rich regions are then located by making linear traverses, the orientations of which are determined by rock fabric. Smaller regions are then mapped for carbon. The backscattered electron and X-ray images are collected, stored, and manipulated digitally.

The mapping techniques are being applied to the study of rocks from the Yukon-Tanana terrane, east-central Alaska, in the vicinity of the Denali fault system. The Yukon-Tanana terrane consists of Paleozoic polymetamorphosed sedimentary, intermediate volcanic, and granitic rocks of continental affinity. The Denali fault system separates it from Mesozoic fly ash and other rocks of oceanic affinity to the south. Like several other tectonic sutures, the Denali system has associated with it a midcrustal ( $>20 \mathrm{~km}$ deep) electrical conductivity anomaly that extends some $200 \mathrm{~km}$ to the north of the Denali beneath the Yukon-Tanana rocks. The carbonaceous fly ash deposits are recognized to be good candidates for the electrically conductive rocks at depth. This has led to the suggestion that the Denali system possesses large-scale thrust as well as strike-slip components. Accordingly, we have studied high-grade metamorphosed Yukon-Tanana rocks to see if these, too, could account for the deep crustal conductivity anomaly.

Four samples ranging from gneisses to garnet-mica schists have been studied in detail. In one of these, sample $\mathrm{TA} 44 \mathrm{~B}$, veinlike stringers of carbon parallel to foliation have been discovered. The textural relations indicate that the carbon was deformed plastically along with the silicate assemblage. For example, the carbon is intergrown with muscovite, and both are observed to bend around rotated 
garnet porphyroblasts. The entire assemblage was subsequently deformed brittly, possibly in resporse to unloading. The observations demonstrate that the carbon piedates brittle deformation and was probably formed before or during peak metamorphic conditions (i.e., under deep crustal conditions). The effect of the brittle deformation was to break the large-scale connectivity of the stringers, as least as observed on the two-dimensional analytical surfacc. This is presumably why TA44B exhibits no anomalous conductivity under ambient conditions. The textural relations suggest that the Yukon-Tanana rocks could as well account for the deep crustal electrical conductivity anamoly associated with the Denali fault system. The carbonaceous material of sample TA44B is not pure graphite but consists in part of chlorinated compounds and exhibits a complex, multiphase structure that is not understood at present.

\section{GRANTEE:}

GRANT:

TITLE:

PERSON IN CHARGE:

\author{
ARIZONA STATE UNIVERSITY \\ Department of Geology, Box 871404 \\ Tempe, Arizona 85287-1404
}

DE-FG02-91ER14218

\section{Organic/Inorganic Interactions of Nitrogen in Oil Fields Part I: Geochemistry}

\author{
L. B. Williams (602-965-0829; FAX 602-965-8102; \\ E-mail atlbw@asuvm.inre.edu)
}

\begin{abstract}
Objectives: This research is a field test of the use of fixed $\mathrm{NH}_{4}$ as an indicator of hydrocarbon migration paths within a basin. Examination of the concentration and isotopic composition of nitrogen in organic and inorganic phases will provide data suggesting correlations that may indicate the source of nitrogen incorporated into clay minerals and how $\delta^{15} \mathrm{~N}$ changes during hydrocarbon migration.

Project Description: Two oil fields in the Eocene Wilcox Group, Louisiana Gulf Coast, are being studied. One is a multireservoir field at a depth of $4 \mathrm{~km}$, and one is located updip at a depth of $2 \mathrm{~km}$. Anomalous fixed- $\mathrm{NH}_{4}$ concentrations occur in producing intervals of the hydrocarbon reservoirs. The approach is to examine the concentration and isotopic composition of nitrogen in kerogen, bitumen, oil, formation fluid, and fixed $\mathrm{NH}_{4}$ extracted from mudstones, nonproductive sandstones, and productive sandstones. The oil in both reservoirs is thought to be generated from the same source region (deep Wilcox shales); therefore, the effect of migration on the quantity and isotopic composition of nitrogen in the fluids and minerals may be observed. The results will provide data for examining diagenetic interactions of nitrogen on a local and regional scale. A correlation of fixed- $\mathrm{NH}_{4}$ anomalies across the oil field may indicate pathways of hydrocarbon migration, which could point to isolated compartments of
\end{abstract}

bypassed oil. Mineralogy and microbiology are examined in Part II of this project.

Results: This year work focused on analysis of nitrogen isotopes extracted from the reservoirs at $\sim 4 \mathrm{~km}$ depth. The reservoir in this oil field is divided by a normal growth fault that separates the productive units by $\sim 500$ vertical meters. The $\delta^{15} \mathrm{~N}$ of kerogen extracted from mudstones at depths of 3500 to $4350 \mathrm{~m}$ are $\sim+3 \%$. The bitumen (soluble organic matter) extracted from the same samples is +3 to $+5 \%$, increasing with depth. Oil in the deeper reservoir $(4 \mathrm{~km})$ has a corresponding $\delta^{15} \mathrm{~N}$ of $\sim+5 \%$ and may have been generated by deeper shales. However, in the upper reservoir $(3.5 \mathrm{~km})$ oils have $\delta{ }^{15} \mathrm{~J}$ values of $+12 \%$. Similarly brines in the deep reservoir are isotopically light ( 0 to $-6 \%$ o), but in the upper reservoir they are $+4 \%$ o. Fluids apparently become enriched in ${ }^{15} \mathrm{~N}$ (up to $10 \%$ ) during migration into the upper reservoir. Inorganic nitrogen extracted from deep reservoir sandstones reflects the isotopic composition of the oil $(+3$ to $+5 \%$ ), whereas nonproductive sandstones have distinctly low $\delta^{15} \mathrm{~N}$ values $(+1$ to $-3 \%$ ), influenced by the brines. Nitrogen extracted from mudstones corresponds isotopically with the bitumen $(+3$ to $+5 \%$ ). The results suggest that authigenic illite incorporates $\mathrm{NH}_{4}^{+}$isotopically proportional to that of the fluid dominating the environment at the time of illitization. It is not isotopically reset during later fluid migration. 
GRANTEE:

GRANT:

TITLE:

PERSON IN CHARGE:
THE UNIVERSITY OF ARIZONA

Department of Geological Sciences

Tucson, Arizona 85721

\section{Electrochemical Determination of the Gibbs Free Energies of Rock-Forming Minerals}

Lawrence M. Anovitz (602-621-4618; FAX 602-621-2672;

E-mail anovitz@ccit.arizona.edu)
Objectives: This project involves measurement of thermodynamic data for rock-forming minerals using an electrochemical approach. Gibbs free energies will be measured directly for oxide buffers anci the joins diopside-hedenbergite and enstatite-ferrosilite using redox equilibria and solid-state electrolytes. Measurement of these data as a function of temperature will strongly constrain both the standard state Gibbs free energies and entropies of these phases. The iron/magnesium ordering state of the orthopyroxenes being measured will also be examined as a function of composition and temperature to further constrain our understanding of the effects of submicroscopic properties on the activity composition relations of this join. The relative accuracy of electrochemical measurements and the fact that this technique is the only one available that directly measures the Gibbs free energy of a phase as a function of temperature makes data obtained in this manner ideal for many types of geochemical calculations. These phases occur in a wide variety of igneous and metamorphic rocks, and high-quality thermodynamic data for them are essential to understanding the conditions under which these rock types form.

Results: Work has been focused on completion and initial tests of the equipment; synthesis of pyroxenes; measurements under a number of conditions of the copper-cuprite, cuprite-tenorite, nickel-bunsenite, and ironwustite oxide buffers, examination of the effects of electrical polarization and thermocouple calibration on the accuracy of these measurements; and a reevaluation of mixing properties on the join diopside-enstatite, which is necessary if the binary data collected in these experiments are to be combined into a ternary model for $\mathrm{Ca}-\mathrm{Fe}-\mathrm{Mg}$ pyroxenes. Orthopyroxene glasses have been synthesized across the enstatite-ferrosilite join, although as expected high-iron glasses crystallize olivine and quartz. Crucibles pressed from 5-mil molybdenum foil have proven an inexpensive alternative to platinum for making reduced iron glasses in a gas-mixing furnace. As with graphite, however, small amounts of molybdenum metal are occasionally found in the glass. The amount varies from run to run, and we are exploring methods to minimize this contamination. The glasses formed in these runs commonly form pyroxene quench crystals. These materials have been crystallized into orthopyroxenes in a piston-cylinder apparatus, although additional runs are needed to homogenize the resulting pyroxenes. Reduced-iron glasses have been made along the diopside-hedenbergite join, and work on both syntheses is ongoing.

Two electrochemical furnace designs are now operational. One directly measures the oxygen fugacity of the unknown buffer relative to air or a solid reference using a single electrolyte and two vacuum chambers. The second measures the oxygen fugacity of the unknown buffer in two steps from air through a $\mathrm{CO} / \mathrm{CO}_{2}$ gas intermediate stage. This allows greater experimental flexibility, cross checking for internal consistency, and direct measurement of the effects of electrical polarization. Very precise results have been obtained from the single electrolyte experiments $( \pm 20 \mathrm{~J}$ at any $\mathrm{T})$. The two-electrolyte method was initially less precise ( $\pm 250 \mathrm{~J}$ at a given $\mathrm{T}$ for the first $\mathrm{Ni}-\mathrm{NiO}$ run), but this deviation was reduced to as little as $\pm 36 \mathrm{~J}$ in later runs. Small differences that occur between results obtained from the two types of experiments may be because of temperature uncertainties and/or electrical polarization. Experiments are under way to evaluate these possibilities. Results are in reasonable agreement with those of O'Neill (1987, 1988), although small systematic differences exist. These may reflect temperature uncertainties, as differences of \pm 5 to $10^{\circ} \mathrm{C}$ are sufficient to explain the observed variations and emphasize the need for improved accuracy in these measurements. 
Reexamination of the diopside-enstatite join was necessary because models available for this join predict that end-member diopside is metastable with regard to a subcalcic diopside and wollastonite. A model in which this is no longer the case has been completed, which suggests that activity-composition relations for ordered intermediate phases such as diopside are strongly model dependent. A manuscript describing this work is in submission. Revisions of this model undertaken this year have yielded more reasonable coefficients and a greater understanding of the effects of strong correlations in solvus-based mixing model parameters on the interpretation of the values derived. Direct measurements of the activities of such materials, especially ordered intermediate compounds, are needed to constrain possible models. Cobalt-diopside appears an ideal candidate for this test using the electrochemical technique, and we are currently synthesizing this material.
GRANTEE:

GRANT:

TITLE:

PERSON IN CHARGE:
THE UNIVERSITY OF ARIZONA

Department of Physics

Tucson, Arizona 85721

DE-FG02-89ER13670

PERSON IN CHARGE:
Solar Variability Observed Through Changes in Solar Figure and Diameter
H. A. Hill (602-621-6782; FAX 602-621-4721;
E-mail hhill@sclera.physics.arizona.edu)

Objectives: Objectives of this project are to obtain measurements of the solar shape, diameter, and limb-darkening function, which may correspond directly with solar luminosity variations or could provide evidence that will illuminate the underlying mechanisms controlling solar irradiance variability.

Project Description: Observations of the solar continuum radiation intensity near the edge of the sun are obtained by continuously tracking the sun and scanning the outermost 32 arcseconds of the solar image over a set of six slits. The arrangement of slits and the associated photodetectors are repositioned every 64 seconds to obtain profiles at 36 different limb positions around the solar circumference. The limb-intensity profiles are analyzed by applying the finite Fourier transform definition (FFTD) of the solar edge, which allows the accurate determination of the solar diameter at a variety of heliographic orientations. The limb-darkening function exhibited by the limb profiles can be characterized by the differential radius - the difference between the FFTD edge locations for 8 and 24 arcsecond scan amplitudes. Temporal variability or positional differences in the differential radius indicate a time- varying or spatially nonuniform photospheric temperature gradient.

Results: During 1992, the set of observations grew by 20 days from March 12 to July 2 and again by 10 days from September 10 to November 7. Data analysis has focused on variation of differential radius with solar latitude. The results of this analysis for the 1991 observations show that there was statistically significant latitudinal variation of the solar limb-darkening function. In particular, differential radius near $20^{\circ} \mathrm{N}$ latitude and $30^{\circ} \mathrm{S}$ latitude is somewhat greater than that of surrounding regions. The latitudinal differential radius variations can be explained qualitatively by assuming that the temperature gradients at different latitudes differ primarily in a shallow layer within several hundred kilometers of the base of the photosphere. This circumstance could arise by differential heating of the base of the convection zone and could also account for the observed effective temperature variations of the photosphere and the shift in p-mode frequencies with the solar cycle. This result is important for understanding solar structure variations and their effect on energy transported out of the sun, which ultimately affects the terrestrial environment. 
GRANTEE:

GRANT:

TITLE:

PERSONS IN CHARGE:
BROWN UNIVERSITY

Department of Geological Sciences

Providence, Rhode Island 02912
DE-FG02-90ER14144

\section{Grain Boundary Transport and Related Processes in Natural Fine-Grained Aggregates}

\author{
R. A. Yund and J. R. Farver (401-863-1931; FAX 401-863-2058; \\ E-mail ray@gech031.geo.brown.edu)
}

Objectives: The objective of this study concerns the direct measure of diffusional transport rates in rocks and how the rates vary with mineralogy and microstructure, as well as temperature and pressure. The results provide much needed data on the nature of grain boundaries in rocks and the rate of transport of chemical components through rocks. Applications of these data include evaluating the retentiveness of different geological media for the isolation and confinement of nuclear and chemical waste, modeling migration of hydrocarbons through different rock types to refine exploration and development strategies for more efficient oil and natural gas recovery, and determining fluid/rock interactions and thermal histories of hydrothermal systems.

Project Description: The research involves determination and comparison of the nature and rates of grain boundary diffusion of oxygen and cations in natural and hot-pressed monomineralic aggregates of feldspar and calcite, and bimineralic aggregates of feldspar and quartz. The diffusional transport rates are determined from profiles of isotopic tracers measured using an ion microprobe (secondary ion mass spectrometry). In addition, select samples are texturally equilibrated with fluids common to natural environments, and the measured $D^{\prime} \delta$ values correlated with the nature of the grain boundaries and sample microstructure that are characterized by transmission and scanning electron microscopy.

Results: Recently, grain boundary diffusion rates of oxygen (as molecular water) and select geologically and environmentally important cations have been determined in feldspar aggregates. Specifically, potassium and calcium grain boundary diffusion rates in hot-pressed orthoclase (Or) and anorthite (An) aggregates, respectively. The potassium diffusion in Or aggregates has been determined both under hydrothermal and anhydrous conditions, and the results indicate that there is no difference when water is present. However, $D^{\prime} \delta$ values for potassium are different from values for oxygen even in those experiments where diffusion profiles of both elements were measured. The ability to measure $D^{\prime} \delta$ values for different chemical species in the same experiment provides clear evidence that the transport process being measured is diffusion. The calcium grain boundary diffusion rates in An aggregates are several orders of magnitude slower than oxygen, and than potassium in Or. This suggests that differences in size and formal charge of chemical species may play an important role in their relative grain boundary diffusion rates.

Samples of hot-pressed aggregates of natural Amelia albite and of synthetic albite and Or composition have been texturally equilibrated with water and dilute $\mathrm{NaCl}$ solutions at a variety of temperatures, durations, and heating and cooling rates, and the sample microstructures were characterized using transmission electron microscopy. Results to date suggest that the equilibrium distribution of water in feldspar aggregates is that of unconnected isolated pockets. Studies continue in order to evaluate the role of pressure and nonhydrostatic stresses on fluid-feldspar interfacial energies. 
GRANTEE:

GRANT:

TITLE:

PERSONS IN CHARGE:
CALIFORNIA INSTITUTE OF TECHNOLOGY

Division of Geological and Planetary Sciences

Pasadena, California 91125

\section{Infrared Spectroscopy and Hydrogen Isotope Geochemistry of Hydrous Silicate Glasses}

\author{
S. Epstein (818-356-6100) and \\ E. Stolper (818-356-6504; FAX 818-568-0935; \\ E-mail ems@expet.gps.caltech.edu)
}

Objectives: The focus of this project is the combined application of the methodologies of experimental petrology, infrared spectroscopy, and stable isotope geochemistry to understanding the behavior of volatile components, particularly water and carbon dioxide, in natural and synthetic silicate melts and glasses.

Project Description: This project integrates (1) a laboratory component directed toward development of analytical techniques and a solid understanding of the physical chemistry of volatile components in melts and glasses through carefully controlled experiments and syntheses and (2) a field-oriented component in which these techniques and chemical principles are applied to specific petrological and volcanological problems. A key feature of this project is the combination of methodologies from stable isotope geochemistry with those from experimental petrology and mineralogy. A unique aspect of the project is the explicit focus on the roles played by different species of dissolved water and carbon dioxide in silicate melts and glasses (e.g., molecules of $\mathrm{H}_{2} \mathrm{O}$ and hydroxyl groups, molecules of $\mathrm{CO}_{2}$ and carbonate ion complexes). Many seemingly complex behaviors of volatiles in liquids, glasses, and magmas can be simply and quantitatively explained if the speciation is understond and taken into account.
Results: (1) The partitioning of $\mathrm{H}$ isotopes between vapor and hydroxyl groups and molecules of $\mathrm{H}_{2} \mathrm{O}$ dissolved in rhyolitic melts was measured. The results of these measurements make it possible to use $\mathrm{H}$-isotope data to model magmatic degassing. (2) Infrared techniques were used to measure concentrations of $\mathrm{H}_{2} \mathrm{O}$ and $\mathrm{CO}_{2}$ in volcanic glasses, especially in inclusions in phenocrysts from recent eruptions. (3) The solubility of $\mathrm{CO}_{2}$ in rhyolitic liquid was measured at pressures up to 1500 bars. These results demonstrate that Henry's law is valid in mixed $\mathrm{H}_{2} \mathrm{O}-\mathrm{CO}_{2}$-bearing melts at high levels in the crust. (4) The fractionation of $\mathrm{O}$ isotopes between $\mathrm{CO}_{2}$ vapor and rhyolitic glass and melt was measured. (5) The kinetics of reactions between $\mathrm{H}_{2} \mathrm{O}$ molecules and anhydrous structural units to form $\mathrm{OH}$ groups in silicate glasses were studied. This is of practical value for developing a cooling rate indicator and geothermometer for hydrous volcanic glasses. (6) The diffusion of water in basaltic melts and of water and $\mathrm{CO}_{2}$ in rhyolitic glasses and melts was studied. Results were used to understand oxygen "self-diffusion" in silicate minerals and glasses and enhanced oxygen diffusion under hydrothermal conditions. These results are important to quantitative understanding of hydration and dehydration of magmas and glasses and could be valuable in applications of glass technology to nuclear waste disposal strategies. 
Objectives: The ages of corals using ${ }^{14} \mathrm{C}$ and ${ }^{230} \mathrm{Th}$ in vertical sections through coral reefs have been used as indicators of past sea level rise. Using mass spectrometry, ${ }^{230} \mathrm{Th}$ ages can be more precise and reliable than ${ }^{14} \mathrm{C}$ ages and are preferred where major discrepancies exist. The limitations of this method are now governed by diagenetic processes. One problem requiring attention is the comparison of sea level at different locations involving continents and ocean islands. Two drill cores were studied from the Abrolhos Islands on the continental shelf of western Australia. The study revealed that at the Abrolhos Islands the present day sea level was reached (and overshot) at 6320 y BP $\left({ }^{23}(1 \mathrm{Th})\right.$ or 5,500 y BP $\left({ }^{14} \mathrm{C}\right)$. This leaves a $10-\mathrm{m}$ discrepancy with the Barbados observations but, surprisingly, is in excellent agreement with the Huon Peninsula results. From this comparison, it was concluded that the local sea level curves are not a direct measure of melt water release but depend on the dynamical response characteristics to mantle flow. These results are in reasonable accord with theoretical models that are based on a global fit to data of mixed quality.

Project Description: We studied the sources and transport of $\mathrm{Sr}, \mathrm{Nd}, \mathrm{Sm}, \mathrm{U}$, and $\mathrm{Th}$ in rivers and estuarine environments. The Baltic Sea was studied as it has major riverine inputs from areas with distinct ages and lithologies and because it provides domains of sharply contrasting oxidation that permit study of the effects of chemical precipitates on the abundance of both conservative and nonconservative species. We established that brackish and saline waters in the Baltic show clear isotopic signatures in $\mathrm{Sr}, \mathrm{Nd}$, and $\mathrm{U}$ of drainage areas of the rivers. Precambrian sources in the north are clearly identified and contrasted to Phanerozoic sources in the south. While strontium behaves largely as a conservative element, vertical sections through oxic-anoxic zones in the Baltic show larger anomalies because of the removal of strontium by the formation of iron oxyhydroxides in the oxic zone and their dissolution in the anoxic zone. The same behavior was also found for uranium. The removal of ${ }^{232} \mathrm{Th}$ and ${ }^{230} \mathrm{Th}$ from the riverine input as soon as it enters the estuarine environment was demonstrated.

A study was made of the diffusion of magnesium in silicate melts and spinels at elevated temperatures. Diffusion couples were prepared of optical quality crystals and a melt that was isotopically labelled. This provided an excellent interface between the two media. By determining the phase diagram precisely in a limited temperature-composition region, it was possible to make diffusion couples of melt/crystal that were in chemical equilibrium with no growth or corrosion but which were isotopically in disequilibrium. For a given experiment rlin, this provides the diffusion coefficient in both phases with high precision by measuring the isotopic compositions in both regions with the ion microprobe. With a series of measurements at different temperatures, it was possible to determine the parameters in the equation $D_{0} \mathrm{e}^{-\mathrm{E} / \mathrm{RT}}$ with high accuracy. The results showed conclusively that some natural assemblages that were out of isotopic equilibrium and had been flash-heated to produce at least $70 \%$ melt must have been cooled at a rate of $20^{\circ} \mathrm{C} / \mathrm{h}$. A preliminary study of simultaneous self-diffusion of $\mathrm{Mg}, \mathrm{Ca}, \mathrm{Sr}$, and $\mathrm{Ba}$ in a silicate glass showed that it is possible to determine the differences in $\mathrm{D}$ between the elements.

The distribution coefficients of uranium and thorium were measured between melt and garnet. It now appears plausible that the problematical low thorium-uranium in mid-ocean range basalt can be explained and that melts originating at mantle depths can be identified by the thorium-uranium signature. 
GRANTEE:

GRANT:

TITLE:
UNIVERSITY OF CALIFORNIA AT BERKELEY

Department of Geology and Geophysics

Berkeley, California 94720

\section{DE-FG03-91ER14200}

\section{Experimental Measurement of Thermal Conductivity in Silicate Liquids}

Objectives: The thermal conductivity of silicate liquids is the most poorly known of their transport properties. These data are paramount for understanding the thermal evolution of magma systems or the formation of glass for industrial purposes.

Project Description: This project is designed to measure the thermal conductivity of a variety of iron-free silicate liquids, covering part of the range found in nature, as a function of temperature and composition at I bar. The temperature range is from the liquidus of each composition to $\sim 16(0)^{\circ} \mathrm{C}$. The apparatus to measure thermal conductivity has been developed from the transient hot-wire technique that has been used for accurate primary measurements of fluids and minimizes uncertainties resulting from convection and radiation. A test cell has been fabricated that is unreactive with silicate liquids and provides isothermal conditions at high temperatures.

Results: Measurements of thermal conductivity have been made on liquid $\mathrm{CaMgSi}_{2} \mathrm{O}_{6}$. Because of the simple geometry of the apparatus, the radiative transport that does occur can be estimated and subtracted from the total response, yielding true "phonon" conductivities. The following values were obtained for $\mathrm{CaMgSi}_{2} \mathrm{O}_{6}$ using a rhodium filament: $-0.31\left(1400^{\circ} \mathrm{C}\right), 0.17\left(1500^{\circ} \mathrm{C}\right)$, and 0.07 $\left.(1600)^{\circ} \mathrm{C}\right) \mathrm{W} \times \mathrm{m}^{-1} \times \mathrm{K}^{-1}$. The se values are considerably lower (by all order of magnitude) than existing measurements on silicate liquids made two decades ago; they can be reconciled with the older measurements if corrections for radiation are made for these. However, values on the National Institute for Standards and Technology standards, water and toluene, at room temperature are disturbingly high. The accepted value at $294.1 \mathrm{~K}$ for water is 0.600 ), whereas our value is 0.74 ; for toluene the accepted value is 0.132 , whereas our value is 0.23 . The reason for this may lie in the very much shorter $(\sim 2 \mathrm{~cm})$ sample cell that must be used at high temperatures, compared to a sample length optimized for room temperature $(20$ to $30 \mathrm{~cm})$. 
GRANTEE:

GRANT:

TITLE:

PERSON IN CHARGE:
UNIVERSITY OF CALIFORNIA AT BERKELEY

Department of Geology and Geophysics

Berkeley, California 94720

DE-FG03-85ER13419

Advective-Diffusive/Dispersive Transport of Chemically Reacting Species in Hydrothermal Systems

Harold C. Helgeson (510-642-1251; FAX 510-643-9980; E-mail brogie.garnet.berkeley.edu)

Objectives: To achieve a better understanding of the effects of chemical mass transfer on the occurrence, evolution, and development of energy resources in the crust of the Earth.

Project Description: The major scientific and technical issues of concern in this project are:

1. How reactive are organic molecules at elevated temperatures and pressures in sedimentary basins?

2. How prevalent are metastable equilibrium states involving these molecules and the minerals and waters in source rocks and reservoirs?

3. What is the role of oxygen fugacity relative to temperature and pressure in breaking down organic matter to hydrocarbons and the maturation of petroleum in source rocks?

4. What are the congruent and incongruent solubilities of detrital minerals in oil-field waters, and what diagenetic role do organic species in petroleum play at the oil-water interface in determining these solubilities and generating secondary porosity resulting from mineral dissolution?

5. What is the role of water and hyperthermobarophilic microbes in the generation and maturation of petroleum at depths in excess of $\sim 3 \mathrm{~km}$ ?

Results: Both thermodynamic and compositional considerations suggest that the fugacity of oxygen in car- bonate-bearing reservoirs may be controlled at the oilwater interface by metastable equilibrium states among hydrocarbons in crude oil with carbon numbers $\geq 6-15$ and/or calcite and the oxidized carbon-bearing species in the aqueous phase. Irreversible reaction of the light paraffins in petroleum with $\mathrm{H}_{2} \mathrm{O}$ at the oil-water interface to form lighter paraffins and $\mathrm{CO}_{2(a q)}, \mathrm{CH}_{3} \mathrm{COOH}_{(a q)}$, and other oxidized carbon-bearing aqueous species is strongly favored by the large chemical affinities of the reactions. It appears that ir le production of carbonic and carboxylic acids hydrolytic disproportionation of the light parai troleum at the oil-water interface may drive much of the diagenetic process in young dynamic basins in which fluid flow is extensive and oil, water, and gas are in pervasive contact. At near-neutral $\mathrm{pHs}$, the reactions favor precipitation of carbonates, but at lower pHs they favor carbonate dissolution, albitization of plagioclase, illitization of smectite, and other diagenetic reactions. Dissociation constants and activity coefficients retrieved from regression analysis of high-temperature/pressure solutility and phase equilibrium data reported in the literature are being used to characterize the chemical and thermodynamic consequences of these reactions and the extent to which secondary porosity may form as a consequence of the irreversible hydrolytic disproportionation of hydrocarbons in petroleum at the oil-water interface. 
GRANTEE:

GRANT:

TITLE:

PERSONS IN CHARGE:
UNIVERSITY OF CALIFORNIA AT BERKELEY

Department of Materials Science and Mineral Engineering Berkeley, California 94720

DE-FG03-92ER14276.000

Multistation Magnetotellurics

H. F. Morrison (510-642-8109; FAX 510-642-3805) and

G. D. Egbert
Objectives: The principal objective of this project is to develop and test new methods for collecting and processing remote reference magnetotelluric (MT) data in areas with significant cultural noise, with special emphasis on the "dead band" (approximately 0.1 to $10.0 \mathrm{~Hz}$ ) where signal levels are low and noise levels are high.

Project Description: The project has three aspects: (1) Data are being collected in a series of three-station MT arrays that span conditions from very noisy (just south of San Jose, California) to very quiet remote sites. Our emphasis is on collecting a large volume of dead-band data at a small number of sites. Multiple remote sites at varying distances, and in various combinations of noisy and quiet, are included to allow us to characterize spatial and temporal properties of signal and noise and to test different approaches to remote reference data acquisition. (2) New approaches to remote reference data processing are being developed. We are adapting multivariate and robust statistical methods to the special problems of MT data processing in the dead band. (3) Using the multistation MT data from our experiment, and other compilations of remote reference MT data, we are testing and comparing various strategies for collecting and processing remote reference MT data.

Results: The project is in its first year. MT data collection is currently under way, and initial work on programming of robust multiple-station and remote reference estimators has been completed. Analysis of the array data and comparison and testing of methods will begin soon. 
GRANTEE:

GRANT:

TTTLE:

PERSONS IN CHARGE:
UNIVERSITY OF CALIFORNIA AT DAVIS

Department of Land, Air, and Water Resources

and the Department of Chemistry

Davis, California 95616

DE-FG03-92ER14307

\section{A New Method for Determining the Thermodynamic Properties of Carbonate Solid-Solution Minerals}

William H. Casey (916-752-3211; FAX 916-752-1552;

E-mail whcasey@ucdavis.edu) and Peter A. Rock (916-752-0940;

FAX 916-752-8995)

Objectives: We are establishing a new method for direct determination of the thermodynamic properties $\left(\Delta_{\mathrm{f}} \mathrm{G}^{\mathrm{o}}, \Delta_{\mathrm{r}} \mathrm{H}^{\mathrm{o}}\right.$, and $\left.\Delta_{\mathrm{r}} \mathrm{S}^{\mathrm{o}}\right)$ of carbonate solid-solution minerals of environmental importance.

Project Description: Our new method is an electrochemical double cell without liquid junction. Such a cell for magnesian carbonate minerals is:

( $\mathrm{Pb}-\mathrm{Hg}$ amalgam) $\left|\mathrm{PbCO}_{3}(\mathrm{~s}), \mathrm{CaCO}_{3}(\mathrm{~s})\right| \mathrm{CaCl}_{2}(\mathrm{aq}) \mid$

$\mathrm{Hg}_{2} \mathrm{Cl}_{2}(\mathrm{~s})|\mathrm{Hg}(\mathrm{l})-\mathrm{Hg}(\mathrm{l})| \mathrm{Hg}_{2} \mathrm{Cl}_{2}(\mathrm{~s}) \mid(\mathrm{Ca}, \mathrm{Mg})$

$\mathrm{Cl}_{2}(\mathrm{aq})\left|\mathrm{Ca}_{x} \mathrm{Mg}_{1-\mathrm{x}} \mathrm{CO}_{3}(\mathrm{~s}), \mathrm{PbCO}_{3}(\mathrm{~s})\right|(\mathrm{Pb} \cdot \mathrm{Hg}$ two-phase amalgam)

yielding a net cell reaction of:

$$
\begin{aligned}
\left(\mathrm{CaCO}_{3}\right)^{\text {calcite }}+x \mathrm{CaCl}_{2}(\mathrm{aq})+(1-\mathrm{x}) \mathrm{MgCl}_{2}(\mathrm{aq}) \\
=\left(\mathrm{Ca}_{x} \mathrm{Mg}_{1-x} \mathrm{CO}_{3}\right)^{\mathrm{Mg} \text {-calcite }}+\mathrm{CaCl}_{2}(\mathrm{aq}) .
\end{aligned}
$$

$\Delta_{\mathrm{f}} \mathrm{G}^{\prime \prime}$ of the solid solution relative to the end members is obtained from the cell voltage and known activities of the electrolytes. In experimentally favorable cases, entropies and enthalpies are obtained from the temperature variation in the cell voltage.

These cells are a technological advance because (1) reversibility can be directly established, (2) models of solute speciation are not required, (3) the chemistry is not significantly perturbed in the measurements.
Results: We are in the first year of this project and are studying solid-solution formation reactions in the $\mathrm{CaCO}_{3}-$ $\mathrm{CdCO}_{3}, \mathrm{CaCO}_{3}-\mathrm{SrCO}_{3}$, and $\mathrm{CaCO}_{3}-\mathrm{MgCO}_{3}$ systems. We choose to begin with minerals in the $\mathrm{CdCO}_{3}-\mathrm{CaCO}_{3}$ system because mixing is anticipated to be nearly ideal and because previous workers were unable to establish reversible equilibria. We conducted measurements on several compositions in the $\mathrm{Cd}_{x} \mathrm{Ca}_{1-\mathrm{x}} \mathrm{CO}_{3}(\mathrm{~s})$ solid solution series using the cell:
$\mathrm{Cd}\left(\mathrm{Hg}\right.$, 2-phase) $\left|\mathrm{CdCO}_{3}(\mathrm{~s})\right| \mathrm{CaCO}_{3}(\mathrm{~s})\left|\mathrm{CaCl}_{2}(\mathrm{aq})\right|$ $\mathrm{Hg}_{2} \mathrm{Cl}_{2}(\mathrm{~s})|\mathrm{Hg}(\mathrm{l})-\mathrm{Hg}(\mathrm{l})| \mathrm{Hg}_{2} \mathrm{Cl}_{2}(\mathrm{~s}) \mid \mathrm{CaCl}_{2}(\mathrm{aq})$, $\mathrm{CdCl}_{2}(\mathrm{aq})\left|\mathrm{Cd}_{x} \mathrm{Ca}_{1-x} \mathrm{CO}_{3}(\mathrm{~s})\right| \mathrm{CdCO}_{3}(\mathrm{~s}) \mid \mathrm{Cd}$

(Hg, 2-phase).

Reversibility of the cell reaction was established through (1) Nernstian response of the potential to changes in solute activities solid-solution activities, (2) the absence of hysterisis in voltage-current plots for the cell [ see figure, part $(a) \mid$, and (3) the rapid and reversible response of the cell voltage to temperature cycling | see figure, part $(b)$ |. Our estimated value of $\Delta_{1} \mathrm{G}^{\circ}$ for otavite $\left(\mathrm{CdCO}_{3}\right)$ and calcite $\left(\mathrm{CaCO}_{3}\right)$ are within $2 \mathrm{~kJ} / \mathrm{mol}$ of the National Bureau of Standards values reported in Wagman et al., J. Phys. Chem. Ref. Data 11 (Suppl. 2) 1-392 (1982). 

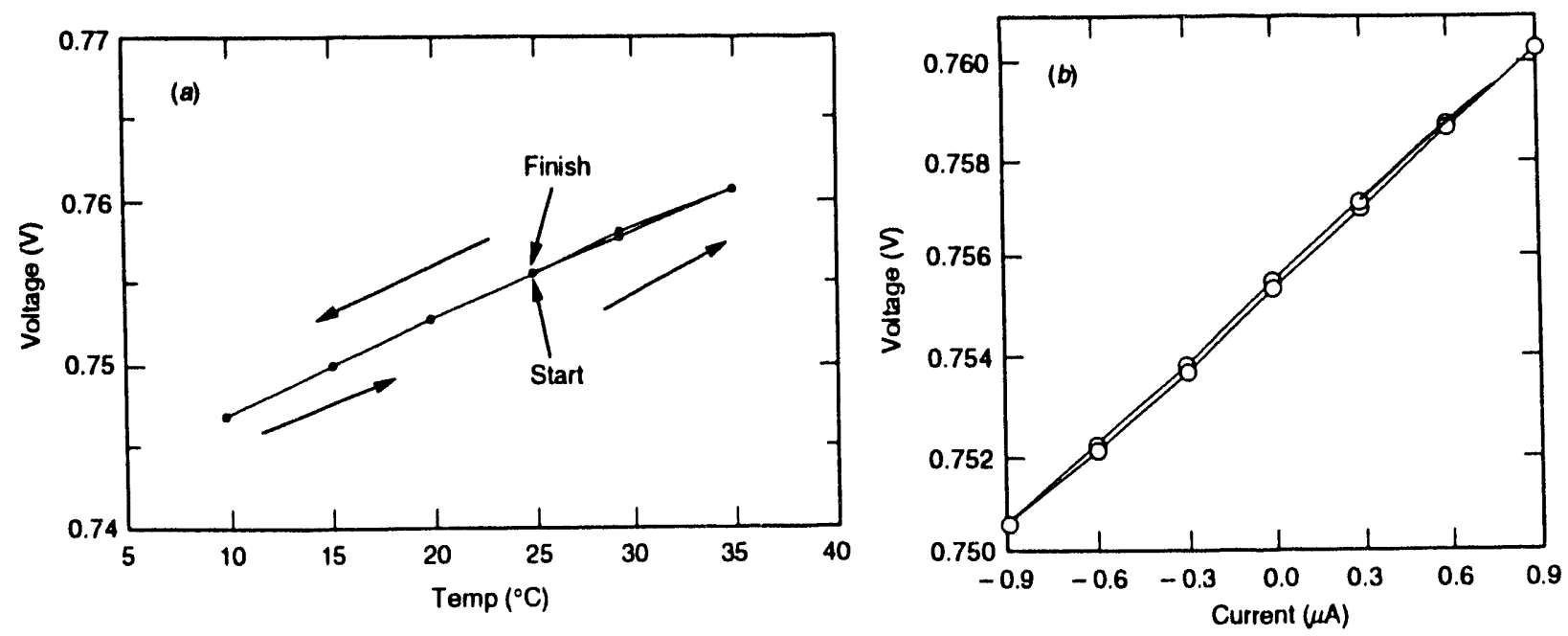

Temperature-voltage (a) voltage-current (b) plots for the cell containing $\mathrm{Cd}_{85} \mathrm{Ca}_{15} \mathrm{CO}_{3}$. 
GRANTEE:

GRANT:

TITLE:

PERSON IN CHARGE:
UNIVERSITY OF CALIFORNIA AT DAVIS

Department of Geology

Davis, California 95616

DE-FG03-92ER14240

Energetics of Melts from Thermal-Diffusion Studies

C. E. Lesher (916-752-9779; FAX 916-752-0951;

E-mail lesher@.geology.ucdavis.edu)

Objectives: This research program characterizes mass transport by diffusion in geological fluids in response to thermal, solubility, and/or chemical gradients to obtain quantitative information on the thermodynamic and kinetic properties of multicomponent systems.

Project Description: Thermal diffusion is the phenomenon of chemical migration in response to heat flow along a thermal gradient. The details of this response are conditioned by the thermochemical properties and constitution of the substance. Silicate liquids undergo substantial thermal diffusion (Soret) differentiation, whereas the response in sulfide, carbonate, and aqueous fluids to an imposed temperature gradient is varied. The experimental observations of this differentiation are used to evaluate the form and quantitative values of solution parameters and to quantify ordinary diffusion coefficients, heats of transport, and activation energies of multicomponent liquids. The diffusion, solution, and element partition coefficients determined for these geological fluids form a data base for understanding magmatic crystallization behavior and for evaluating geothermal, ore deposit, and nuclear waste isolation potentials. Thermal and isothermal diffusion experiments are conducted using the 1-atm gas-mixing apparatus, rapid-quench cold seal apparatus up to $0.3 \mathrm{GPa}$, piston cylinder device at pressures between 0.7 and $3.5 \mathrm{GPa}$, and a simplified multianvil device above 3.5 GPa. The electron and ion microprobes and the infra- red spectrometer are used in the characterization of experimental run products.

Results: During the past year, we have established an active experimental petrology laboratory for thermal-diffusion work following the principal investigator's move from the L-DEO. Current experimental capabilities include two 1-atm gas-mixing furnaces, a rapid-quench cold seal device, two piston cylinder devices, and a Walker multianvil device driven by a 1000-ton Clifton press. Among the research activities of the last year we initiated thermal-diffusion experiments at very high pressure on magmatic silicate liquids in an attempt to use the recovered heats of transport and chemical potentials as monitors of changing speciation with pressure; expanded on our preliminary study of large (4 to $7 \%$ ) mass-dependent oxygen isotope Soret fractionation in silicate liquids at high temperature; documented small $(<1 \%)$ oxygen isotope fractionation under isothermal conditions between liquids of contrasting bulk composition; began studies of Soret separations of water and carbonate species in naturally occurring silicate liquids, discovered that self-diffusivities of silicon and oxygen in basaltic liquid are indistinguishable, suggesting cooperative diffusion of these species; expanded our theoretical treatment of chemical diffusion using Darken's theory of ion mobility; and initiated a comprehensive characterization of thermal, self-, and chemical diffusion of multicomponent liquids of the system $\mathrm{CaO}-\mathrm{MgO}-\mathrm{SiO}_{2}$. 
GRANTEE:

GRANT:

TITLE:

PERSON IN CHARGE:
UNIVERSITY OF CALIFORNIA AT LOS ANGELES

Department of Earth and Space Sciences

Los Angeles, California 90024

DE-FG03-89ER14049

K-Feldspar Thermochronometry

T. M. Harrison (310-825-7970; FAX 310-825-2779;

E-mail tmh@argon.ess.ucla.edu)

Objectives: The ${ }^{40} \mathrm{Ar} /{ }^{39} \mathrm{Ar}$ method can furnish information about both the internal distribution of ${ }^{40} \mathrm{Ar} *$ and argon diffusion parameters. The multidiffusion domain model has shown promise in explaining various effects seen in the laboratory and has been successfuliy applied to a variety of energy-related problems. The objective of this research is to develop K-feldspar ${ }^{40} \mathrm{Ar}{ }^{39} \mathrm{Ar}$ thermochronometry into a robust tool for assessing upper-crustal thermal histories.

Project Description: In our formulation of the multidiffusion domain model, the form of the Arrhenius plot and age spectrum are a function of the diffusion parameters for each discrete domain (activation energy, $E$, and frequency factor, $\left.D_{\iota}\right)$, the domain distribution parameters (domain size, $\rho$, and volume fraction, $\phi$ ), and the thermal history. Because the diffusion parameters may be obtained directly from the Arrhenius plot and we have two independent measures of $\rho$ and $\phi$ (the Arrhenius plot and age spectrum), we have sufficient information to obtain a solution for the thermal history. Both the underlying assumptions and general predictions of the theory can be tested through laboratory investigations, including diffusion experiments and direct imaging (using visible light, $\mathrm{X}$ rays, and transmission electron microscopy methods), or through study of argon isotopic variations in natural K-feldspars.
Results: A notable discovery is that isothermal duplicate heating steps during laboratory argon extraction experiments permit identification of chlorine-correlated components of excess argon (ArE), apparently hosted by fluid inclusions. This relationship, now confirmed in over 18 samples, provides the basis for correction of the excess argon commonly observed in the initial stages of step-heating K-feldspars. One implication of this result is that temperatures that were previously inaccessible using this method of recovery of thermal histories (down to, for example, $\sim 130^{\circ} \mathrm{C}$ ) are now routinely achievable. This permits essentially complete overlap with the apatite fission track thermochronometer. In vacuo crushing experiments reveal that, unlike hypersolvus or authigenic $\mathrm{K}$-feldspars, only $\sim 0.1 \%$ of the potassium in K-feldspar typical of that used for thermochronometry is hosted by nonvolume features such as fluid inclusions. Crushing below the scale of the largest diffusion domain $(\sim 100 \mathrm{~mm})$ appears to induce a serious artifact in the step-heating age spectrum that sheds light on complexities in the internal distributions of ${ }^{40} \mathrm{Ar}$ and ${ }^{39} \mathrm{Ar}$. No adverse consequences arising from the presence of nonvolume potassium, or $\mathrm{K}$ or Cl-correlated ArE, on interpreting the ${ }^{40} \mathrm{Ar}{ }^{39} \mathrm{Ar}$ results in terms of thermochronometric models can be discerned. 
GRANTEE:
UNIVERSITY OF CALIFORNIA AT LOS ANGELES

Department of Earth and Space Sciences

Los Angeles, California 90024

\section{GRANT: $\quad$ DE-FG03-91ER14222}

PERSON IN CHARGE:

\section{TITLE:}

\section{Oxygen and Cation Diffusion in Oxide Materials}

K. D. McKeegan (310-825-3580; FAX 310-825-2779;
E-mail kdm@argon.ess.ucla.edu)
Objectives: The objective of this work is to measure the diffusion parameters for various cations and oxygen in important rock-forming minerals to constrain both geochemical transport processes and diffusive mechanisms affecting physical properties such as creep and electrical conductivity.

Project Description: Diffusion rates are strongly affected by temperature, pressure, and crystal orientation. They may also depend on additional variables such as oxygen fugacity and the activity of water in the system. We are conducting experiments in which all of these variables are controlled and selectively varied. The pressures of current experiments (concentrating on olivine, plagioclase, diopside, garnet, and spinel) range from $1 \mathrm{~atm}$ to $10 \mathrm{GPa}$. The primary analytical tool used in these investigations is an ion microprobe.

Results: Oxygen self-diffusion coefficients have been measured for three natural clinopyroxenes, a natural anorthite, a synthetic magnesium aluminate spinel, and a synthetic akermanite over oxygen fugacities ranging from the $\mathrm{Ni}-\mathrm{NiO}$ to $\mathrm{Fe}-\mathrm{FeO}$ buffers. The experiments employed a gas-solid isotopic exchange technique using $99 \%{ }^{18} \mathrm{O}$ enriched $\mathrm{CO}-\mathrm{CO}_{2}$ gas mixtuies to control both the oxygen fugacity and the isotopic composition of the exchange reservoir. The experimental results yield the following Arrhenius parameters: cpx: $D_{0}=4.3 \times 10^{-4} \mathrm{~m}^{2} \mathrm{~s}^{-1}$, $\mathrm{Q}=457 \mathrm{~kJ} \mathrm{~mol}^{-1}$, akm: $\mathrm{D}_{\mathrm{i}}=4.7 \times 10^{-7} \mathrm{~m}^{2} \mathrm{~s}^{-1}, \mathrm{Q}=278$ $\mathrm{kJ} \mathrm{mol}{ }^{-1}$, sp: $2.2 \times 10^{-7} \mathrm{~m}^{2} \mathrm{~s}^{-1}, \mathrm{Q}=404 \mathrm{~kJ} \mathrm{~mol}^{-1}$, an: $\mathrm{D}_{0}=8.4 \times 10^{-13} \mathrm{~m}^{2} \mathrm{~s}^{-1}, \mathrm{Q}=162 \mathrm{~kJ} \mathrm{~mol}^{-1}$. The clinopyroxenes, from DeKalb, N.Y.; Rajasthan, India; and Ala, Piemonte, are all nominally diopside end members and their oxygen self-diffusion coefficients are indistinguishable. At a given temperature, oxygen diffuses about 100 times more slowly in diopside than indicated by previous bulk-exchange experiments. Our data for anorthite, spinel, and akermanite agree well with prior results obtained by gas-solid exchange and depth profiling methods. Because these other experiments were conducted at different oxygen fugacities, this agreement indicates that diffusion of oxygen in these nominally iron-free minerals is not greatly affected by $f \mathrm{O}_{2}$ in the ranae between pure oxygen and the $\mathrm{Fe}-\mathrm{FeO}$ buffer.

We are currently measuring oxygen diffusion in a series of garnets. Efforts are concentrated on determining the surface stability of these minerals under various conditions prior to contact with a tracer gas or solution. 
GRANTEE:

GRANT:

TITLE:

PERSONS IN CHARGE:

\section{UNIVERSITY OF CALIFORNIA AT SAN DIEGO}

Scripps Institution of Oceanography

La Jolla, California 92093-0215

DE-FG03-92ER14245

\title{
Deuterium/Hydrogen Ratios and Scanning Electron Microscopy Imaging of Fossil Organic Matter from California's Monterey Formation
}

\author{
A. Schimmelmann and C. E. Reimers \\ (619-534-4605; FAX 619-534-0784)
}

Objectives: We tested the hypothesis that bacteria have contributed substantially to the formation and accumulation of organic matter $(\mathrm{OM})$ in the oil-source rocks of California's Monterey Formation. The U.S. Genlogical Survey supplied two stratigraphic series of 22 rock samples to us and to other participating laboratories as part of a large-scale research project entitled the "Cooperative Monterey Organic Geochemistry Study."

Results: Extensive scamning electron microscopy and light microscopy was used to scan for morphological remnants of fossil bacteria and to characterize silica and carbonate preservation. Fossil microbes were discovered in rock samples, but it is unlikely that these bacteria are of Miocene age or that they are a major source of $\mathrm{OM}$. The concentration of organic matter appeared instead to be a function of biogenic silica dissolution.

Determinations of the stable isotope ratios of hydrogen, carbon, and nitrogen in kerogen, humic acid, and fulvic acid were performed to characterize the origin, paleoenvironment, and diagenetic history of the OM. The observed isotopic composition of OM from the Monterey Formation cannot be explained by the theory of significant contribution of bacterial biomass to the overall OM. Re- ported isotopic ranges of filamentous bacteria from a cold seep environment are incompatible with typical values of Monterey OM. On the other hand, deuterium-depleted biolipids and sterols are likely to have formed the fossil OM via the "polyunsaturated fatty acid-polymerization model" (e.g., via oxidative cross-linking of lipids, possibly involving sulfur). A novel approach to determine the relative amount and isotopic composition of isotopically nonexchangeable hydrogen in organic isolates yielded additional results: the ratio of exchangeable versus nonexchangeable hydrogen increases in the sequence kerogen, humic acid, fulvic acid. 'The nitrogen stable isotope ratio in kerogen correlates positively with the relative amount of exchangeable hydrogen, via ${ }^{15} \mathrm{~N}$-enrichment of $-\mathrm{NH}_{2}$ groups contributing to the pool of exchangeable hydrogen. Concentrations of the heavy isotopes ${ }^{2} \mathrm{H}(\mathrm{D})$, ${ }^{13} \mathrm{C}$, and ${ }^{15} \mathrm{~N}$ tend to increase in sequence from bitumen, through kerogen and humic acid, to fulvic acid.

Preparations of kerogen using various methods show significant systematic isotopic differences. Lamination of rocks and inferred degree of oxygenation in bottom waters are not expressed in isotope ratios in OM from the Monterey Formation. 
GRANTEE:

GRANT:

TITLE:

PERSON IN CHARGE:
UNIVERSITY OF CALIFORNIA AT SANTA BARBARA

Institute for Crustal Studies

Santa Barbara, California 93106

\section{DE-FG03-91ER14211}

\section{Physical Modeling of Sadimentary Basins, Magma Mechanics, and Molecular Dynamics of Geological Solutions}

F. J. Spera (805-893-2260; FAX 805-893-8649; E-mail spera@magma.geol.ucsb.edu)

Objectives: Objectives of this project are to:

1. determine the viscometric properties of $\mathrm{NaAlSiO}_{4-}$ $\mathrm{SiO}_{2}$ melts;

2. compute selected thermodynamic and transport properties of melts along the join $\mathrm{NaAlSiO}_{4}-\mathrm{SiO}_{2}$ by molecular dynamics,

3. simulate withdrawal and eruption of magma from density- and viscosity-stratified crustal magma reservoirs, and

4. simulate thermohaline convection in low-porosity porous media with applications to sedimentary basins and hydrothermal systems.

Project Description: Transport of mass, momentum, heat, and chemical species at both macroscopic and microscopic scales in the crust is vital to understanding the evolution of magmatic, hydrothermal, and sedimentary basin systems. This work involves a number of subprojects including study, by concentric cylinder viscometry, of the rheological properties of soda aluminosilicate melts, molecular dynamics, simulations of these melts to understand the relationship between properties and structure, simula- tions of the dynamics of magma withdrawal from crustal magma chambers, and simulations of thermohaline convection in porous media.

Results: Laboratory experiments show that for melts in the system $\mathrm{NaAlSiO}_{4}-\mathrm{SiO}_{2}$, the activation energy for viscous flow depends linearly on bulk composition. Molecular dynamics simulations exhibit similar trends and suggest that effective pair potentials may be used to calculate the properties of silicate melts at high temperatures and pressures. Magma withdrawal calculations enable forward-modeling of magma removal at high rates of discharge through conduit systems connected to densityand viscosity-stratified magma bodies within the crust. Finally, time-dependent simulations of thermohaline convection in fractured (equivalent) porous media show that, at fixed purosity and thermal Rayleigh number, as the salinity Rayleigh number (Rs) increases, the dynamics change from convective steady state at low Rs to chaotic flows at higher Rs and finally to conductive steady state at the highest Rs. The eulerian chaos observed may be relevant to the interpretation of fluid inclusion composition data in that fluid salinities at a fixed location may vary chaotically in time. 
GRANTEE:

GRANT:

TITLE:

\section{CARNEGIE INSTITUTION OF WASHINGTON}

Geophysical Laboratory

5251 Broad Branch Road NW

Washington, D.C. 20015-1305

DE-FG02-93ER 14365

Water-Rock Interaction in the Earth's Upper Mantle: Application of Combined Oxygen Isotope and Infrared Spectroscopic Analytical Techniques

\section{PERSONS IN CHARGE: $\quad$ D. R. Bell (202-686-2410), F. R. Boyd, and D. Rumble}

Objectives: This project will combine detailed infrared (IR) absorption measurements of concentration and speciation of hydrogen and oxygen isotope systematics of coexisting mantle minerals to investigate the interaction of hydrous fluids with mantle rocks.

Project Description: Present indications are that water-rock interactions in the mantle play an important role in the Earth's global hydrogen cycle and strongly influence internal geochemical and geophysical processes. It is known that most nominally anhydrous mantle minerals contain trace amounts of hydroxyl. Given the strong effects that small amounts of water in the mantle can have on (1) depressing the melting temperature of rocks, (2) enhancing mass transfer, (3) facilitating magma migration, (4) reducing rock strength and seismic velocities, (5) enhancing electrical conductivity, and (6) extending the range of igneous differentiation, as well as the great differ- ences in these processes that are to be expected depending on the chemical speciation of these hydrous components, there is strong motivation for research on the distribution of hydroxyl in mantle minerals.

Oxygen for isotopic analysis will be extracted from the mineral samples by laser heating in a fluorinating atmosphere (400- $\mu \mathrm{m}$ resolution). Hydroxyl will be measured in the same minerals by polarized, single-crystal IR spectroscopy (30- $\mu \mathrm{m}$ resolution). Controls on ${ }^{18} \mathrm{O}$ systematics of minerals will be investigated, including effects of bulk composition, intermineral partitioning, fractionation between mantle rock and magma during melting, and isotope exchange between mantle rock and fluids. Correlation patterns between hydroxyl and ${ }^{18} \mathrm{O}$ distributions in the minerals will be sought as a means of defining the role of fluids and fluid recycling in mantle.

Results: This project began September 15, 1993. 
GRANTEE:

GRANT:

TITLE:
THE UNIVERSITY OF CHICAGO

Center for Advanced Radiation Sources

5640 S. Ellis Avenue

Chicago, Illinois 60637

Synchrotron X-Ray Microprobe and Microspectroscopy: Technical Development for Advanced Photon Source Research and Low-Temperature Geochemistry Applications

\section{PERSON IN CHARGE:}

Objectives: The objectives are to develop and apply a synchrotron-based X-ray microprobe that can be used to determine the composition, structure, oxidation state, and bonding characteristics of earth materials with trace element sensitivity and micrometer spatial resolution.

Project Description: The project focuses on enhancements to the X-ray fluorescence microprobe on beamline X26 at the National Synchrotron Light Source (NSLS), Brookhaven National Laboratory. Geochemical problems under investigation include the nature of hydrothermal fluid inclusions, toxic metal and radioisotope speciation in low-level wasteforms and contaminated sediments, determinations of the chemical histories of contaminated sites through microanalytical studies of indigenous organisms, the structures of iron-oxide minerals, aerosol climatology, and manganese chemistry in the wheat take-all disease. The goal is to extend this research at the Advanced Photon Source, the next generation of synchrotron radiation source at Argonne National Laboratory scheduled for commissioning in 1995.

Results: The NSLS X-ray microprobe is capable of trace element analyses $(\leq 1 \mathrm{ppm})$ with $5-\mu \mathrm{m}$ spatial resolution. An incident beam monochromator with a energy band width of $\sim 10^{-4}(\Delta \mathrm{E} / \mathrm{E})$ was installed. X-ray absorption near edge structure (XANES) measurements were made for $\mathrm{Ti}, \mathrm{Cr}, \mathrm{Mn}, \mathrm{Fe}, \mathrm{Ce}$, and $\mathrm{U}$ with detection limits $\leq 100 \mathrm{ppm}$ for $100-\mathrm{mm}$ spatial resolution. A wavelength dispersive spectrometer was commissioned, and a 13-element germanium detector was acquired. Trace element studies of natural fluid inclusions on specimens from extinct seafloor hydrothermal systems and from a major porphyry molybdenum deposit demonstrated the potential for quantifying the chemical state of hydrothermal fluids from a multitude of geochemical settings. A method was

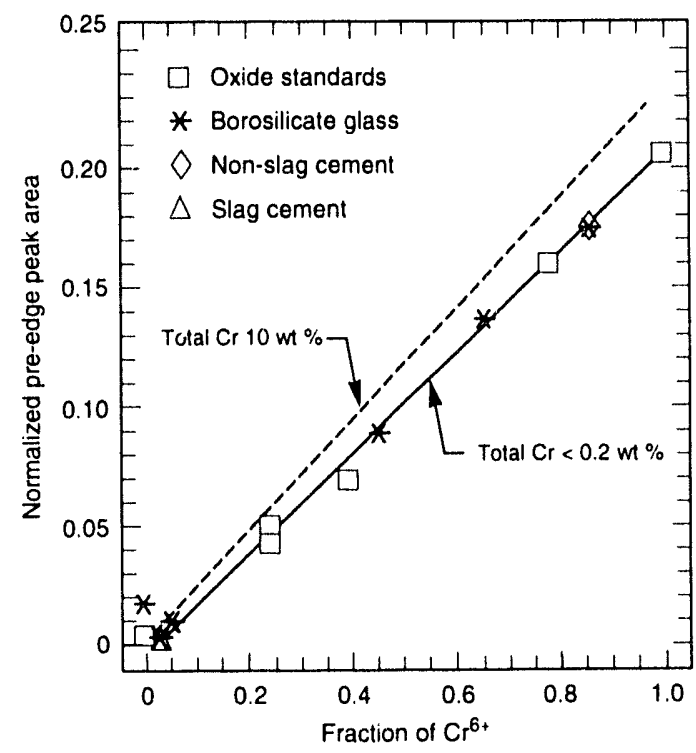

Linear regression of the area of the hexavalent chromium preedge peak versus known hexavalent chromium content for five mixtures of $\mathrm{Cr}_{2} \mathrm{O}_{3}$ and $\mathrm{Na}_{2} \mathrm{CrO}_{4}$ containing less than 0.2 wt \% total chromium and for three borosilicate standards (solid line). Chromium in the slag cement is reduced compared to that in the non-slag cement. The dashed line is for standard mixtures of $10 \mathrm{wt} \%$ total chromium and the three borosilicate standards (from Bajt et al., Anal. Chem. 65, 1800-1804, 1993).

developed to quantify $\mathrm{Cr}^{6+}$ in low-level radioactive wasteforms, and initial results indicated that slag-based cements quantitatively reduce $\mathrm{Cr}^{6+}$ to $\mathrm{Cr}^{3+}$, leading to enhanced retention of chromium in the wasteform (see figure). XANES analyses on individual grains in $>50 \mu \mathrm{m}<200 \mu \mathrm{m}$ isolates from uranium-contaminated soils collected at the Fernald nuclear processing facility near Cincinnati, Ohio, provided evidence for uranium oxidation state heterogeneity $\left(\mathrm{U}^{4+}, \mathrm{U}^{6+}\right)$ within the sand fraction. 
GRANTEE:

GRANT:

TITLE:

PERSON IN CHARGE:

\section{UNIVERSITY OF COLORADO}

Department of Geological Sciences

Boulder, Colorado 80309

\section{DE-FG-02-92ER14233}

\section{Crystal Chemistry of Hydroxyl and Water in Silicate Minerals}

Joseph R. Smyth (303-492-5521; FAX 303-492-2606;

E-mail joesmyth@vaxf.colorado.edu)

Objectives: The first objective is a greater understanding of the exchange mechanisms of hydrated cations in natural zeolites that are present at Yucca Mountain, Nevada. The second objective is to evaluate the hypothesis that nominally anhydrous high-pressure minerals may harbor a large reservoir of hydroxyl, and thus water, deep within the earth and that this reservoir may have exchanged with and buffered the water of the planet's hydrosphere over geologic time.

Project Description: The hydration of various cations substituting into the abundant natural zeolite, clinoptilolite, may control sorption and migration of radionuclides at the Nevada Test Site and Yucca Mountain Nuclear Waste Repository. Cation exchange experiments have been performed to produce single crystals of $\mathrm{K}, \mathrm{Na}, \mathrm{Cs}$, $\mathrm{Mg}, \mathrm{Ca}, \mathrm{Sr}$, and $\mathrm{Ba}$ varieties of this material. Cation positions and hydration geometries are being determined at $100 \mathrm{~K}$ for these samples by $\mathrm{X}$-ray single-crystal diffraction methods.

The stability of hydroxyl-bearing, but nominally anhydrous, silicates such as omphacite, wadsleyite $(\beta$ $\mathrm{Mg}_{2} \mathrm{SiO}_{4}$ ), rutile, and stishovite may control magma generation in the mantle, and these phases together with some nominally hydrous phases may constitute a reservoir of hydrogen in the earth as large as the oceans. The mechanisms of hydroxyl incorporation into these phases are being investigated by $\mathrm{X}$-ray and neutron crystallographic methods.

Results: In cation exchange experiments on natural clinoptilolite, the alkalis, $\mathrm{Na}, \mathrm{K}$, and $\mathrm{Cs}$, are observed to exchange readily, whereas exchange of the alkaline earths, $\mathrm{Ca}, \mathrm{Sr}$ and $\mathrm{Ba}$, is much slower. About one-third of the exchangeable cations in the natural samples are calcium, and very little of this is exchanged at $70^{\circ} \mathrm{C}$ in $2 \mathrm{M}$ chloride solutions. Structural studies of the alkali-exchanged varieties show three different hydrated cation sites, one of which changes very little in geometry and scattering intensity (electron density), characteristics that are both consistent with calcium. This site is in the smaller framework cavity and adjacent to the most aluminum-rich tetrahedra. Thus, it appears that charge-coupling to the framework causes fixation of the divalent calcium ions, which reduces their ability to exchange.

The crystal structures of six omphacites have been refined from $X$-ray data, and one hydrous omphacite from neutron data. The hydrogen position is on the omphacite $\mathrm{O}_{2}$ atom, and the $\mathrm{Si}-\mathrm{O}_{2}$ distance increases and tetrahedral distortion decreases regularly with increasing hydrogen content. This indicates a relatively small molar volume for the hypothetical $\mathrm{HAISi}_{2} \mathrm{O}_{6}$ pyroxene end member, which means that omphacite may serve as a conduit by which hydrogen is recirculated into the mantle in subducting crust.

In a natural hydrous rutile $\left(\mathrm{TiO}_{2}\right)$ of high-pressure origin, neutron and X-ray diffraction data show a 3\%-occupied hydrogen site lying near the short, shared edge of the titanium octahedron. A similar substitution may also occur in the isostructural stishovite. X-ray structural studies of synthetic pure silica and aluminous stishovites show a relative increase in the unit cell edges and in the mean $\mathrm{Si}-\mathrm{O}$ distances with increasing aluminum content. X-ray and neutron structure refinements of natural hydrous clinohumites have locatei the hydrogen position and for the first time have shown that ordering of hydrogen in this structure violates the monoclinic space group $\mathrm{P} 21 / \mathrm{b}$ so that the apparent symmetry is triclinic P-1.

Calculated electrostatic site potentials of hydroxyl and oxygen positions in hydroxyl-bearing silicates show a rough correlation of hydroxyl site potential (assuming a point charge of -1 ) with the oxygen-hydrogen stretching vibration frequency observed in infrared spectra. These studies may lead to a useful predictive model for hydrogen and oxygen stable isotope substitution in silicates that will provide calibration of low-temperature geothermometers. 
GRANTEE:

GRANT:

TITLE:

PERSON IN CHARGE:
UNIVERSITY OF COLORADO

CIRES/Department of Geological Sciences

Boulder, Colorado 80309-0216
DE-FG02-87ER13804

\section{Seismic Absorption in Fluid-Filled Porous Rocks as a Function of Seismic Frequencies, Pressure, and Temperature}

Hartmut Spetzler (303-492-6715; FAX 303-402-1149;

E-mail soetzker_h@cubldr.colorado.edu)
Objectives: The effects of fluids on the complex moduli of porous rocks are being investigated. For monitoring purposes (e.g., in the vicinity of waste sites or in hydrocarbon detection or recovery), it is important to remotely determine the migration of fluids and their chemical and physical properties.

Fluids interact with the rock matrix in diverse ways. Physical properties of fluids, such as viscosity and density, as well as their chemical interaction with the matrix determine the elastic and anelastic properties of the rock-fluid system. By studying the rock properties over a large range in frequency, it appears possible to separate the rate controlling effects of fluid flow on various scales from those resulting from chemical kinetics. A broad-band absorption spectrometer has been designed and built. Absorption $\left(\mathrm{Q}^{-1}\right)$ and Young's modulus (E) measurements can be made from $1 \mathrm{MHz}$ to several hundred $\mathrm{Hz}$ at strain levels on the order of $10^{-6}$, while fluids (gases or liquids) are residing in or flowing through the rock.

Project Description: Measurements have been made on two sandstones: Lyon's Sandstone--porosity 4\%, permeability $<0.01 \mathrm{mD}$ in the axial direction, grain size $\sim 0.3$ to $1 \mathrm{~mm}, \sim 95 \%$ quartz with silica cement, $\sim 4 \%$ feldspar and traces of clay minerals-and Berea Sandstone-porosity $20 \%$, permeability $\sim 400 \mathrm{mD}, 93 \%$ silica, $4 \%$ alumina, and $3 \%$ other minerals, including clay.
Results: The following observations were made.

1. $E$ and $Q^{-1}$ for the dry rocks show little frequency dependence.

2. E and $Q^{-1}$ change drastically when a fluid is added. The higher the fluid saturation, the larger the $Q^{-1}$ and the smaller the E.

3. $\mathrm{Q}^{-1}$ and $\mathrm{E}$ change with time after the addition of fluids. These changes are frequency dependent; that is, the spectra are different at different times.

4. The changes observed in $\mathrm{Q}^{-1}$ and $\mathrm{E}$ were reversible when distilled and deionized water was added. The addition of acetone and subsequent evacuation in a furnace at 25 and $50^{\circ} \mathrm{C}$ caused irreversible changes.

5. In Lyon's Sandstone at water saturation levels below $\sim 80 \%, \mathrm{Q}^{-1}$ increased monotonically with frequency and saturation. At $80 \%$ a pronounced absorption peak occurs at $\sim 0.1 \mathrm{~Hz}$.

6. The frequency dependence of the acetone- contaminated but "dried" rock was the opposite to that of the rock containing water; that is, $\mathrm{Q}^{-1}$ increased toward lower frequencies.

7. Water flowing through Berea Sandstone showed a temporary maximum in $\mathrm{Q}^{-1}$ during the inflow phase. Modeling is in progress to gain an understanding of the observed spectra. 
GRANTEE:

GRANT:

TITLE:

PERSONS IN CHARGE:
COLUMBIA UNIVERSITY

Lamont-Doherty Geological Observatory

Palisades, New York 10964

\section{DE-FG02-86ER13287}

Energetics of Silicate Melts from Thermal-Diffusion Studies

D. Walker and M. C. Johnson

(914-359-2900; FAX 914-365-3183)
Objectives: This research program characterizes mass transport by diffusion in geological fluids in response to thermal, solubility, and/or chemical gradients to obtain quantitative information on the thermodynamic and kinetic properties of multicomponent systems.

Project Description: Thermal diffusion is the phenomenon of chemical migration in response to heat flow along a thermal gradient. The details of this response are conditioned by the thermochemical properties and constitution of the substance. Silicate liquids undergo substantial thermal diffusion (Soret) differentiation, whereas the response in sulfide, carbonate, and aqueous fluids to an imposed temperature gradient is varied. The experimental observations of this differentiation are used to evaluate the form and quantitative values of solution parameters and to quantify ordinary diffusion coefficients, heats of transport, and activation energies of multicomponent liquids. The diffusion, solution, and element partition coefficients determined for these geological fluids form a data base for understanding magmatic crystallization behavior and for evaluating geothermal, ore deposit, and nuclear waste isolation potentials. Thermal and isothermal diffusion experiments are conducted using the 1-atm gas-mixing apparatus, rapid-quench cold seal apparatus up to $0.3 \mathrm{GPa}$, piston cylinder device at pressures between 0.7 and $3.5 \mathrm{GPa}$, and a simplified multianvil device above $3.5 \mathrm{GPa}$. The electron and ion microprobes and the infra- red spectrometer are used in the characterization of experimental run products.

Results: During the past year, we have established an active experimental petrology laboratory for thermal-diffusion work following the PI's move from the L-DEO. Current experimental capabilities include two 1-atm gasmixing furnaces, a rapid-quench cold seal device, two piston cylinder devices, and a Walker multianvil device driven by a 1000-ton Clifton press. Among the research activities of the last year we initiated thermal-diffusion experiments at very high pressure on magmatic silicate liquids in an attempt to use the recovered heats of transport and chemical potentials as monitors of changing speciation with pressure; expanded on our preliminary study of large (4-7\%) mass-dependent oxygen isotope Soret fractionation in silicate liquids at high temperature; documented small $(<1 \%)$ oxygen isotope fractionation under isothermal conditions between liquids of contrasting bulk composition; began studies of Soret separations of water and carbonate species in naturally occurring silicate liquids, discovered that self-diffusivities of silicon and oxygen in basaltic liquid are indistinguishable, suggesting cooperative diffusion of these species; expanded our theoretical treatment of chemical diffusion using Darken's theory of ion mobility; and initiated a comprehensive characterization of thermal, self-, and chemical diffusion of multicomponent liquids of the system $\mathrm{CaO}-\mathrm{MgO}-\mathrm{SiO}_{2}$. 


\section{GRANTEE:}

GRANT:

TITLE:

PERSONS IN CHARGE:
UNIVERSITY OF DELAWARE

Department of Chemistry and Biochemistry

Newark, Delaware 19716

\section{Development of an Experimental Data Base and Theories for Prediction of Thermodynamic Properties of Aqueous Electrolytes and Nonelectrolytes of Geochemical Significance at Supercritical Temperatures and Pressures}

Objectives: The objective of this research is to measure heat capacities and volumes of key compounds of importance to predictions of geochemical phenomena at high temperatures and pressures. A second objective is to use the key compounds as a data base together with simulations to develop empirical and theoretical methods for predicting a wide variety of other compounds.

Project Description: Measurements of volumes and heat capacities of a wide variely of organic electrolytes and nonelectrolytes at temperatures from 25 to $325^{\circ} \mathrm{C}$ will be made. This will allow the development of group additivity schemes to predict a very wide variety of organic species containing these functional groups. Previous measurements on $\mathrm{H}_{2} \mathrm{~S}, \mathrm{CO}_{2}, \mathrm{CH}_{4}, \mathrm{NH}_{3}$, and $\mathrm{H}_{3} \mathrm{BO}_{3}$ are being analyzed to find correlations that can predict other species. Molecular dynamics simulations of the chemical potential of aqueous methane, ethane, and propane at temperatures from 600 to $1200^{\circ} \mathrm{C}$ and water densities from 0 to $1 \mathrm{~g} / \mathrm{cm}^{3}$ have been made. Revisions of the equations of state for aqueous ions and nonelectrolytes to allow better predic- tions of properties at high temperatures and pressures will be developed.

Results: The volumes of 1-propanol, propanoic acid, pyridine, 1,4-butanediol, propylamine, adipic acid, succinic acid, propionamide, 1,6-hexanediol, 1,4-butanediamine, 1,6-hexanediamine, phenol, sodium acetate, propylamine hydrochloride, sodium propionate, and sodium benzenesulfonate have been measured at temperatures up to $250^{\circ} \mathrm{C}$. Measurements of the heat capacities are in progress. Results of the comparison of the Born model and the compressible continuum model to data on aqueous electrolytes up to $420^{\circ} \mathrm{C}$ and with simulations of the chloride ion in water at $450^{\circ} \mathrm{C}$ and $0.012 \mathrm{~g} / \mathrm{cm}^{3}$, as well as $727^{\circ} \mathrm{C}$ and $0.35 \mathrm{~g} / \mathrm{cm}^{3}$, are being written up for publication. It has been found that the equation of Harvey, Sengers, and Tanger is much more accurate in the critical region than that of Shock et al. If we know the volumes we can quite accurately estimate the heat capacities of these substances. There are also reasonable correlations of the magnitude of the critical effects, both volume and heat capacity, with critical points and Henry's law constants. 
GRANTEE:

GRANT:

TITLE:

PERSONS IN CHARGE:

\section{EARTH RESOURCES LABORATORY}

Department of Earth, Atmospheric, and Planetary Sciences

Massachusetts Institute of Technology

Cambridge, Massachusetts 02139
DE-FG02-86ER14084

\section{Reservoir Characterization by Cross Hole Measurements}

Roger M. Turpening (617-253-7850; FAX 617-253-6385;

E-mail roger@erl.mit.edu) and N. Nafi Toksoz (617-253-7852;

FAX 617-253-6385)
Objectives: The objective of this research is to tomographically image a known hydrocarbon reservoir at usual depths and at conventional well spacings. This required the development of a new nonlinear tomographic imaging algorithm.

Project Description: Data acquisition and theoretical efforts proceeded simultaneously. The field effort involved the collection of a large $(40,000)$ ray paths), high-frequency $(>1 \mathrm{kHz})$ data set between the two boreholes at the Massachusetts Institute of Technology's Michigan Test Site in the state's Northern Reef Trend. The survey was centered on the oil-bearing reef that exists between the holes. Important ancillary data such as acoustic logs, engineering data, gyroscopic surveys, and reservoir production data were also collected.

At the same time, algorithm development was taking place. A nonlinear tomographic imaging code was written that also provides estimates of the resolution and errors in the final image; it was based on the Tikhonov regularization for stability. A graph theoretical "ray-tracing" scheme, optimized for MIMD massively parallel computers, was used as the fundamental modeling method.

Results: After data handling, data processing, and travel time picking images of the reservoir (a reef) were produced with accompanying estimates of resolution, as a function of position in the image and error of the image (the image is a map of velocity) as a function of position in the image. The images clearly show a low-velocity zone inside the reef. We know the position of the original oil water contact (1977) and the location of all perforation intervals and these fit very well with the observed lowvelocity zone. 
GRANTEE:

GRANT:

TITLE:

PERSON IN CHARGE:
UNIVERSITY OF HOUSTON

Houston Petroleum Research Center

Houston, Texas 77204-4231

DE-FG05-89ER14058
Cross Hole Geotomography in a Partially Depleted Reservoir

J. A. McDonald (713-743-9150; FAX 713-743-9164; E-mail west76@archie.agl.uh.edu)
Objectives: Research efforts have focused on methods of lithology indication using cross hole seismic methods. Two experiments have been successfully completed that are able to distinguish lithological variations in producing oil fields at 10-ft-depth increments.

Results: Experimental results from a shallow, clastic reservoir show $Q$ variations that correlate with a layered sequence of sandstones and shales. A second experiment in a carbonate reservoir shows that $V_{p} / V_{s}$ and amplitude analysis are able to distinguish lithological variations and delineate a fluid-filled zone at a well spacing of $1000 \mathrm{ft}$.

Crosswell $Q$ in shallow clastics. $Q$ estimates have been made from a set of high-frequency cross hole data recorded in a shallow, clastic sequence in a south Texas oil field. Using a piezoelectric "bender" as a downhole energy source, data were recorded over a $27-\mathrm{m}$ (90-ft) depth interval in 3-m (10-ft) increments. Measurements were made using three inline wells to provide data sets at offsets of 15 and $61 \mathrm{~m} \mathrm{(50} \mathrm{and} 200 \mathrm{ft})$. Q values were calculated using the spectral ratio method.

The bender input was a single-cycle sine wave at frequencies ranging from 500 to $3500 \mathrm{~Hz}$. Q was calculated for each frequency at every depth. Average $Q$ values ranged from 43 to 128 .

A comparison of $Q$ estimates with a resistivity log shows a clear, inverse correlation. High $Q$ values have been interpreted as indicating shale layers and low $Q$ values as sandstones. Previous attenuation studies using vertically propagating waves in unconsolidated clastics have shown lower $Q$ values for shales. High crosswell $Q$ values are attributed to horizontal wave propagation in the intrinsically horizontally layered shales.
The correlation of $Q$ values with well log data suggests that attenuation measurements using horizontally propagating waves can be a sensitive indicator of lithology over much smaller depth intervals than is possible with vertically propagating waves.

Crosswell $V_{P} N_{s}$ as a lithology indicator. Lithology measurements using CMP or vertical seismic profiling (VSP) methods necessarily average across typically horizontally layered formations. Cross hole methods, on the other hand, are able to make use of horizontally propagating waves that have the potential to avoid this averaging.

$\mathrm{V}_{\mathrm{p}} / \mathrm{V}_{\mathrm{s}}$ estimates and amplitude analyses from a cross hole data log recorded in a carbonate reservoir in the Permian Basin of west Texas show good correlation with a well $\log$ and other geological data. The cross hole log consists of horizontal raypath traces recorded with a piezoelectric "bender" source and receiver elements at 3-m (10-ft) depth increments. Well separation is $304 \mathrm{~m}$ (996 ft), and the recorded data contain frequencies up to the cutoff frequency of $3000 \mathrm{~Hz}$ even at this long offset.

A comparison of $\mathrm{V}_{\mathrm{p}} / \mathrm{V}_{\mathrm{s}}$ with the porosity $\log$ from the receiver well shows a clear inverse correlation. This suggests that crosshole $V_{p} / V_{s}$ measurements have the potential for higher spatial resolution of lithology variations than typical VSP or CMP methods.

Additional calculations of $\mathrm{P}$-wave and S-wave amplitude ratios $\left(A_{p} / A_{s}\right)$ from the same data set show two distinct regions. The region of high $\mathrm{A}_{\mathrm{p}} / \mathrm{A}_{\mathrm{s}}$ values has been interpreted as indicating a fluid-filled zone. This has subsequently been confirmed by independent geological analysis. 
GRANTEE:

GRANT:

TITLE:

PERSON IN CHARGE:
INDIANA UNIVERSITY

Department of Chemistry

Bloomington, Indiana 47405

\section{Mechanochemical Self-Organization and Nonlinear Dynamics in Sedimentary Basins}

P. Ortoleva (812-855-2717; FAX 812-855-8300;

E-mail ortoleva@ucs.indiana.edu)

Objectives: A sedimentary basin is viewed as a nonequilibrium reaction-transport-mechanical system. As a result, phenomena such as reaction front fingering, stylolites, diagenetic bedding, and episodic fluid release from overpressured domains are put in the unified framework of instability, and nonlinear dynamics and implications for petroleum are drawn.

Project Description: These phenomena are modeled and simulated numerically. Rate laws for stress-mediated reactions and the dependence of rock rheology, permeability, and dispersion on texture, mineralogy, and fracture parameters are set forth. A quantitative model is constructed based on equations of conservation of mass, force balance, and incremental stress rheology. The models are simulated numerically, and when small-scale features (such as stylolites, differentiated layering, or fractures) affect the basin-scale dynamics, then homogenization techniques are used to make the calculations practical. Parallel numerical algorithms are also developed and $\mathrm{im}$ plemented.

Results: A quantitative model coupling water film diffusion or free face pressure solution rates to supra grain scale diffusion and poroelasticity was used to explain compaction, stylolites, and diagenetically differentiated bedding phenomena in sandstones; effects of clay and pressure of crystallization were also investigated. Homogenization equations for the coupled evolution of sub-meter scale features and basin scale stresses and flows are simulated on a massively parallel platform.

A model of compaction and thermal fluid expansion coupled to hydrofracturing was shown to explain episodic fluid release from the overpressured region through a repetitive cycle. This phenomenon was simulated and shown to be an expression of a Hopf bifurcation to a limit cycle oscillation involving an undulation of the top of overpressure and the fracture front upward through incoming sediment during periods of sufficiently rapid burial.

General basin diagenesis simulators are being developed. The sedimentary basin was shown to be an active site of self-organization and nonlinear phenomena; repetitive textural banding and complex patterns of mineral dissolution and precipitation and of fracturing were explained and shown not to be explicable in terms of classical notions of patterns imposed by a template of sedimentology, fault activity, or other external influences acting on the basin. 
GRANTEE:
THE JOHNS HOPKINS UNIVERSITY

(Subcontract-Lehigh University)

Department of Earth and Planetary Sciences

34th and Charles St.

Baltimore, Maryland 21218
TITLE: $\quad$ High-Resolution Transmission Electron Microscopy/Analytical

\section{GRANT: $\quad$ DE-FG02-89ER14074} Electron Microscopy and Scanning Electron Microscopy Study of Fluid-Rock Interactions: Interaction of Copper-, Silver-, Selenium-, Chromium-, and Cadmium-Bearing Solutions with Geological Materials at Near-Surface Conditions, with an Emphasis on Phyllosilicates
D. R. Veblen (410-516-8487; FAX 410-516-7933) and

E. S. IIton (215-758-5834; FAX 215-758-3677)
Objectives: Oxidation-reduction reactions at the mineral-fluid interface can be responsible for the attenuation or mobilization of multivalent elements in the near-surface environment. This project involves investigation of the interaction of silver-, copper-, selenium $\left(\mathrm{Se}^{4+}\right.$ and $\left.\mathrm{Se}^{6+}\right)$-, and chromium $\left(\mathrm{Cr}^{6+}\right)$-bearing solutions with ferrous phyllosilicates such as biotite, a potential reducing agent, under both oxic and anoxic conditions.

Project Description: Reduced forms of selenium and chromium are less toxic than oxidized forms. The reduction of copper and silver during weathering can be an important process in the supergene enrichment of both these elements. Biotite containing ferrous iron was chosen for initial study because it is a ubiquitous, potential reducing agent in rocks and soils; ferrous iron in biotite can be a stronger reducing agent than $\mathrm{Fe}^{2+}{ }_{\text {ial }}$. Moreover, biotite is capable of simultaneously absorbing and reducing metals (as previously shown for copper and silver). The sorption of cadmium by phyllosilicates is also being studied. Whereas cadrnium is not involved in oxidation-reduction reactions, the sorption of cadmium by phyllosilicates has never been characterized with transmission electron microscopy (TEM).

The objectives of the experimental work are to examine the surfaces and interior portions of the reacted phyllosilicates with TEM, analytical electron microscopy, scanning electron microscopy, and X-ray photoelectron spectroscopy (XPS). The combination of these techniques will help to determine the oxidation state and form of the sorbed species. This information provides constraints on the physical and chemical conditions that are required for mobilization of attenuation of these elements from or by phyllosilicates.

Results: This past year, work was focused on the sorption of both $\mathrm{Cr}(\mathrm{VI})_{\mathrm{iq}}$ and $\mathrm{Cr}(\mathrm{III})_{\mathrm{ay}}$ by phlogopite and biotite. XPS analyses of micas demonstrate that $\mathrm{Cr}(\mathrm{VI})_{\text {ia }}$ can be strongly sorbed and reduced to $\mathrm{Cr}$ (III) at the biotite edge-fluid interface but not at phlogopite surfaces and that scrbed-reduced chromium is strongly enriched on the edge surfaces relative to the basal planes. In contrast, there is little fractionation of $\mathrm{Cr}(\mathrm{III})$ aq between biotite and phlogopite or between edge surfaces and basal planes. Highresolution TEM observations indicate that sheet terminations are enriched in chromium, but that there are no chromium-rich phases. This shows that chromium was sorbed by the micas and did not precipitate from solution. Interestingly, $\mathrm{Cr}$ (III) was strongly enriched on biotite edges that were reacted with $\mathrm{Cr}(\mathrm{VI})_{\mathrm{aq}}$-bearing solutions relative to $\mathrm{Cr}(\mathrm{III})_{\mathrm{aq}}$-bearing solutions, despite the fact that there was orders of magnitude more $\mathrm{Cr}(\mathrm{III})_{\mathrm{aq}}$ in the trivalent chromium solutions than in the hexavalent chromium solutions. XPS analyses indicate that near-surface iron is more oxidized in biotites reacted with $\mathrm{Cr}(\mathrm{VI})_{\mathrm{aq}}$ than with $\mathrm{Cr}(\mathrm{III})_{\text {aq. }}$. Further, the degree of iron oxidation is proportional to the concentration of $\mathrm{Cr}(\mathrm{VI})_{\mathrm{aq}}$. The XPS work on iron has spawned a "spin-off" project that involves developing XPS into an in situ microbeam technique for determining $\mathrm{Fe}(\mathrm{II}) / \mathrm{Fe}(\mathrm{III})$ ratios in minerals in thin sections. 


\section{GRANTEE:}

GRANT:

TITLE:

\author{
LEHIGH UNIVERSITY \\ Department of Earth and Environmental Sciences \\ Bethlehem, Pennsylvania 18015
}

DE-FG02-93ER14373

\author{
Surface and Solution-Interface Geochemistry of Lead Sulfide \\ and Lead Selenide Minerals
}

PERSON IN CHARGE:

Carl O. Moses (215-758-4907)

Objectives: This project will evaluate the aqueous reactivity of sulfide minerals and their selenide analogues, in particular, the rates and mechanisms of metal, sulfur, and selenium release during weathering and the mechanisms of metal, sulfur, and selenium adsorption at the sulfide/selenide mineral-solution interface.

Project Description: Sulfide minerals play important roles in determining the distribution and mobility of metals and sulfur in the hydrosphere. The research goals of this project include characterizing surface stoichiometry, determining the depth of surface-chemical alterations during gas- or solution-phase exposures, identifying changes in surface morphology during exposures, determining the scope of environmental controls on exchange and release rates, and establishing reaction mechanisms for exchange and dissolution. The approach is to integrate surface inves- tigations using electron optics and spectroscopy with wet geochemical investigations of processes at the mineral-solution interface and focuses on how composition variations in both bulk phases (mineral and solution) influence the properties and reactivity of the sulfide/selenide mineralsolution interface. A key first step in the research is to synthesize pure and metal-substituted $\mathrm{PbS}, \mathrm{PbSe}$, and $\mathrm{PbS}-\mathrm{PbSe}$ solid solution mineral phases. The surfaces of these starting samples will then be characterized using scanning electron microscopy and X-ray photoelectron spectroscopy. The mineral-aqueous solution interface characteristics and mass transfer rates will then be measured using wet chemical methods to determine exchange reactions and dissolution rates.

Results: This project began September I, 1993. 
GRANTEE:

GRANT:

TITLE:

PERSONS IN CHARGE:
LOUISIANA STATE UNIVERSITY

Department of Geology \& Geophysics

Baton Rouge, Louisiana 70803-4101
DE-FG05-87ER13748

\section{Organic/Inorganic Interactions of Nitmgen in Oil Fields Part II: Mineralogy and Microbiology}

\author{
R. E. Ferrell (504-388-5306; FAX 504-388-2302;
}

E-mail glferr@lsuvax.sncc.lsu.edu) and M. Walsh

(504-388-4285; E-mail evwals@lsuvm.sncc.lsu.edu)
Objectives: Evaluate the hypothesis that nitrogen derived from maturing organic matter and migrating oil and gas has a unique isotopic signature that is recorded in diagenetic illite/smectite.

Project Description: Samples from representative lithologies and stratigraphic intervals of the Eocene Wilcox Formation in Fordoche Field and other locations in central Louisiana are the basic materials used in this study. They are being analyzed by X-ray diffraction (XRD) and other techniques to identify the minerals present and to assess diagenetic changes affecting the clay minerals. Quantitative mineralogical interpretations provide basic data for the identification of nitrogen anomalies. Selected samples are being tested to identify the types of bacteria present and to evaluate their potential role in the fixation of nitrogen in diagenetic minerals. The data provide basic support for the companion project conducted by Lynda Williams of Arizona State University (Part I: Geuchemistry, agreement No. DE-FG02-91ER 14218).

Results: Samples of formation waters and 22 samples from drilled core from Fordoche Field were collected and examined for bacterial content using modified soil microbiology methods. After three weeks of incubation, only one set of samples (El Plant samples from 13,675 ft; W-12 sandstone gas reservoir) showed signs of bacterial growth. All bacterial isolates are very small gram-negative rods. Tests indicate that all three types grow more quickly at $55^{\circ} \mathrm{C}$ than at $30^{\circ} \mathrm{C}$, suggesting that they were indeed living in the subsurface. Biolog microplates, which assess carbon source utilization capabilities, were used for initial taxonomic screening. All three bacterial isolates showed dif- ferent metabolic capabilities, suggesting that they are not the same bacteria. None of the isolates was matched to a known bacterium in the data base. Tests for nitrifying and denitrifying activity by bacteria were negative.

Approximately 160 samples have been collected from Fordoche Field. XRD analyses of the whole-rock sample powders for 139 of these have been completed, and the tabulated results of mineral abundance have been transmitted to Lynda Williams. The clay fraction has been extracted from 84 of these samples, and XRD patterns (air dried, ethylene glycol saturated, heated to $300^{\circ} \mathrm{C}$, heated to $550^{\circ} \mathrm{C}$ ) of smear mounts have been obtained but not thoroughly interpreted.

Corrected intensity ratios for the whole-rock samples reveal the presence of 10 to $20 \mathrm{wt} \%$ clay minerals. Quartz, feldspars, and carbonates are the other minerals present in samples from Fordoche Field. Clay mineral assemblages are dominated by kaolinite/chlorite. Many samples contain minor quantities of detrital mica and an $\mathrm{R}=1$ illite/ smectite with about 20 to $30 \%$ expandable layers. Quantitative evaluation of these peaks is accomplished by comparing them to theoretical patterns calculated by the NEWMOD procedure, and a least-squares minimalization routine has been written to assess the "goodness-of-fit" of the actual and observed XRD patterns. This provides better ways to estimate the quantities of diagenetic illite associated with the fixation of $\mathrm{NH}_{4}$. Thirty of the clay samples have been analyzed by Fourier transform infrared spectroscopy in an attempt to further assess the applicability of this technique for the simultaneous determination of diagenetic illite and fixed $\mathrm{NH}_{4}$. 


\section{GRANTEE:}

TITLE:

PERSONS IN CHARGE:

\section{GRANT:}

MASSACHUSETTS INSTITUTE OF TECHNOLOGY

Department of Earth, Atmospheric, and Planetary Sciences

Cambridge, Massachusetts 02139

\section{DE-FG02-86ER13636}

\section{In Situ Permeability Determination Using Borehole and Seismic Logging Data}

\author{
N. Nafi Toksoz (617-253-7852; FAX 617-253-6385; \\ E-mail nafi@erl.mit.edu) and \\ C. H. Arthur Cheng (617-253-7206; FAX 617-253-6385; \\ E-mail cheng@erl.mit.edu)
}

Objectives: The objective of this project is to identify, locate, and characterize in situ fractures using downhole and surface seismic methods. The goal is to estimate the permeability of these fractures from the way they interact with seismic waves.

Project Description: The purpose of this work is to study methods of determining in situ permeability or hydraulic conductivity of a fracture or fracture zone using full waveform and shear wave acoustic logging, vertical seismic profiling, and other downhole, crosshole, and seismic imaging techniques. In addition, methods to determine the orientation and extent of natural and human-made fractures are studied. The behavior of full waveform and shear wave logs in a fractured medium is studied using numerical models, laboratory scale model experiments and field data. The method of locating a hydrofrac using microearthquake arrival time is being improved by relative and absolute location techniques. The aim is to characterize and image in situ fractures for the purpose of hydrocarbon production from naturally or artificially fractured reservoirs, nuclear waste disposal planning, and geothermal energy recovery.

Results: In the past year, full waveform and shear wave logging data from a fractured formation were ana- lyzed. Results indicate that the estimated permeability from the Stoneley wave is consistent with core permeability. In addition, there are strong indications of formation shear wave anisotropy in the fractured formation. The shear wave velocity obtained from the inversion of the Stoneley wave data is not consistent with the dipole shear wave measurements in the fractured formation. It is believed that the Stoneley wave is more influenced by the slow shear wave whereas the dipole shear wave measurement is more influenced by the fast shear wave. This observation is confirmed in the laboratory by making scale borehole measurements in an anisotropic material. Thus a combination of the full waveiorm and shear wave log gives a measure of formation anisotropy, although the direction of the anisotropy is not obtainable from this particular data set.

Another part of the fracture characterization project involves the use of microearthquake arrival times to image the location of a hydrofrac. A combination of relative and absolute location techniques were used to locate clusters of microearthquakes, with the results far superior to those using absolute locations alone. 
GRANTEE:

GRANT:

TITLE:

PERSONS IN CHARGE:
UNIVERSITY OF MIAMI

Rosenstiel School of Marine \& Atmospheric Sciences

Miami, Florida 33149

DE-FG05-92ER 14253

Testing the Correlation Between Sequence Stratigraphy, Seismic Reflectors, and Diagenetic Changes in Carbonates: Implication for the Distribution of Porosity and Permeability
G. Eherli (305-361-4678; E-mail eberli@rcf.rsmas.miami.edu) and
P. K. Swart (305-361-4103; FAX 305-361-4632;
E-mail swart@raf.rsmas.miami.edu)

Objectives: To understand the origin of seismic reflectors and their relationship to the sediment composition, early and late diagenesis, and the development of porosity.

Project Description: The recovery of two continuous cores from the western margin of Great Bahama Bank has allowed an excellent opportunity to study the relationship between seismic character and sediment composition and diagenesis. These two cores (recovery $>80 \%$ ) can be correlated to a multichannel seismic line using wire-line logs and a vertical seismic profile. We are performing a detailed sequence stratigraphic aralysis of the seismic and well-log data and examining the diagenesis relative to the stratal geometry and sea level changes. To understand the relationship between diagenesis and rock properties we are conducting a study of the paragenesis of the sediments in combination with experimental physical property measurements.

Results: Initial correlation suggests that both the sediment composition and diagenesis are responsible for development of seismic reflectors. For example, in the following figure it can be seen that the principal seismic boundaries are coincident with large changes in the mineralogy, which are in turn coincident with facies changes. Results from physical property analyses on discrete samples show that sonic velocity in carbonates is controlled by the combined effect of (1) the depositional lithology and (2) the diagenetic alteration that affects porosity and pore types. The development of specific pore types during diagenesis explains the large variability of the sonic velocity at certain porosity values. Based on strontium-isotopic analyses and a paragenetic sequence, developed from thin-section work, we have concluded that the majority of

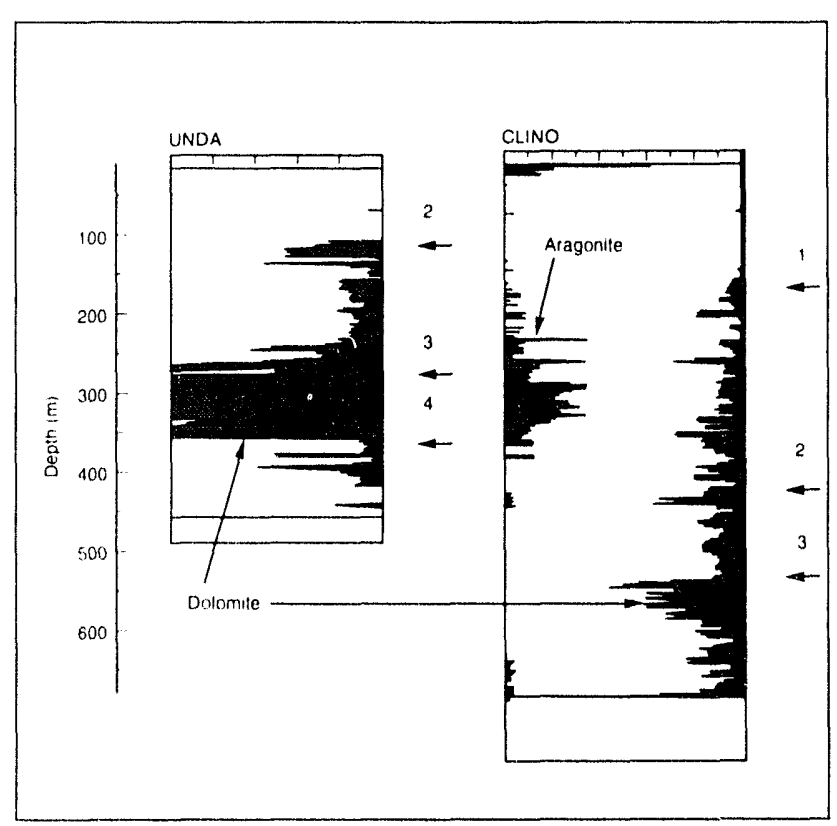

Mineralogy ( 100 to $0 \%$ dolomite; 0 to $100 \%$ aragonite; IMC center) and location of principal sequence boundaries in the studied cores. Note the coincidence of sequence boundaries (marked with arrows) with mineralogy changes.

the mineralogic changes occurred early. This suggests that if the stratal pattern is the result of changing sea-level, then diagenesislike facies may be related to sea-level fluctuations and may follow a predictable pattern. Such information is essential for development of better understanding of the properties of oil-bearing carbonates and will lead to enhanced predictive capabilities for the distribution of porosity and permeability in carbonates. 
GRANTEE:

GRANT:

TITLE:

PERSONS IN CHARGE:
MINERALOGIC SOCIETY OF AMERICA

Suite 330, 113017 th Street NW

Washington, D.C. 20036

\section{DE-FG02-93ER14399}

Workshop on Health Effects of Mineral Dusts

George Guthrie, Los Alamos National Laboratory (505-665-3285), and

Susan L. Meyers, Mineralogic Society of America (202-775-0018)

Objectives: The project will facilitate a two-and-ahalf-day short course/workshop in conjunction with the Geological Society of America and Mineralogic Society of America Meeting in October 1993.

Project Description: The purpose of this short course/workshop is to provide health scientists with both the fundamental understanding of the mineralogy of hazardous dusts and an introduction to the information that can be obtained from modern mineralogic techniques. A second purpose is to provide geoscientists with current information concerning the health effects of inhaled dusts, thereby allowing them to evaluate this research firsthand and to identify important mineralogic issues. Half of the presenters will be medical disease specialists and the other half will be mineralogists. This workshop represents an integration of forefront research in the fields of medical research and geochemistry. This project is co-funded with Health Effects and Life Sciences Research.

Results: This project began September 15, 1993. The workshop is to be held in October 1993. 
GRANTEE:

GRANT:

TITLE:

PERSON IN CHARGE:

\author{
UNIVERSITY OF MINNESOTA, TWIN CITIES \\ Department of Geology and Geophysics \\ Minneapolis, Minnesota 55455
}

DE-FG02-91ER14212

Physical Modeling of Sedimentary Basins, Magma Mechanics, and Molecular Dynamics of Geological Solutions

\author{
D. A. Yuen (612-624-1868; FAX 612-624-8861; \\ E-mail davey@krissy.msi.umn.edu)
}

Objectives: Objectives of this project are to

1. compute selected thermodynamic and transport properties of silicate melts and water,

2. simulate the lithospheric thinning process with Newtonian and non-Newtonian temperature-dependent rheology within the framework of thermal convection,

3 . investigate the role played by lithospheric phase transitions in the thermal subsidence of sedimentary basins, and

4. investigate stress fields of the lithosphere from numerical simulations of convective processes.

Project Description: Transport of mass, momentum, heat, and chemical species at both macroscopic and microscopic scales in the crust is vital to understanding the evolution of magmatic and sedimentary basin systems. This work involves a number of projects including the molecular dynamics of silicate melts and water to understand the relationship between properties and structure, simulations of the dynamics of variable viscosity and non-Newtonian rheology and its consequences on li- thospheric thinning, quantitative assessments of the stress fields developed in the lithosphere from convection in vertically stratified rheological media, and simulations of the effects of lithospheric phase transitions on the subsidence in sedimentary basins following rifting.

Results: The effects of composition on the transport and thermodynamic properties of $\mathrm{MgO}-\mathrm{SiO}_{2}$ suggest the possible existence of immiscibility at low pressures. The calculated compositional dependence of shear viscosity differs significantly from that expected from the StokesEinstein relationship. The infrared spectrum is shifted towards lower frequencies with increasing pressure. A polarizable dissociating molecular dynamics model for liquid water has been developed. Lithospheric thinning has been found to be facilitated by the presence of non-Newtonian temperature-dependent viscosity. The presence of lithospheric phase transitions can offer a correction term to the stretching factor of sedimentary basin models. Smaller stretching factors result from these effects. Pulsating diapirs can cause local stress concentration in the lithosphere of 5 to 10 times the background value and result in the breakup of the weak lithosphereic upper layer. 
GRANTEE:

GRANT:

TITLE:

PERSONS IN CHARGE:

\section{NATIONAL ACADEMY OF SCIENCES}

National Research Council

Washington, D.C. 20418

DE-FG05-89ER14061

Basic Energy Sciences Studies

Jonathan G. Price (202-334-2744; FAX 202-334-1377;

E-mail jprice@nas.edu) and Thomas M. Usselman
Objectives: The Board on Earth Sciences and Resources coordinates the National Research Council's advice to the federal government on solid-earth science issues. These issues range from identifying and enunciating opportunities for advancing basic research and understanding and applying that information for disaster mitigation and resource utilization to analyzing the scientific underpinnings and credibility of earth science information for resource, environmental, and other policy applications and decisions.

Project Description: Committees of the board conduct studies and address specific issues within the earth sciences. The Committee on Earth Resources deals primarily with national energy and mineral resource issues. The U.S. Geodynamics Committee fosters and encourages studies of the dynamic behavior of the Earth and serves as the U.S. counterpart to the International Lithosphere Program. The Committee on Geodesy emphasizes the basic research opportunities and applications of geodetic data to the solution of problems in oceanographic, geophysical, and other earth sciences. The Mapping Science Committee investigates scientific and technical matters related to spatial data handling and analysis, including geographic information systems. The Committee on Seismology analyzes major trends in seismology and conducts studies in areas such as earthquake hazards, structure of the earth's deep interior, and seismic verification of adherence to nuclear test ban treaties. The Committee on Geophysical and Environmental Data advises federal agencies and relevant U.S. data centers on national and international data policies and services, chiefly from the perspective of scientific users, and works closely with the federal Interagency Working Group on Data Management for Global Change. Additional committees and panels are formed to address specitic topics.

Results: The U.S. Geodynamics Committee is completing two repurts, the National Geomagnetic Initiative and Mount Rainier, a Decade Volcano. Two Studies in Geophysics, Global Surficial Geofluxes: Modern to Glacial and The Effects of Past Global Change on Life, are in preparation. The Committee on Status and Research Objectives in the Solid-Earth Sciences: ACritical Assessment completed its report Solid-Earth Sciences and Society in February 1993. The Committee on Geodesy conducted a workshop on Airborne Geophysics in July 1993; a report on the workshop is forthcoming. In May 1993 the Mapping Science Committee issued a report entitled Toward a Coordinated Spatial Data Infrastructure for the Nation. The committee is working on two new reports: National Spatial Data Infrastructure: Core Data and National Spatial Data Infrastructure: State Partnerships. A panel of the Committee on Seismology is reviewing hazard estimates for nuclear power plants. The Committee on Geophysical and Environmental Data reviewed the National Space Science Data Center and the National Climatic Data Center. Three other committees are also preparing reports: the Committee on Advanced Drilling Technologies (jointly with the Geotechnical Board), the Committee to Review Alaskan Outer Continental Shelf Environmental Information (jointly with the Board on Environmental Studies and Toxicology), and the Committee on Nautical Charting (jointly with the Marine Board). A newly formed committee is conducting a study on Rediscovering Geography: New Relevance for the New Century (jointly with the Commission on Behavioral and Social Sciences and Education).

The Board also coordinates activities of various U.S. national committees, including those for the International Union of Geodesy and Geophysics, the International Union of Geological Sciences, the International Geographical Union, and the International Union of Quaternary Research. 
GRANTEE:

PIRSON IN CHARGE:
TITLE:

\section{GRANT:}

UNIVERSITY OF NEW' MEXICO

Department of Earth and Planetary Sciences

Albuquerque, New Mexico 87131-1116

\section{DE-FG03-92ER14296}

\section{Impact Deposits at the Manson Impact Structure: Diagenesis and Postimpact Thermal History}

\author{
L. J. Crossey (505-277-5349; FAX 505-277-8843; \\ E-mail lcrossey@unmb.unm.edu)
}

Objectives: The objectives of the study are to provide a detailed description of authigenic and alteration mineralogy from diverse lithologies encountered in several Continental Scientific Drilling Program cores from the Manson impact structure (drilled 1992-1993).

Project Description: Core materials from the Manson impact site (Manson, Iowa) will be examined to evaluate postimpact alteration processes. Diagenetic interpretation of alteration will be based on petrologic, mineralogic, and geochemical investigations of core materials, including target strata, disturbed and disrupted strata, ejecta, breccias, microbreccias, and impact melt. The study of multiple cores will permit development of a regional model of postimpact history. In addition to standard petrographic techniques, $\mathrm{X}$-ray diffraction analysis of fine-grained separates will be employed for mineral identification. Textural analysis will be performed with scanning electron microscopy (including energy-dispersive $\mathrm{X}$-ray analysis) of fracture surfaces, vugs, and pores within breccia matrix. Geochemical analyses of authigenic phases will be obtained through electron microprobe analysis of selected samples.

Results: Two-hundred fifty samples have been obtained from four holes drilled at the Manson impact site. Samples are categorized as Type I (a systematic downhole coverage of each lithology encountered in the core) and
Type II (veins, fracture surfaces, and vugs). Lithologies encountered include sedimentary clast breccias and crystalline clast breccias (of two types: a high-temperature "melt matrix" with abundant recrystallized clasts, and lower-temperature "sandy matrix" material, still bearing numerous shock features). X-ray diffraction analysis of fine-grained matrix separates from Type I samples reveals ubiquitous expandable mixed-layer clays, with systematic variations in proportion of chlorite. Preliminary trace-element geochemical analysis (performed in collaboration with Randy Korotev of Washington University, St. Louis, Missouri) reveals distinct differences between the two types of crystalline clast breccias. "Melt" matrix breccias are more homogeneous than "sandy" matrix breccias; are consistently lower in $\mathrm{Fe}, \mathrm{Sc}, \mathrm{Cr}$, and $\mathrm{Na}$; and are higher in $\mathrm{Rb}, \mathrm{K}, \mathrm{Cs}$. Petrographic analysis and scanning electron microscopy of Type II samples indicates a phase of hightemperature alteration (depositicn of minerals including laumontite and ferroactinolite in fractures and vugs). Quartz, chlorite, expandable mixed-layer clays, calcite, pyrite, and gypsum have also been noted, with chlorite co-precipitating with quartz, and calcite consistently a late-stage product. Preliminary models of the thermal history of the site indicate that the thermal influence of the central uplift, in addition to impact melt, is significant in development of a hydrothermal system. 
GRANTEE:

GRANT:

TITLE:

PERSON IN CHARGE:
THE CITY COLLEGE OF THE CITY UNIVERSITY

OF NEW YORK

Benjamin Levich Institute and Department of Physics

New York, New York 10031
DE-FG02-93ER14327

Stochastic Transport in Heterogeneous Flows and Media

Joel Koplik (212-650-8162; FAX 212-650-6835;

E-mail koplik@sci.ccny.cuny.edu)
Objectives: We will obtain a description of the transport of passive tracer in flow through porous media with highly-correlated strong disorder, relating measurable tracer characteristics to the geometry and statistical description of the reservoir.

Project Description: This research will seek a better understanding of fundamental physical laws that govern stochastic transport processes in heterogeneous media with macroscopically correlated disorder. For composites with "block" disorder, conventional macroscopic transpert equations generally do not apply, and we will attempt to formulate the appropriate composition laws that permit a macroscopic description of transport in such systems. The superdiffusive motion of Brownian particles in a randomly stratified flow field will then be investigated. Steady-state and first-passage characteristics of this system appear to be controlled by exceptional fluctuations, leading to a multiplicity of basic time scales in the system. We plan theoretical and numerical studies to determine the appropriate macroscopic description. We will also explore the unusual transport properties of Brownian particles that are driven by prototypical random flow fields. Finally, we propose to examine the first-passage characteristics in source-sink flow, where the interplay between spatially varying convection and molecular diffusion are anticipated to yield unusual first-passage properties. We will extend these studies to fractured media, where fast transport in fractures competes in a subtle way with slow transport modes. These latter studies will be closely tied to ongoing experimental work and will also involve largescale simulations on parallel processors.

Results: This project began in March 1993. 
GRANTEE:

GRANT:

TITLE:

PERSON IN CHARGE:
CITY UNIVERSITY OF NEW YORK, QUEENS COLLEGE

Department of Geology

Flushing, New York 11367-0904

DE-FG02-88ER13961

Evaporites as a Source for Oil

B. C. Schreiber (718-997-3300; FAX 718-997-3349)

Objectives: An appropriate geological model was chosen from the Neogene sediments of southeastern Spain in which a test was carried out showing the relationship between organic matter and evaporitic sedimentation. In this region are several intermontane basins that contain marine sequences that became increasingly restricted over a comparatively short span of time and are capped by gypsum and halite. The Lorca Basin was chosen, containing open marine marls, evaporites and intercalated organic-rich sediments (up to $25 \%$ total organic carbon), and estuarine/continental sands and marls.

In this basin the depositional section includes a wide range of normal marine lithofacies together with several types of evaporative carbonates and "true" evaporites, and it has been examined in great detail in terms of sedimentation, diagenesis, and organic geochemistry. Once the depositional microfacies and early diagenetic overprints had been determined, the concomitant organic materials were analyzed. The detailed study of the biomarkers contained in the saturated and aromatic fractions of samples from the preevaporitic and evaporitic sequence of the Lorca basin provide different well-defined groupings of samples. These distinctions are based on the origin of the organic matter and the distinctions inferred concerning the original conditions of deposition (Eh and salinity of the water) that are carried by the biomarkers ( $N$-alkanes, isoprenoids, hopanoids, steroids, sulfur compounds, and chromans). The biomarker groupings tally with the specific depositional conditions within the formative water body and cannot be confused with organic groupings from other environmental settings; thus, these biomarker groupings may be employed in the future to define specific environments of deposition.
Project Description: Organic matter, present in marine and lacustrine sediments, acts as the source for hydrocarbons and has been studied at great length, but organic-rich sediments from hypersaline environments were studied in this project. Many types of organic matter from such restricted environments have been identified, and in this study their maturation pathways and products are explored. Through collection and analysis of identified organic matter produced within modern evaporative environments from a number of different marine and nonmarine settings, an understanding of these materials has been achieved. The organic samples collected were from evaporative marine, sabkha, and saline lacustrine deposits and have been subjected to two types of artificial maturation, hydrous and confined pyrolysis, over a fairly wide range of temperatures $\left(150\right.$ to $\left.350^{\circ} \mathrm{C}\right)$. The biomarker products of these treatments have been analyzed and followed in great detail. Analyses of saturate and aromatic hydrocarbons as well as sulfur compounds in the original and the matured samples provide a comprehensive view of the biomarker assemblages associated with these different depositional environments and at different stages of maturity. Infrared spectroscopy and Rock Eval pyrolysis of both the isolated kerogens from both the original and pyrolyzed samples has permitted clear characterization of the functional groupings on the one hand and the free hydrocarbons, the potential hydrocarbons, and the oxygenated compounds on the other hand. Thus the potential of the organic matter associated with the different evaporitic environments to act as a good source for oil generation has been demonstrated and is being tested in comparable ancient sediments. 
GRANTEE:

GRANT:

TITLE:

PERSONS IN CHARGE:
STATE UNIVERSITY OF NEW YORK (SUNY) AT STONY BROOK

Research Foundation of SUNY

Albany, New York 12201-0009

DE-FG02-85ER13416

Geochemistry and Origin of Regional Dolomites

G. N. Hanson (515-632-8210; FAX 516-632-8240;

E-mail ghanson@ccmail.sunysb.edu) and W. J. Meyers
Objectives: The objective of this research is to develop geochemical approaches for testing models describing the geochemistry and dynamics of fluid systems responsible for development of regional dolomites.

Project Description: This research includes developing and applying geochemical approaches new to diagenetic studies and combining these new data with petrography, field relations, crystallography, and existing trace-element and isotope geochemical data in the quantitative modeling of fluid compositions and processes. These results are then used to test extant models and if necessary to give information that may allow development of new models for the origins of dolomites. Results to date include the development and application of $\mathrm{B}, \mathrm{Sr}, \mathrm{Nd}$, and $\mathrm{Pb}$ isotopes and $\mathrm{Na}, \mathrm{Cl}, \mathrm{F}, \mathrm{SO}_{4}^{2-}$, rare earth elements, $\mathrm{B}$, $\mathrm{U}, \mathrm{Th}$, and $\mathrm{Pb}$ as trace elements in diagenetic studies. Analyses are often possible on individual cements or dolomite types using microsampling or microprobe techniques. The results of these studies have economic ramifications in that porous dolomites are major oil and gas reservoirs, often with better reservoir properties than associated limestones.

Results: The boron isotopic compositions of Mississippian (Waulsortian) marine cements fall within a relatively narrow range $\left(\delta^{\prime \prime} \mathrm{B}=0\right.$ to $+2.5 \%$ ), whereas modern marine carbonates have values of +19 to $25 \%$ o. Pristine Mississippian brachiopods have $\delta{ }^{\prime \prime} \mathrm{B}=+17 \%$ o compared to modern marine carbonate values of $+22 \%$. This would suggest that the $\mathrm{B}$ isotope composition of Mississippian seawater is lighter than modern seawater but not as light as the Waulsortian marine cements might suggest. These data suggest that the Waulsortian marine cements have undergone alteration that did not affect oxygen or strontium isotopes. The isotopic composition of boron may be an important criterion for establishing whether a carbonate phase is pristine.

Biostratigraphy and strontium isotope stratigraphy on shell material have established that the age range of the Seroe Domi carbonates in the Netherlands Antilles is from Middle Miocene to Early Pleistocene. Three petrographically and geochemically distinct dolomites have been mapped. Geochemical data are consistent with these dolomites having precipitated from fluids derived from mixing of normal seawater with fresh water that took place soon after subaerial exposure and stabilization of the host limestone. Each of these successive events of deposition, meteoric stabilization, and dolomitization correlates with significant third-order sea-level lowstands and their ensuing sea-level rises.

In combination with sodium abundances and stable isotope data, the abundances of $\mathrm{SO}_{4}^{2-}, \mathrm{Cl}^{-}$, and $\mathrm{F}^{-}$can be used to distinguish fresh water from seawater-derived brine as the dolomitizing fluid. A high-precision technique for analysis of these anions has been developed using ion chromatography. Miocene dolomites from Spain interpreted to have formed from seawater evaporitic brines generally have greater concentrations of $\mathrm{Na}, \mathrm{Cl}$, and $\mathrm{SO}_{4}^{2-}$ than "non-evaporitic" dolomites. 
GRANTEE:

GRANT:

TITLE:

PERSON IN CHARGE:
STATE UNIVERSITY OF NEW YORK (SUNY)

AT STONY BROOK

Research Foundation of SUNY

Albany, New York 12201-0009

DE-FG02-92ER14261

Three-Dimensional Imaging of Drill Core Samples

Using Synchrotron-Computed Microtomography

W. B. Lindquist (516-632-8361; FAX 516-632-8491;

E-mail lindquis@ams.sunysb.edu)
Objectives: The goal of this work is to produce threedimensional images of rock drill core samples with spatial resolution of $1 \mu \mathrm{m}$. The pore topology of the samples will be analyzed statistically, including measurements of (1) two-point correlation structure; (2) distributions of total pore volumes, disconnected pore volumes, throat areas, and pore connectivity; and (3) tortuosity.

Project Description: Computed microtomographic (CMT) three-dimensional images of core samples are provided by K. W. Jones of Brookhaven National Laboratory using $\mathrm{X}$-ray radiation from the National Synchrotron Light Source. The tomograms are then postprocessed (filtered) to provide specific grain/pore identification to each voxel in the image (i.e., the images are filtered from attenuation signal to binary). The filtered images are subjected to the variety of statistical analyses mentioned previously. It is desired that, for any given drill core sample, the entire reduction procedure, from tomographic image data to final statistical output, be done with software, requiring minimal human input.

Results: Three-dimensional CMT images of five core samples from Berea, Danish Chalk, and packer glass beads have been obtained with voxel resolutions from 2 to $50 \mu \mathrm{m}$. During this past year the binary filtering procedure has been developed. The filter employs an edge-identifying algorithm using numerical computation of the Laplacian of the attenuation signal. Because the background signal (air outside the sample and in the pore spaces) also has edges, care must be taken to subtract the background signal. Two-point correlation studies of the five samples have been completed. In addition to pore correlations (which yield porosity and pore surface area), correlation studies have been done of different grain density regions of the samples (as determined by attenuation signal). Current effort is on construction of software to analyze the connectivity and shape of the pore space. This is being done using the medial axis theorem found in computational geometry. Past work employing the medial axis has been done in two space dimensions, so some extension to three dimensions is required.

Testing of three versions of three-dimensional imaging software for suitability in visually examining the images has also been accomplished. 
GRANTEE:

GRANT:

TITLE:

PERSON IN CHARGE:
NORTHEASTERN UNIVERSITY

Department of Electrical and Computer Engineering

409 Dana Research Center

Boston, Massachusetts 02115

DE-FG02-ER14392

Superresolution in Shallow Geophysics

Anthony J. Devaney (617-373-5284)
Objectives: This project will develop numerical techniques for data processing of seismic and electromagnetic signals, with particular emphasis on ground-penetrating radar, with the aim of substantially improving the resolution of shallow buried structures. This project is collaborative with Oak Ridge National Laboratory.

Project Description: The project will evaluate aspects of wave diffraction tomography in which evanescent wave components, those forward diffracted waves that are normally neglected in most geophysical imaging methods, are incorporated into image reconstruction. The use of these evanescent waves should give super-resolution above the traditional half-wavelength "Rayleigh" resolution criterion imposed by the use of only homogeneous waves in inversion algorithms. These evanescent waves are strongly attenuated in the ground, so the method is applicable to shallow geophysical targets such as buried waste sources and in closely spaced boreholes. The increased spatial resolution promised by this new technique would be a significant advance in imaging capability in those shallow geological contexts for which it is appropriate.

Results: This project began September 1, 1993. 
GRANTEE:

GRANT:

TTTLE:

PERSON IN CHARGE:

\section{NORTHWESTERN UNIVERSITY \\ Department of Civil Engineering \\ Evanston, Illinois 60208-3109}

DE-FG02-93ER14344

\author{
Shear Strain Localization and Fracture Evolution in Rocks
}

J. W. Rudnicki (708-491-3411; FAX 708-491-4011;

E-mail jwrudn@nwu.edu)
Objectives: To obtain an improved understanding of the occurrence, development, and evolution of zones of shear localization (faults) in rocks and their relation to the macroscopic constitutive description and microscale mechanisms of deformation. A correlative objective is an improved constitutive description of multiaxial response.

Project Description: Because of the potential importance of fractures to energy production, waste disposal, and mineral technologies, prediction of their causative stresses, location, orientation, thickness, and spacing is important. This project examines the applicability of a theory of localization that describes faulting as an instability of the constitutive description of homogeneous deformation. Because the predictions of the theory depend strongly on the constitutive description, theoretical work is being done to develop a more realistic and elaborate constitutive model based on the growth and interaction of microcracks and resulting increase in overall compliance of the solid. This constitutive reiation is calibrated by comparison with axisymmetric compression tests and then used to predict the response in more complex experiments (compression-torsion) with abrupt changes in the pattern of loading. Numerical studies will be used for detailed comparison with experiments (to be done at Sandia National Laboratories) to address the effects of realistic geometries and boundary conditions.

Results: Because this work was initiated only recently, work on the constitutive model is just beginning. Preliminary results indicate a strong dependence of the response on the pattern of deformation (orientations of principal axes). These results suggest that the response to an abrupt change in the pattern of deformation is completely nonlinear and cannot be approximated accurately by incrementally linear models, as is often done. For incrementally linear models, the response is fixed by the stress state but does not depend on the ratios of stress components. Because the formation and initial evolution of a zone of localized shearing typically involves an abrupt change in the pattern of deformation, this nonlinear response may be critical to accurate modeling of localization processes. 
GRANTEE:

GRANT:

TITLE:

PERSON IN CHARGE:
UNIVERSITY OF NOTRE DAME

Department of Civil Engineering and Geological Sciences

Notre Dame, Indiana 46556

DE-FG02-93ER14391

Energy Partitioning of Seismic Waves in Fractured Rocks

Laura J. Pyrak-Nolte

(219-631-8377; FAX 219-631-8007)
Objectives: This research will evaluate the effects of spatial variation in mechanical properties and fluid saturation along a fracture and the effects of a finite fracture length on seismic wave propagation. This project is collaborative with Lawrence Berkeley Laboratory.

Project Description: Fractures in rocks are planes of mechanical weakness that can serve as major conduits for fluid flow through rock masses. Seismic techniques have the potential to become quantitative diagnostic tools for detecting fractures and determining the mechanical and hydraulic properties of fractures. This project will combine laboratory experiments and numerical modeling to determine partitioning of seismic energy between body waves, guided waves, and scattered waves produced by sources of finite size that are transmitted, reflected, and channeled along single and multiple fractures. Laboratory and nu- merical studies will be performed on single and multiple (parallel) fractures that are dry and fluid-filled. Wood's metal infiltration of natural fractures and lead strips on fracture interfaces will be used to examine the effects of spatial heterogeneity of fracture properties. Previous work demonstrated the effectiveness of the displacement-discontinuity numerical model in reproducing seismic wave transmission properties of natural and artificial fractures and suggests that planned extensions and generalization of the model to three-dimensions will be fruitful.

Development of the new numerical models and new details on the physical properties gained through laboratory experiments will be directly applicable to development of seismic imaging techniques for fracture location and characterization.

Results: This project began September I, 1993. 
GRANTEE:

GRANT:

TITLE:
THE OHIO STATE UNIVERSITY

Department of Welding Engineering

Columbus, Ohio 43210

DE-FG02-89ER13749.A001

Investigation of Ultrasonic Wave Interactions with Fluid-Saturated Porous Rocks

\section{PERSONS IN CHARGE: $\quad$ L. Adler and P. B. Nagy}

Objectives: The main objective of this research is the investigation of ultrasonic wave propagation in fluid-saturated porous materials. Our objectives are to further develop the (1) slow surface wave inspection and (2) air-saturation techniques for ultrasonic evaluation of porous formations and to adapt these novel techniques to the inspection of highly permeable natural rocks (above $100 \mathrm{mD}$ ). This research effort should find applications in geophysical evaluations of fluid-bearing porous rocks, where parameters such as tortuosity, shape factor, permeability, saturation level, and internal impurity are difficult to measure by conventional techniques using low-frequency acr ustic or other methods.

Project Description: In this research project, we conducted an investigation of ultrasonic wave propagation in fluid-filled porous materials. First, we studied the feasibility of using different surface modes to characterize both synthetic and natural rocks. We introduced a novel experimental technique based on direct generation of surface waves by edge excitation. We used two low-frequency (100 to $500 \mathrm{kHz}$ ) shear transducers in pitch-catch mode to launch and receive the ultrasonic surface wave. The same technique was successfully used to generate Rayleigh-type surface modes on the free surface of both dry and watersaturated specimens, as well as Stoneley-type interface modes on the fluid-loaded surfaces of immersed samples. We developed an experimental technique that is based on transmission of airborne ultrasonic waves through airfilled porous plates. This method can be readily used to study the frequency-dependent propagation properties of slow compressional waves in different porous materials, including natural rocks.

Results: During the last year, we have continued our investigation of ultrasonic wave propagation in fluid-filled porous materials. Previously, we studied the feasibility of using different surface modes to characterize both synthetic and natural rocks. Recently, we developed a special interferometric technique for noncontact detection of ultrasonic vibrations on diffusely reflecting rough surfaces. This method was found to be more suitable for surface wave inspection of porous ceramics and natural rocks than the previously used contact techniques. Our experimental results provide clear evidence of propagation of the new slow surface mode on the free surface of a fluid-saturated porous solid when the pores are closed at the surface by capillary forces.

Besides investigating guided acoustic waves in watersaturated porous materials, we also studied bulk wave propagation in air-saturated specimens. We further developed our experimental technique, which is based on transmission of airborne ultrasonic waves through air-filled porous plates. We have demonstrated that, by measuring the slow wave velocity and attenuation in a wide frequency range covering both diffuse and propagating regimes, we can determine the porcsity, acoustic permeability, and tortuosity of the porous solid. We also showed that the technique can be readily adapted to natural rocks of sufficiently high permeability above $100 \mathrm{mD}$. Transmission of airborne ultrasonic waves through air-filled porous plates was shown to be sensitive to three basic material parameters of a permeable solid. These are the connected porosity, the acoustic permeability, and the high-frequency tortuosity, which is often called the formation factor. The acoustic permeability is a modified value of the static permeability, which also depends on the pore shape factor ratio. Our calculations showed that Attenborough's model for permeable solids of random formation can be readily used to fit the experimental data, except at high frequencies, where the attenuation coefficient is greatly underestimated by this theory. 


\section{GRANTEE:}

GRANT:

TITLE:

PERSON IN CHARGE:
THE OHIO STATE UNIVERSITY

Department of Geological Sciences

Columbus, Ohio 43210

\section{Construction of a Calibrated Sea-Level Curve: Mid-Cretaceous Through Mid-Tertiary}

D. Sahagian (614-292-3984; FAX 614-292-0640;

E-mail dork@hydro.mps.ohio-state.edu)

Objectives: The objective of this project is the construction of a eustatic sea-level curve based on the stratigraphy of the tectonically stable Russian Platform. Sea-level variations measured against this reference frame have been chosen as reliably representing the long-term relation of global ocean-basin volume and ocean-water volume.

Project Description: In construction of the sea-level curve, stratigraphic data from numerous wells distributed across the Russian Platform were backstripped, and then the present elevations of various stratigraphic horizons were used to tie the resulting curve to present sea level. Most strata observed represent very shallow water deposition $(<25 \mathrm{~m})$, so estimates of water-depth variations were more reliable than would have been possible in a deepwater environment. Numerous small unconformities exist as a result of the ability of even minor eustatic fluctuations to cause sea level to drop off the platform. These unconformities are important in accurately fixing sea level (zero water depth) at various times throughout the late Mesozoic to earliest Tertiary.

Results: The results (see figure) show that sea level rose by $120 \mathrm{~m}$ from the mid-Jurassic $(60 \mathrm{~m}$ above present) to the mid-Cretaceous ( $180 \mathrm{~m}$ above present) and remained at about that level until the Tertiary, when it began to drop. The long-term rise was not uniform, but spasmodic, with many shorter-term eustatic rises and falls. These events had magnitudes of tens of meters over time scales of 1 to 5 million years. The eustatic curve resulting from this study can be applied to subsiding basins and passive margins to quantify subsidence history.

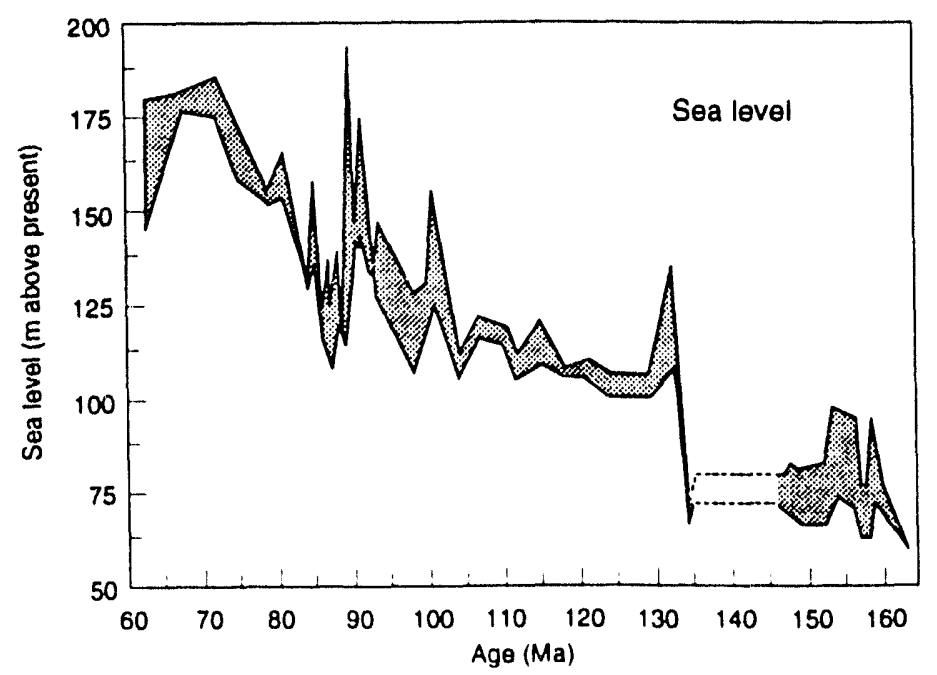


GRANTEE:

GRANT:

TITLE:
UNIVERSITY OF OKLAHOMA

School of Geology and Geophysics

Norman, Oklahoma 73019

DE-FG05-913414209

A Study of Hydrocarbon Migration Events:

Development and Application of New Methods for Constraining the Time of Migration and an Assessment of Rock-Fluid Interactions

\section{PERSONS IN CHARGE:}

R. D. Elmore (405-325-3253; FAX 405-325-3140;

E-mail delmore@geoadm.gcn.uoknor.edu) and M. H. Engel

Objectives: The objective of the research is to test and refine a paleomagnetic method for dating hydrocarbon migration. The specific objectives include field tests of the dating method, comparison of paleomagnetic dates with $\mathrm{Pb}-\mathrm{Pb}$ dating, and laboratory simulation experiments to better understand the mechanism of magnetite precipitation.

Project Description: Investigations of fluid migration are commonly hindered by a lack of temporal control. There is little doubt that the ability to constrain the time of oil migration would be of significant benefit for exploration. The paleomagnetic dating method is based on a genetic connection between hydrocarbons/organic matter and precipitation of authigenic magnetite. Isolation of the magnetization carried by the magnetite and comparison of the corresponding pole position to the apparent polar wander path allows the timing of diagenetic events to be determined. The research involves paleomagnetic field tests of the method, acquisition of $\mathrm{Pb}-\mathrm{Pb}$ dates, and laboratory simulation studies.

Results: Several units that contain hydrocarbons possess secondary magnetizations that reside in authigenic magnetite. Red samples of the Schoolhouse Member (Maroon Formation, Pennsylvanian, northwest Colorado) contain an early magnetization that resides in hematite, whereas hydrocarbon-impregnated samples are remagnet- ized with weaker magnetizations that reside in magnetite. The Belden Formation, the presumed source for the hydrocarbons in the Schoolhouse, contains a chemical remagnetization in magnetite. Observations with the scanning transmission electron microscope indicate that magnetite has replaced pyrite. The magnetization is related to either organic material or to alteration by radiogenic fluids. Organic-rich lithologies (lacustrine carbonates and siltstones) in the Old Red Sandstone (Devonian) contain a late Paleozoic chemical magnetization that resides in magnetite and also possess late Paleozoic $\mathrm{Pb}-\mathrm{Pb}$ dates. Hydrocarbon-impregnated Jurassic limestones in Hils regions in Germany contain a postfolding Cretaceous remagnetization in magnetite. Samples without hydrocarbons have much weaker unstable magnetizations. The results of the field tests are consistent with the hydrocarbon-magnetite connection.

The laboratory simulation experiments are focusing on two diagenetic pathways for magnetite precipitation: in situ mediated conversion of pyrite to magnetite (which was observed in the Belden) and secondary magnetite precipitation by migrating fluids. The chemical variables that are important for the first pathway have been defined and some experiments performed (e.g., precipitation of ferrous hydroxide gels and conversion to magnetite). 
GRANTEE:

GRANT:

TITLE:

\section{UNIVERSITY OF OKLAHOMA}

School of Geology and Geophysics

Norman, Oklahoma 73019

DE-FG05-85ER13412

A Study of the Source Materials, Depositional

Environments, Mechanisms of Generation, and Migration of Oils in the Anadarko and Cherokee Basins

R. P. Philp (405-325-3253; FAX 405-325-3140)

Objectives: The major objectives of this research are directed at understanding the nature of source materials and depositional environments for major oil accumulation in the Anadardo Basin, Oklahoma.

Project Description: To attain these objectives oils and source rocks from a wide variety of locations within the Anadarko Basin have been collected and subjected to detailed geochemical analyses. Techniques used include gas chromatography, gas chromatography-mass spectrometry, various pyrolysis techniques, and carbon isotopic determination. Much of the analytical work is concerned with the determination of compounds known as biomarkers whose presence can be used for oil/oil and oil/source rock correlations and with evaluation of source, maturity, and depositional environments. The concentration of these highly specific organic compounds is often extremely low, requiring extremely sophisticated analytical techniques for their detection. However, once detected they provide a powerful tool for petroleum exploration.

Results: Emphasis was placed on characterization of potential source formations other than the well-characterized Woodford Shale. Detailed geochemical analysis of carefully screened and selected samples of Springer, Morrow, Viola, Sylvan, and Chestcr Formations have been completed. Of particular note here are data obtained that clearly show that the relative abundance of the tricyclic terpanes, a widely used class of compounds, is source/ environment related and less dependent on maturity or extent of biodegradation of the crude oils. In addition, certain fields have been used to develop reservoir geochemistry techniques that can be used to obtain a better understanding of the extent of mixing of oils from different sources in a reservoir, presence of barriers preventing continuity, and alteration of oils in the reservoir. Furthermore, significant source potential has been determined for several of these formations.

Another important area of this project has developed from the discovery of high-molecular-weight hydrocarbons $\left(>\mathrm{C}_{40}\right)$ both in oils from the Anadarko Basin and elsewhere around the world. The discovery of these compounds became possible with the availability of high-temperature gas chromatography columns and has extremely important implications for applications to exploration, reservoir characterization, and enhanced oil recovery studies. 
GRANTEE:

GRANT:

TITLE:

PERSONS IN CHARGE:

\section{OREGON STATE UNIVERSITY}

College of Oceanic and Atmospheric Sciences

Ocean Admin. Bldg. 104

Corvallis, Oregon 97331

\section{DE-FG06-92ER14277}

\section{Multistation Magnetotellurics}

Gary D. Egbert, University of California at Berkeley (503-737-2947;

FAX 503-737-2064; E-mail egbert@oce.orst.edu) and

H. Frank Morrison, University of California at Berkeley

Objectives: The principal objective of this project is to develop and test new methods for collecting and processing remote reference magnetotelluric (MT) data in areas with significant cultural noise, with special emphasis on the "dead band" (approximately 0.1 to $10.0 \mathrm{~Hz}$ ) where signal levels are low and noise levels are high.

Project Description: The project has three aspects: (1) Data are being collected in a series of three-station MT arrays that span conditions from very noisy (just south of San Jose, California) to very quiet remote sites. Our emphasis is on collecting a large volume of dead-band data at a small number of sites. Multiple remote sites at varying distances, and in various combinations of noisy and quiet, are included to allow us to characterize spatial and temporal properties of signal and noise and to test different approaches to remote reference data acquisition. (2) New approaches to remote reference data processing are being developed. We are adapting multivariate and robust statistical methods to the special problems of MT data processing in the dead band. (3) Using the multistation MT data from our experiment, and other compilations of remote reference MT data, we are testing and comparing various strategies for collecting and processing remote reference MT data.

Results: The project is in its first year. MT data collection is currently under way, and initial work on programming of robust multiple-station and remote reference estimators has been completed. Analysis of the array data and comparison and testing of methods will begin soon. 


\section{GRANTEE:}

GRANT:

TITLE:

PERSONS IN CHARGE:

\section{PENNSYLVANIA STATE UNIVERSITY}

Department of Geosciences

University Park, Pennsylvania 16802
DE-FG02-92ER14251
Cretaceous Shallow Drilling in the U.S. Western
Interior: Core Research

M. A. Arthur (814-863-6054; FAX 814-863-7823; Internet: arthur@geosc.psu.edu) and W. E. Dean, U.S. Geological

Survey (303-236-5760; FAX 303-236-0459;

E-mail dean@sedproc.cr.usgs.gov)
Objectives: Construct a subsurface transect of midCretaceous strata that were deposited in the U.S. Western Interior Seaway (WIS), ranging from pelagic, organiccarbon rich, marine hydrocarbon source rocks in Kansas and eastern Colorado to near-shore, coal-bearing units in western Colorado and Utah to provide a basis for paleoenvironmental interpretation of epicontinental, foreland basin organic-carbon burial settings.

Project Description: This project is a multidisciplinary study of Cretaceous carbonate and clastic rocks in cores along a transect across the old Cretaceous seaway that extended from the Gulf Coast to the Arctic during maximum transgressions. In particular, the study focuses on the Graneros Shale, Greenhorn Limestone, Carlile Shale, Niobrara Formation, and lower Pierre Shale in cores from three holes or groups of holes from western Kansas, southeastern Colorado, and eastern Utah. This series of cores provides unweathered samples and continuous smooth exposures required for geochemical studies, mineralogical investigations, and biostratigraphic studies. Major objectives include (1) precise timing of sea-level change, rates of subsidence, and facies change; (2) determination of controls on the accumulation, burial, and diagenesis of organic matter; (3) calibration of depositional cycles using high-resolution stratigraphy; (4) determination of the paleogeography, paleoclimatology, and paleoceanography of the WIS.
Results: The Cretaceous part of a recent AMOCO core from western Kansas was released to the U.S. Geological Survey (USGS) in 1992. Most of the objectives for the eastern (most pelagic marine) end of the transect can be met with this existing core. Three holes that form the western end of the transect, funded by USGS energy programs, were drilled and continuously cored in June 1991, in the Kaiparowits basin near Escalante, Utah.

In June 1992, a 700-ft hole [funded by the U.S. Department of Energy (DOE) | was drilled and continuously cored near Portland, Colorado, east of the Florence oil field. This sequence, deposited in relatively deep water on the west side of the WIS, includes cycles of terrigenousclastic and pelagic-marine sediments in contrast with the pelagic carbonate-dominated cycles of Kansas and the clastic-dominated cycles of western Colorado and Utah. A second, $800-\mathrm{ft}$ hole, also funded by DOE, was drilled in July 1992 about 10 miles southwest of the Portland hole in Pierre Shale that is the reservoir for hydrocarbons in the Florence field.

A core workshop was held in August 1992 at the USGS in Denver during which the research team discussed objectives and interactions, identified sampling requirements, and examined available cores. A sample protocol was developed to guide sampling for the research team and any other investigators. Geochemical analyses and biostratigraphic-paleoecologic determinations are well under way by the WIS research team for all cores. 


\section{GRANTEE:}

GRANT:

TITLE:

PERSON IN CHARGE:
PRINCETON UNIVERSITY

Department of Geological and Geophysical Sciences

Princeton, New Jersey 08544
DE-FG02-91ER14197

The Effects of Natural and Radiation-Induced Defects on Noble Gas Transport in Silicates: A Study of Argon Using Laser, X-Ray, and Electron Microprobes

T. C. Onstott (609-258-6898; FAX 609-258-1274;

E-mail tullis@weasel.princeton.edu)

Objectives: The research goal is twofold: to determine the relationship between argon diffusion and microstructures for K-feldspar from a rock unit with a well-constrained thermal history and to characterize the microstructures resulting from neutron irradiation of $\mathrm{K}$ feldspar.

Project Description: The relative importance of various microstructures in K-feldspar (i.e., exsolution lamella and micropores) in the diffusion of argon over geological times was ascertained by performing ${ }^{40} \mathrm{Ar} /{ }^{39} \mathrm{Ar}$ laser probe analyses on $\mathrm{K}$-feldspar containing both structure types. These structures were characterized by scanning electron microscopy imaging of etched suctions and transmission electron microscopy (TEM) analyses. The ${ }^{40} \mathrm{Ar} /{ }^{39} \mathrm{Ar}$ spectra of clear, highly exsolved K-feldspar and tinted, turbid $\mathrm{K}$-feldspar were then compared to the established thermal history and their integrated ages used to constrain their bulk diffusivity. A numerical model incorporating both lattice diffusion rates and diffusion along extended defects was used to calculate the bulk diffusivity given the density of the observed microstructures.

Characterization of the microstructures caused by neutron irradiation involved X-ray diffraction (XRD) analyses of irradiated K-feldspar powders and high-resolution TEM imaging of irradiated TEM foils. Numerical modeling of the irradiation process was performed using TRIM90. Benson Mines orthoclase was chosen because of its purity and lack of naturally formed microstructures and because its argon diffusion behavior is extremely well determined.
Results: ${ }^{40} \mathrm{Ar} /{ }^{39} \mathrm{Ar}$ analyses indicate that the closure temperature of turbid K-feldspar is lower than that of exsolved K-feldspar and agrees with blocking temperatures calculated from numerical modeling of coupled lattice-defect transport with the established thermal history. Comparison of ${ }^{40} \mathrm{Ar} /{ }^{39} \mathrm{Ar}$ analyses of single grains versus bulk separates indicate that the age spectra of the latter is the result of mixing between turbid and nonturbid varieties of K-feldspar.

XRD analyses detected peak broadening in irradiated orthoclase compared to the unirradiated orthoclase, indicating the presence of a significant amorphous component (see figure).

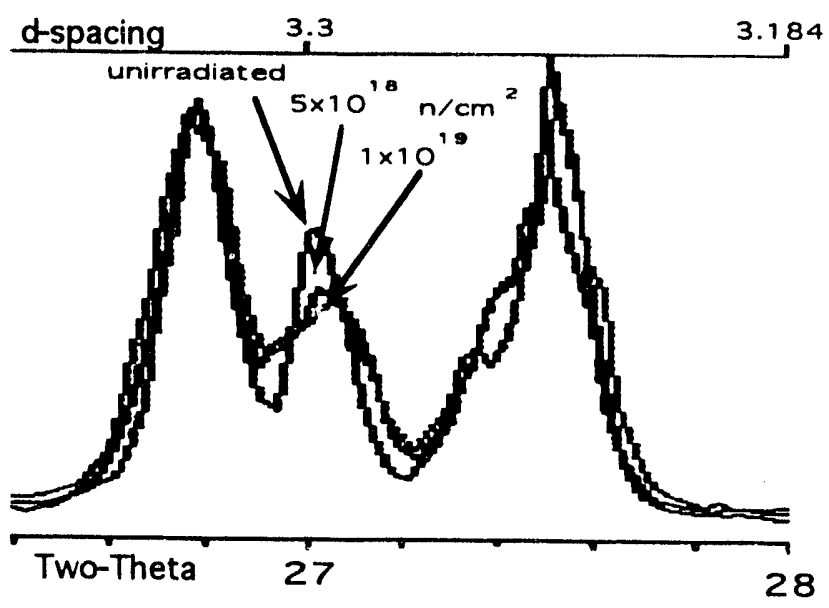


GRANTEE:

GRANT:

TITLE:

PERSON IN CHARGE:
PRINCETON UNIVERSITY

Department of Geological and Geophysical Sciences

Princeton, New Jersey 08544

DE-TG02-85ER13437

Thermodynamics of Minerals Stable Near the Earth's Surface

A. Navrotsky (609-258-4674; FAX 609-258-1274;

E-mail alex@weasel.princeton.edu)

Objectives: The goals of the project are to increase both the data base and the fundamental understanding of the thermodynamics of volatile-bearing mineral phases (amphiboles, micas, clays, zeolites, carbonates) important to surficial, sedimentary, and shallow crustal processes.

Project Description: Using high-temperature solution calorimetry, this research determines the enthalpies of formation of hydrous minerals and carbonates. Systematics in energetics of ionic substitutions are sought in order to predict the thermodynamics of complex multicomponent minerals. Mixing properties of mica, amphibole, and carbonate solid solutions are also studied.

Results: The similarity between $\Delta \mathrm{H}_{\text {mix }}$ of tremoliterichterite and fluortremolite-fluoredenite amphiboles suggests that the A site controls the mixing energetics of both solid solutions, with A-site positional ordering and interactions with other cations playing an important role. Because the richterite and edenite exchanges are the two most important A-site substitutions that occur in calcic amphiboles, the same factors will influence the stability of all amphiboles with sodium in the A site. Therefore, metamorphic calcic amphiboles with small A-site occupancies should be stabilized relative to compositions with zero or high A-site occupancies, and any natural amphiboles with high A-site occupancies must have crystallized at a high temperature and presumably cooled relatively fast, thereby preventing exsolution.

In the micas studied, the $\mathrm{Mg}+\mathrm{Si}=2 \mathrm{Al}$ substitution is associated with a positive heat of mixing asymmetric toward the edenite end. This is consistent with destabilization resulting from layer mismatch, with a solvus in that system, and with limited extent of $\mathrm{Al}$-substitution in natural systems. The X-ray and nuclear magnetic resonance data are consistent with significant Al, Si short-range order and have been used to formulate configurational entropy models.
The energetics of high-silica zeolites pose an intriguing question. In comparing quartz and an open framework such as faujasite, the molar volume increases by a factor of two, but this increase reflects the creation of zeolitic pores rather than major changes in the local bonding within the $\mathrm{SiO}_{4}$ tetrahedra. The enthalpy of the zeolitic silicas relative to quartz is not very destabilizing and about the same as that of silica glass (see figure).

The enthalpy does not increase much as the pores become larger and the density lower. This suggests that the silicate framework is not perturbed much energetically by the presence of these cavities, and the transition from pores behaving as an integral part of the crystal structure to behaving as a second phase with only interfacial interactions is already occurring at this size scale. The data further suggest that zeolite synthesis, whether in nature or the laboratory or chemical plant, is more a matter of controlling steric (entropic) factors by appropriate templates than of stabilizing specific framework topologies energetically.

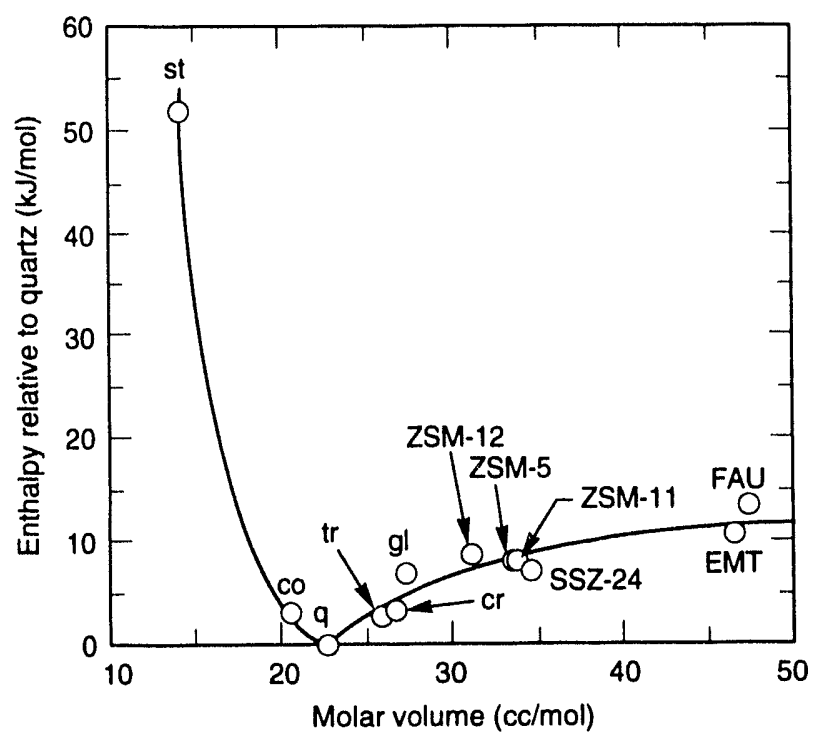


This in turn suggests that there are few limitations on the variety and number of (metastable) structures that can form. There is some evidence for destabilization for $\mathrm{SiO}_{2}$ zeolites having $\mathrm{Si}-\mathrm{O}-\mathrm{Si}$ angles below $140^{\circ}$, suggesting that the formation of small three- and four-membered rings may be energetically limiting to a greater extent than the formation of large pores. This is in accord with the shape of the potential curve for Si-O-Si angles obtained from quantum calculations, which shows a small barrier to linearity but a large increase in energy at $\mathrm{Si}-\mathrm{O}-\mathrm{Si}$ angles below about $135^{\circ}$.

A study of the energetics of radiation damage in $\mathrm{ZrSiO}_{4}$ shows that the enthalpy of annealing of natural zircons as a function of radiation dose exhibits a plateau at metamictization and the large value of the enthalpy, more than twice the heat of formation from the oxides, is consistent with pervasive damage on the nearest and nextnearest neighbor scale, rather than microcrystallinity. The increase in enthalpy of about $60 \mathrm{~kJ} / \mathrm{mol}$ could cause a factor of 3 increase in the equilibrium solubility of $\mathrm{ZrO}_{2}$ in an aqueous fluid in contact with zircon. Thus, damaged zircons are thermodynamically as well as kinetically more reactive. This has ramifications for both radioactive waste disposal and isotope geochronology.
GRANTEE:

GRANT:

TITLE:
PURDUE UNIVERSITY

Department of Earth and Atmospheric Sciences

West Lafayette, Indiana 47907

\title{
DE-FG02-90ER14113
}

\author{
Hyperfiltration-Induced Fractionation of Lithium Isotopes \\ in Geologic Systems
}

Objectives: To evaluate the process of hyperfiltration and its effect on chemical and isotopic fractionation in sedimentary systems.

Project Description: Hyperfiltration through clay membranes induces isotopic fractionation in which a solute's heavy isotope is depleted on the clay membrane's high-pressure side. It should thus be possible to delineate regions of high and low hydrostatic heads in the subsurface by plotting distributions of isotopic ratios obtained from opposing sides of aquitards. High degrees of hyperfiltration-induced fractionation should result when ions of a low-atomic-weight element are hydraulically forced through a highly ideal clay membrane. This study gauges the magnitude of lithium isotope fractionation during hyperfiltration through clay membranes.
Results: A 10-mM LiCl solution was hydraulically forced through $0.3-\mathrm{cm}$-thick smectite membrane to evaluate the effect. When scaled to a realistic solution flux in natural systems, the position of maximum fractionation would occur meters from a shale/aquifer contact in the high-pressure reservoir-a prediction that is corroborated by previous hyperfiltration studies with carbon and chlorine studies. The extent of fractionation increases with higher values of the membrane reflection coefficient. Because shales have substantially lower porosities with higher values of the reflection coefficient, it is concluded that the hyperfiltration phenomenon in the subsurface often results in sampling of waters that are not chemically and isotopically representative of the formation penetrated by the well. 
GRANTEE:

GRANT:

TITLE:
PURDUE UNIVERSITY

Department of Earth and Atmospheric Sciences

West Lafayette, Indiana 47907
PERSON IN CHARGE:
DE-FG02-93ER14365

\section{Character and Origins of Ground Rupturing and Ground \\ Deformation During the June 28, 1992, Landers, California, Earthquake}

Arvid M. Johnson (314-494-0250)

Objectives: To map in detail the ground ruptures and deformation during the June 28, 1992, Landers, California, earthquake and to evaluate the mechanisms of rupture.

Project Description: The ground breakage associated with the 7.5-magnitude Landers, California, earthquake of June 28, 1992, was one of the most extensive in recent history within the United States. This project will carefully map at large scale the surface expression of ground breakage with large-scale base map construction using surveying techniques and air photo stereo-image crosscorrelation methods. The detailed geometric imaging will then be interpreted in light of geomechanics fracture models to gain insight into the physical processes involved in seismic faulting. Detailed documentation of this earthquake is important for understanding the mechanics of potentially damaging earthquakes. The apparent deformation along broad shear zones associated with this earthquake has important implications for siting and engineering design of critical structures such as power plants, dams, and hazardous waste storage facilities.

Results: This project began in August 1993.
GRANTEE:

GRANT:

TITLE:

PERSON IN CHARGE:
RICE UNIVERSITY

Geology and Geophysics

Houston, Texas 77251-1892

DE-FG05-92ER14295

Transition Metal Catalysis in the Generation of Petroleum and Natural Gas

Frank D. Mango (713-527-4880; FAX 713-2 $\div 5-5214)$
Objectives: It is proposed that the light hydrocarbons in petroleum, including natural gas $\left(\mathrm{C}_{1}-\mathrm{C}_{4}\right)$, are formed catalytically, through condensation of $\mathrm{N}$-alkanes and hydrogen in fine-grained carbonaceous sedimentary rocks. The transition metals are suggested as the catalytic agents. The objective of this research is to test this hypothesis and to explore the catalytic properties of transition metals under realistic geologic conditions.

Project Description: Various natural sources of transition metals, including the asphaltene fraction of petro- leum and fine-grained carbonaceous sedimentary rocks, are being analyzed for catalytic activity in the condensation of olefins (ethylene and $\mathrm{N}$-octadecene-1) and hydrogen. Reactions are being conducted in a glass manifold system and in the injection cavity of a HP 5890 II highresolution gas chromatography unit with FID detectors.

Results: $N$-alkenes and hydrogen react catalytically generating a $\mathrm{C}_{1}-\mathrm{C}_{4}$ product that is identical to natural gas in molecular and isotopic composition $(90 \mathrm{~mol} \%$ methane; $\delta^{13} \mathrm{C}=-47.2$ per mil). The reaction is catalyzed by a 
metal-rich, carbonaceous sedimentary rock from the Monterey Formation (California, Miocene). Catalysis proceeds within a temperature range $\left(200^{\circ} \mathrm{C}\right)$ in which the substrates alone, $\mathrm{N}$-octadecene + hydrogen, are indefinitely stable on a laboratory time scale. The $90 \mathrm{~mol} \%$ methane is unprecedented and sharply distinct from acid catalysis under the same conditions $\left(3 \% \mathrm{CH}_{4}\right)$ and thermal cracking at $500^{\circ} \mathrm{C}\left(13 \% \mathrm{CH}_{4}\right)$. Activity is on the urder of $10^{-7} \mathrm{~g}$ $\mathrm{CH}_{4} / \mathrm{d} / \mathrm{g}$ kerogen, suggesting robust catalytic activity over geologic time at moderate sedimentary temperatures. Thus, the evidence supporting catalysis in the generation of natural gas is compelling.
GRANTEE:

GRANT:

TITLE:

PERSON IN CHARGE:

\author{
UNIVERSITY OF SOUTHERN CALIFORNIA \\ Department of Geological Sciences \\ University Park \\ Los Angeles, California 90089-0740
}

\section{The Seismology of Geothermal Regimes}

K. Aki (213-740-5830; FAX 213-740-0011; E-mail aki\%@gamera.usc.edu)
Objectives: Development of effective interpretation theory for the analysis of seismic data collected in geothermal areas characterized by strongly heterogeneous subsurface structure and by seismic sources involving interactions among gas, liquid, and solid.

Project Description: Seismic data from active and passive experiments in geothermal areas are extremely complicated because of the strongly heterogeneous earth's structure and seismic sources involving interactions among gas, liquid, and solid. To develop effective interpretation theory for analyzing the data, we are currently working on the following problems. (1) Development of analysis methods for separately determining the scattering loss and the absorption loss in seismic attenuation as a function of frequency and application of them to various geothermal areas in the world. (2) Three-dimensional modeling of seismic source, path, and site effects on the observed spectra of seismic events in active geothermal areas. (3) Exploration of effective inversion procedures for geometry and mechanical properties of subsurface structure using steady-state (frequency domain) data rather than conventional wave form (time domain) data. These problems are identified as targets of investigation with fruitful outcome in the near future.
Results: Among the three problems described, our current focus is on the separate mapping of scattering loss and intrinsic absorption. We shall, therefore, summarize some of the recent results on this subject. We determined the scattering $\mathrm{Q}^{-1}$ and intrinsic $\mathrm{Q}^{-1}$ separately for the frequency range from 1.5 to $15 \mathrm{~Hz}$ for the island of Hawaii; Long Valley, California; and central California. Despite differences in tectonic conditions, all three regions showed similar results; namely, the scattering $\mathrm{Q}^{-1}$ sharply decreases with increasing frequency, whereas the intrinsic $\mathrm{Q}^{-1}$ is much less frequericy dependent. As a result, the intrinsic absorption becomes dominant at high frequencies.

We extended the frequency range of analysis to lower frequencies down to $0.08 \mathrm{~Hz}$ using the broadband data from southern California. For these low frequencies, however, we found that the agreement between the observed energy curve and the predicted is not as satisfactory as for higher frequencies. We need a new theory and analysis methods applicable to the case of coexisting body and surface wave. We are making some progress in developing such a new theory. In addition to the mentioned studies on the scattering properties of the earth media, we applied our theory on the wave energy propagation for the absolutevalue estimation for seismic source energy. 
GRANTEE:

PERSONS IN CHARGE:
GRANT:

TITLE:

\section{UNIVERSITY OF SOUTH FLORIDA}

Department of Marine Science

St. Petersburg, Florida 33701
DE-FG05-92ER14300

Clay Mineral Diagenesis in the Monterey Formation, California

J. S. Compton and W. M. Sackett (813-893-9158; FAX 813-893-9189;

E-mail compton@marine.usf.edu)
Objectives: To study the progressive burial diagenesis and alteration of discrete vitreous volcanic ash beds to bentonite and metabentonite beds to determine the origin and mass balance of clay mineral reactions.

Project Description: Clay minerals are a significant constituent and are an important factor in silica, carbonate, and organic matter diagenesis of the Miocene Monterey Formation. Many of the clay minerals form as a result of progressive burial diagenesis and overlap with the burial depths associated with oil generation and migration. The mineral, elemental, and isotopic composition of Monterey rocks will be used in this study to (1) quantify the clay mineral reactions that occur in vitreous volcanic ash layers as they undergo increasing burial diagenesis (glass to bentonite to metabentonite), (2) test the hypothesis that the illitization of smectite is limited by the availability of potassium, and (3) determine the relation of clay mineral reactions to the maturation of organic matter. The results of this study will provide detailed analysis of the significance of clay minerals in the complex diagenesis of these hydrocarbon source and reservoir rocks.

Results: More than 50 volcanic ash and bentonite layers were sampled from exposures of the Monterey
Formation in south-central coastal California. The samples cover a large geographic area and have experienced a wide range of low-temperature burial diagenesis $\left(<150^{\circ} \mathrm{C}\right)$. Bentonites are particularly abundant in the lower organicrich and phosphatic-rich units of the Monterey Formation. Vitreous ash alters to highly smectitic mixed-layered illite/smectite at burial depths that generally correspond to the opal-A to opal-CT silica transformation. The alteration to smectite results in the loss of potassium and silicon and an increase in magnesium and aluminum. Some bentonite layers contain abundant diagenetic pyrite as well as clinoptilolite and other zeolite minerals. The highly smectitic illite/smiectite becomes increasingly illitic as a result of progressive burial diagenesis and overlaps burial depths associated with oil generation and migration. Quartz-grade siliceous rocks contain up to $80 \%$ illite layers and contain diagenetic kaolinite and chlorite that form because of an insufficient source of potassium. As much as $35 \%$ of the illite layers contain $\mathrm{NH}_{4}$ that substitutes for potassium. Fixed- $\mathrm{NH}_{4}$ contents of clay minerals may provide a proxy of $\mathrm{NH}_{4}$-rich hydrocarbon fluids. 
GRANTEE:

GRANT:

TITLE:

PERSONS IN CHARGE:
STANFORD UNIVERSITY

Department of Geological and Environmental Sciences

Stanford, California 94305-2115
DE-FG03-93ER14347-A000

Cation Chemisorption at Oxide Surfaces and Oxide-Water Interfaces: X-Ray Spectroscopic Studies and Modeling

G. E. Brown, Jr., and G. A. Parks (415-723-9168;

FAX 415-725-2199; E-mail gordon@ @angea.stanford.edu)
Objectives: This project concerns reactions between aqueous metal ions and oxide surfaces representative of those found in the Earth's crust. These reactions partition chemical species between fluid and solid phases and must be understood at a molecular level to develop the macroscopic models required to predict the fate of contaminants in the environment and to understand the geochemistry of mineral surfaces. Our objectives are to (1) characterize sorption reactions by determining composition, molecular-scale structure, and bonding of the surface complex(es) produced using direct sorption measurements, synchrotron-based X-ray absorption fine structure (XAFS) and ultraviolet/visible/infrared spectroscopy; (2) investigate how these properties are affected by the solid surface and composition of the aqueous solution; and (3) develop molecular-level and macroscopic models of the sorption process.

Results: Though this research program has only recently been initiated, early results are available for three projects. In the first, we conducted grazing-incidence (GI)XAFS studies of $\mathrm{Co}(\mathrm{II})$ and $\mathrm{Pb}(\mathrm{II})$ sorbed on the $(-102)$ surface of $\alpha-\mathrm{Al}_{2} \mathrm{O}_{3}$ from an aqueous solution at a surface coverage of about $1 / 30$ of a monolayer, which is considerably lower than feasible on powdered oxide and silicates. These results indicate fewer Co second neighbors than were found for $\mathrm{Co}$ sorbed on a powdered $\alpha-\mathrm{Al}_{2} \mathrm{O}_{3}$, suggesting the presence of fewer types of Co surface com- plexes and/or reactive sites on the single-crystal relative to the powder surface. This result demonstrates the utility of single-crystal GI-XAFS measurements in distinguishing among the variety of sorption sites presented by particulates.

In the second project, sorpt in measurements show that the simple organic molecule $2,2^{\prime}$-bipyridine (bipy) enhances sorption of $\mathrm{Cu}$ (II) on amorphous silica and inhibits sorption on $\gamma-\mathrm{Al}_{2} \mathrm{O}_{3}$. Quantitative analysis of powder XAFS spectra of $\mathrm{Cu}$ (bipy) and $\mathrm{Cu}$ (bipy) 2 complexes in solution and of $\mathrm{Cu}(\mathrm{II})$ sorbed on the oxides with and without bipy shows that $\mathrm{Cu}$ sorbs as a different complex when bipy is present and that the sorption complex is different from solution com.plexes and $\mathrm{Cu}(\mathrm{OH})_{2}$, suggesting that sorption involves more than simple uptake of a preformed species or precipitation. $\mathrm{Cu}(\text { bipy })_{n}$ sorption complexes on the two solids differ from each other, suggesting that differences in sorbate bonding contribute to the observed differences in macroscopic behavior.

In a third project, we initiated an in situ XAFS study of $\mathrm{Co}$ (II) sorption at $\mathrm{ZnS}$ - and $\mathrm{ZnO}$-water interfaces. Analysis of these data shows that $\mathrm{Co}$ (II) sorbs on $\mathrm{ZnO}$ and $\mathrm{ZnS}$ as both four- and six-coordinated ions but forms both $\mathrm{Co}-\mathrm{S}$ and $\mathrm{Co}-\mathrm{O}$ bonds on the $\mathrm{ZnS}$ surface, indicating that both $-\mathrm{OH}$ and $-\mathrm{SH}$ groups are reactive surface sites on the sulfide in the presence of water. Cobalt on both surfaces is present as inner-sphere, multinuclear species. 
GRANTEE:

GRANT:

TITLE:
STANFORD UNIVERSITY

School of Earth Sciences

Stanford, California 94305-2210

DE-FG03-90ER14154

Fluid Flow, Element Migration, and Petrotectonic

Evolution of the Early Mesozoic Central Klamath Island Arc, Northwesternmost California

PERSON IN CHARGE:

W. G. Ernst (415-723-2750; FAX 415-725-6566;

E-mail dean@pangea.stanford.edu)

Objectives: Few intact island arcs are as well exposed at upper crustal levels as the study area. Knowledge obtained in the Klamaths thus should be readily applicable to older, more dismembered oceanic arcs and to as yet unexposed modern arcs. Shallow levels of such arcs represent suitable case histories for studying rock fracture, fluid migration, and hydrothermal metasomatism.

Project Description: Investigations in the central Klamath Mountains have documented the presence of a polymetamorphosed suite of highly magnesian basaltic rocks in the Sawyers Bar terrane. The metabasalts are interpreted as metasomatized and metamorphosed, immature Salmon River arc basalts (IATs), and interlayered, mildly alkaline North Fork oceanic island lavas (OIBs), erupted following possible subduction of a spreading center. These igneous rocks are intercalated with and are interpreted to predominantly overlie continent-derived distal turbidites. The superjacent assemblage was laid down, altered, and metasomatized in an immature island arc setting during the hypothesized collapse of a Philippine Sea-type back-arc basin that brought the westerly Sawyers Bar oceanic arc into juxtaposition with an inboard, preexisting Stuart Fork subduction complex and more easterly Klamath terranes. At about the same time, a yet more outboard, active calc-alkaline arc, the Western Hayfork terrane, was encroaching eastward as a result of contraction and suturing against the intervening Eastern Hayfork unit. The region is being studied through geologic field mapping at a scale of 1:24,000 and by vein plus bulk-rock and mineralogic analyses of major and minor elements employing X-ray fluorescence, ${ }^{18} \mathrm{O} /{ }^{16} \mathrm{O}$, and ${ }^{40} \mathrm{Ar} /{ }^{39} \mathrm{Ar}$ techniques.

Results: Research over the past 12 months has concentrated on elucidating the areal extent and structural/stratigraphic relations of these metavolcanic units and has documented the insignificant degree of crustal contamination of the mafic melts $(\varepsilon \mathrm{Nd}=+4$ to 8 ) by associated terrigenous metasediments. The physical conditions of transformation and of aqueous fluid-rock interaction accompanying island-arc accretion are as follows: Early-Middle Jurassic regional metamorphism of the Sawyers Bar/Stuart Fork amalgamated terrane took place at 350 to $500^{\circ} \mathrm{C}$ and 2.5 to $4.0 \mathrm{kbar}$; contact aureoles peripheral to the mid-Jurassic calc-alkaline plutons reached maximum physical conditions of 500 to $600^{\circ} \mathrm{C}$ at 2.0 to 3.0 kbar; Permo-Triassic sea-floor exchange, followed by greenschist facies regional recrystallization, and later contact metamorphism in aggregate have resulted in an increase of $\delta^{18} \mathrm{O} /{ }^{16} \mathrm{O}$ from igneous values near +6 to present bulk-rock values ranging from +10 to +15 . Intrusion of the postcollisional granitoids mobilized alkalies, silica, and especially oxygen isotopes in the sedimentary strata intimately interlayered with the IAT (Salmon River) and OIB (North Fork) greenstones, overprinting the effects of an inferred earlier submarine alteration in the mafic volcanics. Several sets of temporally overlapping mafic dike/sill series have been intruded into the amalgamated complex, reflecting sustained orogenic magmatism.

The thermal structure and its evolution in the central Klamath Mountains reflect surfaceward advective transport of magmatic energy derived from the partly fused downgoing oceanic slab plus overlying mantle, as well as hydrothermal fluid circulation. What has recently been documented by new radiometric data is that two volcanic/plutonic arcs were active contemporaneously in the central Klamaths--the outboard Western Hayfork and the inboard, continentalward Sawyers Bar. Furthermore, within the eastern terrane, igneous activity among the North Fork and Salmon River volcanics overlapped each other and the initiation of calc-alkaline plutonism as well. 
Additional samples have been collected from the southern Marble Mountain amphibolitic assembly on the north, the greenschistic Sawyers Bar terrane, and the feebly recrystallized Pony Camp mafic volcanoplutonic complex to the south for intermediate- and shallow-level water-rock interaction studies, utilizing stable isotope frac- tionation. This project is being pursued in cooperation with Yehoshua Kolodny (The Hebrew University) and Mark Barton (The University of Arizona); its goal is to shed light on contrasting water-rock interations at high and middle levels of this oceanic island arc.
GRANTEE:

GRANT:

TITLE:

PERSONS IN CHARGE:
STANFORD UNIVERSITY

Department of Geology

Stanford, California 94305

DE-FG03-93ER14366

Experimental Investigation of Kinetics and Rheology During Diagenesis

J. G. Liou (415-723-2716), B. Hacker, and

W. G. Ernst
Objectives: This project seeks to improve understanding of coupled chemical and mechanical processes that are important in crustal processes through both experiment and theory.

Project Description: Very few experimental data exist on the coupling of low-grade metamorphic mineral reactions and the deformation processes that occur simultaneously in many crustal environments. That they are intimately interrelated is clear, but the details are unexplored, and important implications for large-scale fluid migration and seismic hazards are unknown but suspected. This project seeks to experimentally test the chemical-me- chanical coupling phenomenon relevant to (1) the compaction and porosity reduction of sedimentary aggregates, (2) deformation in the development of hydrocarbon reservoir seals, and (3) dehydration reactions that can influence the deformation behavior of some crustal fault zones.

The project involves experimental investigation of (1) the kinetics of dehydration reaction of a common zeolite mineral found in fault zones and as cement in some petroleum reservoirs and (2) the effects of phase transformation on shear strength of this mineral.

Results: This project began August 1, 1993. 
GRANTEE:

GRANT:

TITLE:

PERSON IN CHARGE:

\section{STANFORD UNIVERSITY}

Geophysics Department

Stanford, California 94305-2215
DE-FG03-86ER13601-A004

\author{
Porous Reservoir Rocks with Fluids: Acoustic and \\ Reservoir Transport Properties
}

Amos Nur (415-723-9526; FAX 415-723-1199;
Objectives: The overall objectives of the proposed research are to (1) relate seismic characteristics of hydrocarbon reservoirs and aquifers to rock and pore fluid properties and (2) apply the results to the design and interpretation of in situ seismic measurements to obtain rock and fluid properties, particularly for subsurface flow description and monitoring.

Our research involves combined laboratory measurements of rock properties, theoretical modeling, and field verification.

\section{Project Description:}

Cementation of unconsolidated sediments. The transition from fluid-supported to matrix-supported stress in rocks is affected by and affects elastic properties and strength as a result of cementation at intergranular contacts. Analytical methods of contact mechanics were used to obtain theoretical mechanical properties of cemented particles subject to hydrostatic and shear deformation. The microstructural contact laws obtained are used to derive macroscopic constitutive laws for cemented granular materials. To validate the model, we measure, on artificial naturally cemented particulate materials, velocities, static moduli, and strength under hydrostatic plus uniaxial loading.

Dynamic poroelasticity. Theoretical poroelasticity is used to calculate the effective moduli of saturated rock at different frequencies by exploring the hydrodynamics of the pore fluid induced by passing waves. This yields complex moduli and phase velocities and attenuation of rock. Available velocities and attenuation data are used to test the theoretical results and explore their applicability to estimating velocity/frequency dispersion in situ down to seismic frequencies.

Seismic mapping of source rocks. Experimental study continues on the relation between acoustic velocities, maturation, and the state of kerogen-rich shales. The re- sults are used to model source-rock anisotropy using effective medium theories. Results suggest that the intrinsic plus crack-induced anisotropy may be detectable in situ through high-resolution seismic measurements.

Frequency and scale. Work to date shows that rock properties affecting fluid flow can be related to seismic properties at laboratory-scale high frequencies, but because in situ frequencies are much lower we attempt to correct for differences between field, log, and laboratory frequencies. Specifically this study involves (1) upscaling modeling of waves in heterogeneous rock systems and (2) frequency dependence of seismic properties of reservoir rocks.

Basis for recovery monitoring. Using seismic imaging to obtain the flow of fluids in a producing reservoir is a promising way to improve the recovery of hydrocarbons. Three main factors control the changes of seismic signatures upon recovery: pore pressure, fluid compressibility, and fluid density. We classify recovery processes in terms of changing pore pressure, fluid compressibility, density, and viscosity. This yields velocity and impedance changes in the rock subject to recovery. We determine velocity sensitivity to changes in pore pressure and pore fluid compressibility and density for key processes and compile a catalog of seismic-related effects.

A crucial task of this study is also experimentally determining ultrasonically the compressibilities and densities of reservoir fluids vs temperature, pressure, and gas-to-oil ratio.

\section{Results:}

Cementation. The amount of cement influences the elastic properties of cemented granular materials much more than the stiffness of the cement.

$B I S Q$. The combined theory of Squirt and Biot solidfluid interaction provides the most general relation of the 
dynamic poroelastic behavior of rock to porosity, permeability, fluid compressibility, and viscosity.

Scale and heterogeneities. Modeling of wave propagation in layered media clarifies the transition from effective media at low frequencies to ray theory at high frequency. The transition is essential for reservoir characterization and description of its heterogeneity.

Source-rock mapping. Strong anisotropy in kerogenbearing rocks is a result of kerogen and bedding parallel microcracks. The resulting anisotropy velocity can be detected in situ via high-resolution seismic measurements.
Tomography interpretation. A combination of rock physics and geostatistics enables us to transform tomographic velocity images of rock between two wells into porosity images.

Velocities in rocks with hydrocarbons. The large effects of hydrocarbons on seismic velocities and their sensitivity to temperature can be used to monitor recovery processes in situ. Together with the effects of pore pressure and saturation these results provide the basis for reservoir characterization and for seismic monitoring of recovery. 


\section{GRANTEE:}

GRANT:

TITLE:

PERSONS IN CHARGE:
STANFORD UNIVERSITY

Department of Applied Earth Sciences

Stanford, California 94305-2225

\section{DE-FG03-89ER14081}

Models of Natural Fracture Connectivity: Implications for Reservoir Permeability

\author{
D. D. Pollard (415-723-4679; FAX 415-725-0979; \\ E-mail dpollard@pangea.stanford.edu) and A. Aydin (415-725-8708; \\ FAX 415-725-0979; E-mail aydin@ pangea.stanford.edu)
}

Objectives: The goals of this project are to document and characterize the geometry of natural fracture systems and their connectivity, analyze the mechanical aspects of their development, and evaluate the influence of fracture connectivity on fracture flow.

Project Description: This project seeks to develop working models for fracture connectivity based on detail mapping and observations from outcrops of sedimentary rocks typical of hydrocarbon reservoirs and ground water aquifers. The physical mechanisms responsible for fracture connectivity are then deduced from computer simulations and laboratory experiments. With a thorough understanding of fracture networks and their connectivity, the researchers then hope to apply this new knowledge in predicting reservoir permeability. Thus, this research has important implications for both the energy industry (for example characterization of fractured oil and gas reservoirs) and environmental problems (for example storage and migration of contaminants in fractured rocks). The grant has supported research carried out by two postdoctoral students and five doctoral students.

Results: Field research has elucidated the mechanism by which multiple sets of opening mode fractures develop. It is now quite obvious that temporal and spatial changes in the state of stress are responsible for the formation of two or more sets of fractures. These changes produce variations in the orientation of primary (continuous) and secondary (discontinuous) sets. Each primary set and associated secondary sets define a fracture domain. A survey of fracture patterns in a given unit in various sandstone formations of the Colorado Plateau and experimental simulation of multiple fracture domains using a brittle coating method indicate that fracture density is greater where adjacent domains overlap laterally. Thus, domain boundaries provide the best lateral fracture connectivity. However, vertically adjacent domains appear to have rather poor connectivity, especially where the strike of the adjacent primary fracture set is markedly different.

Numerical models of fracture network development have produced fracture patterns consistent with those mapped in the field and simulated in the laboratory. One of the most intriguing results is that propagation velocity of fractures may cause joint localization. Fracture propagation velocity is exponentially dependent on the stress intensity factor at the fracture tip, and the exponent is a parameter, $\alpha$, which controls spatial density and clustering. It appears that for $\alpha$ greater than one, fracture networks exhibit clustering, that is, a concentration of fractures into a narrow zone. For networks made up of two orthogonal fracture sets, the conductivity is also most strongly dependent on $\alpha$ : greater conductivity is associated with values of $\alpha$ greater than one even though the spatial density of fractures may be greater for $\alpha$ less than one. 
GRANTEE:

GRANT:

TITLE:

PERSON IN CHARGE:
STANFORD UNIVERSITY

Department of Geophysics

Stanford, California 94305-2215
DE-FG03-90ER14152

Induced Seismicity

P. Segall (415-725-7241; FAX 415-725-7344;

E-mail segall@kilauea.stanford.edu)
Objectives: The goal of this project is to develop a fundamental understanding of induced seismicity based on the mechanics of deformable porous media.

Project Description: The project is addressing two problems related to energy development: induced seismicity associated with (1) hydrocarbon production and (2) geothermal energy production. The goal is to develop appropriate physical models that successfully predict when induced seismicity is likely to occur and to determine to what extent these earthquakes can be used to infer conditions within the energy reservoir. The initial phase of the project focused on earthquakes induced by extraction of oil and gas. The next phase will be to investigate the mechanics of earthquakes induced within geothermal fields. This will involve modeling of thermo- and poroelastic effects of production and water injection. The Global Positioning System will be used to measure vertical and horizontal deformation in The Geysers geothermal field. The thermomechanical modeling will be tested against deformation and seismic data.

Results: Strong evidence exists that induced earthquakes are associated with declining reservoir pressures in hydrocarbon fields. It has been shown that a poroelastic stressing can explain many of the observations associated with induced seismicity. To quantitatively test the poro- elastic model, theoretical predictions are compared with field data from the Lacq deep gas field in southwestern France. This area has been the site of hundreds of shallow, small to moderate earthquakes since 1969. The induced seismicity began when the reservoir pressure had declined by $\sim 30 \mathrm{MPa}$. The relationship between average reservoir pressure drop and subsidence is remarkably linear, lending support to the linear poroelastic model. Displacements and stresses are computed based on a priori knowledge of the reservoir geometry, material properties, and reservoir pressure changes. The computed vertical displacements are found to be in excellent agreement with the subsidence observed from leveling. Stress perturbations accompanying gas extraction, computed using the same parameters, are found to be $\sim 0.2 \mathrm{MPa}$ or less. Changes in Coulomb failure stress are computed assuming that slip occurs on optimally oriented planes. The predicted failure zones correlate very well with the spatial distribution of earthquakes if the perturbing stresses are small in comparison to the ambient regional deviatoric stress and the minimum regional compressive stress axis is vertical. Further work is needed to determine accurate earthquake focal mechanisms. This would allow a more rigorous test of the poroelastic model and could lead to important inferences about the crustal stress state. 
GRANTEE:

GRANT:

TITLE:

PERSONS IN CHARGE:
TEXAS A\&M UNIVERSITY

Center for Tectonophysics

College Station, Texas 77843-3113

DE-FG05-87ER13711

Mechanical Properties and Modeling of Seal-Forming Lithologies

A. K. Kronenberg (409-845-0132; FAX 409-845-6780;

E-mail akk8153@geopsun.tamu.edu), J. E. Russell, and N. L. Carter

Objectives: This research addresses the mechanical properties of two weak sedimentary lithologies, shale and rocksalt, that deform under gravitational and tectonic loads and examines the roles of these lithologies in the development of structural traps and unconventional oil and gas reservoirs.

Project Description: The shapes and physical properties of a wide range of structural traps and barriers to mobile hydrocarbons are governed by the mechanical properties of shale or those of salt and by the loading histories to which they have been subjected. Concurrent experimental and modeling studies are under way to determine the fracture and flow properties of these two lithologies, to determine physically based constitutive relationships that can be applied to geologically relevant conditions, and to make predictions concerning the development and timing of structural traps relative to known depositional histories. Triaxial compression experiments provide mechanical properties for shale and rocksalt over a wide range of conditions $\left(21^{\circ} \leq \mathrm{T} \leq 200^{\circ} \mathrm{C}\right.$, $15 \leq \mathrm{Pe}_{\mathrm{e}} \leq 400 \mathrm{MPa}, 10^{-9} \leq \varepsilon \leq 10^{-3} \mathrm{~s}^{-1}$ ) and numerical modeling of salt diapirs with stratigraphic constraints on loading and ascent rates has extended predictions of mechanical response for rocksalt to strain rates of $10^{-15} \mathrm{~s}^{-1}$.
Results: During this year, experimental investigation of an illite-bearing shale from the Wilcox Formation, Louisiana, has been completed and buoyancy-driven, largely vertical flow of salt structures has been investigated. The transitional brittle-ductile mechanical properties of illite shale have been determined at confining pressures up to $400 \mathrm{MPa}$, temperatures to $200^{\circ} \mathrm{C}$ at strain rates over $10^{-7} \mathrm{~s}^{-1}$ to $10^{-3} \mathrm{~s}^{-1}$. Over these conditions, deformation mechanisms, including microcrack extension, frictional sliding, dislocation glide, and kinking have been identified using optical and electron microscopy. The strength of shale shows a nonlinear dependence on confining pressure and at the highest pressures depends on temperature and strain rate. Sample-scale modes of deformation vary with changes in load direction; however, compressional strengths show only a weak anisotropy relative to bedding. Shale strengths are strongly affected by water content, and two mechanisms of weakening may be important. Modeling studies of salt diapir ascent have been completed using both a power law associated with dislocation creep and a linear viscous law associated with fluid-assisted creep. Effects of initial salt/sediment perturbations, differential loading by sediments, and basement faults have been examined and the results compared with well-characterized salt structures. 
GRANTEE:

GRAN

TITLE:
THE UNIVERSITY OF TEXAS AT AUSTIN

Department of Geological Sciences

Austin, Texas 78712

DE-FG05-92ER14278

PERSON IN CHARGE:

Energy Flux and Hydrogeology of Thermal
Anomalies in the Gulf of Mexico Sedimentary Basin—South
Texas Example

John M. Shiarp, Jr. (512-471-5172; FAX 512-471-9425)
Objectives: The objectives of this study are to (1) evaluate if observed heat flow anomalies in the Gulf of Mexico sedimentary basin, if reconfirmed by extensive data analysis, can be accounted for by conduction alone or if convection is a significant perturbing factor; (2) determine if the present potential field is amenable to convection hypotheses; and (3) develop fluid and heat flux histories compatible with both compiled and newly collected data.

Project Description: To test the hypotheses posed to address these objectives, we have (1) compiled an extensive data base of fluid pressures, water chemistries, and formation temperatures from industrial data services, state well records, and the published literature; (2) installed these data on a geographic information system for analysis; (3) analyzed selected driil cores and cuttings for their mineralogy; (4) obtained samples from which we have collected thermal conductivity, radiogenic heat production, and porosity/bulk density data; (5) analyzed several major commercial and governmental computer codes for possible utilization; and (6) written several codes to simulate heat conduction and analyze the propensity for free convection. We are continuing to collect thermal property data, validating the temperature and pressure data to infer predevelopment conditions, calculating areal buoyancy gradients, and implementing a two-dimensional/three- dimensional model to simulate the study area's temperatures and pressures.

Results: Over 25,000 data points, reflecting basin pressures and temperatures at depths of up to nearly $5 \mathrm{~km}$ (over 16,000 ft) have been assembled for the study area. Analysis of these data reconfirmed the thermal anomalies discerned from earlier, much smaller data bases. The pressure data reveal that petroleum production has created significant depressurization that extends beyond the immediate petroleum reservoirs. This has implications for regional subsidence trends and analysis of predevelopment fluid potentials. The much more sparse water chemistry data reveal several areas with significant buoyancy gradients. The collected thermal property data have had several interesting results. First, radiogenic heat production, although small, is not insignificant and should be accounted for in simulation models. Secondly, sandstone and muddy sandstone thermal conductivities correlated best with the quartz content and much less so with porosity, which has been used in most previous simulation models. The analysis of shale cuttings indicated significant shrinkage; laboratory measurements of shale thermal conductivity, porosity, and bulk density may be suspect. Preliminary numerical modeling, which uses the real data as produced, indicates that convection is a significant factor in regionalscale heat transport over geological time unless highly unusual thermal conductivities can be documented. 
GRANTEE:

GRANT:

TITLE:

PERSONS IN CHARGE:
THE UNIVERSITY OF TEXAS AT AUSTIN

Department of Geological Sciences

Austin, Texas 78713-7909
DE-FG05-92ER14249

The Role of Mudrocks in Burial Diagenesis

Lynton S. Land (512-471-3534; FAX 512-471-9425;

E-mail lynton@maestro.geo.utexas.edu),

Kitty L. Milliken, and Larry E. Mack
Objectives: To quantify the role of mudrocks in providing the sources and sinks for material $\left(\mathrm{CaCO}_{3}, \mathrm{SiO}_{2}\right.$, acid, $\mathrm{K}_{2} \mathrm{O}$, etc.) involved in sandstone porosity loss by cementation and sandstone porosity gain by mineral dissolution.

Project Description: Complex reactions take place in sandstones and mudrocks (shales) during burial as metastable components such as detrital feldspars, unstable heavy (accessory) minerals, smectite, and kerogen are transformed to more stable phases. Mudrocks constitute approximately two-thirds of post-Mesozoic terrigenous sediments in the Gulf of Mexico sedimentary basin, yet our knowledge of the changes that take place in mudrocks during burial is limited to a very few studies of limited geographic extent. This project examines mudrock burial diagenesis in three geographic areas of varying provenance for which data on sandstone diagenesis and formation water chemistry already exist. In addition to conventional whole-rock analyses, modern geochemical (elemental and isotopic) and petrographic (electron-beaminduced luminescence and back-scattered electron imaging) techniques are being applied. It is our goal to quantify the behavior of mudrocks as sources/sinks of material in the sand-shale-water system.

Results: Approximately one-third of Gulf Coast mudrocks are composed of silt-sized calcite, feldspars, and quartz. Calcite loss during burial affects all wells studied to date but does not necessarily proceed to completion. Calcite loss is a result of pressure solution, and except for minor replacement of detrital feldspar, authigenic calcite is not redeposited in the mudrocks. On a regional basis, the volume of calcite lost from the mudrocks exceeds by a considerable margin the volume of calcite deposited as cement in sandstones. Detrital feldspars in mudrocks behave as do feldspars in sandstones, and sodium-rich Kfeldspars and calcium-rich plagioclase grains are preferentially dissolved. Albite, calcite, and sphene are common replacement phases, and albite is commonly the only feldspar that remains in the deepest rocks studied. Despite predictions that considerable authigenic quartz should be added to mudrocks as a result of clay mineral diagenesis, neither electron-beam-induced luminescence nor $\delta^{18} \mathrm{O}$ analyses support such a contention, and quartz silt appears to be quite inert. Many wells display $\mathrm{K}_{2} \mathrm{O}$ (and $\mathrm{Rb}_{2} \mathrm{O}$ ) gain with increasing depth. If zirconium, ytterbium (both determined by isotope dilution), and titanium are immobile during diagenesis, then $\mathrm{K}_{2} \mathrm{O}, \mathrm{Rb}_{2} \mathrm{O}$ (and $\mathrm{Al}_{2} \mathrm{O}_{3}$ ) have been added to the mudrocks during diagenesis, and $\mathrm{CaO}, \mathrm{SrO}, \mathrm{CO}_{2}$ (and LREEs) lost. The alternative, that the more deeply buried rocks initially had different (more potassic) compositions, is currently not supported by several lines of evidence (constant nedymium model ages, lack of correlation between europium and potassium, and inappropriate initial detrial compositions). 
GRANTEE:

GRANT:

TITLE:

PERSON IN CHARGE:
UNIVERSITY OF TULSA

Department of Geosciences

Tulsa, Oklahoma 74104

DE-FG05-88ER13417

Stability of Natural Gas in the Deep Subsurface

Colin Barker (918-631-3014; FAX 918-631-2091;

E-mail geos_cgb@vaxl.utulsa.edu)
Objectives: The main objective of the research has been to use a combined theoretical and experimental approach to estaulish deep gas composition, and to understand the factors controlling the distribution of methane and other gases in the subsurface at depths down to about $50,000 \mathrm{ft}$.

Project Description: Fluid inclusions can provide small samples of gas from deep subsurface environments. The gases in individual fluid inclusions are being analyzed using a fast-scanning, computer-controlled, dual mass spectrometer system. The host minerals are heated in a vacuum system, and as each inclusion ruptures it produces a burst of gas lasting about $25 \mathrm{~ms}$ that is analyzed by the mass spectrometers. Their output is digitized and transferred to magnetic tape for subsequent off-line processing, which provides the composition for each inclusion (background corrected). In addition, release of each gas as a function of temperature and inclusion size is available. Populations of inclusions can be presented on appropriate ternary diagrams, and from 10 to 1000 individual fluid inclusions have been analyzed in a variety of $10-\mathrm{mg}$ samples.

Gas composition in deep reservoils is also being calculated thermodynamically using a free energy minimization program that can handle up to 70 components in 20 phases.
Results: Development of analytical capabilities has continued. Currently the 12-bit analog-to-digital converter is being replaced by a 16-bit unit, and a faster data-acquisition personal computer is being installed. These changes will improve the ability to analyze trace components. Recent extensions in the software have been designed to handle improved calibration procedures and extend the information retrieved from monitoring experiments.

Fluid-inclusion gas analyses and thermodynamic calculations have been combined in a study of the Arkoma Basin of Oklahoma and Arkansas. Burial/thermal histories consistent with present-day vitrinite reflectance and coalrank data show deeper burial and higher temperatures in the past. The temperature data have been combined with mineralogic information from deep Arbuckle Formation cores and used to calculate gas composition thermodynamically. Methane appears to survive in the cooler western part of the basin (Wilburton Field), but carbon dioxide becomes a major component in the hotter eastern areas (Bonanza Field). This predicted gas composition has been confirmed by mass spectrometric analysis of gases in fluid inclusions in fracture-filling cements and overgrowths. In the Wilburton area methane dominates, whereas the fluid inclusions from Bonanza show carbon dioxide as the major gas. 
GRANTEE:
TITLE:

PERSONS IN CHARGE:

\section{GRANT:}

\author{
U.S. GEOLOGICALSURVEY \\ Department of the Interior \\ Branch of Sedimentary Processes \\ MS 939 Federal Center \\ Denver, Colorado 80225
}

\section{DE-FG05-92ER14250.000}

\section{Cretaceous Shallow Drilling in the U.S. Western Interior: Core Research}

Objectives: Construct a subsurface transect of midCretaceous strata that were deposited in the U.S. Western Interior Seaway (WIS), ranging from pelagic, organiccarbon rich, marine hydrocarbon source rocks in Kansas and eastern Colorado to near-shore, coal-bearing units in western Colorado and Utah, to provide a basis for paleoenvironmental interpretation of epicontinental, foreland basin organic-carbon burial settings.

Project Description: This project is a multidisciplinary study of Cretaceous carbonate and clastic rocks in cores along a transect across the old Cretaceous seaway that extended from the Gulf Coast to the Arctic during maximum transgressions. In particular, the study focuses on the Graneros Shale, Greenhorn Limestone, Carlile Shale, Niobrara Formation, and lower Pierre Shale in cores from three holes or groups of holes from western Kansas, southeastern Colorado, and eastern Utah. This series of cores provides unweathered samples and continuous smooth exposures required for geochemical studies, mineralogical investigations, and biostratigraphic studies. Major objectives include (1) precise timing of sea-level change, rates of subsidence, and facies change; (2) determination of controls on the accumulation, burial, and diagenesis of organic matter; (3) calibration of depositional cycles using high-resolution stratigraphy; (4) determination of the paleogeography, paleoclimatology, and paleoceanography of the WIS.
Results: The Cretaceous part of a recent AMOCO core from western Kansas was released to the U.S. Geological Survey (USGS) in 1992. Most of the objectives for the eastern (most pelagic marine) end of the transect can be met with this existing core. Three holes that form the western end of the transect, funded by USGS energy programs, were drilled and continuously cored in June 1991, in the Kaiparowits basin near Escalante, Utah.

In June 1992, a 700-ft hole [funded by the U.S. Department of Energy (DOE)] was drilled and continuously cored near Portland, Colorado, east of the Florence oil field. This sequence, deposited in relatively deep water on the west side of the WIS, includes cycles of terrigenousclastic and pelagic-marine sediments to contrast with the pelagic carbonate-dominated cycles of Kansas and the clastic-dominated cycles of western Colorado and Utah. A second, $800-\mathrm{ft}$ hole, also funded by DOE, was drilled in July 1992 about 10 miles southwest of the Portland hole in Pierre Shale that is the reservoir for hydrocarbons in the Florence field.

A core workshop was held in August 1992 at the USGS in Denver during which the research team discussed objectives and interactions, identified sampling requirements, and examined available cores. A sample protocol was developed to guide sampling for the research team and any other investigators. Geochemical analyses and biostratigraphic-paleoecologic determinations are well under way by the WIS research team for all cores. 
GRANTEE:

GRANT:

TITLE:

PERSON IN CHARGE
U.S. GEOLOGICALSURVEY

345 Middlefield Road

Menlo Park, California 94025

DE-AI03-93ER14338/A000

Causes of Abnormally High Pore Fluid Pressures in the

Uinta Basin, Utah

\section{J. D. Bredehoeft}

Objectives: The objective of this study is to investigate the cause(s) of abnormally high pore fluid pressures in the Uinta Basin, Utah.

Project Description: The Altamont-Bluebell oil field, in the deepest part of the Uinta Basin, has pore pressure that in some places exceeds 0.8 of lithostatic. There are two prevailing explanations for the high pore pressure: (1) sedimentary loading and (2) the volume expansion and collapse of porosity associated with conversion of solid kerogen to liquid oil. The purpose of this research is to test these hypotheses of pressure generation using three-dimensional, multiphase numerical simulation. These simulations will allow us to further investigate migration of oil within the Uinta Basin.

Results: In the past year, both alternative hypotheses concerning the source of the high pore pressures were investigated.

The sedimentary loading hypothesis was tested using both an analytical solution and by numerical calculations. These analyses suggest that the overpressure produced by sedimentary overburden loading alone should dissipate in approximately 10,000 years, following maximum burial-a burial that is thought to have reached maximum depth during Eocene time.

The oil-generation hypothesis was investigated using the numerical code TOUGH2. The analysis was done for a two-dimensional, cross section of the basin in which the coupled flow of oil and water and the transport of heat were simulated. The kinetic rate model for generation of oil from Green River Oil Shale has been the subject of other published investigations. The permeability distribution was taken from our analyses of drill-stem tests in the Uinta basin. The results indicate that pore pressure is sensitive to (1) the permeability distribution, (2) the initial organic content of the rock, (3) the temperature history of the Uinta Basin sediments, and (4) the porosity reduction that accompanies the phase conversion of solid kerogen to liquid oil.

The cross-sectional model analysis suggests that oil generation is a feasible mechanism to create the high pressure observed at the Altamont-Bluebell oil field. The results indicate that oil generation is probably occurring today within the Altamont-Bluebell oil field. Fracture porosity was simulated by increasing the permeability tenfold as fluid pressure reached the local value of the least principal stress.

The goal for this year is to (1) acquire additional permeability data and (2) analyze the relationship between permeability, porosity, and compaction. The data will be used in a three-dimensional, multiphase model analysis that fully represents the divergent nature of the flow regime within the Uinta Basin using a new version of the LBL model TOUGH2. 
GRANTEE:

GRANT:

TITLE:

PERSON IN CHARGE:
UNIVERSITY OF UTAH

Department of Geology and Geophysics

717 Browning Bldg.

Salt Lake City, Utah 84112

DE-FG03-93ER14313

High-Resolution Imaging of Electrical Conductivity Using Low-Frequency Electromagnetic Fields

A. C. Tripp (801-581-4664, 801-462-2112;

FAX 801-581-5560; E-mail actripp@mines.utah.edu)
Objectives: The project objective is to facilitate highresolution, low-frequency multidimensional electromagnetic subsurface imaging by emphasizing forward computation efficiency and multiple data set cooperative inversion via novel methods of regularization and parallel interpretation.

Project Description: The research focuses on three topics. The first goal is to improve three-dimensional (3-D) electromagnetic (EM) imaging via local optimization by accelerating the computations and by implementing novel regularization schemes. The second goal is to investigate distributed global optimization for 3-D EM inverse modeling using optimized forward solution code. The third goal is to use the distributed inversion approach as a platform for cooperative inversion of EM data with other data, particularly seismic data.
Results: Progress in this project has been made on two fronts. First, the 3-D EM integral equations forward code has been made more computationally efficient by coupling the system iteration and group symmetry reduction methods of solution optimization. The code with these improvements, together with the spatial symmetry method, have been compared with independent codes to check numerical accuracy and computational speed. The code agrees well with several other "bench mark" codes and is very fast.

Investigation of inversion problem regularization by optimizing the resolution of deviations from an a priori estimated model of arbitrary form has also been pursued. This method, adapted from previous work done by biomedical investigators, not only permits inverse problem regularization but also gives an adaptive method of optimal data weighing. 
GRANTEE:

GRANT:

TITLE:

\section{UNIVERSTTY OF UTAH RESEARCH INSTITUTE}

Earth Science Laboratory

391 Chipeta Way, Suite C

Salt Lake City, Utah 84108-1295

\section{DE-FG02-89ER14083}

\section{Tensor Controlled-Source Audiomagnetotelluric (CSAMT) Survey over the Sulphur Springs Thermal Area, Valles Caldera: Structural Implications and Tensor CSAMT Methodology}

Philip E. Wannamaker (801-584-4445; FAX 801-584-4453)

Objectives: The controlled-source audiomagnetotelluric (CSAMT) method is one of the principal electromagnetic techniques used in exploration for geothermal and mineral resources and in reservoir assessment and environmental assessment. Because very little geophysics had been carried out in the Quaternary Valles Caldera, the CSAMT method has been applied to extend knowledge of structure and physical state of the western caldera from the "point" truth provided by Continental Scientific Drilling Program (CSDP) drilling and surface mapping. However, this data set proves interesting also in terms of assumptions and methodology of the CSAMT technique itself.

Project Description: In support of CSDP core holes VC-2A and VC-2B, 45 tensor CSAMT soundings of high quality were obtained with our own equipment over the Sulphur Springs thermal area of the western Valles Caldera. The tensor approach has the advantage of independence of source field polarization and a complete estimation of the resistivity response regardless of dimensionality. The electric field component across strike was acquired with contiguous dipoles to ensure against undersampling the lateral response variation, which can severely reduce certainty in model resistivity. Issues addressed in CSAMT methodology include assessment of importance of inhomogeneity in the vicinity of the transmitter, analysis of controls on near-field effects over the survey area, predictability of orientation and coupling of source fields to receivers, and stability and accuracy of scalar vs vector and tensor estimates.

Results: Within the western caldera, 2-D plane-wave regime modeling indicates a resistive Bandelier Tuff section, beneath conductive debris flows, that is similar in properties to the Tuff in the Redondo Graben area and exterior to the caldera. The underlying Paleozoic section here is of much greater conductance than is observed outside the caldera, but this does not per se indicate a hydrothermal reservoir. No particularly high resistivities possibly corresponding to an implied vapor zone in the upper $500 \mathrm{~m}$ are evident in the CSAMT data. However, the Sulphur Creek fault appears to be a locus of iarge structural relief; upthrow to the west appears to be about 400 to $500 \mathrm{~m}$. Comparison and inversion of CSAMT and magnetotelluric data indicate that available depth of exploration in the plane-wave regime is only $1 / 10$ to $1 / 20$ of the transmitter separation. This is much more pessimistic than traditional assumptions of $1 / 3$ to $1 / 5$ and is diagnostic of regions with resistive crystalline basement (common). However, especially for the magnetic fields, agreement between observed and computed ellipse orientations is quite close, suggesting that one may predict incident field orientations for survey design purposes. Scalar data ignore the contributions by the on-diagonal elements of the tensor impedance, and this effect is exacerbated if the source field is poorly coupled to the sensors. Discrepancies up to $1 / 2$ order of magnitude are observed. 
GRANTEE:

GRANT:

TITLE:
UNIVERSITY OF UTAH RESEARCH INSTITUTE

Earth Science Laboratory

391-C Chipeta Way

Salt Lake City, Utah 84108-1295

TE-FG02-90ER14133

Assessing the Role of Active and Ancient Geothermal Processes in Oil-Reservoir Evolution in the Basin and Range Province

\author{
PERSONS IN CHARGE: J. B. Hulen (801-584-4446; FAX 801-584-4453) and
}

F. E. Goff, Los Alamos National Laboratory

Objectives: The project objective is to test the following hypothesis: In multiple ways, convecting, moderateto high-temperature geothermal systems (some still active) have been directly responsible for the formation of produccive petroleum reservoirs in the Basin and Range province.

Project Description: Numerous Basin and Range oil fields, for example Grant Canyon and Blackburn in eastern Nevada, are geothermally active, with reservoir temperatures in excess of $120^{\circ} \mathrm{C}$ at depths as shallow as $1.2 \mathrm{~km}$. Similarly, oil is abundant in some of the region's Carlintype, sediment-hosted gold deposits, which as epigenetic orebodies are clearly fossil geothermal systems. Is this geothermal/oil connection simply a coincidence, or is there a true genetic affiliation? To answer that question, we are studying the Nevada oil occurrences using an array of geological and geochemical techniques of proven effectiveness in characterizing not only active geothermal systems but their fossil analogues, the epithermal ore deposits. Methods include but are not limited to: (1) detailed geologic mapping as well as logging of drill cuttings and cores, with emphasis on lithology, porosity characteristics, and alteration, as well as vein mineralogy and paragenesis; (2) three-dimensional stratigraphic and structural analysis to allow reconstruction of fluid-flow paths used by both thermal waters and liquid hydrocarbons; (3) fluid-inclusion microthermometry; (4) whole-rock and vein-mineral geochemistry; (5) hydrogeochemistry of oil-field vs regional waters; and (6) light-stable-isotope systematics of these waters as well as selected vein and alteration minerals.

Results: Work this year on the thermally active Grant Canyon/Bacon Flat oil-field complex in east-central Railroad Valley, eastern Nevada, has confirmed a direct geothermal influence in forming the fields' productive oil reservoirs. Oil-bearing and aqueous primary fluid inclu- sions in late-stage quartz cementing the fields' highly porous, brecciated Devonian dolomite reservoir rock have homogenization temperatures $\left(\mathrm{T}_{h}\right)$ very close to the modern measured 1 _servoir temperature. The temperature is virtually identical when a slight pressure correction corresponding to present-day hydrostatic reservoir pressure is added to the $T_{h}$. Apparent salinities of the aqueous inclusions match the modern measured salinity of the modern oil-reservoir water. The $\delta^{18} \mathrm{O}$ value of the quartz conforms to that theoretically calculated assuming precipitation from the contemporary meteoric reservoir water at the temperature both indicated by primary fluid inclusions and measured in the modern reservoir. The quartz and contained fluid inclusions therefore record the physi$\mathrm{cal} /$ chemical setting at the onset of oil migration and entrapment, differing little from the one observed today. Oil was transported and entrapped in a still-active, moderate-temperature geothermal system. The system also helped seal the margins of the reservoir by precipitating quartz and other secondary phases, possibly developed critical secondary porosity through hydrothermal carbonate dissolution (by organic acids?), and very likely helped generate oil from otherwise submature hydrocarbon source rocks by heating these rocks to temperatures normally prevailing several kilometers deeper.

Some of the oil-rich Carlin-type gold deposits of the Alligator Ridge district, centrally locatud within the $\mathrm{Ne}$ vada oil province, are also remarkably similar in geologic setting, porosity characteristics, secondary mineralogy, and fluid-inclusion systematics to the Grant Canyon/Bacon Flat oil reservoirs. Unlike these reservoirs, however, the deposits are exposed in three dimensions through open-pit mining. These oil-bearing gold systems are being investigated as exhumed analogs of the thermally active oil fields. 
GRANTEE:

GRANT:

TITLE:

PERSON IN CHARGE:
VIRGINIA POLYTECHNIC INSTITUTE AND

STATE UNIVERSITY

Fluids Research Laboratory

Department of Geological Sciences

Blacksburg, Virginia 24061

DE-FG05-89ER14065

PVTX Properties of Fluid Systems: $\mathrm{H}_{2} \mathrm{O}-\mathrm{CO}_{2}-\mathrm{NaCl}$

R. J. Bodnar (703-231-7455; FAX 703-231-3386;

E-mail rjb@vtvml.cc.vt.edu)
Objectives: The objective of this project is to experimentally determine the pressure-volume-temperaturecomposition (PVTX) relationships of $\mathrm{H}_{2} \mathrm{O}-\mathrm{CO}_{2}-\mathrm{NaCl}$ mixtures over the complete range of PTX conditions encountered in crustal energy-, resource-, and waste-related environments. These data will then be used to develop empirical equations of state to predict the volumetric properties of these fluids in crustal rocks.

Project Description: Volumetric data provide the fundamental information needed to understand the physical and chemical behavior of fluids in energy-, resource-, and waste-related environments. Further, these data represent the foundation for developing empirical or theoretical equations of state to predict the thermodynamic properties of fluids over crustal PTX conditions. In this study, the PVTX properties of $\mathrm{H}_{2} \mathrm{O}-\mathrm{CO}_{2}-\mathrm{NaCl}$ are being experimentally determined using the synthetic fluid inclusion technique. With this technique, fluids of known composition are trapped as inclusions by healing fractures in quartz at known temperatures and pressures. Phase relations and $\mathrm{P}-\mathrm{T}$ locations of isochores in the $\mathrm{H}_{2} \mathrm{O}-\mathrm{CO}_{2}-\mathrm{NaCl}$ system are then obtained by observing the temperatures and modes of homogenization of the synthetic fluid inclusions during subsequent heating and cooling experiments in a fluid inclusion stage mounted on a petrographic microscope.

Results: During the past year the following results were achieved:

- Recently obtained experimental data for the freezing point depression (FPD) of $\mathrm{NaCl}-\mathrm{H}_{2} \mathrm{O}$ were used to develop a revised equation describing the relationship between salinity and FPD. These data are needed to interpret microthermometric data from saline natural fluid inclusions and to interpret results from synthetic fluid inclusions trapped along the $\mathrm{H}_{2} \mathrm{O}-\mathrm{NaCl}$ binary in the $\mathrm{H}_{2} \mathrm{O}-\mathrm{CO}_{2}-\mathrm{NaCl}$ system.

- The halite liquidus and isochores for a composition of 40 wt $\% \mathrm{NaCl}$ in the $\mathrm{NaCl}-\mathrm{H}_{2} \mathrm{O}$ system were determined. These data are the first and only data available for moderate salinity brines in this system. Results show that the liquidus for this composition has a negative slope in P-T space, similar to the ice I-liquid phase boundary for water, and unlike the positively sloped liquidi that characterize pure $\mathrm{NaCl}$ and the very high salinity portion of the $\mathrm{NaCl}-\mathrm{H}_{2} \mathrm{O}$ system.

- Isochores for $\mathrm{NaCl}-\mathrm{H}_{2} \mathrm{O}$ solutions having salinities from 0 to $30 \mathrm{wt} \% \mathrm{NaCl}$ were determined from the liquid-vapor curve to $5 \mathrm{kbar}$ and $700^{\circ} \mathrm{C}$. These data are being used to develop an empirical equation relating the slopes of the isochores to $T, P$, and $X$. This equation will be incorporated into a numerical model for interpreting microthermometric data obtained from water-salt inclusions from various energy-related environments.

- The effect of $\mathrm{CO}_{2}$ on the solubility of $\mathrm{NaCl}$ in aqueous solutions was determined for a composition of $40 \mathrm{wt} \%$ $\mathrm{NaCl}$ relative to $\mathrm{H}_{2} \mathrm{O}$. Results indicate a slight "gassing out" effect, which raises the temperature at which halite dissolves in this system. These experiments are aimed at trying to better understand the behavior of salt-saturated solutions as they enter a gas-rich environment and are applicable to the WIPP environment. The data suggest that if salt-saturated brines from the surrounding units flow into the repository and mix with the $\mathrm{CO}_{2}$-rich atmosphere in the repository, salt is likely to precipitate from the solutions and act as a mechanism to seal the fractures. This process will prohibit the further incursion of external fluids and lessen the probability that fluids from within the repository will flow outward and into the accessible environment. 
GRANTEE:

GRANT:

TITLE:

PERSON IN CHARGE:
VIRGINIA POLYTECHNIC INSTITUTE AND

STATE UNIVERSITY

Department of Geological Sciences

Blacksburg, Virginia 24061
DE-FG05-88ER13951

Zircons and Fluids: An Experimental Investigation with Applications for Radioactive Waste Storage

A. K. Sinha (703-231-5580; FAX 703-231-3386;

E-mail searches@vtvml.cc.vt.edu)
Objectives: The research objective of this program is to develop a predictive correlation between the physical and chemical (including uranium-lead isotopic studies) stability of $\mathrm{ZrSiO}_{4}$ and metamictization for its consideration as host for high-level radioactive waste. Past efforts have been focused on developing techniques for preparation of synthetic zircons (for use in hydrothermal experiments), developing analytical techniques for highsensitivity electron microprobe analyses, and conducting hydrothermal experiments for studying the chemical, physical and isotopic response of zircons to fluids.

Results: Our current research is focused on developing theoretical correlations between physical properties of zircons and generation of microcracks through stresses generated by volume expansion associated with amorphitization. Using elasticity theory, we have developed a model that describes the state of stress in a number $(n)$ of concentric spherical shells with different radii, bulk moduli, and shear moduli. For a zircon with a metamict core and undamaged outer shells, the model predicts that the normal stresses $\left(\sigma^{n}\right)$ will be compressional, and tangential stresses $\left(\sigma^{\mathfrak{l}}\right)$ will be extensional in the outer shells, potentially resulting in radial fractures. Alternatively, for a zircon with a metamict rim and an undamaged core, $\sigma^{n}$ may be extensional and $\sigma^{\prime}$ may be compressional, potentially causing concentric fracturing. In our model studies generating stress gradients across metamict/nonmetamict boundaries within single crystals, we estimate pressures of $\sim 450 \mathrm{MPa}$ that may be sufficient to cause natural zircon samples to show both radial and concentric fractures (also Chakoumakos et al., 1987). These fracture mechanisms must be more fully evaluated, as they will provide easy pathways for fluids and increase the surface area for fluid-solid reactions. The physical degradation must be considered one of the most fundamental issues associated with wasteform characterization. Because natural zircons of varying levels of amorphitization are available for study, we are currently in the process of characterizing such stress-induced fractures and the enhanced permeability and porosity that may accompany such a process. 
GRANTEE:

GRANT:

TITLE:

PERSON IN CHARGE:
PERSON IN CHARGE
WASHINGTON STATE UNIVERSITY

Department of Geology

Pullman, Washington 99164-2812

(Cooperative study with Westinghouse Haniord Co.)

\section{DE-FG06-91ER14172}

\author{
Origin of Flood-Basalt Volcanism on the Columbia \\ Plateau: An Integrated Approach Using Geology, Geophysics, \\ and Petrology
}

S. P. Reidel (509-376-9932 or 509-335-3009;

FAX 509-376-7816 or 509-335-7816; E-mail w65395@fepl.rl.gov)
Objectives: The principal objectives of this project are to understand the causes and evolution of flood-basalt volcanism on the Columbia Plateau, the relationship between flood-basalt volcanism and the tectonic history of the Pacific Northwest, and how flood-basalt volcanism has influenced the post-flood-basalt tectonic development of the Columbia Plateau and its resources.

Project Description: The study involves five areas: (1) a study of the main eruptive units of the Columbia River Basalt Group, including a detailed analysis of the physical and chemical aspects of the large-volume flows; (2) the structural development of the Columbia Plateau prior to, during, and following the eruption of the Columbia River Basalt Group; (3) the timing and rates of structural deformation on the Columbia Plateau and their relationships to the timing and rates of eruption of the Columbia River Basalt Group; (4) an assessment of the tectonic implications of paleomagnetic data from the Columbia River Basalt Group; and (5) a synthesis of results from studies of the Columbia River Basalt Group, tectonism in the Pacific Northwest, and resource potential.

Results: A major controversy in the petrogenesis of the Columbia River Basalt Group is the role of crustal assimilation. This study provides new evidence for crustal assimilation based on tectonic data. It has been found that the principal enuptive centers for the flood-basalts occur along the weak suture zone between the continental craton and accreted terranes where major structural basins are found. A spacial and temporal association between these features suggests that crustal material was assimilated by the basalt and forms an important component in the composition of the basalts.

Surface processes also have been found to have influenced the composition of the basalts, thus obscuring mantle signatures. Among the processes, surface mixing of rapidly erupted flows with varying compositions appears to be important in many flows.

Paleomagnetic data from the Columbia River Basalt Group suggest (1) clockwise rotation continued on the Columbia Plateau through the Miocene to the present, (2) rotations appear to correlate with the presence of weak mechanical layers like interbeds, (3) rotations are not spatially distributed west to east across the Columbia Plateau as previously argued by others but are controlled by major structural features. 
GRANTEE:
GRANT:

TITLE:

PERSON IN CHARGE:
WASHINGTON STATE UNIVERSITY, TRI-CITIES

Environmental Sciences Program

Richland, Washington 99352
DE-FG06-91ER14217

Transport in Porous and Fractured Media of the Creede Formation
Objectives: The objective of this investigation is to determine the hydrologic transport parameters of Creede Formation rocks for use in transport model development and to support geochemical and isotopic water-rock interaction models using recently developed open-flow centrifugation techniques (the UFA ${ }^{T M}$ apparatus).

Project Description: Because transport parameters have traditionally been difficult to measure in fractured and porous media, the newly developed flow apparatus, the UFA ${ }^{T M}$, based on open-flow centrifugation, is being used to directly determine hydraulic conductivity in Creede Formation rocks. In the UFA ${ }^{\mathrm{TM}}$, hydraulic steady state can be achieved in a matter of hours in fractured and porous geologic materials using a centripetal acceleration, a whole-body force, as the fluid driving force, which prevents compaction, dewatering of clays, or induced fracturing that can occur with high-pressure techniques.

The UFA ${ }^{\mathrm{TM}}$ consists of a rock core ultracentrifuge with a constant, ultralow flow-rate pump that will provide the Creede groundwater (or any fluid) to the sample through a rotating seal assembly and microdispersal system. Accelerations up to $20,000 \mathrm{~g}$ are attainable at temperatures from -20 to $150^{\circ} \mathrm{C}$ and flow rates as low as $0.001 \mathrm{~mL} / \mathrm{h}$. The effluent is collected in a transparent, volumetrically calibrated container at the bottom of the sample assembly, which is observed during centrifugation using a strobe light.

Results: Twenty plugged cores from CCM-1 and CCM-2 have been run in the UFA ${ }^{\mathrm{TM}}$ to determine hydraulic conductivity. The results show that clay alteration products dominate the present permeability characteristics of the Creede Formation, making the samples less permeable than anticipated. However, in the large alteration zone of which the $1306.9-\mathrm{ft}$ sample is a part, the permeability is significantly increased. There is no obvious correlation between permeability and any other rock property, including porosity, density, depth, resistivity, or magnetic susceptibility. As an example, two samples $3 \mathrm{ft}$ apart, $1141.5 \mathrm{ft}$ and $1144.5 \mathrm{ft}$, having very different permeabilities, $4.8 \times 10^{-12} \mathrm{~cm} / \mathrm{s}$ and $3.9 \times 10^{-8} \mathrm{~cm} / \mathrm{s}$, respectively, are identical in mineralogy, physical appearance, color, density, porosity, alteration mineralogy, in both hand specimen and in thin section. The only difference observed between the two specimens was under the scanning electron microscope (SEM), where the authigenic minerals in the sample from $1144.5 \mathrm{ft}$ appeared more euhedral and the smectite minerals had not grown across the pore spaces as much as in the sample from $1141.5 \mathrm{ft}$. This is a seemingly minor effect that would ordinarily escape notice, but it has severely affected the flow porosity and probably resulted from a slight difference in alteration history involving fluid migration rates and glass shard dissolution. This suggests that generalizations based on bulk rock properties will be misleading. Dr. Laura Crossey performed the SEM work at the University of New Mexico.

Another important result has been the observation that the downhole neutron porosity determinations matched the laboratory-determined saturated porosity measurements very well. 
GRANTEE:

GRANT:

TITLE:
WASHINGTON UNIVERSITY

Department of Earth \& Planetary Sciences

St. Louis, Missouri 63130
DE-FG02-92ER14297

PERSONS IN CHARGE:

E. L. Shock (314-935-4258) and R. H. Wood (302-831-2941)

\begin{abstract}
Developiment of an Experimental Data Base and Theories for Prediction of Thermodynamic Properties of Aqueous Electrolytes and Nonelectrolytes of Geochemical Significance at Supercritical Temperatures and Pressures
\end{abstract}

\section{Objectives: The objective of this research is to meas-}

Objectives: The objective of this research is to measure heat capacities and volumes of key compounds of importance to predictions of geochemical phenomena at high temperatures and pressures. A second objective is to use the key compounds as a data base together with simulations to develop empirical and theoretical methods for predicting a wide variety of other compounds.

Project Description: Measurements of volumes and heat capacities of a wide variety of organic electrolytes and nonelectrolytes at temperatures from 25 to $325^{\circ} \mathrm{C}$ will be made. This will allow the development of group additivity schemes to predict a very wide variety of organic species containing these functional groups. Previous measurements on $\mathrm{H}_{2} \mathrm{~S}, \mathrm{CO}_{2}, \mathrm{CH}_{4}, \mathrm{NH}_{3}$, and $\mathrm{H}_{3} \mathrm{BO}_{3}$ are being analyzed to find correlations that can predict other species. Molecular dynamics simulations of the chemical potential of aqueous methane, ethane, and propane at temperatures from 600 to $1200^{\circ} \mathrm{C}$ and water densities from 0 to $1 \mathrm{~g} / \mathrm{cm}^{3}$ have been made. Revisions of the equations of state for aqueous ions and nonelectrolytes to allow better predic- tions of properties at high temperatures and pressures will be developed.

Results: The volumes of 1-propanol, propanoic acid, pyridine, 1,4-butanediol, propylamine, adipic acid, succinic acid, propionamide, 1,6-hexanediol, 1,4-butanediamine, 1,6-hexanediamine, phenol, sodium acetate, propylamine hydrochloride, sodium propionate, and sodium benzenesulfonate have been measured at temperatures up to $250^{\circ} \mathrm{C}$. Measurements of the heat capacities are in progress. Results of the comparison of the Born model and the compressible continuum model to data on aqueous electrolytes up to $420^{\circ} \mathrm{C}$ and with simulations of the chloride ion in water at $450^{\circ} \mathrm{C}$ and $0.012 \mathrm{~g} / \mathrm{cm}^{3}$, as well as $727^{\circ} \mathrm{C}$ and $0.35 \mathrm{~g} / \mathrm{cm}^{3}$, are being written up for publication. It has been found that the equation of Harvey, Sengers, and Tanger is much more accurate in the critical region than that of Shock et al. If we know the volumes we can quite accurately estimate the heat capacities of these substances. There are also reasonable correlations of the magnitude of the critical effects, both volume and heat capacity, with critical points and Henry's law constants. 
GRANTEE:

GRANT:

TITLE:

PERSON IN CHARGE:

\section{UNIVERSITY OF WASHINGTON}

Geophysics Program

Seattle, Washington 98195

\title{
DE-FG06-92ER14231
}

\author{
Two- and Three-Dimensional Magnetotelluric Inversion
}

John R. Boctrer (206-543-9492; FAX 206-543-0489;

E-mail booker@geophys.washington.edu)

Objectives: The objective of this project is to develop efficient techniques for high-resolution imaging of the multidimensional electrical structure of the earth's subsurface.

Project Description: Because the electromagnetic inverse problem for natural sources is generally multidimensional, most imaging algorithms saturate available computer power before the complete data set can be addressed. An algorithm called the Rapid Relaxation Inverse (RRI) has been developed to directly invert large multidimensional magnetotelluric (MT) data sets. This algorithm is orders of magnitude faster than competing methods. The key to its efficiency is that an improvement in the structure directly beneath an MT site can be calculated from a one-dimensional (1-D) inverse problem if one has information about the multidimensional fields as a function of depth beneath the site. The capability of RRI for two-dimensional (2-D) structure is being enhanced and extended to fully three-dimensional (3-D) structure. In addition, related holographic electromagnetic imaging techniques are being investigated.
Results: The main enhancements to the 2-D version of RRI are incorporation of vertical-to-horizontal magnetic field transfer function data and implementation of two kinds of side conditions: arbitrary discontinuities within the model and model nodes frozen at their starting values. These constraints permit geologic, well log, and seismic structural constraints to be easily incorporated. The largest 3-D effect in most MT data is distortion of the electric field by near surface structure. As part of the effort to invert 3-D data, we have developed an improved method to decompose the MT impedance tensor into the 3-D distortion plus the response of a deeper 2-D structure that is physically simpler, computationally more linear, and statistically more stable than competitors such as Groome and Bailey. Using the efficient and accurate 3-D forward algorithm developed earlier, a 3-D RRI inversion has been tested on synthetic data with added noise with excellent results. Finally, this study has demonstrated the stability of the holographic technique called electromagnetic migration in the presence of noise. 
GRANTEE:

GRANT:

TITLE:

PERSON IN CHARGE:
UNIVERSITY OF WISCONSIN

Department of Geology and Geophysics

1215 W. Dayton St.

Madison, Wisconsin 53706

DE-FG02-93ER14328

HRTEM Investigation of Interactions between Minerals, Fluids, and Lithobiotic Communities During Natural Weathering

J. F. Banfield (608-262-0915; FAX: 608-262-0693;

E-mail jill@geology.wisc.edu)
Objectives: To examine intact lichen-mineral interfaces at the unit cell scale [primarily using high-resolution transmission electron microscopy (HRTEM)], to infer mechanisms by which lichen communities impact mineral weathering, and to compare inorganic with organically mediated reactions.

Project Description: Mineral weathering in the nearsurface involves a complex sequence of interactions between crystalline phases and fluids. The contribution of organisms to the physical and chemical degradation of crystalline materials represents an important but relatively poorly understood aspect of this important process. Organisms, specifically the members of lichen communities, participate in mineral weathering in a highly interactive way. Lichen communities release acids that accelerate mineral breakdown, thus providing nutrients essential for metabolic processes. Crystals formed on the lichen surfaces may act as sinks for relatively insoluble elements or toxic elements. HRTEM techniques will be used to characterize (at a near-atomic scale) the structure and chemistry of primary minerals and secondary minerals at the lichen-silicate mineral interface. These data will be compared with observations from minerals altered within weathering rinds and thus not subjected to direct attack by lichen-derived compounds. This investigation will enhance our understanding of how predominantly inorganic mineral weathering reactions occur in the natural environment and will reveal details of the role of lithobiotic organisms in promoting mineral dissolution.

Results: This project was only recently begun. 
GRANTEE:

GRANT:

TITLE:

PERSON IN CHARGE:
UNIVERSITY OF WISCONSIN

Department of Materials Science and Engineering

Madison, Wisconsin 53706

\section{DE-FG02-93ER14352}

\author{
The 34th U.S. Symposium on Rock Mechanics
}

Beialel C. Haimson (608-262-2563; FAX 608-262-8353;

E-mail haimson@macc.wisc.edu)
Objectives: The objectives of the symposium were (1) to promote the synthesis of diverse rock mechanics activities in professional societies, academia, industry, and government related to energy extraction, construction and basic earth sciences; (2) to advance technology transfer between the research and development rock mechanics community and industry; and (3) to focus on the latest advances in the field of rock mechanics and identify specific areas where research and development are particularly needed.

Project Description: The 34th U.S. Symposium on Rock Mechanics took place June 27-30, 1993, in Madison, Wisconsin, and was hosted by the University of Wisconsin. The conference was sponsored jointly by the U.S. National Committee for Rock Mechanics, the International Society for Rock Mechanics, and the Department of Energy Office of Basic Energy Sciences. The technical program combined 25 sessions and 3 related workshops; in addition, two 2-day short courses were offered during the preceding weekend (June 26-27). Topics for the technical sessions included Geophysical Properties of Rocks, Borehole Instability and Breakouts, Rock Mechanics in Tunneling, Modeling in Underground Mining, Experimental Techniques, Laboratory Investigations, Hydraulic Fracturing for Enhanced Recovery, Rock Mechanics in Reservoir Engineering, Building Stones and Quarries, Acoustic Emission and Failure Prediction, Yucca Mountain Project, Numerical Methods in Rock Mechanics, Constitutive Models in Rock Mechanics, Coupled Me-
chanical/Hydrologic Processes, In Situ Stress Measurements, Rock Fractures and Joints, Coal and Metal Mining and Ground Control, and Large Underground Facilities. The three workshop topics were: Stochastic Methods in Rock Engineering, Block Theory, and Coupled Fluid/Solid Mechanisms. The two short courses, Poroelasticity in Rock Mechanics and Modern In Situ Stress Measurement Methods, were designed to provide engineers and scientists with a comprehensive and coherent knowledge of the theory, the practice, and the newest developments in these areas. Three keynote papers presented new ideas in rock mechanics related to rock engineering systems, the role of pore pressure in rock mechanical process, and brittle mass failure.

Results: The symposium was attended by over 400 scientists and engineers from the United States and 23 foreign countries and supported the attendance of almost 100 graduate students in the geosciences and geotechnical engineering who came from places as remote as Beijing, China, and Lulea, Sweden, as well as from most rock mechanics centers within the United States. Preprint proceedings, containing four-page summaries of each of the more than 190 presentations (selected from over 330 submitted), were distributed at the symposiur.ı. Some 160 peer-reviewed manuscripts were accepted for publication in a supplemental issue of the International Journal of Rock Mechanics and Mining Sciences to be available in December 1993. 


\section{GRANTEE:}

GRANT:

TITLE:

PERSON IN CHARGE:
UNIVERSITY OF WISCONSIN

Department of Geology and Geophysics

Madison, Wisconsin 53706

DE-FG02-93ER14389

Microanalysis of Stable Isotope Ratios in Geothermal

Systems: Long Valley and Skye

John W. Valley (608-263-5659; FAX 608-262-0693;

E-mail valleyegeology.wise.edu)
Objectives: This project will evaluate the different styies of isotopic zonation recorded in the product of hydrothermal alteration in the Long Valley Caldera system and the Isle of Skye system and elucidate the causes of such heterogeneity.

Project Description: This project will use laser probe, ion microprobe, and conventional techniques to study submillimeter-scale zoning of stable isotope ratios of $\mathrm{O}$, $\mathrm{C}$, and $\mathrm{H}$ in hydrothermally altered rocks from the Long Valley Caldera, California, and the Isle of Skye, Scotland. The project will document the different styles of isotopic zonation and elucidate the causes of such heterogeneity. Results of the study will address longstanding questions relating to hydrothermal alteration, for instance: Was fluid flow homogeneous or localized along cracks or grain boundaries? What portion of a mineral equilibrated with a fluid and when? What was the dominant mechanism of exchange? Enhanced understanding of these processes is essential for improving computer models of fluid flow through hot rocks. Studies of mineral zonation will also permit refinements in thermometry for paleogeothermal systems, enhancing the information gained through drilling.

The research will be performed using two laser probes at the University of Wisconsin to provide rapid and highly precise analysis of samples for $\delta^{18} \mathrm{O}$ at 300 to $500 \mu \mathrm{m}$ spatial resolution. Ion-probe analysis at the University of Edinburgh will be used on selected samples for extra-high spatial resolution ( 2 to $10 \mu \mathrm{m}$ ). Conventional isotope techniques will be used fc. $\delta{ }^{13} \mathrm{C}$ and $\delta \mathrm{D}$ and will guarantee accuracy for $\delta^{18} \mathrm{O}$ measurements.

Results: This project began September 1, 1993. 


\section{GRANTEE:}

GRANT:

TITLE:

PERSON IN CHARGE:

\section{UNIVERSITY OF WISCONSIN}

Department of Geology and Geophysics

Madison, Wisconsin 53706

\title{
DE-FG02-91ER14194
}

\author{
Poroelasticity of Rock
}

H. F. Wang (608-262-5932; FAX 608-262-0693;

E-mail wang@geology.wisc.edu)

Objectives: The primary objective is to obtain laboratory measurements of poroelastic parameters to predict rock mass behavior under conditions from quasistatic (Darcy flow) to dynamic (seismic, borehole, and ultrasonic frequencies). A secondary objective is to develop fluid-flow models for rock masses containing deformable fractures.

Project Description: The main scientific issue is to understand the fluid response of a rock mass to stress and vice versa. The goal is to characterize this coupled response from quasistatic Darcy flow through seismic, well $\log$, and ultrasonic regions. The quasistatic poroelastic constants characterize such coupled phenomena as fluid extraction from reservoirs and fluid pressure response to the stress field generated by an earthquake. The dynamic poroelastic response allows interpretation of elastic wave velocity and attenuation data in terms of rock lithology, permeability, porosity, and compressibility.

Results: The pulse decay method is a standard technique for obtaining permeability and specific storage of low-permeability rocks. The sensitivity coefficients of pressure decay with respect to permeability and specific storage are greatest during the rapid portion of the pulse decay. The error in specific storage is lowest when the sample storage approximates the upper reservoir storage.

The pulse-echo method for shear waves has been used to measure wave attenuation in Berea sandstone as a function of pressure, saturation, and frequency. The dry samples all show a strong decrease of attenuation with increasing pressure as a result of microcrack-dominated loss. The attenuation in a $90 \%$ saturated sample is intermediate between that for dry samples and the relatively high attenuation in fully saturated samples. The high attenuation in the fully saturated sample implies some form of fluid-flow loss.

Skempton's coefficient (pore pressure buildup with increase in confining pressure under undrained conditions) on a series of synthetic sandstones and Massillon sandstone is essentially 1.0 at low effective pressure but decreases to 0.7 to 0.8 at higher effective pressures. These values indicate that significant stress field coupling will occur for typical sandstones at depths approaching $1 \mathrm{~km}$.

A computer code has been developed to model a well in a horizontally fractured reservoir separating matrix blocks. The principal new feature of the code is accounting for the fracture compressibility as a function of the effective stress on the fracture. 
Woods Hole, Massachusetts 02543

GRANT:

TITLE:

PERSON IN CHARGE
DE-FG02-92ER14232

\author{
Geochemical Incorporation of Sulfur into Organic Matter: \\ Role of Sulfur in the Formation and Diagenesis of \\ Macromolecular Organic Matter in Sediments
}

Timothy I. Eglinton (508-457-2000 Ext. 2627; FAX 508-457-2164;

E-mail teglinton@whoi.edu)

Objectives: The three major objectives of the project are as follows:

- development and evaluation of structural models quantitatively describing organically bound sulfur in sediments,

- assessment of sulfur incorporation into organic matter as a preservation (kerogen formation) mechanism, and

- appraisal of proposed diagenetic pathways for organically bound sulfur.

Project Description: Important questions concerning organic sulfur in fossil fuels are: How and when is sulfur introduced into the natural biogenic materials that are the precursors of fossil fuels? Why and how do the abundance and forms of organically bound sulfur differ in various geologic environments? And how does organically bound sulfur evolve with geological maturation? Sulfur (as H2S or polysulfides) is believed to be incorporated during the early stages of diagenesis and may react with organic matter in an intra- or intermolecular fashion. The latter mechanism has been proposed to give rise to the formation of sulfur cross-linked macromolecules ("natural vulcanization"), which are believed to be responsible for early petroleum generation from organic sulfur-rich source rocks.

An integrated analytical approach has been adopted using complimentary techniques to provide gross and molecular-level information on organically bound sulfur: $\mathrm{X}$-ray absorption spectroscopy (XANES) is used to quantitatively assess sulfur speciation and, in particular, to distinguish between organic sulfides, thiophenes, and sulfoxides. Chemical degradation experiments are employed to selectively cleave organic molecules linked by sulfur, providing information on linkage type, the sites of sulfur attachment, the number of linkages involved, and the molecular structures of the sulfur-containing molecules. Analytical pyrolysis is used to derive additional structural information and to provide estimates on organic sulfur content. This information is assimilated and used to develop structural models quantitatively describing macromolecularly bound sulfur.

The Peru margin was selected as the primary study area because of its high sedimentary organic carbon and organic sulfur contents (total organic carbon $>10 \%$; Sorg. up to $10 \%$ ) and because of the perception of these sediments as a modern immature analog of Monterey Formation and other sulfur-rich source rocks.

Results: Preliminary data confirm that sulfur incorporation is an early diagenetic phenomenon in Peru margin sediments, with the majority of organically bound sulfur forming in the upper few meters of sediment. XANES analyses of both total sediment and bitumen fractions reveal that most of the organically bound sulfur in these sediments is present as organic sulfides. In contrast to Peru margin sediments, XANES analyses of Monterey and other consolidated sediments reveal that thiophenic sulfur equals or exceeds the concentration of organic sulfides. Pyrolysis-gas chromatographic analyses of kerogens from the Peru depth sequence also reveal a dominance of organic sulfides in the macromolecular materials; however, evidence was found for a significant increase in thiophenic sulfur with depth, even in these unconsolidated sediments. An on-line derivitization method has been developed for analysis of polar and volatile sulfur-containing pyrolysis products.

Two sediment samples (a surficial, $<1 \mathrm{~m}$, Peru sample and an immature Monterey Formation sample) were solvent extracted, and the resulting bitumens were separated into a series of molecular-size fractions by preparative gel 
permeation chromatography. XANES analyses of these fractions isolated from the Monterey shale sample revealed a distinct trend, with the percentage of sulfide sulfur increasing with increasing molecular size. This relationship is consistent with the concept of sulfide bridges as determinants of molecular size. No such trend was apparent in the Peru-size sample suite, suggesting that this relationship has no importance to the very earliest stages of diagenesis.

\section{GRANTEE:}

GRANT:

TITLE:

PERSON IN CHARGE:

\section{WOODS HOLE OCEANOGRAPHIC INSTTTUTION \\ Department of Marine Chemistry and Geochemistry \\ Woods Hole Oceanographic Institution \\ Woods Hole, Massachusetts 02543}

\section{DE-FG02-89ER13466}

\author{
Organic Geochemistry of Outer Continental \\ Margins and Deep-Water Sediments
}

J. K. Whelan (508-457-2000 Ext. 2819; FAX 508-457-2164; E-mail jwhelan@whoi.edu)
Objectives: To develop a better understanding of processes of hydrocarbon generation and migration in coastal and offshore sedimentary basins, particularly with respect to gas, as an aid in (1) better understanding of basin fluid flow processes, (2) developing better quantitative tools for gas and oil exploration, and (3) predicting favorable exploration areas.

Project Description: Recently, our collaboration with other academic and industrial laboratories as part of the Global Basin Research Network (GBRN) has shown that the wide variety of hydrocarbon parameters currently used in oil exploration are also valuable in understanding basic sedimentary basin fluid flow processes, crucial to production of drinking water, metal ore deposits, and gas and oil. Research focuses on

1. Insertion of Louisiana Gulf Coast organic geochemical data into a GBRN "data cube," which allows a threedimensional overlaying of geological, geophysical, and geochemical data, thereby providing a "reality check" for computer models.

2. Hydrous pyrolysis experiments on immature analogs of potential Gulf Coast petroleum source rocks to define amounts and rates of gas generation potentially available for oil migration processes, sediment overpressuring, and opening of faults as migration conduits. The resulting kinetic and thermodynamic parameters are being included in GBRN "process" computer mod- els currently under development on the supercomputer at Cornell.

3. Development of new organic geochemical methods for examining fluid migration pathways and calibrating sediment maturation.

\section{Results:}

1. A variety of hydrocarbon indicators are consistent with a remarkable picture of "dynamic injection" of gas and oil into Louisiana Gulf Coast Eugene Island-330 (EI330) reservoirs at present. These parameters include (a) the presence of gas together with biodegraded oils; (b) very mature gases in the presence of considerably less-mature oils; (c) $\mathrm{C} 7$ hydrocarbon ratios indicative of recently migrated condensate; and $(d)$ biomarker and carbon-specific isotopic evidence for a common source for all EI-330 oils that is different from that of more typical Gulf Coast shelf oils, such as those in nearby South Marsh Island 128 (SMI-128). These data are consistent with other GBRN geological and geochemical indicators of dynamic injection, including $(a)$ overproduction in EI-330 in comparison to surrounding blocks, $(b)$ temporal variation in gas and oil compositions over the last 15 years, $(c)$ coherent pressure and temperature anomalies, and $(d)$ temporal variations in seismic amplitude anomalies (bright spots) associated with the EI-330 fault system. 
2. Isothermal hydrous pyrolysis results from the oxidized gas-prone Gulf Coast Eutaw Shale that can be fitted to a distributed activation energy model in which carbon dioxide evolves at both low and high energies (maxima at 42 and $62 \mathrm{kcal} / \mathrm{mol}$ ), ethane at about $54 \mathrm{kcal} / \mathrm{mol}$, and methane at high energy $(75-78 \mathrm{kcal} / \mathrm{mol})$. Variations in the frequency factors, which are not assumed in these calculations, depend on the spacing picked for the distribution model and were found to cause geologically significant variations in the resulting Ea values. These initial results also suggest that even this relatively poor source rock could generate sufficient methane to solubilize and aid in migration of indigenous oil at depth.

The apparatus used in these experiments had no gas head space, thus eliminating artifacts caused by the gases partitioning into the gas phase during the experiment. Liquids and gases, including hydrogen, were sampled and measured on-line during the experiment. Work is in pro- gress to determine how general these results are for other Gulf Coast rocks.

Results from other hydrous pyrolysis rock-buffer experiments suggest that water may be a source of at least part of the hydrogen required for gas generation at depth, thus suggesting that some gas generation occurs to much greater depths than previously thought.

3. Middle valley sediments recovered from the northern end of the Juan de Fuca Ridge in the eastern Pacific, off British Columbia, provided an excellent opportunity to compare various methods of measuring and estimating thermal maturity. Maximum subsurface temperature, as determined by bottom hole temperature measurements, vitrinite reflectance measurements, nuclear magnetic resonance values and pyrolysis thermal gravimetric Fourier transform infrared pyrolysis measurements, was calibrated and found to agree to within $\pm 10^{\circ} \mathrm{C}$. 
GRANT:

TITLE:

PERSONS IN CHARGE:
DE-FG02-90ER14153

\section{Reactive Fluid Flow and Applications to Diagenesis, Mineral Deposits, and Crustal Rocks}

A. C. Lasaga (203-432-3114; FAX 302-432-3134) and

D. M. Rye
Objectives: Objectives of this project are to integrate new results and develop new techniques along three directions: (1) experimental studies of water-rock reactions, (2) theoretical modeling of coupled fluid flow-chemical reactions, and (3) isotopic measurements of both regional isotopic compositions as well as isotopic zoning within individual mineral grains.

Project Description: The main thrust of the theoretical modeling has been to develop further the differences between equilibrium, steady-state, and non-steady-state behavior of the chemical evolution of open fluid-rock systems. These differences have not been fully appreciated in previous models. This project will continue the development of a computer code that numerically treats multicomponent, finite-rate reactions combined with advective and dispersive transport in one, two, and three dimensions and which incorporates isotopic exchange and heat and mass transfer. In particular, current research is focusing on the proper approaches to modeling flow that can occur along both fractures and porous media simultaneously. Another important goal is to include a sophisticated algorithm that enables the code to track evolving reaction fronts efficiently and without introduction of numerical dispersion.

To apply the models to field data, the project plans to develop techniques to measure isotopic zonation within individual mineral grains. These techniques include: (1) micro-drilling of samples with a fine dental drill coupled with a micro volume inlet system on the mass spectrometer and (2) separation of minerals from fine grain rocks by a series of dissolution steps.

Numerical codes and sampling techniques are being tested in a number of fields. These include: (1) the Marysville contact aureole, (2) the Wepawaug metamorphic schist, (3) the Irish base-metal ore system, (4) the Naxos metamorphic complex, and (5) the Pijiguaos bauxite deposit.

The numerical codes, isotopic measurements, and field studies will be integrated with extensive ab initio research and surface chemistry studies on the kinetics of water-rock reactions.

Results: We have found that mixing fluids in two-dimensional models (from processes such as dispersion) has profoundly different chemical patterns from those found in the one-dimensional models.

Several major conclusions were drawn from the Marysville work. First and foremost, both fluid flow and the kinetics of metamorphic reactions can have a major effect in modifying isograd development. The kinetics of metamorphic reactions can also have an important effect on fluid composition. As a result, the equilibrium $\mathrm{T}-\mathrm{XCO}_{2}$ curves need not be followed during metamorphic events. Of great note is that this conclusion can be reached using kinetics that are actually measurable in the laboratory. The kinetic effects, when coupled with fluid flow considerations, allow extensive reaction to occur along the univariant $T-X$ curves. This drastic deviation from the usual assumptions based on no-flow and infinite-kinetics leads to the conclusion that invariant points may not necessarily be the loci of identifiable isograds in the field. To properly interpret the field data, additional factors such as mineral abundances, rock texture, heating rate, and reaction kinetics must be introduced.

The experimental work pioneered in our laboratories has produced several startling results on the kinetic rate laws of silicate-water reactions. The approach to equilibrium has been shown to follow a nonlinear path in rate constant-free energy space. This behavior is quite distinct from most work done by geochemists on modeling silicate behavior in diagenesis, weathering, hydrothermal systems, or environmental models. To date, work has involved 
albite, kaolinite, muscovite, analcime, clinoptilolite, and gibbsite. Atomic force microscope studies of the surfaces of reacted kaolinite and muscovite have been successfully carried out, and in situ studies are just beginning.

In the Wepawaug Schist, the application of the experimental data to the kinetics of isotopic exchange of water with quartz and the model results has shown that fluid flow was transient in the crack. Analysis of the overall fluid flow systematics in the Wepawaug Schist was approached by looking at data from the entire metamorphic complex. In particular, the paragenetic, chemical, mineralogical, and field data were compared to the coupled fluid flow models and to the known kinetic data to put realistic constraints on the fluid flux through the complex. The realization that scale is important is precisely why Wepawaug Schist was studied at three different length scales (grain-grain, lithologic-lithologic unit, and metamorphic complex scale). 
TOPICAL INDEX

GEOPHYSICS AND EARTH DYNAMICS

Large-Scale Earth Dynamics . . . . . . . . . . . . . . . . . . . 27, 49, 94, 95, 105, 108, 113, 127, 128 Evolution of Geologic Structures . . . . . . . . . . . . . 11, 26, 31, 34, 50, 51, 62, 96, 113, 134 Properties of Earth Materials . . . . . 15, 16, 17, 19, 24, 25, 27, 28, 37, 49, 62, 78, 80, 82, 100, 102,103, $104,110,111,118,119,123,141$

Rock Mechanics, Fracture, and Fluid Flow . . . 5, 9, 10, 15, 16, 17, 18, 49, 82, 85, 91, 94, 97, 100, 102, $103,118,119,121,122,123,124,135,139,141$

Underground Imaging $\ldots \ldots \ldots \ldots \ldots$. $\quad \ldots, 9,10,16,23,25,26,28,37,50,71,85,86,92,101,103,108$, $114,122,129,130,137$

\section{GEOCHEMISTRY}

Thermochemical Properties of Geologic Materials . . . 12, 21, 22, 32, 38, 39, 40, 41, 43, 53, 64, 67, 69, $72,74,75,80,81,83,84,110,111$, $116,118,132,133,136,138$

Rock-Fluid Interactions $\ldots . .3,5,13,26,28,29,30,31,33,39,41,42,43,44,52,63,66,79,87,88,89$, $90,96,112,116,117,125,131,132,133,140,145$

Organic Geochemistry . . . . . . 4, 5, 20, 38, 40, 63, 70, 77, 84, 90, 98, 106, 107, 113, 128, 136, 142, 143 Geochemical Transport . . . . 3, 12, 26, 28, 29, 30, 31, 32, 33, 38, 39, 40,41, 42, 43, 44, 52, 53, 66, 67, $68,70,74,75,76,83,88,89,99,110,112$, $117,125,126,131,132,133,138,145$

\section{ENERGY RESOURCE RECOGNITION, EVALUATION, AND UTILIZATION}

Resource Definition and Utilization $\ldots \ldots \ldots .14,31,45,46,55,56,113,115,117,130,131,143$ Reservoir Dynamics and Modeling . . . . . 13, 33, 50, 51, 54, 55, 87, 97, 98, 99, 100, 106, 107, 121, 122 , $124,126,128,131,137,140,143$ Properties and Dynamics oi Magma $\ldots \ldots \ldots \ldots \ldots \ldots \ldots \ldots \ldots \ldots, 34,74,8 \ldots, 94$ Continental Scientific Driiling . . . . . . . . . . . 24, 34, 54, 56, 60, 96, 109, 114, 127, 130

\section{HYDROGEOLOGY AND EXOGEOCHEMISTRY}

Fluid Transport Dynamics and Modeling $31,50,52,78,87,91,94,97,124,140,141,145$ Thermochemical Properties of Energy Materials $78,90,128$ Perturbations of Fluid Flow $116,121,135$

\section{SOLAR-TERRESTRIAL INTERACTIONS}

Magnetospheric Physics $35,36,47,59$ Upper Atmosphere Chemistry and Physics 


\section{INDEX OF TECHNICAL CONTRIBLTORS}

CONTRIBUTOR

Adler, $\mathrm{L}$.

Akasofu, S.-1.

Aki, $\mathrm{K}$.

Anovitz, L. M.

Arehart, G. B.

Arnold, G. W.

Arthur, M. A.

Attrep, M., Jr.

Aydin, A.

Bakel, A. J.

Baldridge, W. S.

Banfield, J. F.

Barker, C.

Becker, A.

Bell, D. R.

Bell, J. L. S.

Berryman, J. G.

Birn, J.

Bish, D. L.

Blair, S. C.

Blencoe, J. G.

Bodnar, R. J.

Bonner, B. P.

Booker, J. R.

Boyd, F. R.

Braun, R. L.

Bredehoeft, J. D.

Brown, G. E., Jr.

Burch, T

Burnham, A. K.

Carmichael, I. S. E.

Carter, N. L.

Casey, W. H.

Charles, R. W.

Cheng, C. H. A.

Chiarello, R. P.

Cole, D. R.

Compton, J. S.

Conca, J. L.

Cook, N. G. W.

Crossey, L. J.

Curtis, D. B.

Cygan, R. T.

Daily, W. D.

Dean, W. E.

DePaolo, D. J.
INSTITUTION

PAcils

The Ohio State University . . . . . . . . . . . 104

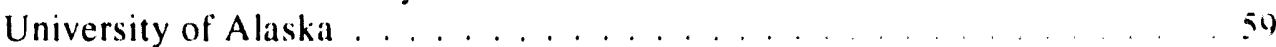

University of Southern California ............ 114

The University of Arizona . . . . . . . . . . . . . . . . . . . . . ot

Argonne National Laboratory . . . . . . . . . . . . . . . . . . . . . . . 3

Sandia National Laboratories . . . . . . . . . . . . . . . . . . . 53

Pennsylvania State University . . . . . . . . . . . . . . . . . . 109. 127

Los Alamos National Laboratory . . . . . . . . . . . . . . . . . . 31

Stanford University . . . . . . . . . . . . . . . . . . . 121

Argonne National Laboratory . . . . . . . . . . . . . . . . . . . . . . . 4

Los Alamos National Laboratory . . . . . . . . . . . . . . . . . . . . 26

University of Wisconsin . . . . . . . . . . . . . . . . . . . . . . . 138

University of Tulsa . . . . . . . . . . . . . . . . . . . . . 126

Lawrence Berkeley Laboratory . . . . . . . . . . . . . . . . . . . 8

Carnegie Institute of Washington . . . . . . . . . . . . . . . . . . . . 79

Oak Ridge National Laboratory . . . . . . . . . . . . . . . . . . . . . . 38,40

Lawrence Livermore National Laboratory . . . . . . . . . . . . . . . 16, 23

Los Alamos National Laboratory . . . . . . . . . . . . . . . . . . . . . 35

Los Alamos National Laboratory . . . . . . . . . . . . . . . . . . . . . 29

Lawrence Livermore National Laboratory . . . . . . . . . . . . . . . . . . . . 16

Oak Ridge National Laboratory . . . . . . . . . . . . . . . . . . . . . . 35, 40,42

Virginia Polytechnic Institute and State University . . . . . . . . . . . 132

Lawrence Livermore National Laboratory . . . . . . . . . . . 15, 16, 17, 28

University of Washington . . . . . . . . . . . . . . . . . 137

Carnegie Institute of Washington . . . . . . . . . . . . . . . . . . . . . . 79

Lawrence Livermore National Laboratory . . . . . . . . . . . . . . . . 20

U.S. Geological Survey . . . . . . . . . . . . . . . . . . . . . 128

Stanford University . . . . . . . . . . . . . . . . . . . . . 116

Oak Ridge National Laboratory . . . . . . . . . . . . . . . . . . . . . . . 39

Lawrence Livermore National Laboratory . . . . . . . . . . . . . . . . 20

University of California at Berkeley . . . . . . . . . . . . . . . . 69

Texals A\&M University . . . . . . . . . . . . . . . . . . . . . . . 123

University of California at Davis . . . . . . . . . . . . . . . 53,72

Los Alamos National Laboratory . . . . . . . . . . . . . . . . . . 26

Massachusetts Institute of Technology . . . . . . . . . . . . . 91

Argonne National Laboratory . . . . . . . . . . . . . . . . . . . . . 3

Oak Ridge National Laboratory . . . . . . . . . . . . . . . . . 38, 39, 41, 42,43

University of South Florida . . . . . . . . . . . . . . . . . . . 115

Washington State University, Tri-Cities . . . . . . . . . . . . 135

Lawrence Berkeley Laboratory . . . . . . . . . . . . . . . . . . . 9, 10

University of New Mexico . . . . . . . . . . . . . . . . . . . . 96

Los Alamos National Laboratory . . . . . . . . . . . . . . . . . 30

Sandia National La'uoratories . . . . . . . . . . . . . . . . . . . . 52,53

Lawrence Livermore National Laboratory . . . . . . . . . . . . . . . . . 23

U.S. Geological Survey . . . . . . . . . . . . . . . . . . . . . . . 109, 127

Lawrence Berkeley Laboratory . . . . . . . . . . . . . . . . . . . 12 
Devaney, A. J.

Dixon, P. R.

Duba, A. G.

Durham, W. B.

Eberli, G.

Egbert, G. D.

Eglinton, T. I.

Eichelberger, J. C.

Elbring, G. J.

Elmore, R. D.

Engel, M. H.

Epstein, S.

Ernst, W. G.

Fabryka-Martin, J. T.

Fakui, L.

Farver, J. R.

Fehler, M.

Felmy, A. R.

Ferrell, R. E.

Foley, M. G.

Foote, H. P.

Fritz, S. J.

Gardner, J. N.

Gary, S. P.

Gisler, G. R.

Goff, F. E.

Goff, S. J.

Goldstein, S. J.

Guthrie, G. D., Jr.

Hacker, B.

Hackett, W. R.

Haimson, B. C.

Hanson, G. N.

Harrison, T. M.

Heasler, P. G.

Heiken, G.

Helgeson, H. C.

Hill, H. A.

Holcomb, D. J.

Holt, B. D.

Hones, E. W., Jr.

Hoover, K. A.

Horita, J.

House, L.

Hulen, J. B.

Ilton, E. S.

Jacobs, G. K.

Jacobson, R.

Janecky, D. R.

Johnson, A. M.

Johnson, P. A.
Northeastern University

37,101

Los Alamos National Laboratory . . . . . . . . . . . . . . . . . . . 30

Lawrence Livermore National Laboratory . . . . . . . . . . . . . . . 17,27

Lawrence Livermore National Laboratory . . . . . . . . . . . . . . . . 15, 16

University of Miami . . . . . . . . . . . . . . . . . . . . . 92

University of California at Berkeley . . . . . . . . . . . 71, 108

Woods Hole Oceanographic Institution . . . . . . . . . . . . . . . 142

University of Alaska . . . . . . . . . . . . . . . . . . . . . 60

Sandia National Laboratories . . . . . . . . . . . . . . . . . . 50

University of Oklahoma . . . . . . . . . . . . . . . . . . . . . 106

University of Oklahoma . . . . . . . . . . . . . . . . . . . . . 106

California Institute of Technology . . . . . . . . . . . . . 67

Stanford University . . . . . . . . . . . . . . . . . . . 117,118

Los Alamos National Laboratory . . . . . . . . . . . . . . . . . . . 30

UNC, Grand Junction . . . . . . . . . . . . . . . . . . . . . . . . . 34

Brown University . . . . . . . . . . . . . . . . . . . . . . . 666

Los Alamos National Laboratory . . . . . . . . . . . . . . . . 25, 26, 27

Pacific Northwest Laboratory . . . . . . . . . . . . . . . . . . . . . . . 44

Louisiana State University . . . . . . . . . . . . . . . . . . . . . . 90

Pacific Northwest Laboratory . . . . . . . . . . . . . . . . . . . . . 45

Pacific Northwest Laboratory . . . . . . . . . . . . . . . . . . . . . . . . 46

Purdue University . . . . . . . . . . . . . . . . . . . . . . . . . 112

Los Alamos National Laboratory . . . . . . . . . . . . . . . . 33

Los Alamos National Laboratory . . . . . . . . . . . . . . . . . . . 35

Los Alamos National Laboratory . . . . . . . . . . . . . . . . . . . . . . 36

Los Alamos National Laboratory . . . . . . . . . . . . . . . . . . 33, 131

Los Alamos National Laboratory . . . . . . . . . . . . . . . . . . . 34

Los Alamos National Laboratory . . . . . . . . . . . . . . . . . . . . . 28

Los Alamos National Laboratory . . . . . . . . . . . . . . . . . . . 29,93

Stanford University . . . . . . . . . . . . . . . . . . . . . . . 118

Idaho National Engineering Laboratory . . . . . . . . . . . . . 7

University of Wisconsin . . . . . . . . . . . . . . . . . . . . . . . . . . . 139

State University of New York at Stony Brook . . . . . . . . . . . . . . . . 99

University of California at Los Angeles . . . . . . . . . . . . . 75

Pacific Northwest Laboratory . . . . . . . . . . . . . . . . . . . . . 45

Los Alamos National Laboratory . . . . . . . . . . . . . . . . . . . . 34

University of California at Berkeley . . . . . . . . . . . . . . 70

The University of Arizona . . . . . . . . . . . . . . . . . . 65

Sandia National Laboratories . . . . . . . . . . . . . . . . . . . . . . 24,55

Argonne National Laboratory . . . . . . . . . . . . . . . . . . . 3

Los Alamos National Laboratory . . . . . . . . . . . . . . . . . . 35

Pacific Northwest Laboratory . . . . . . . . . . . . . . . . . . . . . 45

Oak Ridge National Laboratory . . . . . . . . . . . . . . . . . . . . . 41,43

Los Alamos National Laboratory . . . . . . . . . . . . . . . . . . . . . 25

University of Utah Research Institute . . . . . . . . . . . . . . 33, 131

The Johus Hopkins University . . . . . . . . . . . . . . . . . . . . 88

Oak Ridge National Laboratory . . . . . . . . . . . . . . . . . . . . . . 37

Sandia National Laboratories . . . . . . . . . . . . . . . . . . . . . 54

Los Alamos National Laboratory . . . . . . . . . . . . . . . . . . 31, 32

Purdue University . . . . . . . . . . . . . . . . . . . . 113

Los Alamos National Laboratory . . . . . . . . . . . . . . . . 28 
Johnson, M. C. Jones, K. W. Joyce, D. B.

Kennedy, B. M. Kleckner, E. W. Koplik, J.

Krier, D.

Kronenberg, A. K. Lambert, S. J.

Land, L. S.

Larson, N. R.

Lasaga, A. C.

Lee, L. C.

Lee, K. H.

Lesher, C. E.

Lindquist, W. B.

Liou, J. G.

Long, J. C. S.

Lysne, P.

Mack, L. E.

Majer, E. L.

Mango, F. D.

Manowitz, B.

Mathez, E. A.

McDonald, J. A.

McEvilly, T. V.

McKeegan, K. D.

McTigue, D. F.

Meyers, S. L.

Meyers, W. J.

Miller, D. G.

Milliken, K. L.

Morrison, H. F.

Moses, C. O.

Murrell, M. T.

Myer, L. R.

Myers, C. W.

Nagy, P. B.

Naney, M. T.

Navrotsky, A.

Newman, G. A.

Noorishad, J.

Norton, S.

Nur, A. M.

Onstott, T. C.

Ortoleva, P.

Parks, G. A.

Philp, R. P.

Pickett, D. A.

Pitzer, K. S.

Pollard, D. D.
Columbia University

Brookhaven National Laborator!

Oak Ridge National Laboratory

Lawrence Berkeley Laboratory

Pacific Northwest Laboratory

The City College of the City University of New Yord _ . . . . . . . 97

Los Alamos National Laboratory . . . . . . . . . . . . . . . . 34

Texas A\&M University . . . . . . . . . . . . . . . . . . 123

Sandia National Laboratories . . . . . . . . . . . . . . . . . . . . 52

The University of Texas at Austin . . . . . . . . . . . . . . 125

Pacific Northwest Laboratory . . . . . . . . . . . . . . . . . . . . 47

Yale University . . . . . . . . . . . . . . . . . . . . . . . . 145

University of Alaska . . . . . . . . . . . . . . . . . . . . . . . . . 59

Lawrence Berkeley Laboratory . . . . . . . . . . . . . . . . . . . 8

University of California at Davis . . . . . . . . . . . . . . 74

State University of New York at Stony Brook . . . . . . . . . . . . . . 5, 100

Stanford University . . . . . . . . . . . . . . . . . . . . . . 118

Lawrence Berkeley Laboratory . . . . . . . . . . . . . . . . . . . . 10

Sandia National Laboratories . . . . . . . . . . . . . . . . 54,56

The University of Texas at Austin . . . . . . . . . . . . . . . 125

Lawrence Berkeley Laboratory . . . . . . . . . . . . . . . . . . . 9, 10, 14

Rice University . . . . . . . . . . . . . . . . . . . . . . . 113

Brookhaven National Laboratory . . . . . . . . . . . . . . . . 5

American Museum of Natural History . . . . . . . . . . . . . . . 62

University of Houston . . . . . . . . . . . . . . . . . . 86

Lawrence Berkeley Laboratory . . . . . . . . . . . . . . . 9, 10, 11, 14, 28

University of California at Los Angeles . . . . . . . . . . . . . . 19,76

University of Washington at Seattle . . . . . . . . . . . . 55

Mineralogic Society of America . . . . . . . . . . . . . . . . 93

State University of New York (SUNY) at Stony Brook . . . . . . . . . . 99

Lawrence Livermore National Laboratory . . . . . . . . . . . . . . . . . . 21

The University of Texas at Austin . . . . . . . . . . . . . . . . . . 125

University of California at Berkeley . . . . . . . . . 8, 10, 14, 71, 108

Lehigh University . . . . . . . . . . . . . . . . . . . . . . . . . . 89

Los Alamos National Laboratory . . . . . . . . . . . . . . . . . . . 28

Lawrence Berkeley Laboratory . . . . . . . . . . . . . . . . . . . 9, 10,28

Los Alamos National Laboratory . . . . . . . . . . . . . . . . . . 26

The Ohio State University . . . . . . . . . . . . . . . . . . . . . . . . 104

Oak Ridge National Laboratory . . . . . . . . . . . . . . . . . . . . . . . . . . . . . . . . . . . . .

Princeton University . . . . . . . . . . . . . . . . . . . . 111

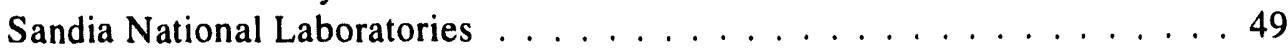

Lawrence Berkeley Laboratory . . . . . . . . . . . . . . . . . . 10

Oak Ridge National Laboratory . . . . . . . . . . . . . . . . . . . . 37

Stanford University . . . . . . . . . . . . . . . . . . . . . . . 119

Princeton University . . . . . . . . . . . . . . . . . . . . . . 110

Indiana University . . . . . . . . . . . . . . . . . . . . . 87

Stanford University . . . . . . . . . . . . . . . . . . 116

University of Oklahoma . . . . . . . . . . . . . . . . . . . . . 107

Los Alamos National Laboratury . . . . . . . . . . . . . . . . . . 28

Lawrence Berkeley Laboratory . . . . . . . . . . . . . . . . . . . 12

Stanford University . . . . . . . . . . . . . . . . 121 
Poths, J.

Price, J. G.

Pyrak-Nolte, L. J.

Rard, J. A.

Raymond, R., Jr.

Reeves, G. D.

Reidel, S. P.

Reimers, C. E.

Reneau, S. L.

Reynolds, J. G.

Riciputi, L.

Risch, J. S.

Rock, P. A.

Rokop, D. J.

Rudnicki, J. W.

Rumble, D.

Rundle, J. B.

Russell, J. E.

Rye, D. M.

Rycrson, F. J.

Sackett, W. M.

Sahagian, D.

Sattler, A.

Schimmelmann, A.

Schreiber, B. C.

Schwandt, C. S.

Segall, P.

Seitz, J. C.

Shankland, T. J.

Sharp, J. M., Jr.

Shaw, B. R.

Shaw, H. F.

Sherman, D. M.

Shock, E. L.

Sims, K. W. W.

Sinha, A. K.

Slater, D. W.

Smyth, J. R.

Spall, W. D.

Spanne, $P$.

Spera, F. J.

Spetzler, $\mathrm{H}$.

Stockman, H. W.

Stolper, E.

Sturchio, N. C.

Sutton, S. R.

Swanson, S. E.

Swart, P. K.

Sweeney, J. J.

Tait, C. D.

Teufel, L. W.
Los Alamos National Laboratory . . . . . . . . . . . . . . . . . . . 32

National Academy of Sciences . . . . . . . . . . . . . . . . . .95

University of Notre Dame . . . . . . . . . . . . . . . . . . . . . . 103

Lawrence Livermore National Laboratory . . . . . . . . . . . . . . . 21

Los Alamos National Laboratory . . . . . . . . . . . . . . . . . . . . . . 29

Los Alamos National Laboratory . . . . . . . . . . . . . . . . . . . . 36

Washington State University . . . . . . . . . . . . . . . . . . . . . . 134

University of California at San Diego . . . . . . . . . . . . . . 77

Los Alamos National Laboratory . . . . . . . . . . . . . . . . . . . . . 29

Lawrence Livermore National Laboratory . . . . . . . . . . . . . . . . 20

Oak Ridge National Laboratory . . . . . . . . . . . . . . . . . . . . . . 42

Pacific Northwest Laboratory . . . . . . . . . . . . . . . . . . . . . 46

University of California at Davis . . . . . . . . . . . . . . . 72

Los Alamos National Laboratory . . . . . . . . . . . . . . . . . . . 30

Northwestern University . . . . . . . . . . . . . . . . . . . . . 102

Carnegie Institute of Washington . . . . . . . . . . . . . . . . 79

Lawrence Livermore National Laboratory . . . . . . . . . . . . . 18, 24, 55

Texas A\&M University . . . . . . . . . . . . . . . . . . . . . 123

Yale University . . . . . . . . . . . . . . . . . . . . . . . . . . . 145

Lawrence Livermore National Laboratory . . . . . . . . . . . . 15, 19, 20, 22

University of South Florida . . . . . . . . . . . . . . . . 115

The Ohio State University . . . . . . . . . . . . . . . . . . . . . . . . . . . . . . . . .

Sandia National Laboratories . . . . . . . . . . . . . . . . . . . . 54

University of California at San Diego . . . . . . . . . . . . . . . 77

City University of New York, Queens College . . . . . . . . . . . . . 98

Sandia National Laboratories . . . . . . . . . . . . . . . . . . . . . 52

Stanford University . . . . . . . . . . . . . . . . . . . . . . . . . 55, 122

Oak Ridge National Laboratory . . . . . . . . . . . . . . . . . . . . 40

Los Alamos National Laboratory . . . . . . . . . . . . . . . . 17, 27, 28

The University of Texas at Austin . . . . . . . . . . . . . . . . . . 124

Pacific Northwest Laboratory . . . . . . . . . . . . . . . . . . . . 45

Lawrence Livermore National Laboratory . . . . . . . . . . . . . . . . . . 22

Pacific Northwest Laboratory . . . . . . . . . . . . . . . . . . . . . . 44

Washington University . . . . . . . . . . . . . . . . . . . . . . . . . . 84, 136

Los Alamos National Laboratory . . . . . . . . . . . . . . . . . . 28

Virginia Polytechnic Institute and State University . . . . . . . . . . . 133

Pacific Northwest Laboratory . . . . . . . . . . . . . . . . . . . . . 47

University of Colorado . . . . . . . . . . . . . . . . 81

Los Alamos National Laboratory . . . . . . . . . . . . . . . 31

Brookhaven National Laboratory . . . . . . . . . . . . . . . . . 5

University of California at Santa Barbara . . . . . . . . . . . 78

University of Colorado . . . . . . . . . . . . . . . . . . 82

Sandia National Laboratories . . . . . . . . . . . . . . . . . . . 49

California Institute of Technology . . . . . . . . . . . . . . . . 67

Argonne National Laboratory . . . . . . . . . . . . . . . . . . . . 3,4

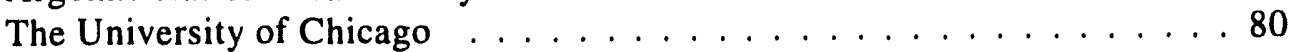

University of Alaska . . . . . . . . . . . . . . . . . 660

University of Miami . . . . . . . . . . . . . . . . . 92

Lawrence Livermore National Laboratory . . . . . . . . . . . . . . . . . 20

Los Alamos National Laboratory . . . . . . . . . . . . . . . . . . . 32

Sandia National Laboratories . . . . . . . . . . . . . . . . 24,55 
Toksoz, N. N.

Tripp, A. C.

Tsang C.-F.

Turpening, R. M.

Usselman, T. M.

Vairavamurthy, A.

Valley, J. W.

Veblen, D. R.

Walck, M. C.

Walker, D.

Walsh, $M$.

Wang, H. F.

Wannamaker, P. E.

Wasserburg, G. J.

Wawersik, W. R.

Wesolowski, D. J.

Westrich, H. R.

Whelan, J. K.

Williams, L. B.

Williams, P. L.

Williams, R. T.

Witten, A. J.

Wogelius, R. A.

Wollenberg, H. A.

Wood, R. H.

Wukelic, G. E.

Yuen, D. A.

Yund, R. A.
Massachusetts Institute of Technology . . . . . . . . . . . . 85,91

University of Utah . . . . . . . . . . . . . . . . . . . . . . . . . . . . . . . . 129

Lawrence Berkeley Laboratory . . . . . . . . . . . . . . . . . . . 10

Massachusetts Institute of Technology . . . . . . . . . . . . . 50,85

National Academy of Sciences . . . . . . . . . . . . . . . . . . . 95

Brookhaven National Laboratory . . . . . . . . . . . . . . . . . . . 5

University of Wisconsin . . . . . . . . . . . . . . . . . 140

The Johns Hopkins University . . . . . . . . . . . . . . . . . 888

Sandia National Laboratories . . . . . . . . . . . . . . . . . . . . 51,54

Columbia University . . . . . . . . . . . . . . . . . . . . . . . 83

Louisiana State University . . . . . . . . . . . . . . . . . . . . . . 90

University of Wisconsin . . . . . . . . . . . . . . . . . 17, 141

University of Utah Research Institute . . . . . . . . . . . . . . . . 130

California Institute of Technology . . . . . . . . . . . . . . 688

Sandia National Laboratories . . . . . . . . . . . . . . . . . . 24,55

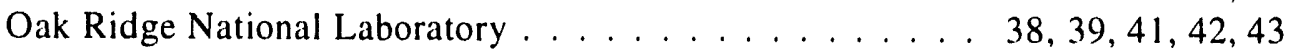

Sandia National Laboratories . . . . . . . . . . . . . . . . 52,53

Woods Hole Oceanographic Institution . . . . . . . . . . . . . . . 143

Arizona State University . . . . . . . . . . . . . . . . . . 63

Lawrence Berkeley Laboratory . . . . . . . . . . . . . . . . . . . . 11

Oak Ridge National Laboratory . . . . . . . . . . . . . . . . . . . . . 37

Oak Ridge National Laboratory . . . . . . . . . . . . . . . . . . . . . 37

Argonne National Laboratory . . . . . . . . . . . . . . . . . . . . . 3

Lawrence Berkeley Laboratory . . . . . . . . . . . . . . . . . . . 13

University of Delaware . . . . . . . . . . . . . . . . . . . . . 84, 136

Pacific Northwest Laboratory . . . . . . . . . . . . . . . . . . . . 46

University of Minnesota, Twin Cities . . . . . . . . . . . . . . . . . . 94

Brown University . . . . . . . . . . . . . . . . . . . . . . . . . . 66 


\section{GEOSCIENCES RESEARCH PROGRAM \\ Division of Engineering and Geosciences \\ Office of Basic Energy Sciences \\ Office of Energy Research \\ U.S. Department of Energy}

\begin{tabular}{|c|c|c|c|c|c|}
\hline ON-SITE INSTITUTIONS & FY 1989 & FY 199n & FY1991 & FY 1992 & FY 1993 \\
\hline Argonne National Laboratory & 440 & 454 & 385 & 440 & 540 \\
\hline Brookhaven National Laboratory & 90 & 49 & - & 213 & 384 \\
\hline Idaho National Engr. Laboratory & - & - & - & 35 & 50 \\
\hline Los Alamos National Laboratory & 2638 & 2613 & 2518 & 2730 & 2622 \\
\hline Lawrence Berkeley Laboratory & 2265 & 2372 & 2109 & 2225 & 2340 \\
\hline Lawrence Livermore National Laboratory & 2121 & 2169 & 2103 & 2288 & 2025 \\
\hline Oak Ridge National Laboratory & 944 & 1226 & 1097 & 1209 & 1041 \\
\hline Pacific Northwest Laboratory & 848 & 819 & 735 & 780 & 975 \\
\hline Sandia National Laboratories & 2213 & 1828 & 2167 & 2098 & 1987 \\
\hline Westinghouse Hanford Laboratory & - & - & 44 & 46 & 45 \\
\hline Grand Junction Project Office & $\cdot$ & $\cdot$ & $\cdot$ & $\cdot$ & 87 \\
\hline total, on-site & 11559 & 11530 & 11158 & 12064 & 12096 \\
\hline total, off-site & 5755 & 5685 & 5987 & 7114 & 7250 \\
\hline total, operating & 17314 & 17215 & 17145 & 19178 & 19346 \\
\hline total, equipment & 1150 & 1150 & 1110 & 1302 & 1270 \\
\hline Total, Geosciences & 18464 & 18365 & 18255 & $\underline{20480}$ & $\underline{20616}$ \\
\hline \multicolumn{6}{|l|}{ OFF-SITE INSTITUTIONS } \\
\hline U/Alaska (Lee) & 143 & 140 & 145 & 125 & 151 \\
\hline U/Alaska (Eichelberger) ${ }^{\star}$ & $\cdot$ & $\cdot$ & $\cdot$ & 149 & 120 \\
\hline Am. Geophys. Union (Spilhaus) & 5 & - & $\cdot$ & - & - \\
\hline Am. Mus. NY (Mathez) & $\cdot$ & - & $\cdot$ & 49 & 39 \\
\hline U/Arizona (Anovitz) & - & 60 & 47 & $\cdot$ & - \\
\hline U/Arizona (Hill) & 121 & 120 & 126 & 130 & - \\
\hline Arizona St. (Williams) & $\cdot$ & $\cdot$ & 108 & $\cdot$ & - \\
\hline Brown U (Yund) & - & 70 & 71 & 141 & 146 \\
\hline Cal Tech (Clayton) & $\cdot$ & $\cdot$ & $\cdot$ & $\cdot$ & 139 \\
\hline Cal Tech (Stolper) & 82 & 85 & 87 & 90 & 150 \\
\hline Cal Tech (Wasserburg) & 250 & 250 & 300 & 345 & 370 \\
\hline Calif, Univ of-Berk (Carmichael) & $\cdot$ & $\cdot$ & 117 & 109 & 115 \\
\hline Calif, Univ of-Berk (Heigeson) & 121 & 120 & 135 & 140 & 150 \\
\hline Calif, Univ of-Berk (Morrison) & $\cdot$ & $\cdot$ & $\cdot$ & 68 & - \\
\hline Calif, Univ of-Berk (Reynolds) & 236 & 245 & 245 & 264 & - \\
\hline Calif, Univ of-Davis (Lesher) & $\cdot$ & $\cdot$ & $\cdot$ & 65 & 65 \\
\hline Calif, Univ of-Davis (Rock) & - & - & $\cdot$ & 83 & 77 \\
\hline Callf, Univ of-LA (Harrison) & 54 & 54 & 54 & 57 & $\cdot$ \\
\hline Calif, Univ of-LA (McKeegan) & $\cdot$ & - & 64 & $\cdot$ & 40 \\
\hline Calif, Univ of-Riv (McKibben)* & 77 & 49 & $\cdot$ & $\cdot$ & - \\
\hline Calif, Univ of-SB (Spera) & 64 & 47 & 101 & - & 43 \\
\hline Calif, Univ of-SD (Harding) & 63 & $\cdot$ & $\cdot$ & - & - \\
\hline Calif, Univ of-SD (Schimmelmann) & $\cdot$ & $\cdot$ & $\cdot$ & 110 & - \\
\hline Chicago, Univ of (Smith/Sutton) & $\cdot$ & $\cdot$ & - & 105 & 126 \\
\hline Colo, Univ of (Smyth) & $\cdot$ & - & - & 93 & 81 \\
\hline
\end{tabular}


GEOSCIENCES RESEARCH PROGRAM

Division of Engineering and Geosciences

Office of Basic Energy Sciences

Office of Energy Research

U.S. Department of Energy

\begin{tabular}{|c|c|c|c|c|c|}
\hline ON-SITE INSTITUTIONS & FY 1989 & FY 1990 & FY1991 & FY 1992 & FY 1993 \\
\hline Colo, Univ of (Spetzler) & 91 & $\cdot$ & 50 & 64 & 57 \\
\hline Colo Sch Mines (Larner) & 192 & 195 & 200 & . & $\cdot 1$ \\
\hline Columbia Univ (Jacob) & 290 & 203 & . & 25 &. \\
\hline \multirow[t]{2}{*}{ Columbia Univ (Walker) } & 90 & 127 & 127 & 77 & 110 \\
\hline & - & 4 & - & 110 & 31 \\
\hline Delaware, Univ of (Wood) & 62 & 56 & 67 & 176 & \\
\hline DOSECC (Friedman)* & - & 65 & 70 & 71 & - \\
\hline Florida, So. Univ of (Compton) & - & - & - & 122 & - \\
\hline Florida St, Univ of (SCC) & - & - & - & - & 99 \\
\hline Geophys. Lab, CIW (BelI) & - & - & . & . & 92 \\
\hline Houston, Univ of (McDonald) & 273 & 295 & 221 & - & - \\
\hline Headquarters Services & 3 & 5 & 2 & 5 & 5 \\
\hline Indiana, Univ of (Hayes) & 162 & 150 & - & - & \\
\hline Indiana, Univ of (Ortoleva) & - & - & 80 & 85 & 63 \\
\hline Johns Hopkins Univ (Veblen) & 63 & 66 & 135 & 134 & 138 \\
\hline JPL, IAU Coloq (Tobiska) & $\cdot$ & - & - & - & 3 \\
\hline Lehigh Univ (Moses) & . & - & . & - & 223 \\
\hline Loulslana St. Univ (Ferrell) & 64 & - & 127 & - & - \\
\hline Miami, Univ of (Eberli) & - & - & - & 127 & 155 \\
\hline Min. Soc. Amer (Guthrie) & . & - & - & - & 5 \\
\hline Minn., Univ of (Yuen) & 48 & 42 & 102 & - & 47 \\
\hline MIT (Toksoz) & 370 & 498 & 485 & 372 & 342 \\
\hline MT BuMines (Bartholomew) & $\cdot$ & $\cdot$ & 9 & $\cdot$ & $\cdot$ \\
\hline NAS/NRC (Carter) & 3 & 3 & - & - & - \\
\hline NAS/NRC (Hart/Long/Burke) & 100 & 105 & 200 & - & 100 \\
\hline NSF (Johnson) & 30 & - & - & - & - \\
\hline Nevada, Univ of (Karlin) & - & - & - & 48 & - \\
\hline New Mexico, Univ of (Crossey) & - & - & - & 43 & 43 \\
\hline New Mexico, Univ of (Paplke) & - & 200 & - & - & - \\
\hline NY, Clty Univ of-CC (Koplick) & - & - & - & - & 125 \\
\hline NY, Clity Univ of-Q (E. Schreiber) & $\cdot$ & $\cdot$ & $\cdot$ & $\cdot$ & \\
\hline NY, Clty Univ of-Q (C. Schrelber) & 105 & NFX & 119 & 126 & 92 \\
\hline NY, State Univ of-P (Wolosz) & 56 & 42 & - & - & - \\
\hline NY, State Univ of-SB (Hanson) & 120 & 119 & 124 & 128 & $\cdot$ \\
\hline NY, State Univ of-SB (Lindquist) & - & - & - & 21 & 22 \\
\hline Northeastern Univ (Devaney) & - & - & - & - & 145 \\
\hline Northwestern Univ (Rudnicki) & - & - & - & - & 75 \\
\hline Notre Dame Univ (Pyrak-Nolte) & $\cdot$ & - & - & - & 61 \\
\hline Ohio St. Univ (Adier) & 55 & 54 & 56 & 59 & 62 \\
\hline Ohio St. Univ (Sahagian) & $\cdot$ & - & 40 & - & - \\
\hline Okla, Univ of (Elmore) & $\cdot$ & - & 109 & 112 & 247 \\
\hline Okla, Univ of (Engel) & 112 & 106 & - & - & - \\
\hline Okla, Univ of (Philp) & 124 & 121 & 143 & - & - \\
\hline Oregon St. Univ (Egbert) & 43 & 41 & - & 111 & - \\
\hline Penn St. Univ (Arthur) & - & - & - & 129 & 134 \\
\hline Princeton Univ (Navrotsky) & 125 & 123 & 125 & 130 & 198 \\
\hline
\end{tabular}


GEOSCIENCES RESEARCH PROGRAM

Division of Engineering and Geosciences

Office of Basic Energy Sciences

Office of Energy Research

U.S. Department of Energy

\begin{tabular}{|c|c|c|c|c|c|}
\hline ON-SITE INSTITUTIONS & FY 1989 & FY 1990 & FY1991 & FY 1992 & FY 1993 \\
\hline Princeton Univ (Onstott) & - & $\cdot$ & 103 & $\cdot$ & - \\
\hline Princeton Univ (Phinney) & 97 & - & - & - & - \\
\hline Purdue Univ (Aydin) & 56 & 56 & - & - & - \\
\hline Purdue Univ (Fritz) & - & 71 & 44 & 47 & - \\
\hline Purdue Univ (Johnson) & - & - & - & - & 170 \\
\hline Rlce Univ (Mango) & - & - & - & 127 & 100 \\
\hline San Diego St. Univ (Jiracek) & - & 5 & - & 10 & - \\
\hline So Dak Sch M\&T (Papike) & 115 & - & - & $\cdot$ & $\cdot$ \\
\hline Calif, Univ of So. (AkI)" & 164 & 147 & 160 & 160 & 160 \\
\hline Stanford Univ (Brown) & - & - & - & - & 241 \\
\hline Stanford Univ (Ernst) & - & 100 & 101 & 158 & - \\
\hline Stanford Univ (Liou) & - & - & - & - & 160 \\
\hline Stanford Univ (Nur) & 175 & 328 & - & 176 & - \\
\hline Stanford Univ (Pollard)* & 73 & 30 & $\cdot$ & $\cdot$ & - \\
\hline Stanford Univ (Pollard) & 79 & 75 & 183 & 159 & - \\
\hline Stanford Univ (Segall) & $\cdot$ & 80 & - & 70 & 87 \\
\hline Texas, Univ of-Aus (Land) & - & - & - & 100 & 104 \\
\hline Texas, Univ of-Aus (Sharp) & - & - & - & 98 & . \\
\hline Texas, Univ of-Dallas (Mitterer) & - & 119 & 112 & 114 & 0 \\
\hline Texas A\&M Univ (Dorobek) & 57 & - & - & - & - \\
\hline Texas A\&M Univ (Gilbert) & 10 & - & - & - & - \\
\hline Texas A\&M Univ (Kronenberg) & 197 & 149 & 143 & 149 & 155 \\
\hline Tulsa, Univ of (Barker) & 76 & 71 & 84 & 205 & - \\
\hline USGS (Bredehoeft) & $\cdot$ & $\cdot$ & $\cdot$ & $\cdot$ & 29 \\
\hline USGS (Dean)* & - & - & $\cdot$ & 99 & - \\
\hline USGS (Kharaka) & - & - & - & 18 & - \\
\hline USGS (Russ) & 12 & - & 137 & 56 & - \\
\hline Utah, Univ of (Hulen) & - & - & - & - & 204 \\
\hline Utah, Univ of (Hulen)* & - & 85 & 126 & - & - \\
\hline Utah, Univ of (Tripp) & - & - & - & - & 57 \\
\hline Utah, Univ of (Wannamaker) & 91 & - & - & 75 & \\
\hline VPI \& SU (Bodnar) & 114 & 78 & - & 127 & 129 \\
\hline VPI \& SU (Sinha) & 60 & 87 & 74 & 63 & 28 \\
\hline Washington, Univ of (Booker) & 78 & 81 & - & 101 & 104 \\
\hline Washington, Univ of (Malone) & 32 & - & - & - & - \\
\hline Washington St. Univ-R (Reidel) & $\cdot$ & $\cdot$ & 45 & 48 & 49 \\
\hline Washington St. Univ-TC (Conca)" & - & - & 95 & $\cdot$ & - \\
\hline Wash Univ, St. Louis (Shock) & - & - & $\cdot$ & 46 & - \\
\hline Wisconsin, Univ of (Banfield) & - & - & - & - & $7 \varepsilon$ \\
\hline Wisconsin, Univ of (Haimson) & - & - & - & - & 10 \\
\hline Wisconsin, Univ of (Valley) & $\cdot$ & - & - & - & 144 \\
\hline Wisconsin, Univ of (Wang) & 92 & - & 97 & 99 & 105 \\
\hline WHOI (Eglinton) & $\cdot$ & - & - & 99 & 82 \\
\hline WHOI (Whelan) & 220 & 208 & 197 & 199 & 180 \\
\hline Yale University (Lasaga) & $\cdot$ & 50 & 91 & 113 & 385 \\
\hline Other & 160 & 5 & 4 & . & 5 \\
\hline
\end{tabular}

Page 155 


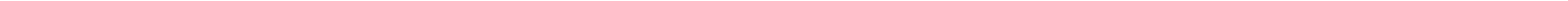



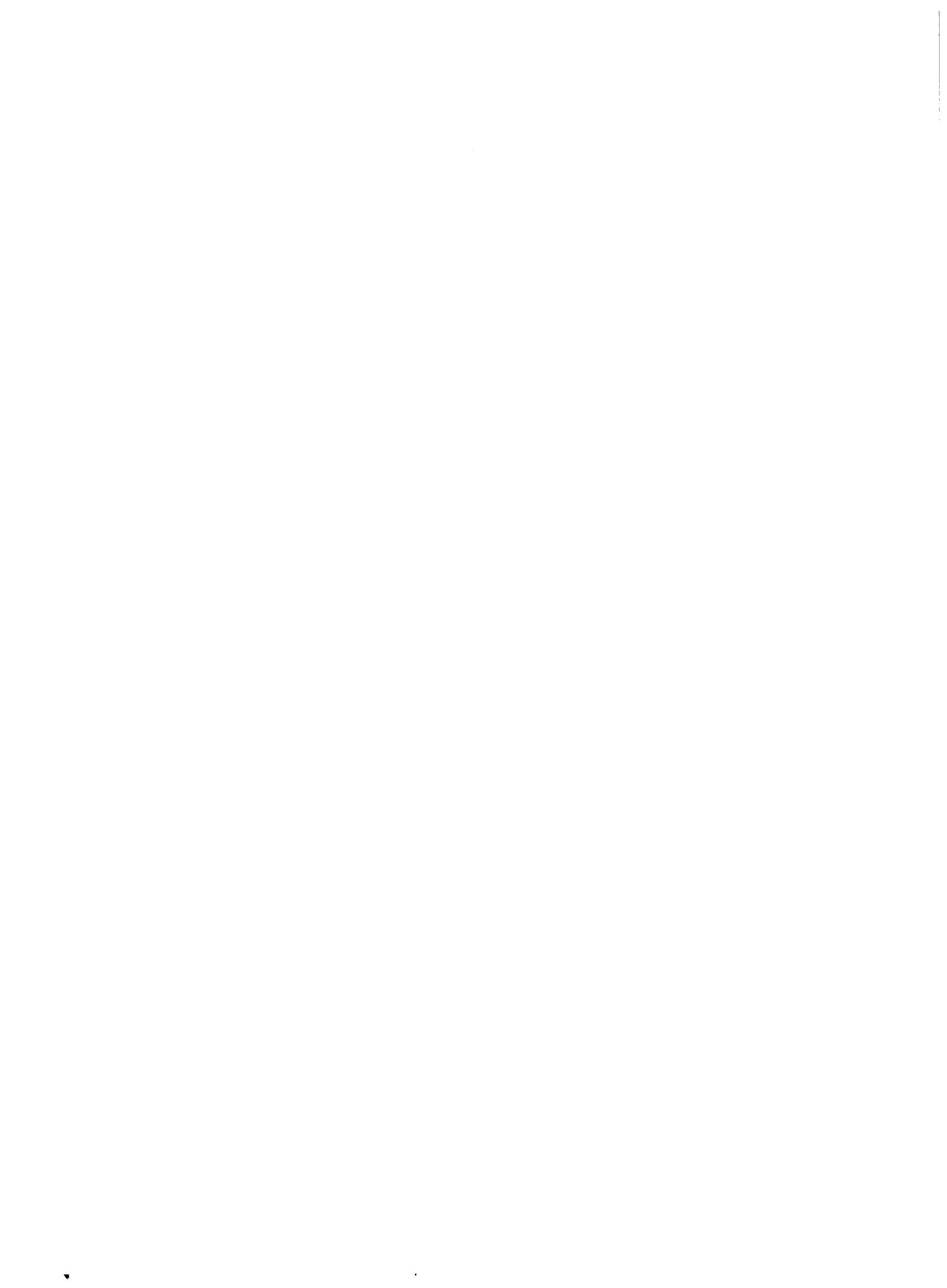